\title{
Väestöliitto
}

\section{Riikka Shemeikka}

FERTILITY IN NAMIBIA:

Changes in fertility levels in North-Central Namibia 1960-2000, including an assessment of the impact of HIV

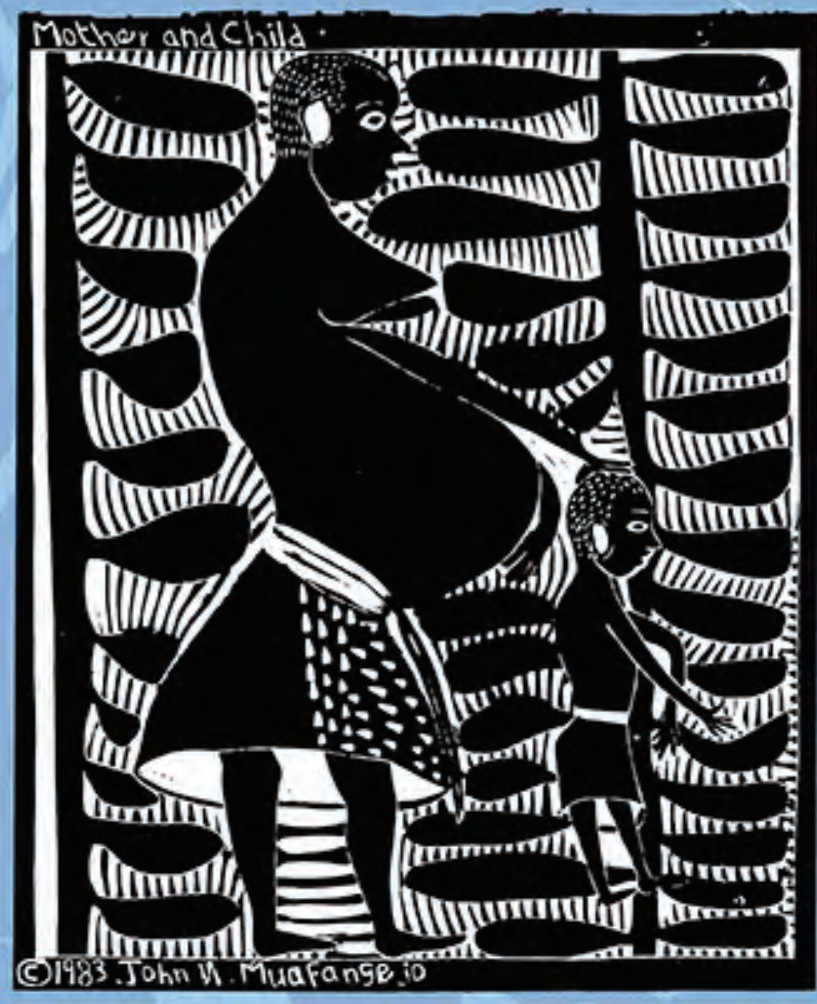

Yearbook of Population Research in Finland MMVI 2006 supplement

The Population Research Institute Helsinki Finland 


\title{
Riikka Shemeikka
}

\section{FERTILITY IN NAMIBIA:}

Changes in fertility levels in North-Central Namibia 1960-2001, including an assessment of the impact of HIV

\section{Yearbook of Population Research in Finland XLII 2006 supplement}

\author{
Väestöliitto
}

The Population Research Institute Helsinki Finland 


\title{
YEARBOOK OF POPULATION \\ RESEARCH IN FINLAND \\ XLII 2006
}

\author{
SUPPLEMENT \\ Advisory Board \\ HELKA HYTTI \\ SEIJA ILMAKUNNAS \\ OSMO KONTULA \\ SEPPO KOSKINEN \\ MAURI NIEMINEN \\ IRMA-LEENA NOTKOLA \\ KARI PITKÄNEN \\ MATTI SIHTO \\ ISMO SÖDERLING \\ STINA FÅGEL (Secretary)
}

Editor in Chief

ISMO SÖDERLING

Special Editors

SEPPO KOSKINEN

KARI PITKÄNEN

Editorial Assistant

MIKA TAKOJA

ISBN 951-9450-44-0

ISSN 0506-3590

Vammalan Kirjapaino Oy

\section{The Population Research Institute} Väestöntutkimuslaitos

Väestöliitto, The Family Federation of Finland (Iso Roobertinkatu 20-22 A) PO Box 849, FIN-00101 Helsinki, Finland Telephone +358-9-228 050, Fax +358-9-612 1211

E-mail:pop.inst@vaestoliitto.fi 


\section{Contents}

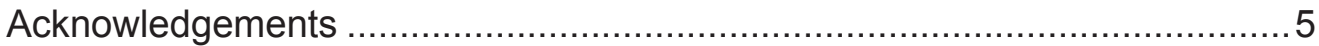

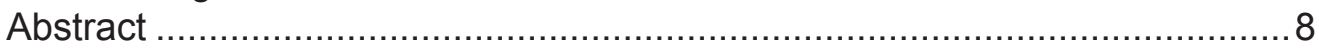

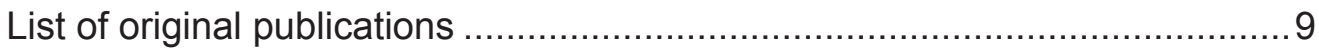

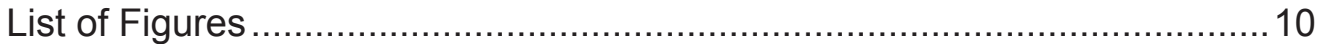

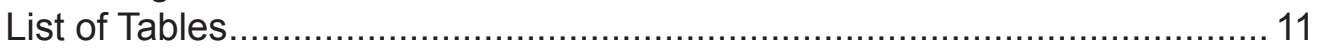

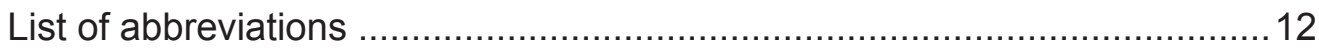

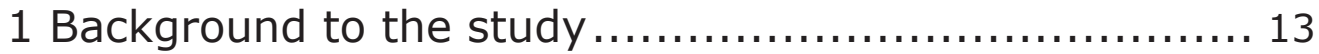

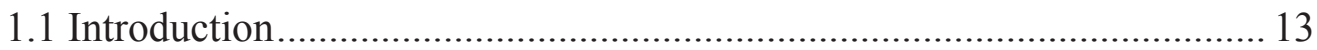

1.2 Theories, approaches and explanations of fertility transition ................... 16

1.2.1 Fertility decline and the theory of demographic transition ........................................ 16

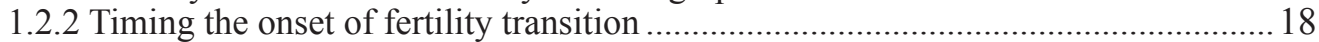

1.2.3 Explanations of fertility decline......................................................................... 19

1.2.4 Current approaches used in research into fertility decline in Africa........................22

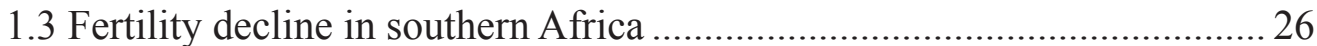

1.3.1 The state of fertility transition in Namibia's neighbours .........................................26

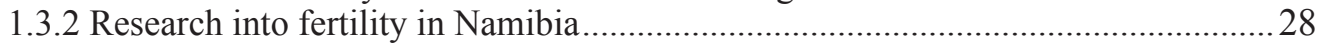

1.4 Research into fertility - HIV connections in sub-Saharan Africa..............31

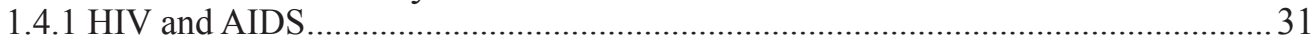

1.4.2 The impact of HIV on fertility in sub-Saharan Africa based on earlier studies.........33

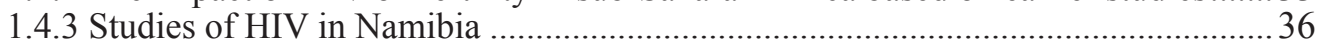

1.5 Demographic research using parish registers in sub-Saharan Africa........ 37

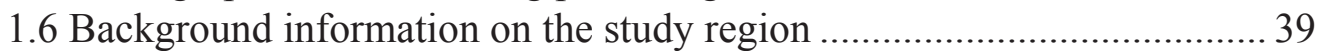

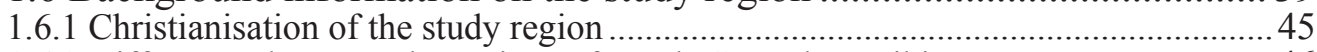

1.6.2 Differences between the regions of North-Central Namibia ……………………......4 46

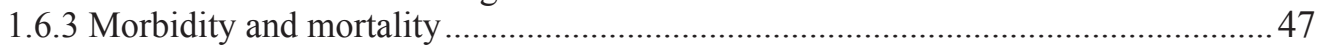

1.6.4 Gender issues in North-Central Namibia ...........................................................4

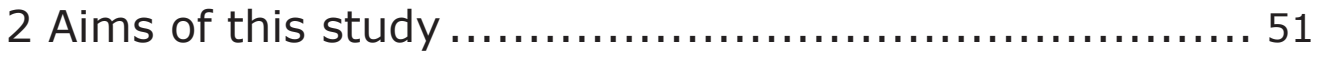

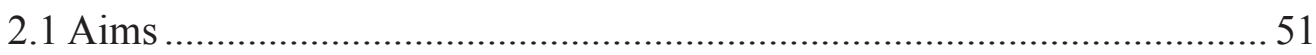

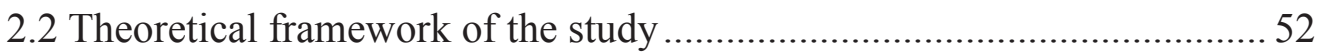

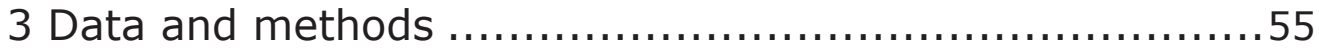

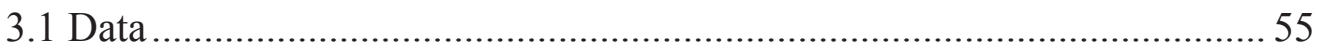

3.1.1 Parish registers from North-Central Namibia ..........................................................5

3.1.2 Namibia Demographic and Health Surveys in 1992 and 2000 ...............................57

3.1.3 Population and Housing Censuses 1991 and 2001 ...............................................58

3.1.4 HIV sentinel surveillance and other HIV data ........................................................59

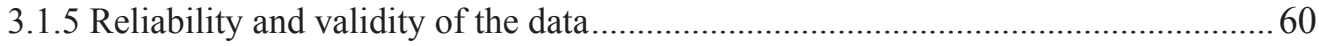

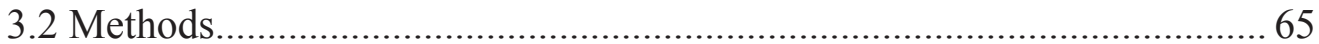

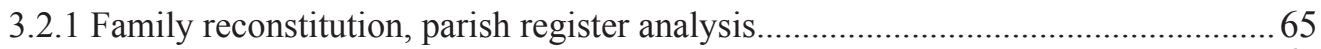

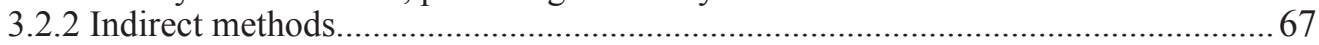

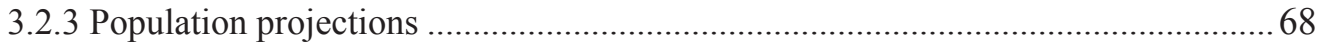




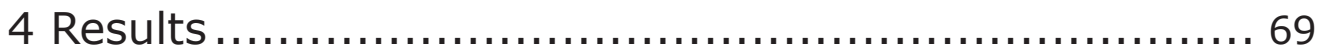

4.1 Fertility prior to independence: fertility trends in 1960-1989 .................69

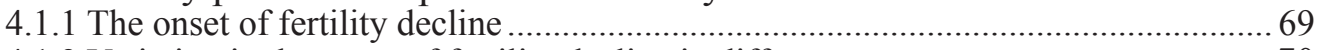

4.1.2 Variation in the onset of fertility decline in different age groups ............................70

4.1.3 The age structure of fertility …………………………................................. 72

4.1.4 Fertility determinants at the onset of fertility decline ..........................................74

4.1.5 Fertility prior to independence compared to other regions.......................................76

4.2 Fertility in the study region at the beginning of independence.................. 77

4.2.1 Levels of fertility compared to other regions in Namibia............................................77

4.2.2 Regional differences in the age structure of fertility .............................................78

4.2.3 Fertility determinants and regional differences in fertility ...................................... 79

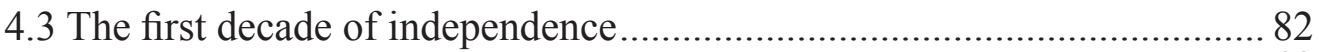

4.3.1 Fertility decline and proximate determinants .................................................... 83

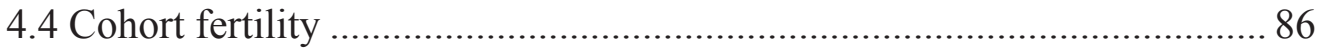

4.5 Comparison of parish-register fertility levels with census

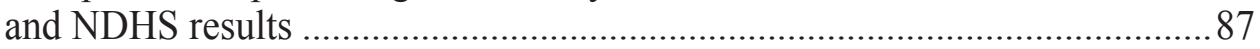

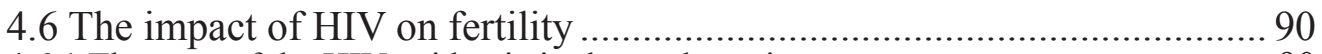

4.6.1 The state of the HIV epidemic in the study region ................................................90

4.6.2 The impact of HIV on the fertility of HIV-infected women .....................................92

4.6.3 The impact of HIV on fertility determinants ........................................................95

4.6.4 The impact of HIV on fertility at population level and its contribution

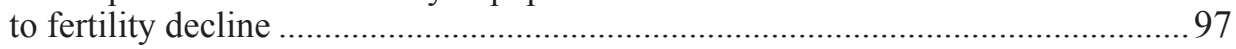

5 Conclusion and discussion................................ 101

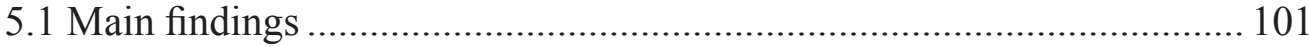

5.2 Explanations for fertility decline in the study region................................103

5.3 Comparison to other regions in southern Africa .................................... 106

5.4 Factors contributing to the spread of HIV infection and

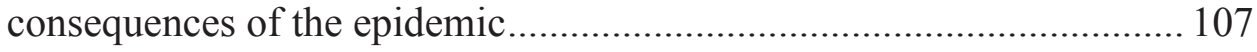

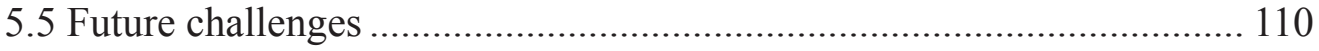

5.6 Requests for future research............................................................... 112

References.................................................. 113

Appendices .................................................. 139

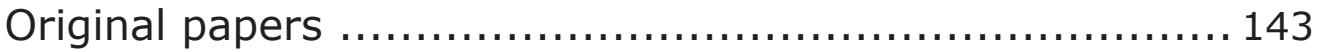




\section{Acknowledgements}

Firstly, I wish to thank my supervisor, docent Veijo Notkola PhD. Since 1994, he has provided me an opportunity to work with him in several research projects concerning demographic development in Namibia. It has been a privilege to work in his research groups which have pioneered Finnish studies of African demography. Without his patience, support and skilful guidance, this study would not have been made.

I am also greatly indebted to Professor Harri Siiskonen of the Department of History, University of Joensuu, who has helped me in many ways, for example by commenting on my texts and assisting me to obtain the maps used in this publication. It has been a great benefit to be able to lean on his expertise concerning both past and present circumstances in North-Central Namibia.

I am grateful to the Evangelical Lutheran Church in Namibia and to its clergy for providing our research projects with access to parish-register data. I am also much obliged to all my informants in Namibia, including the family-planning workers I interviewed in Oshakati and Oshigambo, and to all the other people I interviewed to obtain background information for this study. During my visits to Namibia, I received invaluable help from my research assistants Ms Olivia Shilunga and Ms Auguste Pelema.

Ossi Lemström MSc has been an invaluable expert in connection with parish register data. Project members from the University of Joensuu: Kari Miettinen PhD, Jan Kuhanen PhD, Anssi Taskinen MA and Mr Olli Alm, among others, have been a very pleasant group to work with. Special thanks go to Dr Miettinen and Dr Kuhanen for their most useful comments on the thesis summary, as well as to everyone who participated in the time-consuming and demanding process of entering data extracted from the microfilmed parish registers.

I am grateful to all members of the Population Research Unit of the Department of Sociology at the University of Helsinki, especially Professor Tapani Valkonen, whose positive response to my interest in population studies encouraged me to explore this field. I wish to thank all other former and current members of the informal Population Research Unit for their friendship and for the knowledge they have shared with me. I am also obliged to members of the so-called 'support group' for my thesis, Pekka Peltola PhD and Riitta Saarinen MSc, for their useful suggestions in the early phases of my research.

During the period that I worked at the International Institute for Systems Analysis (IIASA) I had a chance to participate in a most interesting project concerning Namibia. 
I am grateful to Professor Wolfgang Lutz, leader of the Population Project, for the opportunity to work at IIASA and for the skills I learned there. I wish to express my special gratitude to Andrew Noymer $\mathrm{PhD}$ for the instructive and pleasant co-operation concerning population projections, including the impact of HIV. I am also grateful to Anne Goujon PhD, who, as well as being a very good friend, also taught me a great deal about population projections. I am also grateful to other good friends and colleagues at IIASA, including Professor Warren Sanderson, Isolde Prommer MA, and Iliana Kohler (née Natchevska) PhD, to mention just a few among many. Special thanks also go to Ms Marilyn Brandl for all her help during my IIASA years.

I am also grateful to project partners and other people who co-operated with in Namibia and Botswana, including Vice-Chancellor Lazarus Hangula, Professor Peter H. Katjavivi, Professor O.O. Arowolo, Ben Fuller PhD, Oddvar Jakobsen MBA, Sylvia Hamata BSc, Werner Hillebrecht PhD, Ms Gerhild Kölling, Pelad P. Namfua PhD, and Hassan Musa Yousif PhD, among others. During my visits to Namibia I was helped by many people, including workers from the Finnish Missionary Society, who provided me with accommodation during my field trips to North-Central Namibia, and many others who provided practical assistance.

I wish to express my gratitude to the Population Research Institute of the Family Federation of Finland, especially to the institute's director, Ismo Söderling $\mathrm{PhD}$ and the editing board for agreeing to publish this study in their series of publications. I am also grateful to Mika Takoja BA for his skilful editing. I also wish to thank $\mathrm{Mr}$ Rick McArthur, who patiently and efficiently worked to revise the language of this summary publication and one of the published papers.

I am grateful to the Department of Sociology at the University of Helsinki and its Head Professor Kari Pitkänen for providing good working facilities at the department of sociology as well as financial support for this publication. I also wish to thank Professor Pitkänen in his role as the chairman of the Finnish Demographic Society, as well as the other members of the board of the society, for financial support for this publication.

I wish to thank both the two official pre-examiners of the thesis manuscripts, Professor Irma Elo and Docent Ossi Rahkonen, and all the anonymous referees of the published papers for their sympathetic attitude and valuable comments. I would also like to thank the papers' publishers for permission to reprint the papers in this thesis publication.

My colleagues in the Department of Sociology at the University of Helsinki have provided important information, useful guidance and moral support over the years. I am grateful to all the people with whom I have shared my office during this time - you have 
been good friends. Although I have shared office space with many colleagues, I wish to especially mention Airi Pajunen, Tiina Arppe, Anne Ruokolainen, Marika Jalovaara and Liisa Voutilainen. During the final stages, I troubled Tiina Pensola with many practical questions and received both good advice and encouragement - thank you.

I also wish to express gratitude to Docent Altti Majava, Professor Paul Fogelberg, Professor Paavo Talman and Docent Ritva Kivikkokangas-Sandgren for their support in the early phases of this research. I wish to give my special thanks to Professor Emerita Elina Haavio-Mannila, my first project leader at the Department of Sociology. A great number of other people have also helped me in a whole variety of ways during the production of this thesis. The space required to name you all is not available, but please accept my sincere thanks.

I am grateful to the Academy of Finland for providing grants for the Namibia research projects and thus financing my research through working periods in these projects, to the Population, Health and Living Conditions Graduate School for working periods and financial support from this source for language revision of one of the original papers, and to the Väinö Tanner Foundation, the Alli Paasikivi Foundation, the Sasakawa Young Leaders Fellowship Fund (SYLFF), the Olga and Vilho Linnamo Foundation, and the Emil Aaltonen Foundation for providing grants for this dissertation research.

Finally, I am deeply indebted to my family. I wish to thank Päivikki Kaskinen, my mother, and Rauha Shemeikka and Seppo Shemeikka, my parents-in-law, who helped me to combine the nursing of small children with preparation of a doctoral thesis. Moral support from Moina van der Heijden, Pekko Parikka, Teppo Parikka, Pekka Shemeikka and Ulla Shemeikka has helped me greatly.

I am endlessly indebted to my husband Tero Shemeikka and our children Benjamin and Anna. Tero was there for me from the very beginning of the process, always encouraging me in my academic endeavours, as well as bringing me scientific publications from his trips around the world. Benjamin and Anna, now seven and four, have also truly been part of the process. I acknowledge their patience and helpfulness with all my love.

Helsinki, June 2006, Riikka Shemeikka 


\section{Abstract}

The aim of this study was to estimate the development of fertility in North-Central Namibia, former Ovamboland, from 1960 to 2001. Special attention was given to the onset of fertility decline and to the impact of the HIV epidemic on fertility. An additional aim was to introduce parish registers as a source of data for fertility research in Africa.

Data used consisted of parish registers from Evangelical Lutheran congregations, the 1991 and 2001 Population and Housing Censuses, the 1992 and 2000 Namibia Demographic and Health Surveys, and the HIV sentinel surveillances of 1992-2004. Both period and cohort fertility were analysed. The $\mathrm{P} / \mathrm{F}$ ratio method was used when analysing census data. The impact of HIV infection on fertility was estimated indirectly by comparing the fertility histories of women who died at an age of less than 50 years with the fertility of other women. The impact of the HIV epidemic on fertility was assessed both among infected women and in the general population.

Fertility in the study population began to decline in 1980 . The decline was rapid during the 1980s, levelled off in the early 1990s at the end of war of independence and then continued to decline until the end of the study period. According to parish registers, total fertility was 6.4 in the 1960s and 6.5 in the 1970s, and declined to 5.1 in the 1980s and 4.2 in the 1990s. Adjustment of these total fertility rates to correspond to levels of fertility based on data from the 1991 and 2001 censuses resulted in total fertility declining from 7.6 in 1960-79 to 6.0 in 1980-89, and to 4.9 in 1990-1999. The decline was associated with increased age at first marriage, declining marital fertility and increasing premarital fertility. Fertility among adolescents increased, whereas the fertility of women in all other age groups declined.

During the 1980s, the war of independence contributed to declining fertility through spousal separation and delayed marriages. Contraception has been employed in the study region since the 1980s, but in the early 1990s, use of contraceptives was still so limited that fertility was higher in North-Central Namibia than in other regions of the country. In the 1990s, fertility decline was largely a result of the increased prevalence of contraception. HIV prevalence among pregnant women increased from 4\% in 1992 to $25 \%$ in 2001. In 2001, total fertility among HIV-infected women (3.7) was lower than that among other women (4.8), resulting in total fertility of 4.4 among the general population in 2001. The HIV epidemic explained more than a quarter of the decline in total fertility at population level during most of the 1990s. The HIV epidemic also reduced the number of children born by reducing the number of potential mothers.

In the future, HIV will have an extensive influence on both the size and age structure of the Namibian population. Although HIV influences demographic development through both fertility and mortality, the effect through changes in fertility will be smaller than the effect through mortality. In the study region, as in some other regions of southern Africa, a new type of demographic transition is under way, one in which population growth stagnates or even reverses because of the combined effects of declining fertility and increasing mortality, both of which are consequences of the HIV pandemic. 


\section{List of original publications}

Paper I: Raitis, Riikka. 1995. Fertility in the Northwest Region of Namibia. Yearbook of Population Research in Finland 32: 106-117.

Paper II: Shemeikka, Riikka. 1999. HIV/AIDS: The major demographic challenge of Namibia. Yearbook of Population Research in Finland 35: 65-81.

Paper III: Shemeikka, Riikka, Veijo Notkola, and Harri Siiskonen. 2005. Fertility decline in North-Central Namibia: An assessment of fertility in the period 1960-2000 based on parish registers. Demographic Research [Online]. 30 August 2005, Volume 13, Article 4, Pages 83-116.

Paper IV: Shemeikka, Riikka and Veijo Notkola. 2005. Fertility reduction caused by HIV/AIDS and its demographic impact in northern Namibia. In: What are we doing there? Experiences and lessons learned from development cooperation in health care and social welfare (1990-2005), edited by Ursula Aaltonen and Simo Mannila, pp. 207-226. Saarijärvi: National Research and Development Centre for Welfare and Health (STAKES).

Papers are reproduced with permission from the publishers:

- Väestöliitto (the Family Federation of Finland) (I-II),

- the Max Planck Institute for Demographic Research (III), and

- STAKES (the National Research and Development Centre for Welfare and Health) (IV). 


\section{List of Figures}

Figure 1. 'Homelands' and the regions reserved mainly for 'whites' in South-West Africa (Namibia) before independence

Figure 2. Current administrative regions, and the health directorates of the Ministry of Health and Social Services used until 2001-2003

Figure 3. Theoretical framework for the study 53

Figure 4. Locations of the sample congregations 56

Figure 5. Total Fertility Rate and Total Marital Fertility Rate in North-Central Namibia, 1960-1989 69

Figure 6. Coale's index of marital fertility, North-Central Namibia, 1960-1999 70

Figure 7. Age-Specific Fertility Rates (yearly values of 5-year moving averages) among women aged 15-34 in 1960-1989, by 5-year age group

Figure 8. Age-Specific Fertility Rates (yearly values of 5-year moving average) among women aged 35-49 in 1960-1989, by 5-year age group

Figure 9. Age-Specific Fertility Rates (ASFR) in North-Central Namibia, 1960-1989

Figure 10. Standardized age distributions of fertility in North-Central Namibia, 1960-1989

Figure 11. Standardized age distributions of fertility in Namibia by region according to the 1991 census

Figure 12. Age-Specific Fertility Rates in North-Central Namibia, 1980-89 and 1990-2000

Figure 13. Standardized age distributions of fertility in North-Central Namibia, 1980-89 and 1990-2000

Figure 14. Age-Specific Fertility Rates by birth cohort in North-Central Namibia, 1935-39 to 1955-59 birth cohorts

Figure 15. Age-Specific Fertility Rates for the sample congregation regions, parish registers 1990-2000 and 1991 census data

Figure 16. Standardized age distributions of fertility for the sample congregation regions, parish registers 1990-2000 and 1991 census data

Figure 17. Adjusted Total Fertility Rate in the sample congregation areas in North-Central Namibia, 1960-1999

Figure 18. Age-Specific Fertility Rates among HIV-infected and other women in North-Central Namibia, 1980-2000

Figure 19. Total fertility in Northwest Health Directorate in 1991-2001, and the reduction in fertility resulting from HIV infection and other factors compared to the TFR in 1991 


\section{List of Tables}

Table 1. Hypothesised mechanisms for interaction between the HIV epidemic and the proximate determinants of fertility in sub-Saharan African settings, according to Gregson (1994)

Table 2. Members of Evangelical Lutheran congregations, the later Evangelical Lutheran Ovambo-Kavango Church, and the Evangelical Lutheran Church in Namibia (only congregations located in North-Central Namibia are included), and the estimated population in NorthCentral Namibia, 1900-2001

Table 3. Mean age at baptism in the sample congregations, months

Table 4. Sex ratio at birth in North-Central Namibia in parish registers, in the 1992 Namibia Demographic and Health Survey, and in the 2001 Population and Housing Census

Table 5. Total fertility in congregations, in congregation regions based on the 1991 Population and Housing Census data, and in constituencies where congregations are located based on data from the 2001 Population and Housing Census

Table 6. HIV prevalence among pregnant women in the Northwest Health Directorate (NWHD), 1992-2004 


\section{List of abbreviations}

\begin{tabular}{|c|c|}
\hline AIDS & Acquired immunodeficiency syndrome \\
\hline AIM & AIDS Impact Model \\
\hline $\mathrm{ANC}$ & Antenatal clinic \\
\hline ART & Antiretroviral therapy \\
\hline ARV & Antiretroviral \\
\hline ASFR & Age-Specific Fertility Rate \\
\hline CBD & Community Based Distribution \\
\hline CFR & Cohort Fertility Rate \\
\hline CPS & Contraceptive Prevalence Survey \\
\hline DHS & Demographic and Health Survey \\
\hline ELCIN & Evangelical Lutheran Church in Namibia \\
\hline ELOC & Evangelical Lutheran Ovambo-Kavango Church \\
\hline GRN & Government of Republic of Namibia \\
\hline HAART & Highly-active antiretroviral therapy \\
\hline HIS & Health Information System \\
\hline HIV & Human immunodeficiency virus \\
\hline$I_{g}$ & Index of marital fertility \\
\hline IIASA & International Institute for Applied Systems Analysis \\
\hline IRD & Institute for Resource Development \\
\hline LAC & Legal Assistance Centre \\
\hline MASFR & Marital Age-Specific Fertility Rate \\
\hline MBESC & Ministry of Basic Education, Sport and Culture \\
\hline MoHSS & Ministry of Health and Social Services \\
\hline NDHS & Namibia Demographic and Health Survey \\
\hline NPC & National Planning Commission \\
\hline NWHD & Northwest Health Directorate \\
\hline PDEPROJ & Population-Development-Environment Population Projection Software \\
\hline STD & Sexually transmitted disease \\
\hline SWA & South West Africa \\
\hline SWAPO & South West African People's Organization \\
\hline TFR & Total Fertility Rate \\
\hline TMFR & Total Marital Fertility Rate \\
\hline UNAIDS & Joint United Nations Programme on AIDS \\
\hline UNDP & United Nations Development Programme \\
\hline UNICEF & United Nations Children's Fund \\
\hline USAID & United States Aid for International Development \\
\hline WFS & World Fertility Survey \\
\hline WHO & World Health Organisation \\
\hline
\end{tabular}




\section{Background to the study}

\subsection{Introduction}

Two important current demographic issues in Africa are the onset of fertility transition in several countries and the spread of the HIV pandemic and its consequences.

Past decades have witnessed the onset of fertility transition, i.e. the shift from regimes of high natural fertility to declining levels of fertility controlled by the use of contraceptives in many sub-Saharan African countries, making this phenomenon a global issue. In Kenya, for example, fertility began to decline in the late 1970 s or early 1980s (e.g. Westoff and Cross 2006). Countries in southern Africa have led the fertility transition in sub-Saharan Africa. The extent of fertility decline varies in Namibia's neighbours: while South Africa, Botswana and Zimbabwe have been forerunners in the fertility transition, the decline in fertility has been less rapid in Zambia (e.g. Garenne and Joseph 2002; Letamo and Letamo 2002: Moultrie and Timæus 2002, 2003; Muhwava 2002a; Muhwava and Timæus 1996, Rutenberg and Diamond 1993). In Angola, it appears that fertility decline had not yet started in the late 1990s (Agadjanian and Prata 2001).

At the same time when many countries in sub-Saharan Africa entered fertility transition, another issue, even more urgent, became topical in the region: the HIV pandemic strengthened its hold. HIV is a major challenge for demographic and societal development in the affected countries. At the end of 2005, 39 million people in the world were infected by HIV, and 63\% of these lived in sub-Saharan Africa (UNAIDS 2006). The spread of HIV was very rapid in the 1990s and thereafter, and the focus of the pandemic has moved from the east and centre of the continent to southern Africa.

This study addresses both the fertility transition and the HIV pandemic. The consequences of the HIV pandemic are examined from the viewpoint of fertility research. HIV affects levels of fertility among those who are infected. It influences demographic development in an affected region through both fertility and mortality. In the regions in Africa most severely affected by the pandemic, HIV also contributes to the decline in fertility. For this reason, when studying fertility decline in North-Central Namibia, this study places additional emphasis on an assessment of the role of HIV in this decline.

Namibia was among the last of the colonies in Africa. Until the 1990s, reliable data for demographic analysis was scarce in Namibia, as was demographic research in the country. Studies of fertility in Namibia are few. The major demographic data sources in Namibia date from the beginning of the era of independence, which was gained on 21st March 1990. 
In northern Namibia, however, there is a data source which includes long-term data concerning births, deaths, and migration among the study population. Finnish missionaries began to use the Scandinavian parish register system in their newly-founded congregations, and this practice was continued by the Evangelical Lutheran OvamboKavango Church, later the Evangelical Lutheran Church in Namibia. A vital registration system is therefore available with details of parishioners in these regions. Sources of parish register data also exist elsewhere in Africa. In spite of the lack of longitudinal data sources in Africa, it is probable that data from these sources have hitherto been under-utilized.

This study is part of a long tradition of Finnish research concerning Namibia which includes the fields of, for example, history, anthropology, international politics, forestry, demography and theology. This tradition begins with research carried out by missionaries in northern Namibia, and with data collected by them and used at a later date by other researchers (for Namibia collections in Finland, see Eirola 1985; Taskinen 2004). The rich content of data collected by missionaries in northern Namibia, as well as the archive sources of the Finnish Missionary Society, have been utilised in several studies including doctoral dissertations, unpublished licentiate and master's theses, conference and working papers, and other scientific publications (e.g. Gustafson 2003, 2004; Hiltunen 1986, 1993; Kemppainen 1998; Kuusi 1970, 1974; Miettinen 2005; Raiskio 1997; Teinonen 1949; Tuupainen 1970; Weiss 1999).

Research concerning Namibia has been a subject of particular focus at the University of Joensuu (Erkkilä and Siiskonen 2003), but has also been conducted at other universities in Finland. In the 1980s, a special research project was undertaken which studied the history of northern Namibia from different scientific viewpoints (Cultural and Social Change in Ovamboland, 1870-1915, see e.g. Eirola et al. 1983; Siiskonen 1986), and this resulted in several master's, licentiate and doctoral theses (e.g. Salokoski 1992, 2006; Siiskonen 1990; Williams 1988, 1991). Other research projects concerning Namibia carried out at the University of Joensuu include, for example, Colonial Rule and Underdevelopment in Namibia, 1915-1970, Forests and Woodlands in the Development of Namibia (see e.g. Erkkilä and Siiskonen 1992), Deforestation Processes in Namibia (see e.g. Löfman 1997; Tokola, Löfman, and Erkkilä 1999), and Indigenous land use systems in Namibia (see e.g. Erkkilä 2001).

Although Finnish research concerning Namibia has mostly concentrated on the country's northern regions, especially the former Ovamboland region, other research exists (e.g. Metsola 2001; Peltola 1995; Tanskanen 2000; Zeller 1998, 2000). In addition to the historical connections between Finland and Namibia based on missionary activities, there is another connection between the two countries, the background for which 
lies in Namibia's long struggle for independence and the involvement of Finland and other Nordic countries in this (e.g. Koponen 1981; Soiri 1996; Soiri and Peltola 1999). Naturally, there is considerable interaction between these connections, since churches also played a significant role during the processes which resulted in independence (Katjavivi 1989).

In addition to collections made by missionaries and other archival sources of the Finnish Missionary Society, the history of the Finnish mission to Namibia indirectly provides another type of data set. Finnish missionaries began to use a Scandinavian-type parishregister system, and this practice was continued by Namibia's established Evangelical Lutheran Church. These registers have provided demographic data for three successive research projects carried out jointly by the Department of Sociology at the University of Helsinki, the Department of History at the University of Joensuu, and the London School of Hygiene and Tropical Science at the University of London. These research projects have been conducted in co-operation with the Evangelical Lutheran Church in Namibia and the University of Namibia. The first of these projects (Population Development in Northern Namibia) concentrated on long-term demographics in the study region. The second project (AIDS in Namibian Society, 2001-2004) studied the demographic impact of HIV in the study region among other HIV-related issues. The third project (Coping with the HIV pandemic in African communities, 2005-2008) was launched at the beginning of 2005. Parish-register data has also been utilised in other research (Miettinen 2005; Saarelma-Maunumaa 2003).

In addition to being a chapter in the long continuum of Namibian research in Finland, this study is also part of another scientific tradition. The Population Project of the International Institute for Applied Systems Analysis (IIASA), an international research institute located in Laxenburg, Austria, has conducted a series of research projects studying population-development-environment (PDE) interactions. These projects started in Mauritius (see Lutz 1994), included Cape Verde (see Wils 1996), and the Yucatán Peninsula in Mexico (see Lutz, Prieto, and Sanderson 2000), and continued to three countries in southern Africa, i.e. Namibia, Botswana and Mozambique (see e.g. Sanderson et al. 2001). The second original paper in this study was one of the results of this project. 


\subsection{Theories, approaches and explanations of fertility transition}

\subsubsection{Fertility decline and the theory of demographic transition}

One of the best-known empirical generalisations in the social sciences and demographic research is the theory of demographic transition. The classical theory of demographic transition portrays the transition of societies from a regime of high levels of mortality and fertility to one where levels of mortality and fertility are low through a series of stages (Notestein 1945, Blacker 1947, as cited by Newell 1988). This theory has been criticised, for example, on the basis that mortality decline has not always preceded fertility decline (especially in the case of France), and also because it is unclear whether the theory is merely descriptive or whether it includes statements concerning causes of the transition. The theory of demographic transition is based on experience in European societies, and its applicability to Africa has also been criticised. It has not, however, been abandoned in demographic discussions (e.g. Cleland 2001b; Sinding 2001), even though a large part of the current debate concentrates on shifts in fertility.

Theories and approaches to fertility transition may be seen as connected with the theory of demographic transition, describing that part of the process in which fertility declines from its high pre-transition level to a new, lower, post-transition level. The names given to this shift in fertility vary. It has been called, for example, the "modern decline" in fertility by Coale and Treadway (1986), the "fertility revolution" by Easterlin and Crimmins (1985), and "fertility change" by Cleland, Onuoha, and Timæus (1994). The concepts used most commonly are sustained fertility decline, fertility decline (e.g. Caldwell 1982), and fertility transition (e.g. Bongaarts 2002, 2003).

Fertility transition, decline or revolution have mostly been defined as a shift from high to low levels of fertility combined with the shift from a natural fertility regime to fertility controlled by the use of contraceptives and abortion (e.g. Easterlin and Crimmins 1985). In their research into fertility decline in Europe, Coale and Treadway (1986) defined "modern decline" as the fall in the fertility of married couples as they began to employ both contraception and abortion, initially to stop further births after having had the desired number of children and later to space the births they chose to have.

Natural fertility was defined by Louis Henry as being that which exists in the absence of fertility control, and he further defined fertility control as existing "when [the] behaviour of a couple is bound to the number of children already born and is modified when this number reaches the maximum which the couple does not want to exceed" 
(Henry 1953, cited and translated by Menken 1979). In other words, in a population with natural fertility, there is no fertility-limiting behaviour which depends on the number of children already born (Newell 1988). Leridon (1975) also included the spacing of births in this definition. According to him, a natural system of fertility exists if "neither of the individuals, nor the couple jointly, consciously attempt to limit the number of births or space them." Levels of natural fertility vary among populations, and are determined by socio-cultural factors such as matrimonial customs, breastfeeding practices and sexual taboos, and may also vary in accordance with biological factors such as health levels and nutritional status in populations. In a population with controlled fertility, the number of children is limited in a deliberate manner, usually by the use of contraceptives and induced abortions (Bongaarts and Potter 1983; Leridon 1975; Newell 1988).

This shift in fertility from high to low levels is often seen as connected with societal changes that can be called economic and societal "modernisation" (e.g. Easterlin and Crimmins 1985), "development" (e.g. Lindert 1980; United Nations 1990), or "westernisation" (Caldwell 1976, 1982). These different concepts do not carry identical meaning, but reflect the differences in the underlying theories. While "development" carries strong positive connotations of a change from one stage to another in an upwards direction, the meaning of "modernisation" is more variable. While modernisation may have a positive connotation comparable to that of development, it may also be used to describe a change from one type of society to another without indicating any preference between these two. Modernisation is usually used to describe the shift from "traditional" to "modern" societies, combined with changes in both socioeconomic and cultural systems, i.e. increasing levels of formal education, urbanisation and industrialisation, even if this often reflects a simplified view in which "traditional" is viewed as something that stagnates and is unchanging. It is also possible to describe these changes as such, without using any simplifying terms such as, for example, modernisation. Westernisation, in its turn, means the adoption of western values, which Caldwell $(1976,1982)$ stated as being the main cause of fertility transition in the third world, not modernisation per se, although he currently refers to socioeconomic change and the globalisation of fertility attitudes and behaviour (Caldwell 2001).

In low-fertility societies, fertility decline has continued beyond the replacement level, and there has been discussion of both how low fertility levels will fall and whether a new equilibrium between fertility and mortality will be established. At the same time, while discussion in low-fertility countries (or post-transitional countries) is moving to the "second demographic transition" (see e.g. Surkyn and Lesthaeghe 2004) and to the "lowest-low fertility" (see e.g. Kohler, Billari and Ortega 2002), most of the other countries in the world have become part of the global decline in fertility. Even 
sub-Saharan Africa, which has so far lagged behind in the onset of fertility decline, has now become part of the general trend, even though high fertility regimes still exist in many parts of this region. In the sub-Saharan African context, many countries in southern Africa have been forerunners in fertility decline.

\subsubsection{Timing the onset of fertility transition}

Timing of the onset of fertility transition has conventionally been based on a rule applied by the Princeton European Fertility Project: fertility transition has begun when fertility has fallen by $10 \%$ or more below its plateau level in a sustained decline which continues until a greatly-reduced level of fertility is attained (Coale and Treadway 1986). "Sustained fertility decline" means that the decline is generally monotonic, except for post-war reversals, and that the decline continues until low levels of fertility have been achieved. This rule has been applied to sub-Saharan Africa by e.g. Caldwell, Orubuloye, and Caldwell (1992).

Casterline (2001) has criticised the appropriateness of this standard. Starting levels of fertility in current societies that are experiencing fertility transition is around seven, meaning that according to the Princeton convention, fertility decline is not considered to have begun until the decline equals 0.7 births or more. According to Casterline, it is also defensible to use the peak or plateau of fertility from which fertility begins to decline as the starting point of fertility transition. In countries where the pace of fertility decline is slow, the difference between these two approaches may result in significant differences in timing the beginning of fertility decline. Societal characteristics (e.g. levels of mortality and education etc.) may vary substantially between the two dates. In his research into fertility transition in developing countries, Bongaarts (2002) accepts Casterline's criticism and defines the onset of fertility transition as being the year in which the total fertility rate (TFR) drops to a point that is $5 \%$ below the maximum observed level.

Also, among countries in which fertility decline started prior to 1995, almost twothirds experienced an increase in fertility before the decline in fertility levels began. Increasing fertility levels often appear to be part of the process of departing from traditional fertility regimes (Dyson and Murphy 1985). There is even justification for starting the study of societal change that results in fertility decline from the point at which fertility begins to increase (Casterline 2001). Other definitions concerning the onset of fertility transition are also used by researchers. For example, Garenne and Joseph (2002) use a different set of criteria: the point at which the discrepancy between fertility trends in urban and rural areas of a country begins, the point when the slope of fertility trends becomes negative (by a minimum value of $-0.5 \%$ per year), and the 
point where the fertility level is, from a statistical viewpoint, significantly lower than earlier baseline levels.

\subsubsection{Explanations of fertility decline}

There are different explanations for and approaches to fertility decline. In the following, some simplified examples of the commonly-used approaches to fertility transition are presented. Microeconomic theories of fertility are specialised versions of the microeconomic theory of decisions applied to the choice that is made by a couple to have a child (see e.g. Leibenstein 1982; Lindert 1980). This theory is based on the assumption that people make decisions by doing things which result in the maximisation of utility, profit, etc. People are therefore considered to decide on family size by selecting a combination of children and goods which maximises utility, given the income constraint. Fertility transition begins because economic development results in children being more costly and less of an asset (Lindert 1980). Concurrently, an improved supply of efficient contraceptives provides means for limiting the number of children born.

John Caldwell (e.g. 1976, 1982, 2005) developed a theory of fertility transition based on the flow of wealth. He states that fertility is rational in societies of every type and at every stage of demographic transition, and that fertility levels depends on the direction of intergenerational wealth flows, i.e. all the money, goods, services and guarantees that one set of persons provide for another set. In traditional family-based production systems, this flow is from younger generations to older ones, while in a capitalist production system, the flow is reversed. According to Caldwell, this shift occurs after a family becomes nuclear, both emotionally and economically. He emphasises the role played by older generations, not only the biological parents, in decision making that concerns reproduction.

While microeconomic theories, in addition to those of Caldwell, mostly concentrate on the "demand" side, Easterlin's theory consisted of three central determinants: the demand for children, the supply of children and costs associated with fertility control (e.g. Easterlin and Crimmins 1985). The demand for children is the number of children that parents would like to have, taking into account child mortality, if the costs of fertility control are zero. The supply of children is the number of surviving children parents would have if they made no deliberate attempt to limit family size. This reflects natural levels of fertility and child mortality. The costs of fertility control consist of a couple's attitudes towards, and access to, fertility control methods, and thus includes both psychological and economic costs.

The innovation-diffusion framework for fertility transition emphasises the role played by social interaction in fertility decline (e.g. Cleland 2001a; Durlauf and Walker 2001). 
The spread of new ideas related to fertility control and information concerning its methods are important in explaining fertility transitions. According to Cleland (2001a) changes in reproductive behaviour are social transformations and thus influenced by climates of opinion and perceptions of the behaviour of others, and social influences are equally strong in pre-transitional, transitional and post-transitional societies.

In the 1990s and the 2000s, in parallel with the growing experience of fertility decline, a wide diversity in explanations for this phenomenon exists. No single theory has achieved hegemony in explaining the fertility transition. Every country has followed its own transition path, and the diversity of paths does not conflict with the universality of the transition (Kirk 1996). Current explanations for fertility decline include, for example, declining mortality levels, changes in the costs and benefits received from children (the economic approach), the opportunity costs of children, the transformation of families towards a nuclear model and weakening cultural support for high levels of fertility, improved access to effective methods for fertility regulation, the diffusion of ideas that family size should be limited and methods for achieving this, "modernisation", and government policies that promote family planning (see e.g. Bulatao 2001; Mason 1997).

In theoretical discussion of possible explanations for fertility decline, there appears to be a demand for a comprehensive explanatory framework (see e.g. Hirschman 1994). Scholars have attempted to satisfy this demand from different perspectives. For example, John Cleland (2001b) emphasises the role of declining mortality levels as an underlying cause of fertility decline, and Karen Oppenheim Mason (1997) suggest a perceptual, interactive approach which is allied to existing theories but focuses on the conditions which lead couples to switch from postnatal to prenatal controls on family size.

In the following, some approaches which are central to the theoretical framework for this study, which is presented in greater detail in Chapter 2.2, are discussed.

\section{Proximate determinants of fertility}

The proximate determinants of fertility approach employed by Bongaarts has proved a useful tool in fertility analysis in Africa (Bongaarts 1982; Bongaarts and Potter 1983). This approach was based on the framework of intermediate fertility determinants developed by Davis and Blake (1956), and it has been developed further by e.g. Stover (1998).

Proximate determinants are the most-immediate determinants of fertility. They also act as intermediate factors, for example socioeconomic and cultural factors affect some of the proximate determinants and these proximate determinants then affect 
fertility. Bongaarts defines the proximate determinants of fertility as follows (Bongaarts 1982): the proportion of females that are married, contraceptive use and effectiveness, the prevalence of induced abortion, the duration of postpartum infecundability, fecundability (or frequency of intercourse), spontaneous intrauterine mortality and the prevalence of permanent sterility.

The proximate determinants approach has been used in this study in several settings: firstly when comparing fertility in different regions of Namibia, secondly when assessing the factors that underlie fertility decline and changes that take place in these, and thirdly when examining the impact of HIV infection on fertility.

\section{The impact of mortality on fertility levels}

The link between declining mortality and declining fertility is one of the basic principles in the demographic transition theory. In terms of population levels, mortality decline has (in most cases) preceded fertility transition, but the mechanism by which this shift occurs has not been easy to detect. Child mortality has a biological effect on fertility by shortening the period of breastfeeding and thus the period of postpartum insusceptibility, and also a behavioural influence through replacement and insurance effects. In his reassessment of the link between mortality and fertility, Cleland (2001b) states that declining mortality is the most probable answer to the question of why fertility began to decline in almost all developing countries between 1960 and 1995. His view is that through, for example, rising costs caused by increased number of surviving children, a large decline in mortality puts pressure on families. Sooner or later, this pressure results in behavioural change, i.e. the limitation of births by contraception and abortion. The causal link between declining mortality and declining fertility cannot however be empirically tested, because a wide range of mediating factors obscure the relationship between trends in survival and fertility.

Infant and child mortality can be connected to fertility either through biological or behavioural effects. Biological effect is based on the impact of breastfeeding on the return of ovulation. Long and intensive breastfeeding postpones the return of menstrual cycle, i.e. lengthens the period of postpartum infecundability. If an infant dies, this consequence of breastfeeding is shortened or lacking, which shortens postpartum infecundability and thus the interval before the next birth. There is also a reverse biological connection between infant mortality and fertility: short birth intervals tend to increase levels of infant mortality.

Behavioural influences include replacement and insurance effects (Knodel 1979; Preston 1978, 1985). The replacement effect means that parents would like to have another child to replace the child who has just died, while the insurance effect means 
that a couple would like to have more children than their "ideal" number because of the possibility that some of their children will die when the parents are no longer at an age when reproduction is possible. In the theoretical framework for this study, the influence of infant mortality on fertility is combined with the ideal child number in a group called "motivation determinants".

\section{Socioeconomic and cultural factors}

Among socioeconomic differentials in fertility, the most-extensively-studied - and consequently the best-known - are educational fertility differentials (e.g. Bongaarts 2003; Cleland 2002; Jejeebhoy 1995; Lutz and Goujon 2001; Martín 1995; Wils and Goujon 1998). In general, women with a higher educational status have lower fertility than their counterparts with lower educational status. Education can impact fertility via many different routes. For example, in addition to the impact of a woman's own educational level on her fertility, increased levels of education in a society may reduce the ideal number of children by increasing the costs associated with education. Other socioeconomic factors are also linked to fertility. Higher socioeconomic status (urban, better-educated, and higher occupation) usually results in lower levels of fertility in Africa, although there are some exceptions. For example, in some regions that are in the early phases of fertility transition, women with some primary education have had higher levels of fertility than those with no education, primarily because of shortened periods of breastfeeding and, consequently, shorter periods of postpartum amenorrhoea.

In addition to socioeconomic factors, cultural factors affect fertility. In a context of a natural fertility regime, conventional practice and traditions connected with, for example, the length of breastfeeding and female age at first marriage are important determinants of fertility. Customs may also affect fertility levels, for example in some cultures the achievement of grandmother status marks the end of the reproductive period from a cultural viewpoint. Socioeconomic and cultural factors are combined into the group titled "basic factors" in the theoretical framework for this study.

\subsubsection{Current approaches used in research into fertility decline in Africa}

In the beginning of the 1990s, evidence concerning the onset of fertility decline in some sub-Saharan African countries began to accumulate. In research into this decline, scholars mostly leant on theories and approaches based on experience with fertility transition in other regions. In the following, some examples of the approaches to and explanations for fertility decline in sub-Saharan Africa (with a special emphasis on studies concerning southern Africa) during the 1990s and thereafter are presented. This sub-chapter is not, however, intended to be a comprehensive literature review of the topic. 
Some scholars, perhaps the best-known being John Caldwell, emphasise the unique features of fertility decline in Africa. In the opinion of some researchers, however, highlighting the unique nature of fertility decline in sub-Saharan Africa perhaps went somewhat too far, since in some respects, fertility transition in sub-Saharan Africa fitted the original transition theory better than fertility decline in European countries.

In the 1990s and thereafter, the approach widely used when studying fertility decline in sub-Saharan Africa has been that of proximate determinants of fertility. This approach was used in, for example, the Mbamaonyeukwu (2000) study of Nigeria, by Mhloyi (1994) in Zimbabwe and by Letamo and Letamo (2002) in Botswana, Zambia and Zimbabwe. Lamlenn (2000) tested Bongaarts' model in Cameroon, Gaisie (1995a, 1995b) used proximate determinants in his research on Botswana, with special emphasis on nuptiality, and Sibanda et al. (2003) used this framework in their research in Addis Ababa, Ethiopia. In the broader geographical context of sub-Saharan Africa, the proximate-determinants approach has been used by, for example, Kirk and Pillet (1998).

Explanations for fertility decline in sub-Saharan Africa, especially in the southern part of the continent, vary. Most often, explanations refer to societal changes which could be described by the concept of modernisation, even though this concept is seldom used as such.

Researchers tend to avoid monocausal explanations. Socioeconomic change, especially increasing levels of education, is often viewed as an important factor underlying declining fertility levels. Researchers who take an economic approach, such as Mbamaonyeukwu (2000) in work concerning Nigeria, link education to the increasing cost of having children that results in reduction of the ideal family size. Urbanisation is also one of the socioeconomic changes connected with fertility decline.

In his research into fertility decline in Botswana, Gaisie (1995a, 1995b) emphasised the role played by nuptiality and explored the impact of labour migration on marital patterns. He states that the penetration of capitalism caused political, social and economic changes that are linked to declining levels of fertility. Gaisie also acknowledges the role played by education and participation in the labour force, as well as the development of health services and governmental family-planning policies. Labour migration was also used in studies carried out before the 1990s to explain fertility patterns in southern Africa (Timæus and Graham 1989). The crucial role played by the migrant labour system in fertility decline in South Africa was highlighted by Makiwane (1996), who explains declining fertility levels by, for example, a dearth of marriageable young men, spousal separation and high rates of marital dissolution, with increasing levels of illegitimate births not being high enough to compensate for these effects. 
In Addis Ababa, Ethiopia, a reduced proportion of married women together with the increasing use of contraceptives were major mechanisms in fertility decline (Sibanda et al. 2003). According to this study, unemployment and high housing costs were the most probable explanations for delayed marriage and reduced marital fertility in Ethiopia's urban regions.

The impact of socioeconomic factors, especially education, on fertility has been studied by several researchers. Using World Fertility Survey (WFS) and Demographic and Health Survey (DHS) data from seven sub-Saharan African countries, Feyisetan and Casterline (2000) investigated the impact of the socioeconomic status of women on their fertility preferences and their use of contraceptives in 1970-1990. The results obtained provided some support for the idea that reduced demand for children is the primary cause of fertility decline in Africa, and that changes in socioeconomic factors are likely to be the forces that are driving this process. The results of this study, however, also revealed that if there is an already-existing but unsatisfied need for fertility control, an increase in the use of contraceptives may result without either socioeconomic change or changes in the preferred number of children. Uchudi (2000), in his turn, used DHS data from 15 countries in sub-Saharan Africa in the period 1991-1996 to study the impact of socioeconomic factors on the desire to stop having children and use contraceptives, with special attention being given to the role played by the spouse's education.

In their studies of fertility levels in South Africa, Moultrie and Timæus (2002, 2003) emphasised multiform explanations for fertility decline including urbanisation, education, the increasing availability of contraceptives after 1974 and again in 1984, together with the gradual freeing-up of South African society since the mid 1970s. They link the decline in fertility to a situation in which the whole political and economic fabric of society changed and state that the relatively-slow pace of fertility decline until the 1980s was a result of structural constraints imposed on African women by the apartheid system.

In his study concerning the relationship between service factors and the use of contraceptives in Zimbabwe, Muhwava (2003) utilises the approach of intermediate determinants proposed by Davis and Blake (1956) (which is closely related to Bongaarts' framework of proximate determinants), as well as Easterlin's synthesis framework (Easterlin and Crimmins 1985) for the supply and demand for children and the costs of contraception.

Muhwava (e.g. 2002b, 2003) highlighted the role of family planning services in fertility decline in Zimbabwe, and (2002b) concluded that the acceleration phase of fertility 
transition in Zimbabwe was linked to the availability of family planning services, especially the Community Based Distribution (CBD) system. He failed, however, to demonstrate any connection between the onset of fertility transition and family planning service availability, possibly because strong family planning programmes were already in place in the early 1980s and because data for his study was based on the 1988 and 1994 Zimbabwe Demographic and Health Surveys. Muhwava (2003) also showed that women in rural Zimbabwe with access to CBD services were more likely to use contraceptives.

There are other explanations for fertility decline in southern Africa. Rutenberg and Diamond (1993) state that fertility decline was a consequence of the economic crisis caused by conditions of severe drought during most of the 1980s. They concluded that a severe period of drought in Botswana resulted in an environment that was conducive to accepting the idea of delaying the next birth, while an increase in family planning services provided the means to do this. They state that a decline in fertility levels was connected with drought in several ways, for example by impacting marital patterns, causing spousal separation and by being a coping strategy in an era of drought. In a study among the Herero in Ngamiland, Botswana Poukouta (1994) states that because of the Herero's different economic and social organization, they followed different survival strategies in drought conditions and did not experience a decline in fertility. The approach which emphasises the role of economic hardship in fertility decline has sometimes been termed "crisis-driven fertility decline".

The impact of war on fertility levels in Africa has been studied by Agadjanian and Prata in Angola $(2001,2002)$ and Lindstrom and Berhanu (1999) in Ethiopia. Agadjanian and Prata $(2001,2002)$ found a war-related decline and rebound in regions most directly affected by war in Angola, and a similar decline and rebound among the best-educated and more-affluent people who were both more willing and able to control their fertility. They did not, however, find any evidence that war has an enduring, direct effect on fertility. In Ethiopia, according to Lindstrom and Berhanu (1999), there were also declines in conception probabilities during the famine and periods of political and economic upheaval, with these being followed by rebounds in fertility in the 1970s. Lindstrom and Berhanu argue that part of this effect was due to the intentional postponing of births, in addition to spousal separation and temporary migration. In addition, they concluded that the continuation of civil war and economic hardship played an important role in the decline in fertility levels in the 1980s. 


\subsection{Fertility decline in southern Africa}

There appear to be some features that are typical of fertility transition in several regions in southern Africa. These include an increase in age at first marriage and high levels of adolescent and premarital fertility and are found in South Africa, Namibia and Botswana (e.g. Chimere-Dan 1997; Dickson 2003; Gage 1998; Gaisie 1995a; 1995b; Garenne, Tollman and Kahn 2000; Garenne et al. 2006; Garenne and Zwang 2006; Letamo and Letamo 2002; Potts and Marks 2001). The background to these phenomena appears to be the influence of labour migration, which does, however, vary according to marital patterns and agricultural systems. In addition, socioeconomic and cultural changes such as increasing levels of formal education and weakened control by communities and relatives over adolescent reproduction and sexual behaviour have contributed to increasing levels of premarital fertility in certain regions (e.g. Gaisie 1995a, 1995b; Potts and Marks 2001; Timæus and Graham 1989). Premarital fertility is not uniformly high in southern Africa, however, one exception being Lesotho, where it has remained relatively low (Potts and Marks 2001).

In many other respects, however, fertility decline in southern Africa shares features observed in the remainder of sub-Saharan Africa. To a significant degree, contraception is used to space births and fertility decline also therefore occurs in what are the central childbearing ages, in contrast to the situation in Europe and Asia where the decline in fertility began among older women (Caldwell et al. 1992).

\subsubsection{The state of fertility transition in Namibia's neighbours}

Recent decades have witnessed the onset of fertility decline in sub-Saharan Africa. Based on DHS data from 1986-1995, Kirk and Pillet (1998) found fertility decline in two-thirds of the 23 countries covered by their research. Garenne and Joseph (2002), who also used DHS data as a basis, stated that fertility was declining almost everywhere in urban areas of sub-Saharan Africa. The point at which the onset of this decline occurred varied from the 1960 s to the 1980 s, and in general terms, a decline in rural areas followed after some 10 to 20 years.

Among countries in southern Africa, sustained fertility decline is on-going in South Africa, Zimbabwe, Botswana, Lesotho, Namibia and Swaziland (Potts and Marks 2001). Modest fertility decline has also taken place in Mozambique, Zambia and Malawi, while Angola was still in the pre-transitional phase at the end of the 1990s. On the whole, countries in southern Africa have been the forerunners in fertility transition in sub-Saharan Africa, and are accompanied by Kenya in eastern Africa, where fertility began to decline in the early 1980s or already in the late 1970s (GRK/NCPD, 
GRK/CBS, and Macro International 1999; Westoff and Cross 2006). A summary of the state of fertility transition in Namibia's neighbours follows.

Recent research shows that fertility transition in South Africa, including women classified as Africans, began already in the 1960s (Moultrie and Timæus 2002, 2003) and predated the establishment of a family planning programme in 1974. At the beginning, the pace of fertility decline was slow but it accelerated during the 1980s. Fertility in South Africa is lower than fertility in other countries in sub-Saharan Africa (Swartz 2003). Moultrie and Timæus $(2002,2003)$ estimate that TFR in South Africa was 3.2 in 1996, and the South African Demographic and Health Survey 1998 estimated that TFR was 2.9 in the three-year period prior to the survey (GRSA/DoH, MRC and Macro International 2002). Based on the 2001 census, Moultrie and Dorrington (2004) estimated that total fertility in South Africa had declined to 2.8 among all women and to 3.0 among African women.

Botswana, another of Namibia's neighbours, was also among the first nations in subSaharan Africa in which fertility began to decline. In Botswana, the decline began in the late 1970s or in the early 1980s, even though adjustments to the census and survey results show that estimations of fertility decline in the 1980s may have been exaggerated, and that the onset of decline varied among different sub-populations (e.g. Blanc and Rutstein 1994; Gaisie 1995a, 1995b; Poukouta 1994; Rutenberg and Diamond 1993; Thomas and Muvandi 1994a, 1994b; Udjo 1998). According to Garenne and Joseph (2002), fertility decline in Botswana began before 1974 in urban areas and in 1974 in rural areas. In 1999, the TFR in Botswana was estimated to be 4.0 (GRB/CSO 2004).

As in the case of Botswana, fertility decline in Zimbabwe was a subject of discussion in the early 1990s, with contradictory opinions being expressed concerning the pace of fertility decline, real levels of fertility, and the comparability of the 1984 Zimbabwe Reproductive Health Survey and the 1988 Zimbabwe Demographic and Health Survey (e.g. Blanc and Rutstein 1994; Thomas and Muvandi 1994a, 1994b). Later, Muhwava and Timæus (1996) claimed that the estimate for Zimbabwean fertility published in DHS 1994 (GRZ/CSO and Macro International 1995) was too low, with the real level being 5.2 instead of 4.3. They also concluded that fertility in Zimbabwe declined slowly during the 1970s civil war (Muhwava and Timæus 1996; Muhwava 2002a). In the early 1980s, there was possibly a short post-war baby boom, following which a sustained decline in fertility levels began in the mid-1980s and then continued into the 1990s. According to Zimbabwe's DHS 1999, TFR was 4.0 in 1995-99 (GRZ/CSO and Macro International 2000). 
In contrast to the countries already mentioned, fertility in Zambia remains high despite a slowly-declining trend (GRZa/CSO, GRZa/CBH, and ORC Macro 2003). Garenne and Joseph (2002) estimate that fertility transition in both urban and rural regions of Zambia began in 1977. According to the Zambia DHS 2001-2002, TFR was 5.9 during the three-year period that preceded this survey. Among Namibia's neighbours, fertility is highest in Angola and fertility decline in this country had still not started at the end of the 1990s (Agadjanian and Prata 2001). In 1996, TFR in Angola was estimated to be 6.9. According to an estimation by UNDP, fertility levels in Angola exceed 7.0 and are not falling (United Nations 2004), whereas Casterline (2001) considers that fertility decline in Angola began in the period 1990-1995.

\subsubsection{Research into fertility in Namibia}

Research into fertility in Namibia was scarce before independence. On the eve of this historical event, a demographic study concerning fertility-related issues was carried out, but this unfortunately excluded the region dealt with in the current study (Mostert 1989, as cited in UNICEF Namibia 1991). Following independence, the use of contraceptives was a subject of interest to researchers. In the early 1990s, some smaller-scale surveys collected information on contraception in selected regions of Namibia (Ahrenson-Pandikow 1992), sometimes as a part of a survey with a wider scope, for example the health of households (UNICEF Namibia 1990) or gender issues (Namibia Development Trust 1994). Lucas (1992) reviewed fertility and family planning in Namibia and other countries in southern and central Africa.

These studies were important, and the results were used when setting up family planning services in the newly-independent nation. The picture they revealed was that a country with wide differences in both the availability of family planning services and in the use of contraceptives in different regions and ethnic groups. During South African rule, the provision of family planning services and choice of methods were both segregated along the lines set by apartheid (Lucas 1992). A survey of attitudes towards contraceptives showed that at the beginning of independence, prejudices against contraception and fear of the possible side effects appear to have been obstacles against their use (Ahrenson-Pandikow 1992). The study region was characterized by high fertility, low use of contraceptives and poor family-planning services (Namibia Development Trust 1994; UNICEF Namibia 1990, 1991).

Collection of more comprehensive data-sets on fertility also started in the early 1990s. The principal sources of information concerning fertility levels and regional differentials in Namibia are the 1992 and 2000 NDHS surveys, together with the 1991 and 2001 censuses. When data from the 1992 NDHS and the 1991 Population and Housing Census became available, most researchers investigating fertility-related issues 
in Namibia concentrated on these two data sets (Arowolo 2000; Chimere-Dan 1997, Gage 1998; Garenne and Zwang 2006; Hamata n.d.; Pulkkinen 1997; Raitis 1995).

The Demographic and Health Survey data sets from several countries in sub-Saharan Africa have been used in research into the state of fertility transition in different regions of this part of the continent. Some studies have utilized the NDHS data from Namibia. At national level in Namibia, Garenne and Joseph (2002) estimate that fertility transition started before 1979 in both urban and rural areas and that the urban and rural fertility patterns began to deviate in 1970. Kirk and Pillet (1998), also working at national level, classified Namibia as belonging to the group of countries in which there is a steady fertility decline. Both these estimations were based on data from the 1992 Namibia Demographic and Health Survey (NDHS). Based on the same data, Tabutin and Schoumaker (2001) stated that there were pronounced differences in the progress of fertility transition in different regions in Namibia, and in many other countries in sub-Saharan Africa. In addition to international comparisons, the 1992 and 2000 NDHS and 1991 and 2001 Population and Housing censuses have all provided data for the study of fertility in Namibia.

Connections between socio-economic factors and fertility in Namibia have been studied by Sylvia Hamata (n.d.) and O.O. Arowolo (2000). Hamata (n.d.) examined the impact of socioeconomic factors (including education, urban/rural residence, region of residence, and ethnicity) and proximate determinants (including marital status, age at first birth, and current use of contraception) on fertility using data from the 1992 NDHS and the 1991 Population and Housing Census. In this analysis, Hamata (n.d.) used the 1992 NDHS data to study differences in the mean number of children ever born in relation to the background characteristics of women. In the region examined in the current study, the background characteristics which provided the strongest explanation for differences in fertility were marital status and education. After controlling for current age, women who had never been married had an average of one child less than women who were currently married or had previously been married. Secondary or higher education was also an important factor in reducing fertility.

Arowolo (2000) used data from the 1991 Population and Housing Census, the 1992 NDHS, and preliminary results from the 1996 Intercensal Demographic Survey. He analysed the impact of socioeconomic factors on differentials in TFR at regional level. According to his results, education had a strong negative impact on fertility levels. The proportion of households with electricity and higher levels of urbanisation also had a negative effect on fertility, whereas lack of modernisation had the opposite effect. 
Pulkkinen (1997) studied differences in fertility between Namibia's ethnic groups. When comparing the TFR of women in different language groups using 1992 NDHS data, she discovered that fertility was highest among women speaking the San, Kwangali and Oshiwambo (i.e. Ovambo) languages, followed by speakers of the Herero, Lozi and Damara/nama languages. According to Hamata (n.d.), the fertility of women in different ethnic groups varied in accordance with their place of residence in different regions of the country.

Issues related to premarital fertility, teenage pregnancies and adolescent sexuality were also of interest in the early days of independence and this focus of attention has continued up to the present day. Adolescent sexuality and premarital fertility have been studied using either data collected specifically for that purpose in certain regions of Namibia (e.g. Hailonga 1993, 2005) or by using the NDHS data sets (Chimere-Dan 1997, Gage 1998; Garenne and Zwang 2006).

In her $\mathrm{PhD}$ research, Hailonga (2005) studied adolescent sexuality and reproductive behaviour based in the main on interview data collected in the Katutura township of Windhoek and in Tsandi, which is located in North-Central Namibia. According to Hailonga, adolescent sexuality and reproductive behaviour is a complex issue, affected by, among other things, the historical and contemporary social environment, the cultural role played by men, the contradictory roles of adolescents in modern society, and a lack of proper guidance from either one's own traditions or from modern or western values.

Based on the 1992 and 2000 NDHS data, Garenne and Zwang (2006) revealed that premarital fertility was very prevalent in Namibia. Among the country's ethnic groups, premarital fertility among the Ovambo was at intermediate levels. Garenne and Zwang concluded that the high levels of premarital fertility were due to a high mean age at first marriage and low levels of contraception use before marriage. Chimere-Dan (1997) studied non-marital teenage fertility on the basis of the 1992 NDHS data, reaching the conclusions that teenage mothers are common in Namibia and that this finding was in line with the emerging reproductive regime of Southern Africa where motherhood is separated from marriage. A comparison of DHS data from Kenya (1993) and Namibia (1992) by Gage (1998) showed that premarital births were more common in Namibia, and that in both countries, women with premarital births were less likely to seek prenatal care during the first trimester of their pregnancy than women with marital births. In Namibia, this effect is smaller among women in ethnic groups with higher rates of premarital pregnancies, possibly indicating a greater social acceptance of premarital mothers and their children in these societies. 
Research into parish registers in Northern Namibia conducted by researchers at the University of Helsinki, the University of Joensuu and the London School of Hygiene and Tropical Medicine has provided a longer-term view of developments in fertility in Namibia's northern regions (Lemström 1999; Notkola 1996; Notkola and Siiskonen 2000; Shemeikka and Notkola 2005; Shemeikka, Notkola, and Siiskonen 2005). These studies provided detailed information on levels of fertility and variations in them, as well as information on the factors that influence such variations. The current study is part of these research projects.

A separate but interesting line of research has been studies into connections between body dimensions, nutrition and fertility among the !Kung San hunter-gatherers in northern Namibia (see e.g. Kirchengast and Winkler 1996; Winkler and Kirchengast 1994) and on the Botswana side of the Kalahari desert, a region shared by Namibia and Botswana (e.g. Pennington 1992). These studies show that among !Kung females, under-nutrition was associated with high fertility and low child mortality, whereas among the Kavango, it was well-nourished females who had higher levels of fertility and lower child mortality (Kirchengast and Winkler 1996). Female "shortness" was associated with high fertility but also with high child mortality in both ethnic groups (Kirchengast and Winkler 1996). Among males, however, a robust build was associated with larger numbers of male children and lower child mortality, compared to more slender men (Winkler and Kirchengast 1994). While an improved supply of food did not increase fertility levels among the !Kung in the Botswana Kalahari, it did reduce infant and child mortality (Pennington 1992).

\subsection{Research into fertility - HIV connections in sub-Saharan Africa}

\subsubsection{HIV and AIDS}

HIV (Human Immunodeficiency Virus) is a retrovirus that infects cells of the human immune system, e.g. CD4-positive T-cells and macrophages. The virus enters cells of the immune system and destroys them, progressively weakening the host system and causing 'immune deficiency'. 'Opportunistic diseases', i.e. some types of infection and cancers that are often easily treated in a person with healthy defences, take advantage of the weakened immune system. The most advanced stage of HIV infection is AIDS (Acquired Immunodeficiency Syndrome). AIDS is identified either on the basis of particular infections (WHO Clinical Stage IV HIV infection) or on the basis of a CD4-

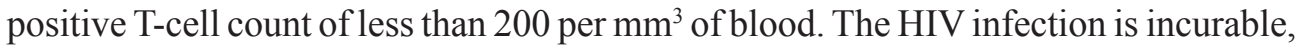
but antiretroviral therapy (ART), i.e. treatment using antiretroviral drugs (ARV), suppresses viral replication and reduces symptoms. Treatment regimens recommended 
by leading HIV experts for aggressively suppressing viral replication and thus the progress of HIV is called highly-active antiretroviral therapy (HAART). (Barnett and Whiteside 2002; Evian 2000; UNAIDS 2005a, 2005b; WHO 2004, 2005).

An epidemic is a disease which spreads rapidly through a demographic segment of a human population, e.g. the inhabitants of a specific region. The word pandemic describes epidemics of global proportions. UNAIDS recommends use of the term 'pandemic' when referring to global aspects of HIV/AIDS, and that 'epidemic' be used at country or regional level. Incidence is the number of new infections that occurs in a given time period. The incidence rate is the number of new infections per specific unit of population, e.g. per 1,000 or per 10,000 in a given period. Prevalence is the number of infected people at any given time. The prevalence rate is the percentage of population which exhibits the disease at a point in time, or averaged over a period of time. UNAIDS, however, recommends that the term "prevalence" rather than "prevalence rate" also be used in the latter meaning. In developing countries, regular monitoring of the prevalence rates in certain sub-populations, e.g. pregnant women, blood donors, or STD patients, is usually the major means of collecting data concerning the state of an epidemic. (Barnett and Whiteside 2002; UNAIDS 2005a.)

For some of the terms connected with HIV and AIDS, UNAIDS published new recommendations for preferred use in 2005. In the original articles included in this study, some of these new recommendations have not yet been taken into account. For example, it is recommended that 'HIV and AIDS', or 'HIV disease and AIDS', should be used instead of 'HIV/AIDS'. The concept of 'vulnerable groups' should be replaced by the concept 'most likely to be exposed to HIV', and instead of the concept 'high(er) risk group', the concept 'key populations at higher risk' should be used. The term 'HIVpositive' may sometimes have been used in cases where 'HIV-infected' would have been more accurate (because of the sometimes false-positive HIV test results).

Current knowledge indicates that the human immunodeficiency virus (HIV) originated in Africa (e.g. Barnett and Whiteside 2002; Iliffe 2006; Löytönen 2003). It is probable that in western equatorial Africa, simian immunodeficiency virus (SIV) in monkeys and chimpanzees was transmitted to humans (see e.g Iliffe 2006). This view is supported by a recent finding from southern Cameroon, where a high prevalence of SIV, which is closely related to HIV, was found among isolated chimpanzee communities (Keele et al. 2006). There are, however, alternative theories of the origins of HIV.

The oldest known HIV-infected blood specimen was collected in 1959 in Kinshasa, at that time Leopoldville, in the Belgian Congo (Nahmias et al. 1986; Zhu et al. 1998). This blood sample was originally collected for research into malaria, but the frozen 
specimens were tested for HIV when testing techniques became available in the mid 1980s. There are other cases which also indicate that HIV already existed in the 1950s (Iliffe 2006), even though the number of occurrences was rare. Attempts have been made to date the origin of HIV virus by studying its mutation speed using specimens of stored blood with a known date. Assessed in this manner, the common ancestor of the current subgroups of HIV was estimated as having existed in the 1930s.

Although HIV has been present since at least 1959, it took 20 years for the visible epidemic to develop. Iliffe (2006) gives three explanations for this slow pace of development: firstly, HIV is not easily transmitted (compared to, for example, airborne influenza). Secondly, the disease develops only very gradually in humans, and this long incubation period gives the HIV epidemic its unique character. Thirdly, HIV and AIDS kill people through other so-called opportunistic diseases, which made it difficult to discover the presence of a new disease. The first epidemic of HIV was in Kinshasa in the mid 1970s, and was followed by an epidemic among homosexual men in San Francisco (USA) at the end of the 1970s and in the early 1980s, and an epidemic in eastern Africa in the 1980s. The human immunodeficiency virus was first recognised in the early 1980s in the USA. At the same time, cases of the disease began to be recognised in many different parts of the African continent.

At the end of 2005, 24.5 million people were living with HIV infection in sub-Saharan Africa. This represents $63 \%$ of all the cases of HIV infection in the world (UNAIDS 2006). During the HIV pandemic, its focus has shifted southwards in sub-Saharan Africa (Kalipeni, Craddock and Gosh 2004). In the 1980s, the prevalence of HIV was highest in central and eastern Africa. During the 1990s, HIV prevalence increased rapidly in southern Africa. By the end of 2005, the countries most seriously affected, i.e. Botswana, Lesotho, Namibia, South Africa, Swaziland and Zimbabwe, were all located in southern Africa (UNAIDS 2006). In these countries, $19-33 \%$ of the population between the ages of 15 and 49 years was estimated to be suffering from HIV infection.

\subsubsection{The impact of HIV on fertility in sub-Saharan Africa based on earlier studies}

Earlier research shows that HIV infection is associated with reduced fertility in several sub-Saharan African countries (e.g. Fabiani et al. 2006; Glynn et al. 2000; Gray et al. 1998; Hunter et al. 2003; Lewis et al. 2004; Ntozi et al. 1997). Compared with HIVnegative women, HIV-infected women have lower rates of conception and increased rates of foetal loss (Carpenter 1997; Crampin et al. 2003; Gray et al. 1998). Fertility reduction starts at the earliest asymptomatic stage of HIV infection and increases as the HIV disease progresses (Ross et al. 2004; Sedgh et al. 2005). Co-infection with other sexually transmitted diseases is associated with sub-fecundity and explains a 
part of the foetal losses suffered by HIV-infected women. (Gray et al. 1998; Zaba and Gregson 1998). Low gravidity prior to HIV infection explained almost half the reduction in fertility among HIV-infected women in rural Uganda (Ross et al. 1999; see also Sule-Odu et al. 2005).

In societies with a high prevalence of HIV infection, the HIV epidemic affects the reproductive behaviour - and thus the fertility - of both those who are infected and the remainder of the population (Ntozi 2002; Terceira et al. 2003). Some of the resulting behavioural changes act to reduce fertility but others operate in the opposite direction, i.e. to increase it (Zaba and Collumbien 1997). In Uganda, changing sexual behaviour, for example the increased use of condoms, has run in parallel with a reduction in HIV prevalence and reduced fertility, especially among unmarried teenagers (Kamali et al. 2000), whereas in Zambia, Rutenberg and her colleagues (2000) suggested that HIV epidemic only affected behaviour among infected people, and only after the first symptoms of their disease had been recognised.

The impact of HIV infection on fertility at population level has been estimated by, for example, Zaba and Gregson (1998), who, based on experience with several studies primarily carried out in eastern Africa, estimated that a $1 \%$ increase in female HIV prevalence resulted in a $0.4 \%$ reduction in total fertility at population level. This is in line with findings by Lewis et al. (2004). Terceira et al. (2003) discovered that HIVassociated sub-fertility possibly accounted for one-quarter of the decline in fertility levels since the 1980s in the high-contraceptive-use setting of rural Zimbabwe. Lewis et al. (2004) estimated that because of excess mortality and HIV-associated sub-fertility, there was a 6\% reduction in number of births in Uganda between 1980 and 2000. The impact of HIV on fertility levels may change according to the duration of the epidemic in a region (Heuveline 2003).

While proximate determinants of fertility and adult HIV prevalence overlap, they do not always exert influence in the same direction (Table 1) (e.g. Gregson 1994; Gregson et al. 1997; Gregson, Zaba, and Hunter 2002; Ntozi 2002). For example, a high rate of condom use reduces both HIV prevalence and fertility, whereas high rates of divorce and widowhood often reduce fertility (assuming that fertility is lower outside marriage) but increase HIV prevalence (in cases where the new partner is infected or when a series of short-term relationships occurs before a new regular partner is found). While socioeconomic and cultural factors affect both fertility and HIV through these proximate determinants, their impact can work in the same or in different directions if they affect other proximate determinants. For example, urbanisation tends to result in lower levels of fertility but a higher prevalence of HIV. 
Table 1. Hypothesised mechanisms for interaction between the HIV epidemic and the proximate determinants of fertility in sub-Saharan African settings, according to Gregson (1994).

\begin{tabular}{|c|c|c|}
\hline $\begin{array}{l}\text { Proximate } \\
\text { determinant of } \\
\text { fertility }\end{array}$ & Possible mechanism for interaction & $\begin{array}{l}\text { Hypothesised } \\
\text { effect on } \\
\text { fertility }\end{array}$ \\
\hline \multirow{7}{*}{$\begin{array}{l}\text { Marriage: exposure } \\
\text { to sexual relations }\end{array}$} & Delayed onset of sexual relations & Negative \\
\hline & Reduction in premarital sexual relations & Negative \\
\hline & $\begin{array}{l}\text { Delayed marriage - possibly resulting in increased } \\
\text { non-marriage }\end{array}$ & Negative \\
\hline & Reduced polygyny & Positive \\
\hline & Increased divorce & Negative \\
\hline & Increased widowhood & Negative \\
\hline & Reduced remarriage & Negative \\
\hline \multirow{5}{*}{$\begin{array}{l}\text { Contraception and } \\
\text { abortion }\end{array}$} & $\begin{array}{l}\text { Reduced desired family size due to the fear of } \\
\text { passing on infection or leaving orphans }\end{array}$ & Negative \\
\hline & $\begin{array}{l}\text { Increased desired family size to ensure survival of } \\
\text { preferred minimum and increasing "replacement } \\
\text { effect" due to HIV related child mortality }\end{array}$ & Positive \\
\hline & Increased condom use to protect against HIV/STDs & Negative \\
\hline & $\begin{array}{l}\text { Switching of family planning method from pill to } \\
\text { condom }\end{array}$ & Positive \\
\hline & $\begin{array}{l}\text { Increased abortion to avoid bearing an infected } \\
\text { child or potential orphan }\end{array}$ & Negative \\
\hline \multirow{3}{*}{$\begin{array}{l}\text { Breastfeeding and } \\
\text { postpartum } \\
\text { abstinence }\end{array}$} & $\begin{array}{l}\text { Reduction in breastfeeding due to concerns re } \\
\text { vertical transmission of HIV infection }\end{array}$ & Positive \\
\hline & $\begin{array}{l}\text { Reduction in postpartum abstinence to avoid } \\
\text { regular partners having other relationships and } \\
\text { contracting HIV infection }\end{array}$ & Positive \\
\hline & $\begin{array}{l}\text { Reduction in breastfeeding and postpartum } \\
\text { abstinence due to increase in infant mortality } \\
\text { (natural "replacement effect") }\end{array}$ & Positive \\
\hline \multirow[b]{2}{*}{$\begin{array}{l}\text { Pathological } \\
\text { sterility }\end{array}$} & HIV induced sterility & Negative \\
\hline & $\begin{array}{l}\text { Reduction in existing STDs due to greater condom } \\
\text { use, lower rates of partner change and increased } \\
\text { access and resort to treatment }\end{array}$ & Positive \\
\hline \multirow{3}{*}{ Natural fecundity } & Increase in spontaneous abortions and stillbirths & Negative \\
\hline & $\begin{array}{l}\text { Reduced coital frequency due to increased } \\
\text { morbidity }\end{array}$ & Negative \\
\hline & $\begin{array}{l}\text { Reduction in spousal separation due to HIV control } \\
\text { interventions by employers }\end{array}$ & Positive \\
\hline \multicolumn{2}{|c|}{$\begin{array}{l}\text { Reduced nutrition, deteriorating health and reduced quantities of } \\
\text { spermatozoa }\end{array}$} & Negative \\
\hline
\end{tabular}

Source: Gregson 1994. 


\subsubsection{Studies of HIV in Namibia}

In the early days of the pandemic, the number of HIV-related studies was modest, but the growing prevalence of the disease resulted in an explosion of work (see van Zyl 2003). A pilot study of the topic was the National AIDS Awareness Survey (NISER 1991), and this was followed by a comprehensive presentation of the state of the AIDS epidemic in Namibia by Slotten (1995), a survey of sexual knowledge, attitudes and practices by NANASO (1995), and an analysis of the social epidemiology of HIV and AIDS in the former Ovamboland region by Webb and Simon (1995). UNDP Namibia assessed the state of the HIV pandemic in its Human Development Reports (e.g. UNDP Namibia 1997, 2000). Information on the state of the HIV epidemic in Namibia is provided by HIV Sentinel Surveillance Reports and by epidemiological reports from the Ministry of Health and Social Services (e.g. GRN/MoHSS 2003a, 2003c, 2005).

Although the number of HIV-related reports increased rapidly in the latter half of the 1990s and in the 2000s, the proportion of these made from a demographic viewpoint is not particularly large. The demographic consequences of HIV and AIDS have been assessed by e.g. Jakobsen (2000), Notkola, Timæus, and Siiskonen (2004), Ojo and Delaney (1997), Phororo and Venditto (2003), Sanderson et al. (2001), Shemeikka (1999), Shemeikka and Notkola (2005), van Dillen, Meguid and van Roosmalen (2006), and the World Bank (2001), in some cases as a part of a wider analysis of the economic consequences of the HIV pandemic.

The prevention of HIV infection among adolescents has been studied by e.g. Fitzgerald et al. (1999), Olenick (1999) and Stanton et al. (1998), and Yamakawa (2001) has studied sexual knowledge, attitudes and practices among secondary-school pupils in Katutura. Research into the socio-cultural factors and gender roles behind the rapid spread of HIV infection in Namibia is of interest from the viewpoint of the present study (e.g. Brown, Sorrell and Raffaelli 2005; Fox 2002; Iipinge, Hofnie, and Friedman 2004; LeBeau et al. 1999, 2002; Mufune 2003; Talavera 2002a, 2002b).

A substantial proportion of current research into HIV concentrates on assessment of the consequences of HIV and AIDS on different sectors or population groups in Namibia (see e.g. Cownie 2001; Engh, Stloukal, and du Guerny 2000; GRN/MoHSS and UNICEF 1998; Impact of HIV/AIDS... 2001; Lwin 2001; Matanyaire and Timpo 1999; Phororo 2001, 2002, 2003; Phororo and Mohamed 2001; Phororo and Venditto 2003; Pendukeni 2004; Plattner and Meiring 2006; Rompel 2003; Sanderson et al. 2001; SIAPAC 2002, 2003).

Conditions associated with the state of the HIV epidemic deteriorated quickly during the 1990s (see e.g. GRN/MoHSS 2003c, 2005). Research into HIV in Namibia shows 
that although knowledge concerning HIV has improved during the epidemic (see e.g. NISER 1991; NANASO 1995; GRN/MoHSS 2003b), this enhanced understanding has not been quickly transferred to behavioural changes, despite some promising indications (e.g. Stanton et al. 1998). The spread of HIV is fuelled by, for example, poverty, sexual inequality and traditional gender roles, and alcohol abuse, among other factors (e.g. Fox 2002; Brown et al. 2005; Iipinge et al. 2004; LeBeau at al. 1999, 2002; Mufune 2003). Currently, the HIV epidemic has a pronounced effect on both families and communities (e.g. Phororo 2002; Rompel 2003; SIAPAC 2002, 2003) as well as on different sectors of the economy (e.g. Phororo 2003; Phororo and Muhamed 2001; Phororo and Venditto 2003; Sanderson et al. 2001; World Bank 2001).

The HIV epidemic has had a pronounced effect on mortality in Namibia. Based on parish register data, Notkola et al. (2004) reported a substantial increase in infant, child and adult mortality in the 1990s in North-Central Namibia, while van Dillen et al. (2006) showed that HIV was the single most important factor influencing maternal mortality, resulting in $45 \%$ of maternal deaths at the Onandjokwe hospital, located in the study region, in 2001-2003. In future, the HIV epidemic will influence both the size and demographic structure of populations in both the study region and the whole country (e.g. Jakobsen 2000; GRN/NPC 2006a; Sanderson et al. 2001: Shemeikka 1999; Shemeikka and Notkola 2005; World Bank 2001).

The state of HIV epidemic is discussed in additional detail in Section 4.6.1 of this study, while factors contributing to the HIV pandemic and the resulting consequences are discussed further in the Conclusions and Discussion sections.

\subsection{Demographic research using parish registers in sub-Saharan Africa}

Two of the original papers of this study are based on parish-register data, a type of data which is rather exceptional in demographic research in sub-Saharan Africa. Both this field of research and African studies in general suffer from a lack of sources of long-term written data. Parish-register data could provide at least a partial solution to this problem.

Parish-register data is a result of missionary activity in sub-Saharan Africa. Missionaries attempted to spread the Christian doctrine among Africans, and where they succeeded, founded congregations and began to use parish registers of a form often similar to those used in the missionaries' countries of origin. In many cases, however, the old registers have suffered physical damage or even disappeared, or there are other reasons which may make their utilisation in research work impossible. 
In contrast to historical demographic research conducted in Europe, the use of parish registers in African population studies has so far been relatively unusual. A.M.M. Nhonoli (1954, as cited by Colwell 2000) studied infant mortality in the period 19411952 in Unyamwezi, in the British colony of Tanganyika (Tanzania) using parish records from the Ndala mission, and Stacie Colwell (2000) studied infant and child mortality in Kilimanjaro, Tanzania, during 1894-1935 using both Lutheran and Catholic parish registers. J. Katzenellenbogen, D. Yach and R.E. Dorrington (1993) used parish registers from the Moravian Mission at Mamre in Western Cape, South Africa, to study mortality in rural South Africa in the period 1837-1909. John Thornton used baptismal registers from the 17th and 18th Century to study the demographic history of the Kingdom of Kongo (Thornton 1997b) and baptismal registers from the 18th Century to study the demographic history of the Manguenzo district, located in the current Republic of Congo (Thornton 1977a). Gaëtan Feltz (1990) used parish registers to study the demographic history of Burundi in 1900-1962. Daniel Benoit and Bernard Lacombe (1977) used parish registers in their demographic research concerning Senegal and Burkina Faso in the period 1910-1920. Parish registers were also used in research into the demography of 'whites' in South Africa during the 18th century (Ross 1975) and from the 18th century to 1820 (Gouws 1987).

The parish registers of Evangelical Lutheran congregations in northern Namibia have been used in several demographic studies conducted at the University of Helsinki, the University of Joensuu and the London School of Hygiene and Tropical Medicine (Joutsenniemi 2006; Lemström 1999; Notkola 1996, 2004; Notkola and Siiskonen 2000; Notkola, Timæus, and Siiskonen 2000; Notkola et al. 1998, 2004; Shemeikka and Notkola 2005; Shemeikka et al. 2005; Siiskonen 1998; Siiskonen, Taskinen, and Notkola 2005). The present study is one of the results of joint research projects by these institutions.

In addition to demographic research, parish registers from sub-Saharan Africa have been used in other scientific fields. For example, the ELCIN parish registers from North-Central Namibia have been used in research into the Ovambo naming system (Saarelma-Maunumaa 2003) and the conversion of Ovambo to Christianity (Miettinen 2005), while parish registers from Angola have been used in historical research concerning slavery (Curto 2002). 


\subsection{Background information on the study region}

Namibia is a country with very scarce water resources, few perennial rivers, low and varying rainfall and high levels of evaporation. Northern regions are the most densely populated because more water is available there than in other parts of the country. Most of the former Ovamboland region is located on the floodplain of the Cuvelai catchment, an area characterized by floodwater courses called oshanas in which surface water is available during the rainy season between December and March (Erkkilä and Siiskonen 1992). The availability of surface water, salt-free water from wells along the middle slopes of the oshanas, and relatively-good soil conditions have resulted in inhabitation and economic activity being concentrated in and around the Cuvelai catchment.

In addition to the influence exerted by natural conditions, the regional distribution of population has been affected by colonial policies of ethnic segregation. The historical Ovamboland region was defined during the German colonial period of 1884-1915 and was one of the 'homelands' founded during South African rule (see Figure 1 on page 40). While Ovamboland is the most-commonly-used English form of the name for this historical region (e.g. Eirola 1992; McKittrick 2002; Siiskonen 1990; Tuupainen 1970), other English forms are also sometimes used, for example Owamboland (e.g. Salokoski 2006), Owambo (e.g. Webb and Simon 1995), Ovambo (Hiltunen 1986, 1993), the Ambo area (Saarelma-Maunumaa 2003), the Ambo country, and Wamboland. In this study, this historical region has been called Ovamboland. When references are made to different language (or ethnic) groups in Namibia, the forms used in this study are the Ovambo, the Herero etc., as commonly used in English literature concerning Namibia (e.g. Katjavivi 1988).

The former Ovamboland is now part of the current administrative regions of Omusati, Oshana, Ohangwena and Oshikoto (see Figure 2 on page 41). These regions include some areas outside the former Ovamboland. Until 2001-2003, these four regions together formed the Northwest Health Directorate. In the 1992 NDHS, the former Ovamboland region was called the Northwest Region, and in the 2000 NDHS it was called the Northwest Directorate. Sometimes, these four regions are called by the common name of the '4 O's Regions' (e.g. Phororo and Venditto 2003). In this study, the former Ovamboland region is called North-Central Namibia (e.g. Erkkilä 2001). Because the 2000 NDHS and population and housing census data are based on the current administrative regions, reference is sometimes made to information concerning the Northwest Health Directorate, a somewhat larger region than North-Central Namibia. 
Figure 1. 'Homelands' and the regions reserved mainly for 'whites' in South-West Africa (Namibia) before independence.

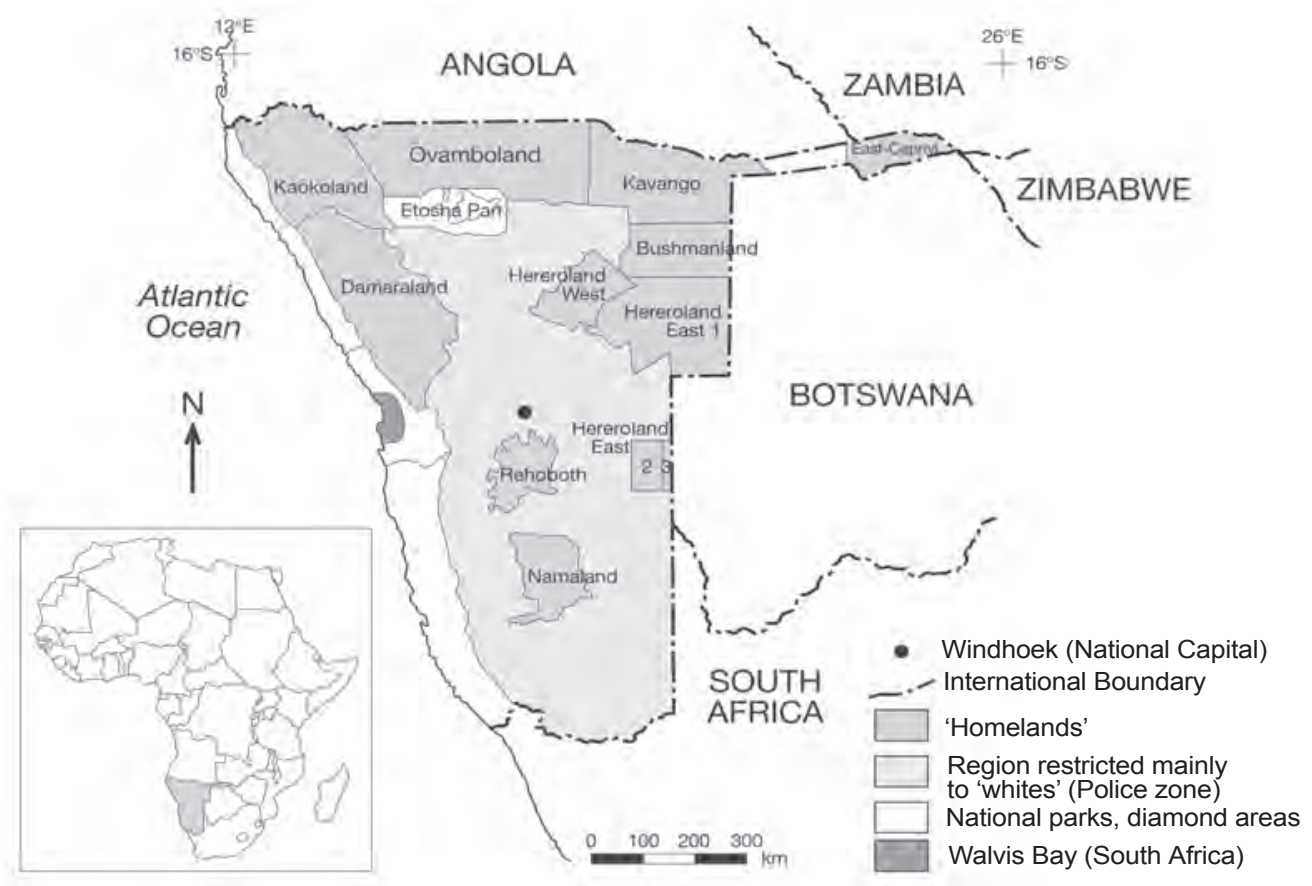

Sources: Modified from Erkkilä 2001 and Kiljunen 1980.

Estimations of the total population of Ovamboland made before the 20th century were based on assessments by missionaries, explorers and colonial officers. There is no consensus concerning the size of the total population, but most estimates offer figures of around 90-100,000 in the 1880s and 1890s (see Siiskonen 1990). In 1877, Special Commissioner Palgrave, a special envoy of the Cape government, estimated that the population of the Ovambo and Herero communities totalled 98,000 and 84,000 respectively. The Ovambo appear to have already been the largest group in the late 19th century, but the difference compared to the Herero was not as substantial as it is today. The situation changed following the War of Resistance in 1904-1907, in which the Germans killed $75-80 \%$ of the Herero population and $35-50 \%$ of the Nama population (Katjavivi 1988). In 1921, the Herero and the Ovahimba were together estimated as totalling 31,000 (Katjavivi 1986).

Since at least the 1930s, approximately half of Namibia's population have been speaking inter-intelligible Ovambo dialects (GRN/NPC 1994a, 2003; Report of the Commission... 1964). In the study region in 2001, these dialects were spoken by 93 $97 \%$ of the people living in the Ohangwena, Omusati and Oshana regions and by $87 \%$ of the people living in the Oshikoto region. 
Figure 2. Current administrative regions, and the health directorates of the Ministry of Health and Social Services used until 2001-2003.

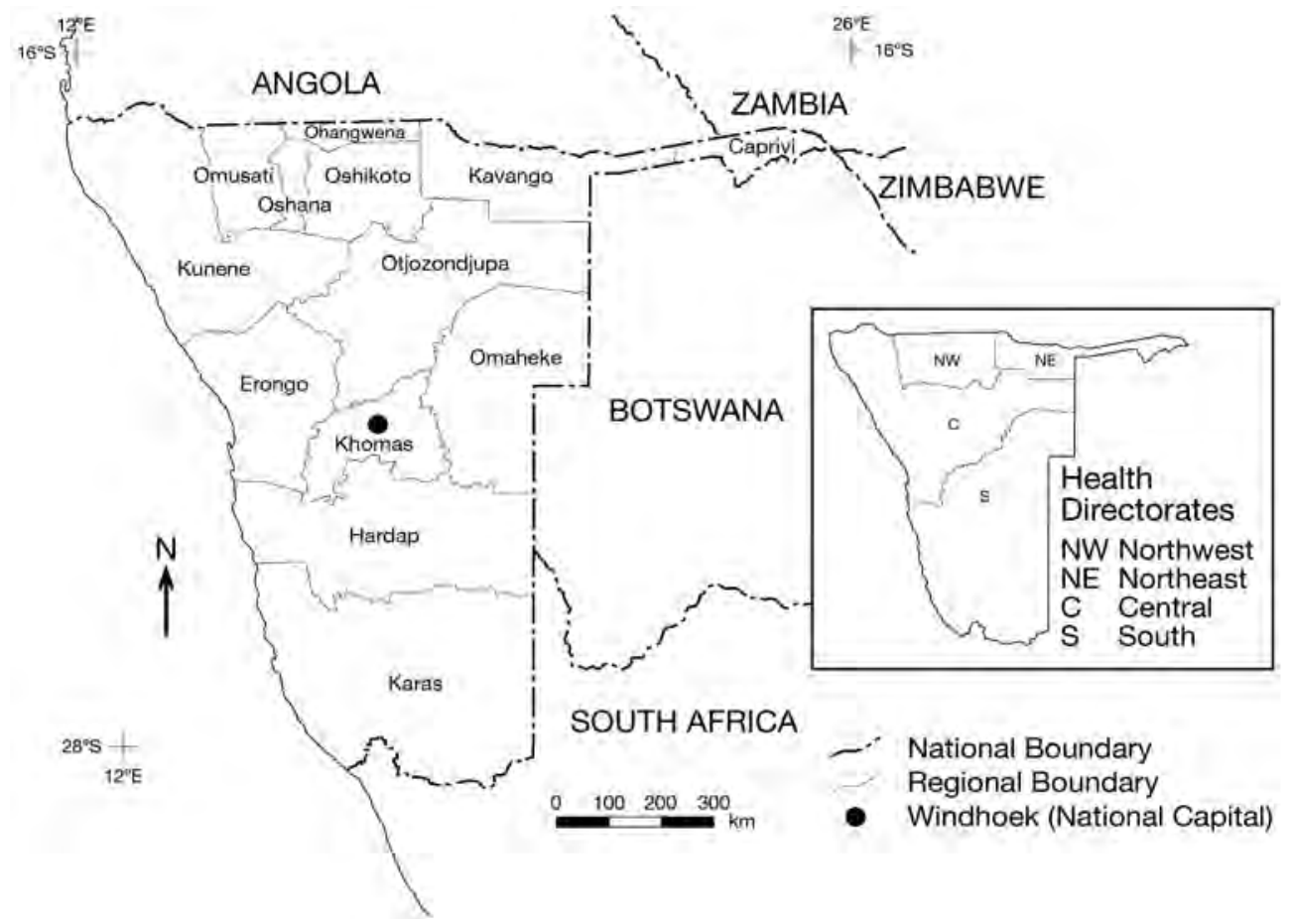

Sources: Modified from Erkkilä 2001 and El Obeid et al. 2001.

In 2001 , more than 780,000 people (i.e. $43 \%$ of Namibians) lived in the Ohangwena, Omusati, Oshana and Oshikoto administrative regions (see Table 2 on page 42) on an area of land which totalled $10 \%$ cent of Namibia's total land area. Namibia is sparselypopulated, with the average population density as determined by the 2001 census being 2.2 persons per sq. $\mathrm{km}$ (GRN/NPC 2003). Figures from this census show that the average population density in the Northwest Health Directorate was 9 persons per sq. $\mathrm{km}$. There are, however, wide differences in population densities within administrative regions as well as between them. 
Table 2. Members of Evangelical Lutheran congregations, the later Evangelical Lutheran Ovambo-Kavango Church, and the Evangelical Lutheran Church in Namibia (only congregations located in North-Central Namibia are included), and the estimated population in North-Central Namibia, 1900-2001.

\begin{tabular}{lcrr}
\hline Year & $\begin{array}{l}\text { Members of the } \\
\text { Evangelical Lutheran } \\
\text { congregations }\end{array}$ & Population & $\begin{array}{l}\text { Proportion of congregation } \\
\text { members, \% }\end{array}$ \\
\hline 1900 & $827^{1}$ & $92,000^{5}$ & 1 \\
1910 & $2,006^{1}$ & $159,000^{6}$ & 1 \\
1921 & $10,412^{2}$ & $91,500^{7}$ & 11 \\
1933 & $28,162^{3}$ & $107,861^{7}$ & 26 \\
1942 & $42,223^{3}$ & $126,418^{7}$ & 33 \\
1951 & $64,159^{3}$ & $200,253^{7}$ & 32 \\
1960 & $127,187^{3}$ & $231,438^{3}$ & 55 \\
1970 & $185,366^{1}$ & $305,561^{9}$ & 61 \\
1981 & $301,017^{4}$ & $452,036^{10}$ & 67 \\
1991 & $409,949^{4}$ & $633,182^{11}$ & 65 \\
2001 & $552,006^{4}$ & $780,149^{12}$ & 71 \\
\hline
\end{tabular}

Notes:

${ }^{1}$ Source: Notkola and Siiskonen $(2000,28)$ based on ELCIN statistics.

${ }^{2}$ Source: McKittrick $(1995,311)$ based on information from Finnish Missionary Society.

${ }^{3}$ Source: Finnish Missionary Society 1933, 1942, 1951, 1960.

${ }^{4}$ Source: ELOC 1982; ELCIN 1992, 2002.

${ }^{5}$ Population estimate for 1896, source: Siiskonen 1990, 42-43, based on estimates by Möller, an explorer

${ }^{6}$ Population estimate for 1911, source: Tönjes 1996, 4-5. This estimate includes the Kwanyama living on the Angolan side of border, and is therefore notably higher than most of the estimates produced in the late 19th century.

${ }^{7}$ Source: Notkola and Siiskonen $(2000,19)$ based on several archive sources.

${ }^{8}$ De facto population in Ovamboland according to the 1960 census, including 27,771 employees temporarily employed in the southern sector. Source: Report of the Commission... (1964, table XXIV).

${ }^{9} 1970$ Census, as reported in GRN/NPC 1992, 3.

101981 Census, as reported in GRN/NPC 1992, 3.

111991 Population and Housing Census, administrative regions of Ohangwena, Omusati, Oshana and Oshikoto. Source: GRN/NPC 1994a. According to the same census, the census districts of Ondangwa and Oshakati - which are a closer representation of North-Central Namibia (i.e. former Ovamboland) than the new administrative regions - had a total population of 618,117 in 1991. Source: GRN/NPC 1993.

122001 Population and Housing Census, administrative regions of Ohangwena, Omusati, Oshana and Oshikoto: Source: GRN/NPC 2003, 3.

The Ovambos belong to South-Western Bantu language group. According to current knowledge, they migrated to what is now Namibia together with the Hereros and Kavangos as a part of the so-called 'Bantu migration' between 12th and 17th Centuries. The region was populated from the north and the north-east in phases by migrating 
groups of South-Western Bantu (see e.g. Hiltunen 1986; Saarelma-Maunumaa 2003; Salokoski 2006; Williams 1988, 1991).

The Ovambos developed several polities in their region, each of which had its own administration and spoke their own variety of the Ovambo language. With the exception of Ombalantu, Uukolondhadhi and Eunda, which were ruled by council of chiefs, these polities were ruled by kings. Communities were located in the current regions of northern Namibia and southern Angola, but the start of the colonial era split these communities and divided them into two countries. In 1970, these polities were (ordered by population size, largest first): Uukwanyama, Ondonga, Uukwambi, Ongandjera, Ombalantu, Uukwaludhi, Uukolonhadhi and Eunda. Work by Finnish missionaries has resulted in there being a common written language based on a linguistic variant of the Ndonga subgroup (Notkola and Siiskonen 2000; Saarelma-Maunumaa 2003; Siiskonen 1990).

From the 1850s, after the first Europeans travelled to Ovamboland, their influence increased. During the German colonial period, attempts at the peaceful annexation of Ovamboland failed, primarily because of the resistance shown by the local population, and the Ovamboland Reservation was created without subjugating the local polities (Eirola 1992). Germans began building their colony of German Southwest Africa from the southern parts of the country and left the Ovamboland until last. Although they planned to increase their influence in Ovamboland, the First World War changed the situation and the region remained free of local colonial authority until South African forces occupied Namibia in 1915.

Between 1915 and 1919, Namibia was under military rule by South Africa. In 1919, the Treaty of Versailles dispossessed Germany of rights to its former colonies. In 1920, the League of Nations assigned South Africa mandatory power over South West Africa (SWA, current Namibia) and it was entrusted to South Africa as a C-mandate, which means that the territory was to be administered under the laws of the mandatory power. In 1946, the League of Nations was replaced by the United Nations. South Africa refused to acknowledge the authority of the United Nations and continued to govern SWA. In 1963, the Odendaal Commission of Inquiry suggested that the system of apartheid and 'separate development' be extended to South West Africa. The commission's plan proposed that Ovamboland be made one of the 'homelands' or Bantustans and the region gained its own legislative assembly and executive council, a "government" with a prime minister and six "ministers" for the Ovambo sub-groups in 1968, and the status of a Self-Governing Territory in 1973. Partial self-government was rescinded in 1983. (Dierks 2002; du Pisani 1986; Eirola 1992; Katjavivi 1988). 
During the colonial period, movements of population between regions were strictly regulated by the colonial administration. Through a contract labour system, the populous northern regions of the country provided the labour required by the farms and mines of the so-called "police zone" in central and southern regions (Katjavivi 1989; Peltola 1995). This temporary migration of labour almost exclusively involved male contract workers who were supposed to return their home regions after finishing their periods of work.

In pre-colonial times, land in North-Central Namibia was considered as the property of the king, or the clan chiefs in polities which do not have a king. Polities were divided into smaller regional units whose leaders were involved in the process of land allocation. The usufruct for farming land had to be paid for, while grazing land, water and forests were utilised on a communal basis. The land usufruct was not inheritable: for example in cases where the father of the family which had the land usufruct died, new negotiations and payments had to be made by a child who wished to continue farming the fields. Despite legal changes in principle concerning land ownership, this system of communal land tenure continued during both the German and South African colonial periods. Although communal land areas in independent Namibia are, from a legal viewpoint, the property of the state, in practice the system described above persists. There are, however, disagreements in the study region resulting from, for example, the illegal fencing of communal land by some farmers for their private use. (Adams and Werner 1990; Becker 2003; Eirola 1992; Miettinen 2005; Williams 1988.)

Seed agriculture prevails. The most important crops are millet (omahangu) and sorghum. Beans, wild pumpkins, ground nuts, spinach and some other vegetables are also cultivated. Chickens, goats, cattle, pigs and donkeys are the most common domestic animals (GRN/NPC 2006b). Like agriculture, cattle-rearing is an important part of the economy and also an important part of Ovambo culture. The staple food is thick porridge made of millet or other meal, often supplemented by vegetables or meat. Fishing is possible during the floods. The hunting and gathering of, for example, wild fruits are also practised. Dairy products such as milk, buttermilk, and butter were already being produced in the early 1900s. Nourishing beverages based on sorghum and millet are also an important part of people's diet. (Becker 2003; Miettinen 2005; Tönjes 1996; Williams 1988.)

Tönjes (1996, reprinted from 1911) reported on the specialized crafts practiced by Ovambos in the early 1900s. These included the working of iron, pottery manufacture, the production of plaited and woven items (e.g. baskets, mats), and wood carving. While a proportion of production was made for each household's own use, items were also produced for sale. Handicrafts, for example basket plaiting and wood carving, are still practised. 
Subsistence agriculture is the most important source of income among households in the study region (GRN/NPC 2006b). Farming is often supplemented by other income strategies, however. Although the contract labour system ended with the colonial period, temporary migration to central and southern regions of the country continues. This migration is fuelled by harsh and varying environmental conditions and the low productivity of subsistence agriculture, as well as a lack of working and educational opportunities in the region. Currently, however, both employment and educational opportunities in North-Central Namibia are growing in number (Phororo and Venditto 2003). The most important centre of urban growth is the Oshakati-Ongwediva-Ondangwa complex, which, when calculated as a single unit, forms the second-largest population concentration after Windhoek, the country's capital. The majority of businesses in northern Namibia are located in the Oshakati-Ongwediva-Ondangwa complex and the University of Namibia has established its "Northern Campus" in the region.

North-Central Namibia was strongly affected by the War of Independence. The South West African People's Organization (SWAPO), the leading nationalist movement during the war, had its origins in an organization called the Ovambo People's Congress. SWAPO is still the largest party in the country. Since independence, SWAPO has received the votes of more than $90 \%$ of registered voters in North-Central Namibia in both national and regional elections. (Becker 2003; Katjavivi 1988.)

\subsubsection{Christianisation of the study region}

The Finnish Missionary Society began its work in Ovamboland in 1870 following an invitation from the Rhenish Missionary Society. Evangelical Lutheran missionaries were followed by other Christian denominations.

The first baptisms of members of the Ovambo by Evangelical Lutheran missionaries in the study region occurred in 1883 (Peltola 1958). Conversion to Christianity in the study region has been studied by Miettinen (2005) and McKittrick (1995, 2002). In the beginning of the 20th century, converts were found among younger people, i.e. teenagers and people in their early twenties. The proportion of converts older than this began to increase in the 1950s. At the beginning, men were more often converted than women, but after the 1920s this changed, and the majority of converts were women from that point onwards. Until the 1940 s, converts were relatively poor, but wealthier and more influential people then started to figure among the converts. Research into converts only covers the period up to the 1960 s.

According to Becker (2003), North-Central Namibia is especially characterized by the strong impact of Christianity. The proportion of "church-going Christians" is estimated to be $90 \%$ of the population of North-Central Namibia, and Christian churches are 
major social institutions in this region. The Evangelical Lutheran Church in Namibia (ELCIN) is the largest religious denomination in North-Central Namibia $(556,042$ members at the end of 2002) (ELCIN 2003). The next-largest denominations were Roman Catholic (40,000 members in the 1990s) and Anglican (40,000 members in the 1970s) churches. Currently, Zionists, Seventh Day Adventists and the Reformed Church are also working in the region, but their following is marginal (SaarelmaMaunumaa 2003).

Precise information on the proportion of Christians in the total population of the study region is not available. Some surveys, however, have included questions concerning the survey participants' religious denomination. The Household Health and Nutrition Survey by UNICEF (1990) report that in 1990, the proportion of people interviewed who did not belong to the Lutheran, Roman Catholic or Anglican Church in the rural Northern (former Ovamboland) regions was negligible. In this survey, some $79 \%$ of the survey participants in the rural Northern (Ovamboland) regions and $60 \%$ of those in peri-urban Northern (Ovamboland) regions claimed to be Lutherans. The question of religion was also included in the Namibia Demographic and Health Surveys of 1992 and 2000 (NDHS 1992, 2000). In the study region, the proportion of Protestants among interviewed women was $81 \%$ in 1992 and $85 \%$ in 2000, and the proportion of Roman Catholics among interviewed women was 19\% in 1992 and 14\% in 2000. In both NDHS surveys, less than $1 \%$ of the interviewed women reported that they either followed no religion or a (Christian or non-Christian) religion that was neither Protestant or Roman Catholic. Based on this information, the vast majority of the population of North-Central Namibia is Christian.

\subsubsection{Differences between the regions of North-Central Namibia}

Although all the four administrative regions Ohangwena, Omusati, Oshana and Oshikoto used to belong to the former Ovamboland, there are regional differences. Ohangwena and Omusati are the most rural, with the proportion of the population that lives in rural areas being 99\% according to the 2001 Population and Housing census (GRN/NPC 2003). Oshana has several urban centres, the most important being Oshakati, the largest town in North-Central Namibia. In 2001, 31\% of the people living in the Oshana region were recorded as living in urban areas. In terms of the Human Development Index (HDI), an index which consists of measures of life expectancy, adult literacy, school enrolment and income, the lowest index was found in Ohangwena (0.544) and the highest in Oshikoto (0.654) in 2000 (UNDP Namibia 2000). In the same year, the HDI of Omusati was 0.585 and that of Oshana was 0.618 , with the national average for Namibia being 0.648. Primary reasons for the low HDI in Ohangwena included a lower literacy rate and lower per capita income than in the other regions. 
It should be noted that the addition of regions from outside the former Ovamboland is the basis for some differences. For example, there are places in the southern Oshikoto region where communal land owning is not practised.

\subsubsection{Morbidity and mortality}

At national level, communicable diseases are responsible for the majority of the disease burden. HIV prevalence among pregnant women was almost $18 \%$ in 2004 at national level, and $22 \%$ at the sentinel sites located within the study region. The incidence of tuberculosis has been increasing, partly because of its connection with HIV. In 2001, the incidence rate of tuberculosis in the population was 680 per 100,000. Between 1995 and 1999 at national level, the number of hospital inpatients with tuberculosis increased by $27 \%$ and the number of deaths resulting from it rose by $64 \%$. Malaria is endemic in northern Namibia and is a major health problem in the study region - for example, a severe outbreak of malaria occurred in 2002-3. In 2001, the annual incidence of malaria in the population was 225 per 1,000. HIV infection also increases the risk and severity of malaria. Non-communicable diseases such as cancer and cardiovascular problems are also increasing at national level. Malnutrition among children is also a common problem: at national level, the proportion of stunted children (i.e. children with low height for a specific age) among children younger than five years old was $24 \%$ in 2000, and the figure for northern Namibia is higher than elsewhere in the country. (El Obeid et al. 2001; GRN/MoHSS 2003b, 2004a, 2004b, 2004c, 2004d, 2005; Korenromp et al. 2005.)

In the study region, lack of access to safe water and inadequate sanitation represent major health problems which result in the high prevalence of diarrhoea. According to a survey carried out in 2003-2004, 19-28\% of households in Omusati, Oshikoto and Ohangwena regions used water collected from streams or stagnant water as their main source of drinking water. Of the four administrative regions of the North-Central Namibia, only in Oshana was drinking water mostly collected from water pipes, boreholes, or protected wells. With the exception of Kavango, the north-eastern neighbour of the study region, water safety was poorer in the study region than in other regions of Namibia (El Obeid et al. 2001; GRN/MoHSS 2004a, 2004b, 2004c, 2004d; GRN/NPC 2006b.)

On the basis of parish registers, Notkola and Siiskonen (2000) reported a substantial decline in mortality in the study region during the 20th Century. Levels of infant mortality began to decline in the 1930s, and levels of child and adult mortality began to decline at the end of the 1940s or in the early 1950s. In the period from 1925 to 1954, male life expectancy at birth was 39-43 years and female life expectancy at birth was 45-48 years. In the period 1955 to 1986, male life expectancy at birth was 61-63 years 
and female life expectancy at birth was 64-65 years. According to the 1991 Population and Housing Census, average life expectancy at birth in the four administrative regions was 61 years for males and 65 years for females (GRN/NPC 1994a).

During the 1990s, however, this positive trend reversed, and life expectancy at birth fell between 1991 and 2001 in all four administrative regions (GRN/NPC 1994a, 2003). In 2001, life expectancy at birth was lowest in Ohangwena, where it was 45 years for females and 43 years for males. In the four regions, the highest figures for life expectancy at birth, i.e. 50 years, were recorded among females in Omusati and Oshikoto and among males in Oshikoto. The average life expectancy at birth in the four regions in 2001 was 48 years for females and 46 years for males. The largest fall in life expectancy at birth occurred among females in Ohangwena, whose life expectancy dropped by 20 years in the ten years from 1991 to 2001. Analysis of parish registers shows a pronounced increase in mortality during the 1990s, starting in 1991 for infants and children and in 1993 for adults (Notkola et al. 2004).

\subsubsection{Gender issues in North-Central Namibia}

In pre-colonial Ovambo societies, women were not without political and social power. In many communities, women had access to property and were valued as agricultural producers. Women had power over both production and reproduction. A matrilineal descent system mitigated the control of a husband over his wife or wives and children. Divorce was not uncommon, and made easier by the fact that no substantial material transfers occurred at marriage. Women also had significant roles as healers and participants in cultural and ritual performances. Female members of royal clans, especially the king's mother, held political power, and the king's sisters and king's mother's sisters also wielded strong "behind the scenes" political influence. Royal women also held the post of district headman, for example. The Ongandjera polity in the western part of the study region was frequently ruled by women until the 1860s. (Becker 2003; Hiltunen 1986, 1993; Miettinen 2005; Salokoski 1992; Tönjes 1996; Williams 1988).

It is not completely clear why and how the traditional positions of authority became the exclusive province of men. Becker (2003) suggests a link to the increasing degree of centralisation and the militarization of Ovamboland after contact with white traders and the introduction of firearms. According to her, this process was reinforced by the onset of colonial rule. Recently, however, the Kwanyama, one of the most important Ovambo sub-groups, crowned Queen Mwadinomho Martha Kristian Nelumbu as its traditional leader (Shivute 2005).

The Ovambo people belong to the central African matrilineal belt, which means that the kinship system, inheritance and succession follow the maternal line (Tuupainen 
1970). Traditional marriage was a long process which involved participation by both families (Elonheimo 1994; Tuupainen 1970). Although, in a strict sense, there was no bridewealth (or lobola), i.e. "payment" from the groom to the family of the bride, the process of marriage was expensive and involved gifts to the family of the bride, and the offering of a "wedding ox" which was slaughtered and served up at the wedding celebrations. Polygyny was practised, even though it was banned by Christian religious authorities.

The current systems for marriage and courtship in the study region are complicated. Different forms of marriage exist (LAC 1999, 2000). According an interview study, legal, financial and religious factors influence whether and how people will get married (Research Facilitation Services 2004). For example, the simplest, fastest and cheapest way is marriage in a court without expensive celebrations. The advantage of a church wedding is the Christian marriage blessing, the disadvantage is the cost of the celebrations. The advantages and disadvantages of getting married in the traditional manner are probably dependent on the different traditions among ethnic groups in Namibia. Some people refer to ease and speed, and also to how easy it is to dissolve a marriage, but a marriage contracted in the traditional way is not always viewed as a "marriage proper". A willingness to remain independent was the main reason for not getting married. The courtship system often includes economic support given to women by men (see e.g. Tersbøl 2002). With economic support and gifts from older lovers, young women can obtain items that would otherwise be out of their reach. Economic support is important for women who are single parents.

There is evidence that permissive attitudes towards sexual relations between young people has existed in the study region (Becker 2004; Tuupainen 1970). After initiation, girls were regarded as women, and births among them were not considered illegitimate. Because of the matrilineal system, children belong to the mother's kin. As well as being an important dividing point in a woman's life, the initiation rite also played an important role in reproductive education and controlling adolescent sexuality, since births prior to initiation were subjected to heavy sanctions (McKittrick 2002; Tuupainen 1970). Missionaries were strongly opposed to the female initiation rite, but despite the punishment of participants and all the efforts made to root the practice out of the community, the institution has survived and appears to have even grown stronger in current times (Becker 2004; Miettinen 2005).

The roles of women and men have changed with societal changes in the last century. Introduction of the Christian model of a life-long monogamous marriage and the missionaries' concept of a patriarchal nuclear family with the man at its head changed the role of women and their position in marriage (McKittrick 1997, 2002). Combined 
with the absence of men caused by labour migration, women became more vulnerable. On the other hand, the churches also educated girls and women and helped them to be trained for professions, thus providing them with access to the wage economy and increased independence, and in some cases offered them protection (Cooper 1997).

During the war of independence, women played active roles (Cleaver and Wallace 1990; Soiri 1996) and many women gained higher education in exile. While this may have increased both the resources available to them and their self-esteem (and also had an impact on their position in the community), women sometimes encountered difficulties when competing with men in the formal job markets following the war. Although the constitution of independent Namibia is intended to protect the right of women (Cooper 1997), legislative problems still exist in connection with, for example, inheritance rights (LAC 2005). Although some reports indicate that women have relatively good access to education in Namibia - the majority of the students who begin their university studies are women (Cooper 1997) - there are also contrary statements concerning girls in rural regions who lack equal educational opportunities (Iipinge et al. 2004), and young women in school hostels who are subject to sexual pressures. Also, even high levels of education among women do not result in equality in terms of society's leading positions. 


\section{Aims of this study}

\subsection{Aims}

The aim of the present study is to contribute to the scarce demographic research on Namibia by examining fertility in the North-Central region of the country. It is also hoped that the study will increase knowledge concerning both fertility decline and the connections between HIV and fertility in southern Africa. Special attention is given to 1) the period before independence and especially the onset of fertility transition, and 2 ) the state of the HIV epidemic and the impact this has on fertility. One other important goal of the present study is to contribute to the selection of data for demographic research conducted in developing countries by introducing an additional source, i.e. parish registers, which has not yet been fully utilized. These registers could provide at least a partial solution to the lack of longitudinal data in developing countries.

The major aim of the study is to establish how fertility has developed from the beginning of the 1960s to 2001, and the impact of HIV on this. Stated in more detail, the aims of this study are to establish:

1. How fertility developed prior to independence in the study region. Very little evidence has so far appeared concerning this period. (Original paper PIII, see the list of original papers on page 9)

2. The point in time at which fertility decline began in the study region and the mechanisms that led to this decline. (PIII)

3. The state of fertility in the study region at the beginning of independence compared to other regions in Namibia. (PI)

4. The current state of fertility in the region. (PIII)

5. The state of the HIV epidemic in the region, how it has developed during the study period, and how it affects fertility. (PII, PIII, PIV)

6. The way or ways in which HIV epidemic will affect fertility and demographic development in the future. (PII, PIV)

In regional terms, this study concentrates on the former Ovamboland, now known as North-Central Namibia. Currently, North-Central Namibia is part of four administrative regions, i.e. Ohangwena, Omusati, Oshana and Oshikoto. The primary reason for selecting this region was the availability of a fairly unique data set, i.e. parish registers of the Evangelical Lutheran parishes in this region. The actual basis for selection of the study region is therefore the long common history of Finland and Namibia, especially in the former Ovamboland region. Parish registers originated from the work of Finnish missionaries who began to use Scandinavian-type parish-register system in their newly-founded congregations. 
The time period which is the focus of this study is the four decades from 1960 to 2001 . It begins before the armed struggle of the war of independence and also includes the period before the era of the HIV epidemic in the study region. Most importantly, using this period makes it possible to capture the onset of fertility decline in the study population. As it continues close to the present day, the study makes it possible to estimate how the factors contributing to fertility decline have changed during the study period, and how the acceleration of the HIV epidemic has influenced fertility levels. The study also provides some estimation of future demographic challenges, especially the impact of the HIV epidemic on the population of the study region.

\subsection{Theoretical framework of the study}

In this research, factors affecting fertility have been assessed within a framework of proximate determinants. These are influenced by cultural and socioeconomic factors which are here combined under the common concept of "basic determinants". The ideal number of children and levels of infant and child mortality are combined under the concept of "motivation determinants", since they affect motivation for the use of contraception to reduce the number of births. Basic determinants influence the proximate determinants of fertility either directly, or through these motivation determinants. As well as being related to Bongaarts approach of proximate determinants (Bongaarts 1982; Bongaarts and Potter 1993), this framework is closely related to Easterlin's framework (see e.g. Easterlin and Crimmins 1985) with some modifications. For example, the cost of fertility control is not separated out as an individual factor. $\mathrm{HIV}$ is also considered to be a factor affecting fertility which is a combination of the influence of HIV infection on the fertility of infected women and the general effects of HIV being widely spread in a society.

The theoretical framework to be described is a simplified presentation of the connections between different determinants of fertility (see Figure 3 on page 53). In this study, the purpose of the theoretical framework, which is only one way of presenting these complex relationships, is to illustrate the ways in which the different factors are linked. The framework is made from a viewpoint that seeks to explain fertility changes, and some of the interactions have therefore been omitted. For example, some of the proximate determinants of fertility are also determinants of HIV prevalence. Marital pattern is one example. Basic determinants, for example cultural and socioeconomic factors, have an influence on age at first marriage, the proportion of people who remain single (terminal celibacy), divorce, and remarriage by widows and divorced women. In turn, behaviour in these contexts influence HIV prevalence and also affect the proportion of women in regular sexual (marital) unions, one of the proximate 
determinants of fertility. Basic determinants therefore influence both the proximate determinants of fertility (the proportion who are married) and the prevalence of HIV, while HIV prevalence influences the proximate determinants of fertility, and thus levels of fertility.

The HIV pandemic influences fertility via multiple routes: directly via some proximate determinants of fertility, for example HIV infection in women is associated with increased levels of intrauterine mortality, and HIV infection can also result in the continuing use of condoms by infected persons in order to avoid the transmission of HIV to sexual partners. HIV influences motivation determinants: it increases child mortality and may also have an influence on the ideal number of children. These, in their turn, influence the proximate determinants of fertility. For example, while HIV increases rates of infant and child mortality, the possible replacement effect may result in reduced usage of contraceptives.

Figure 3. Theoretical framework for the study.

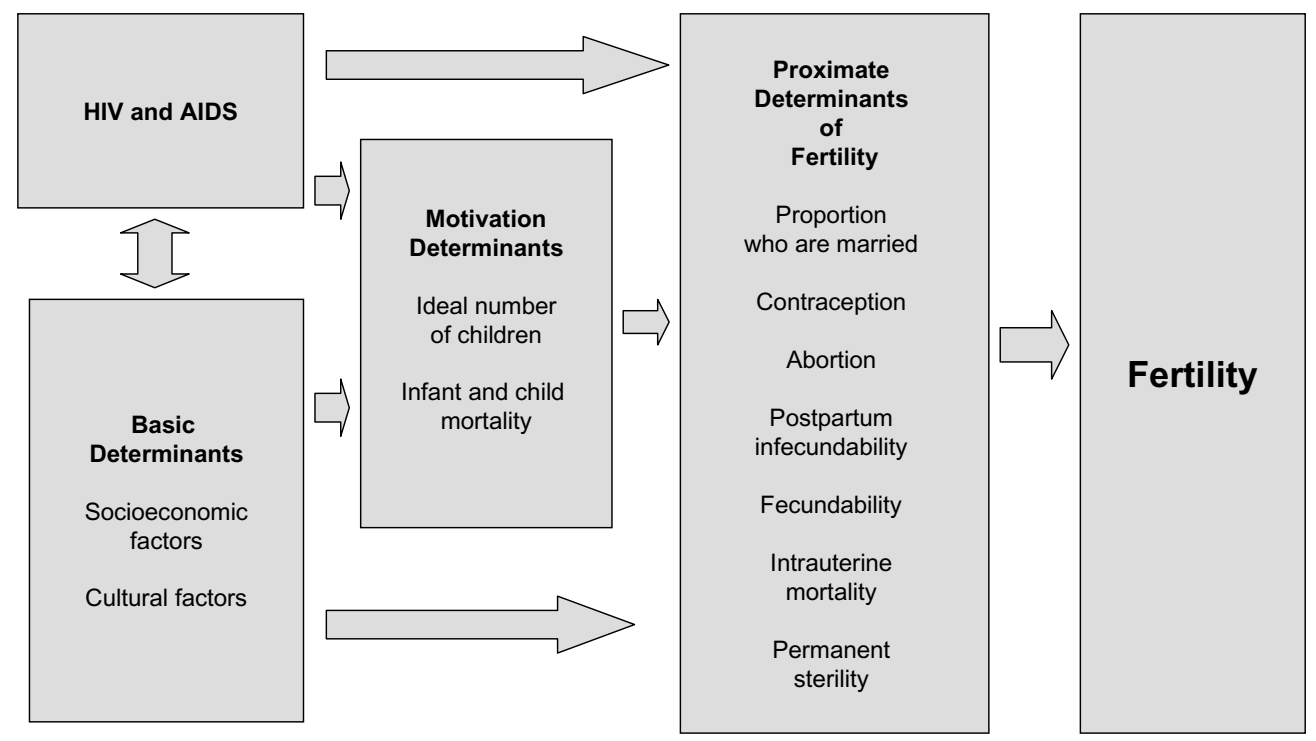

The HIV pandemic may also have an influence on the ideal number of children, and thus affect the use of contraceptives, by, for example, the insurance effect of child mortality, or through attempts to avoid having HIV-positive babies or leaving orphans. In addition, increased levels of infant mortality shorten periods of breastfeeding and thus also periods of postpartum infecundability. The HIV pandemic may also affect basic determinants, for example socioeconomic or cultural factors, and influence both motivation and proximate determinants of fertility via this route. The relationship between HIV and basic determinants is bi-directional: for example, the economical 
vulnerability of women (or young people, or some other population group) increases the risk of HIV infection and thus also influences fertility. On the other hand, contracting HIV may affect an infected woman's socioeconomic status. Also, HIV that is widely disseminated in a society may result in changes in sexual culture towards a reduced number of sexual partners or increased celibacy.

This study begins with a brief introduction to the background: a brief presentation of some theoretical viewpoints concerning fertility decline and a short visit to earlier research into both fertility decline and the connection between fertility and HIV in sub-Saharan Africa, with special emphasis on the situation in southern Africa. This is followed by a brief introduction to the study region.

The aims of the study, its theoretical framework, regional focus and the time period covered are then presented, followed by a short description of the data and the methods employed. The major results of the study are then presented. Fertility in the study region is examined in a chronological manner, starting from the period prior to the independence (1960 to 1989) and investigating the onset of fertility decline which occurred during this period. The state of fertility and some of its determinants in the study region at the beginning of independence, i.e. in the early 1990s, is then compared to the other regions in Namibia. Attention then moves to the first decade of independence and consideration is given to how the decline in fertility progressed and how its determinants changed during this period. Particular emphasis is given to the contribution of HIV to fertility decline. Predictions concerning the extent to which the region's demographic future will be shaped by the fertility-reducing effect of HIV are then made.

The Conclusion and Discussion sections include remarks concerning the background to fertility changes, a comparison of what has taken place in North-Central Namibia with the situation in some other regions in southern Africa, and a consideration of future challenges in the study region. 


\section{Data and methods}

\subsection{Data}

\subsubsection{Parish registers from North-Central Namibia}

The central source of data in this study is parish registers from Evangelical Lutheran congregations located in the northern part of Namibia. Finnish missionaries started their work in the former Ovamboland region, now North-Central Namibia, in 1870, and used Scandinavian parish register systems for their new congregations. Later, congregations were placed under the leadership of local ministers, and the independent Evangelical Lutheran Ovambo-Kavango Church (ELOC), the predecessor of the Evangelical Lutheran Church in Namibia (ELCIN), was established in 1954. The parish register system has continued almost unchanged since the beginning of the 20th century with only minor alterations (Siiskonen et al. 2005). Baptisms, deaths, migrations, and some other events such as confirmations are recorded in these registers. Parishioners therefore participate in a vital registration system.

The data employed in this study consists of the records of eight congregations located in the Omusati and Oshikoto administrative regions, i.e. Elim, Nakayale, Oshigambo, Okahao, Tshandi, Onankali, Oshitutuma and Omulonga (see Figure 4 on page 56). To achieve a more representative view of developments in the study region, the sample congregations were chosen from different parts of North-Central Namibia. Some are the administrative and economic centres of their region, others are more peripheral. Okahao, the oldest of the sample congregations, was established in 1906, the youngest, Oshitutuma, was established in 1982.

The parish registers of the sample congregations were microfilmed. The registers include the main books (also called the family books) and records of deaths, baptisms and migration. From this data, information concerning all couples married during the period 1956-2000 was collected. This information included deaths, migrations and baptisms in these families, and also information on other events such as confirmations or possible expulsions from the congregation. The follow-up period continued until October 2003.

The original parish register data of the 1956-2000 marriage cohorts consisted of 6,354 marriages, from which 1,651 (26\%) had to be excluded because the couple concerned could not be followed from one main book to the next, or because no information concerning the couple was listed following their marriage. Of the women, $9 \%$ lacked information concerning their year of birth and these cases were excluded from the fertility analysis. In cases where the day of birth was missing, the 15th day of the birth 


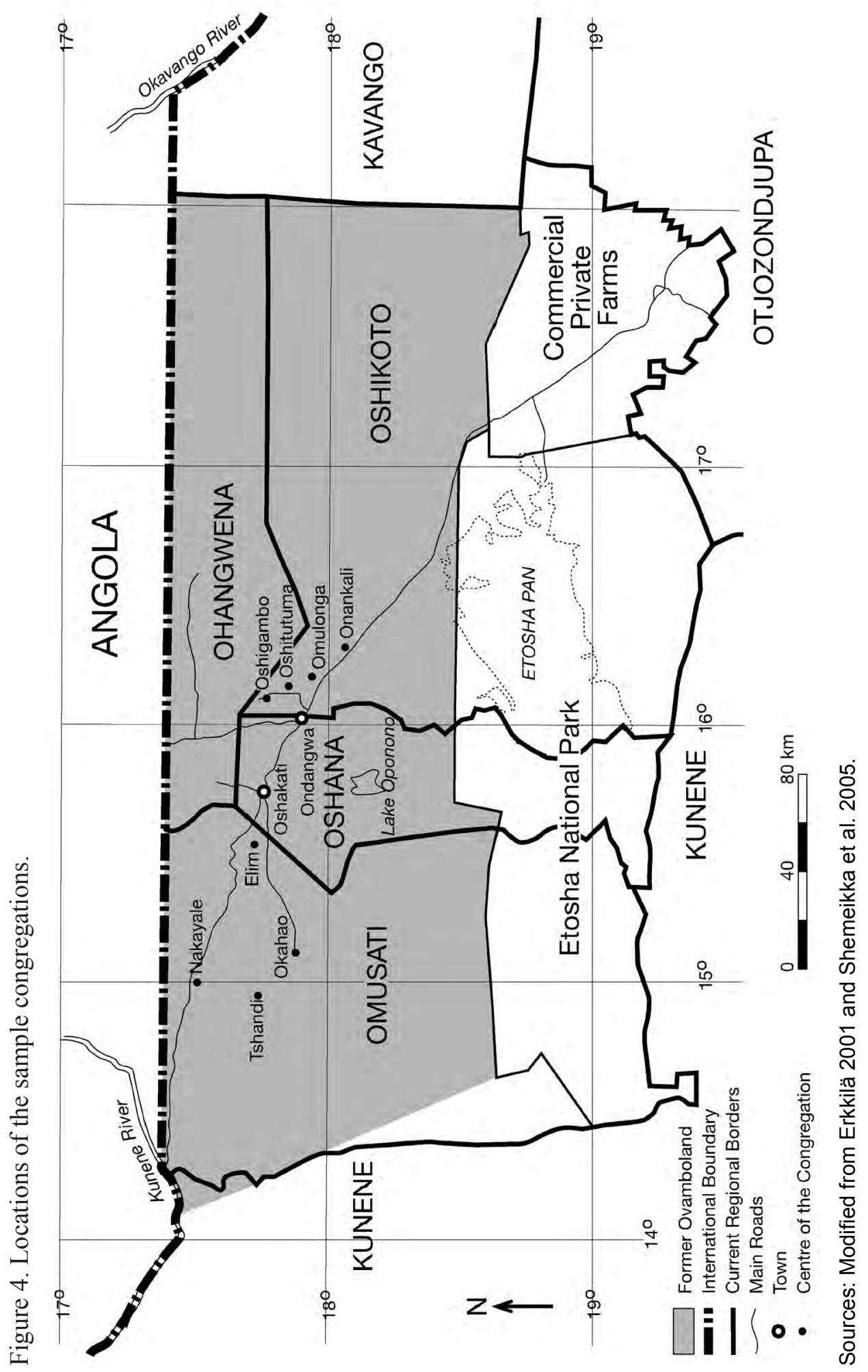


month was used as the person's birthday, and if the month of birth was missing, the sixth month (i.e. June) was used. The final parish register data set consists of 4,703 marriages and information on births, deaths, migrations, and some other events occurring among these families (Appendix 1). The data used in fertility analysis for the period 1960-2000 consists of information on 4,421 women, and data used for analysis of the impact on HIV on fertility in the period 1980-2000 consists of information on 2,749 women. Some women married twice during the follow-up period. The number of marriages for women featuring in the fertility analysis totalled 4,474 and 2,770 in the periods 1960-2000 and 1980-2000 respectively.

The original parish register data included 18,400 births in the period 1950-2003. Some of these births were, however, excluded from the final data set. The most common reason for excluding a birth was that the mother was not in follow-up when the birth took place. Other reasons for exclusion were poor follow-up of a marriage, the mother's birthday being unknown, or the mother being under 15 or over 50 years old at the time of giving birth. Children whose birthdays were unknown and children born before 1950 were also excluded. The total number of births in the final data set was 15,134 (Appendix 2). The number of births included in the fertility analysis for 19602000 totalled 14,365, and the number of births included in the analysis of the impact of HIV on fertility from 1980 onwards totalled 4,783.

\subsubsection{Namibia Demographic and Health Surveys in 1992 and 2000}

Demographic and Health Surveys (DHS) are large-scale surveys conducted in co-operation with Macro International Inc. and national institutions. Established in 1984, the DHS programme is a successor to the World Fertility Survey (WFS) (1972-1984) and Contraceptive Prevalence Survey (CPS) (1977-1985) programmes. In 1997, the DHS programme was linked to the USAID MEASURE programme as MEASURE DHS+. The aim of this programme is to produce data on the population, health and nutrition of women and children in developing countries. The international donor community usually provides external funding for these surveys. More than 200 Demographic and Health Surveys have now been conducted in 75 countries in Africa, Asia, the Near East, North Africa, Latin America and the Caribbean. Because of the almost-identical interview questions and standard procedures used for sample selection, these surveys offer the opportunity to make comparisons between different points in time or between different countries.

To date, there have been two Demographic and Health Surveys in Namibia, they were carried out in 1992 and 2000. Although one of the goals is comparability, the DHS 
system is continually being developed, and surveys made at different times vary: for example, the Namibian NDHS 2000 included a male sample in addition to the household and women samples, and additional questions on attitudes and knowledge concerning HIV and AIDS. While HIV tests for interviewees have subsequently become part of the DHS, this addition was unfortunately only made after the most recent DHS in Namibia was conducted.

Data from the Namibia Demographic and Health Surveys (NDHS) of 1992 and 2000 are available both as individual level data sets for computer analysis, and as published reports presenting the main results of the surveys (GRN/MoHSS 2003b; GRN/MoHSS and Macro International 1993). Data in the 1992 NDHS consisted of information on 5,421 women and was representative for four large regional units, i.e. the Northwest, Northeast, Central and South Regions (or, in some cases, for the combined Central/ South Region). In the region covered by the present study, i.e. the Northwest Region, 2,149 women were interviewed. Data in the 2000 NDHS data consisted of information on 6,755 women and was representative for all of Namibia's 13 regions. In Omusati, Ohangwena, Oshana and Oshikoto regions, the regions featuring in the current study, 1,993 women were interviewed.

In the current study, the information from the 1992 and 2000 NDHS is utilized both by using the published results and by primary analysis data sets concerning individual women. In this summary publication, in cases where published results are used, references are made to either the 1992 Namibia Demographic and Health Survey final report (GRN/MoHSS and Macro International 1993) or to the 2000 Namibia Demographic and Health Survey final report (GRN/MoHSS 2003b). When presenting results based on our own calculations, references are made to NDHS 1992 and NDHS 2000 data files (NDHS 1992, 2000).

\subsubsection{Population and Housing Censuses 1991 and 2001}

Reliable and available censuses for Namibia are the Population and Housing Censuses conducted in 1991 and 2001. The results of these censuses were published as analytical reports. Aggregate-level tables were also published by region, and these included, for example, information about all children ever born and children born in the 12 months preceding the census. These regional tables provide data which can be used, for example, in fertility analysis (GRN/NPC 1993, 1994a, 1994b, 2003).

The 1991 Population and Housing Census was published by two different regional divisions: firstly by 27 census districts (GRN/NPC 1993) and later by 13 administrative regions (GRN/NPC 1994b). Statistics Namibia also produced some extra census 
tables from the 1991 Population and Housing Census for five out of the eight sample congregations in this study, i.e. for Elim, Nakayale, Oshigambo, Okahao, and Tshandi (GRN/NPC 1994c). These extra tables were used when estimating fertility, education, and the marital status of women in sample congregation areas.

In addition to being published for the 13 administrative regions, the 2001 Population and Housing Census results and tables were published at the level of administrative subregions, i.e. constituencies (e.g., GRN/NPC 2004a, 2004b, 2005a, 2005b). An additional source of data is the 1996 Intercensal Demographic Survey, which provides information on levels of fertility between the two censuses, i.e. in 1996 (GRN/NPC n.d.).

\subsubsection{HIV sentinel surveillance and other HIV data}

The main source of data on the state of the HIV epidemic in Namibia is HIV sentinel surveillance, i.e. anonymous HIV tests of pregnant women who seek antenatal care. These tests are usually conducted every second year at selected sentinel sites. There were 24 sentinel sites in Namibia in 2004. In 1992, only one of these sentinel sites (Oshakati) was located in a study region. In 2004, there were five sentinel sites in the former Ovamboland region, and a sixth sentinel site in Tsumeb, which is outside the study region but still part of the Oshikoto administrative region. HIV sentinel data includes information concerning the sentinel site and the age of women tested, but no other background information. Information on HIV prevalence by age group has been published for five-year age groups at national level. The report on 2004 HIV sentinel surveillance (GRN/MoHSS 2005) provided information on HIV prevalence in two broad age groups (less than 25 years and 25 years or more) for individual sentinel sites in 2002 and 2004. In the next round of HIV sentinel surveillance, to be organised in 2006 , consideration is being given to the collection of data concerning women's socioeconomic background, for example levels of education. (For more detailed information on HIV sentinel surveillance, see PII).

Another important source of data on HIV has been the Health Information System (HIS) maintained by the Ministry of Health and Social Services which started operating shortly after independence. This system collects information from all government health facilities using standard forms. A new revised and computerised system was introduced in the beginning of 1995. Another reform was carried out five years later, and HIS2000 began operation in the beginning of 2001. Information on the provision of health services, morbidity and mortality is recorded at government health facilities, and summary data is collected in monthly reports. Data is summarised and computerised at health-district level by District Development Committees who use standard forms, and this data is then sent to regional administrative offices to further processing by Regional Management Teams. At regional level, information is summarized once 
again using standard forms, and then forwarded to national level at which an overall Ministry of Health and Social Service annual report is compiled by the Directorate for Policy, Planning and Human Resource Development (El Obeid et al. 2001; GRN/ MoHSS 1992, 2002a, 2002b, n.d.).

In the 1990s, health information was still being summarised at health-directorate level, instead of by administrative region as is current practice. The geographical area examined in the present study belongs to the administrative regions of Omusati, Oshana, Ohangwena and Oshikoto, which together form the Northwest Health Directorate. In the current decade, each administrative region is collecting its own health data (El Obeid et al. 2001; GRN/MoHSS 1992, n.d.). This health information system provides regional information on, for example, the number of positive HIV tests, hospitalisations resulting from HIV infection and AIDS, and deaths in hospitals resulting from AIDS. Additional data concerning HIV is also provided by, for example, HIV tests on STD or tuberculosis patients, and HIV tests on potential blood donors.

\subsubsection{Reliability and validity of the data}

\section{How well do members of the ELCIN represent the whole population of North-Central Namibia?}

When estimating how well the members of ELCIN represent the whole population of the North-Central Namibia, answers to the following questions are useful: Firstly, how large a proportion of the population do ELCIN members represent at the different time points? Secondly, was the conversion to Christianity a selective process, and if so, how? Thirdly, how do current ELCIN members differ from other populations in the study region?

During the 1950s, membership of the Evangelical Lutheran Church in Namibia rose to half the region's total population. During the period covered by the current study, i.e. 1960-2001, a majority of inhabitants of the study region (60-70\% of the population for most of the period) belonged to ELCIN, so ELCIN members do represent the vast majority of the population of the study region. According to ELCIN statistics, congregations in the former Ovamboland had 552,000 members at the end of 2001. Approximately $71 \%$ of the 780,000 inhabitants of the Ohangwena, Omusati, Oshana and Oshikoto regions were therefore members of the Evangelical Lutheran Church (ELCIN 2002; GRN/NPC 2003).

Information on selectivity of the conversion to Christianity is available for the first half of the 20th century (McKittrick 2002; Miettinen 2005). It appears that conversion was selective. In 1900-1950, converts seemed to be younger than the average population, but this phenomenon weakened as the middle of the century approached. 
Converts were also less wealthy and powerful than the population of the study region in general, but after the 1940s, wealthier people also began to convert. Men formed the majority of converts until the 1920s, and women thereafter.

Possibilities for comparing ELCIN members with other members of the population in the study region are limited. NDHS data includes a question on each respondent's religion. In the 1992 and 2000 NDHS, almost all the respondents were either Protestant or Roman Catholic. According to the 2000 NDHS, Protestants appeared to have higher levels of education than Roman Catholics (NDHS 2000). Age at first delivery and at first marriage appeared to be about the same in both groups. The proportion of those who did not use contraceptives was also similar in both groups.

In conclusion, the large proportion of ELCIN members among the population of the study region means that knowledge of the demography of ELCIN members provides information about the majority of the population of the study region. According to an estimate based on ELCIN statistics, $71 \%$ of the population of the study region were members of the Evangelical Lutheran Church in 2001, and according to the 2000 NDHS, $85 \%$ of the interviewed women were Protestants (NDHS 2000) (see Section 1.6.1 of the current study). The conversion to Christianity was selective during the first half of the 20th century, but the selectivity seemed to lessen as approaching to the study period. Currently, it seems that Protestants have a slightly higher level of education than Roman Catholics (NDHS 2000). ELCIN members can therefore be taken to be a fairly-good representation of the population of the study region.

\section{Reliability of parish register data}

One possible limitation of data from parish registers is that children who died before baptism are missing. Nevertheless, the influence of this factor is reduced by the parental wish to have a weak or sick child baptised before he or she dies. The mean age of children at baptism was 6.4 months in the whole of the data and 5.7 months during the period 1960-2000 (see Table 3 on next page). There were differences between the congregations in children's age at baptism. The mean age at baptism during the period 1960-2000 was lowest in Elim (3.1 months) and highest in Omulonga (7.0 months). 
Table 3. Mean age at baptism in the sample congregations, months.

\begin{tabular}{lcc}
\hline Year & Age at baptism & $(\mathbf{N})$ \\
\hline $1960-1969$ & 5.6 & $(5,213)$ \\
$1970-1979$ & 5.0 & $(6,302)$ \\
$1980-1989$ & 6.4 & $(3,590)$ \\
$1990-2000$ & 7.5 & $(2,026)$ \\
\hline Total & $\mathbf{5 . 7}$ & $\mathbf{( 1 7 , 1 3 1 )}$ \\
\hline
\end{tabular}

Source: Parish-register data.

According to the 2000 NDHS (GRN/MoHSS 2003b), the infant mortality rate in the study region was 50 per thousand live births during the period 1991-2000. Of deceased children, $62.3 \%$ died in the neonatal period, i.e. within one month after birth and $37.7 \%$ died in the post-neonatal period, i.e. at an age of between one and eleven months. Assuming that deaths were distributed evenly during the post-neonatal period, some $80 \%$ of infant deaths would have occurred during the first six months after birth. This means that about 40 of each thousand children born would have died before baptism, assuming that children are baptised at an age of about six months and that weak and sickly children are not baptised at a younger age than others. This would lead to a deficiency of 0.2 children in TFR in the period 1990-2000. Instead of being 4.2, TFR would have been 4.4 during this ten-year period.

The level of infant mortality in the 2000 NDHS is, however, relatively low. According to estimates by Notkola et al. (2004) based on parish register data, post-neonatal mortality was 49 per thousand in the period 1994-2000, compared to 19 per thousand in the period 1991-2000 when assessed using data from the 2000 NDHS (GRN/MoHSS 2003b). It is possible that register-based data is more accurate than data based on interviews when estimating levels of infant mortality in a population where the prevalence of HIV is high. This is because women who are infected with HIV are more likely to be missing from the interview data than other mothers (because of their higher mortality and morbidity), and also because the children of these HIV-infected women are more likely to be infected by HIV than other children, increasing the level of their mortality. Assuming this higher level of infant mortality, the TFR would have been around 4.6 in the period 1990-2000 when taking into account children who died at an age of less than six months, i.e. before their baptism. In 1960-1989, if 5-10\% of children had been lacking from the parish registers because they died before being baptised, this would have resulted in a deficit of $0.3-0.7$ in the TFR. 
The sex ratio at birth (i.e. the number of males per 100 females) in parish register data was 97 for the whole of the data and 96 for the period 1960-2000. In most of the world's populations, boys form a majority among new-born babies. In sub-Saharan Africa, however, the sex ratio at birth (103.3) is lower than the average for the whole world (105.5). There are also regional differences within sub-Saharan Africa: among the Bantu of southern and eastern Africa, the sex ratio at birth is 101 (Garenne 2002, 2004a). According to Garenne (2002, 2004a), the sex ratio at birth in the 1992 Namibia Demographic and Health Survey was 98.5. Furthermore, according to the 2001 Population and Housing Censuses, the sex ratio at birth among babies born during the 12 months preceding the census was 100 in the Northwest Health Directorate and 101 in the whole of Namibia (Table 4). In the 1991 Population and Housing Census, information concerning the sex of children born was not collected. The sex ratios in parish register data are therefore relatively well in line with those from other sources, indicating only a modest effect from the under-registration of children who died before baptism.

Table 4. Sex ratio at birth in North-Central Namibia in parish registers, in the 1992 Namibia Demographic and Health Survey, and in the 2001 Population and Housing Census.

\begin{tabular}{|c|c|c|}
\hline Region and year & Sex ratio & (N) \\
\hline North-Central Namibia, parish registers, $1960-2000$ & 96 & $(17,368)$ \\
\hline North-Central Namibia, parish registers, 1970-1979 & 95 & $(6,405)$ \\
\hline North-Central Namibia, parish registers, 1980-1989 & 91 & $(3,655)$ \\
\hline North-Central Namibia, parish registers, 1990-2000 & 98 & $(2,038)$ \\
\hline Northwest Region, NDHS $1992^{1}$ & 100 & $(4,759)$ \\
\hline Northwest Health Directorate, 2001 Census $^{2}$ & 100 & $(18,630)$ \\
\hline Namibia, NDHS $1992^{3}$ & 99 & $(13,372)$ \\
\hline Namibia, 2001 Census $^{4}$ & 101 & $(45,157)$ \\
\hline
\end{tabular}

Notes:

${ }^{1}$ Source: NDHS 1992.

${ }^{2}$ Births in the 12 months preceding the 2001 Population and Housing Census in the Omusati, Oshana, Ohangwena and Oshikoto regions. Source: GRN/NPC 2003 (data tables).

${ }^{3}$ Source: Garenne 2002, 2004a.

${ }^{4}$ Births in the 12 months preceding the 2001 Population and Housing Census.

Source: GRN/NPC 2003 (data tables).

It should be noted that a delay in the registration of births to families which moved to central and southern regions of Namibia may have some effect in reducing apparent levels of fertility. This type of explanation probably applies especially to the period following independence, since the restrictions on movement between regions were then removed and it was possible for whole families to migrate. The majority of the people who did this remained members of the congregations in their previous place 
of residence. Registration in their home parishes of population events experienced by these migrants is thus wholly dependent on their own activity. While no method for estimating the magnitude of this effect exists, the possible consequences are however reduced by the fact that women migrate to a lower extent than men. This is shown, for example, in sex ratios, which show that in 2001 there was an average of 80 men for each 100 women in the constituencies where congregations were located (GRN/NPC 2004a, 2005a). It is also possible that modern communications and better methods of transportation have helped in maintaining the accuracy of the parish registers. Furthermore, there were no ELCIN parishes in migrant destination regions until the 2000s, a situation which probably resulted in the accuracy of registers in home regions being enhanced.

\section{Population and Housing Censuses and Demographic and Health Surveys}

Population censuses conducted prior to Namibia's independence have been considered unreliable (Siiskonen et al. 2005) and are not accessible. As in sub-Saharan Africa in general, the Population and Housing Censuses of 1991 and 2001 must also be used with caution. For example, there is a tendency for women to omit births occurring long before the census interview, especially if the children concerned subsequently died. To correct the error resulting from omitted births, demographers have developed so-called indirect methods, and these have also been used in this research.

Survey data, and especially that collected in developing countries, should always be used with caution. Demographic and Health Surveys are part of a large entity, and their reliability and validity are subject to continuing evaluation. This type of survey also suffers from some special problems. For example, a tendency has existed to "lift" the age of children who are close to their fifth birthday in order to reduce the amount of work involved in weighing and measuring all children who are less than five years old. When analysing fertility, problems resulting from this tendency were avoided by using a reference period of 0-3 years before survey. DHS studies have also been designed to be representative of certain regions - in 1992 Namibia was divided into four (or in some analyses three) large regions, while the 2000 NDHS was representative of all the country's 13 administrative regions. The quality of DHS surveys has also been questioned, for example results in the published version of the Zimbabwe DHS 1994 were criticised by Muhwava and Timæus (1996). 


\section{HIV sentinel surveillance data}

HIV sentinel surveillance based on antenatal clinic (ANC) data is an important source of information concerning levels of HIV prevalence in sub-Saharan countries. Their representativeness for the whole of the female and male populations has been discussed and assessed by demographers (e.g., Bos 1998; Dzekedzeke and Fylkesnes 2006; Fabiani et al. 2006; Fylkesnes et al. 1998; Gregson et al. 2002; Heuveline 2003, Saphonn et al. 2002; WHO and UNAIDS 2003; Zaba et al. 2000). Most scholars have concluded that HIV prevalence among pregnant women is a good indicator of average HIV prevalence in the whole adult population (e.g. Dzekedzeke and Fylkesnes 2006), while male HIV prevalence is lower and female HIV prevalence is higher (e.g. Fabiani et al. 2006). HIV sentinel data concerning pregnant women tends to overestimate actual HIV prevalence among younger women and underestimate levels among older women (Bos 1998). Also, the selection of sentinel sites has an impact on the average HIV prevalence revealed in these surveys, for example, too much weight can be given to the urban population. Changes in HIV prevalence at the same sentinel sites at different points in time do however provide information on the state of the HIV epidemic in these regions.

Another type of HIV data which includes information on both men and all women, not just women who are pregnant, is gradually being provided for sub-Saharan African countries by, for example, a new generation of Demographic and Health Surveys which include a test for HIV (Calleja et al. 2005). These surveys have already been conducted in some countries, but Namibia was unfortunately not one of them.

\subsection{Methods}

\subsubsection{Family reconstitution, parish register analysis}

The family reconstitution method (Wrigley 1966) was used to collect data from microfilmed parish registers of the sample congregations (see Siiskonen et al. 2005). As they were collected according to the principles of the Scandinavian parish register system, these data allow the direct analysis of fertility. In the context of sub-Saharan Africa this data is quite exceptional, since analyses of fertility have in the main been based on population censuses and retrospective surveys.

When analysing fertility, the follow-up of women began on each individual's fifteenth birthday or if she was an adult convert, following baptism. The data also therefore includes information on births taking place before a woman was married. In cases where the time of baptism was unknown, follow-up started from the date of a woman's marriage. Follow-up stopped if a woman was excommunicated from the parish or migrated out of it, and started again when she returned. If the time of inwards migration 
was not known, the woman concerned was not included in the data unless she had migrated before marriage. In such cases, follow-up began from the time of marriage. Follow-up ended when a woman died or when she reached the age of 50.

Fertility levels during the 1960-2000 period were studied using Age-Specific Fertility Rates (ASFR) and the total fertility rate (TFR). These are the classic demographic tools used in fertility analysis. Both period fertility and cohort fertility were examined. Cohort fertility (CFR) was calculated from the 1920-24 birth cohort to the 1975-79 birth cohort. It was possible to calculate the full set of Age-Specific Fertility Rates by birth cohort for the five-year birth cohorts from 1940-44 until 1950-54, while the birth cohorts from 1935-39 and 1955-59 were only modestly affected by age truncation.

Marital fertility was examined using Marital Age-Specific Fertility Rates (MASFR), total marital fertility (TMFR), and Coale's index of marital fertility $\left(I_{g}\right)$. Coale's index of marital fertility is an indirectly-standardised ratio which expresses the level of fertility as a proportion of the fertility a population would have had if it had experienced the highest fertility pattern reliably recorded, i.e. the Hutterites in Northern America (Newell 1988).

Estimation of the impact of HIV on fertility was carried out by comparing the fertility histories of women who died at an age of less than 50 years in 1990 and thereafter to the fertility of women who survived to the end of their reproductive period. The basic idea in this comparison is the assumption that a substantial proportion of deaths among females during their reproductive period are the result of HIV infection and AIDS. This assumption was supported by the finding of Notkola et al. (2004) that during the HIV epidemic, the mortality of women aged between 20 and 64 years increased by a factor of 3.5 times compared to its former level. It is therefore possible to estimate that approximately two-thirds, or as a conservative estimation, at least half of the deaths among these women were the result of HIV infection and AIDS. Evidence from elsewhere in Africa also shows that in the regions most severely affected by HIV, the major cause of mortality among women of working age is HIV infection and AIDS. For example, in KwaZulu Natal, only $27 \%$ of the deaths among women aged 15-44 resulted from causes other than HIV infection and AIDS (Hosegood, Vanneste, and Timæus 2004). In the Congo, according to a mortuary investigation of all deaths among women aged 15-44, mortality among HIV-infected women was 32 times higher than among non-HIV-infected women (Le Coeur et al. 2005). 


\subsubsection{Indirect methods}

Since reliable measures of demographic parameters by direct analysis of traditional demographic data sources, i.e. vital registers and population censuses, is simply not possible in many developing countries, demographers have developed so-called 'indirect' estimation techniques. These techniques are important tools when making demographic estimates from inadequate and incomplete data sources.

Data from the 1991 and 2001 Population and Housing Censuses was analysed using indirect demographic analysis techniques. Fertility was analysed using the Brass-type method, which is based on a comparison of period fertility with reported average parities, i.e. the so-called $\mathrm{P} / \mathrm{F}$ ratio method based on data for all children (United Nations 1983). This technique uses information from the census questions concerning the number of children ever born to women (lifetime fertility or parity) by age of the mother, and the number of children born during the 12 months preceding the census (period fertility) by age of mother. The rationale behind this technique is that even if the information on the number of children born during the last 12 months is not complete, the proportion of children omitted is probably more or less constant regardless of the mother's age, and the age pattern of fertility will thus be an acceptable estimate even if the level of fertility is too low. Lifetime fertility, on the other hand, is probably more accurately reported by younger than by elderly women, since births among the former group have occurred more recently. The age pattern of period fertility is therefore scaled to match the level of fertility indicated by the lifetime fertility (parity) of young women. The version of this technique that was applied in this study utilizes the Coale-Trussell model fertility schedules (United Nations 1983, 33). The correction factor used to adjust fertility levels was based on the weighted average of $\mathrm{P} / \mathrm{F}$ ratios among 20-24 and 25-29 year-old women. Although the P/F ratio technique is recommended for use in a context where fertility is constant, it was chosen on this occasion because of its comparability with the published Population and Housing Census results produced using this method.

Census data was also used to produce estimates of life expectancy at birth and AgeSpecific Mortality Rates, both of which are required when making population projections. Mortality estimates were produced using indirect estimation methods. The technique used was Trussell's variant of the original Brass method, which is based on information on all children ever born, on children who survive, both classified by age of the mother, and on the Coale and Demeny Regional Model Life Table West (Coale and Demeny 1983; United Nations 1983, 76). The basic idea of this method is to convert the children who have died as a proportion of the children ever born to women in five-year age groups into a probability of dying between birth and a certain 
age. The age pattern of fertility is used to estimate the children's length of exposure to the risk of dying among mothers in different age groups.

\subsubsection{Population projections}

The impact of HIV infection and AIDS on demographic development was demonstrated using population projections. So-called multi-state population projections, in which the population was divided into subgroups either by both education and HIV status or just by HIV status, were made using PDEPROJ software developed at the International Institute for Applied Systems Analysis (IIASA). Data acquired from HIV sentinel surveys on HIV prevalence among pregnant women were converted to figures for HIV and AIDS prevalence in whole male and female populations using software developed by the Futures Group, i.e. the DemProj and the AIDS Impact Model (AIM) of the Spectrum System.

Both population size and its demographic structure are based on the 1991 and 2001 Population and Housing Censuses. The effect of HIV infection on demographic development in the study population was compared to demographic development in the hypothetical situation where the population was not subject to this effect. This was done to produce estimates for the impact of HIV infection and AIDS on population size and structure in the whole of Namibia (PII), and to examine in more detail how the fertility-reducing effect of HIV will influence demographic development in NorthCentral Namibia (PIV). Mortality and fertility estimates for HIV-negative sub-populations and comparative population projections for situations without any impact from HIV infection were based on published estimates and indirect calculations made on aggregate-level tables from the 1991 and 2001 Population and Housing Censuses, and on the published results of the 1996 Demographic Sample Survey. For HIV-negative sub-populations, mortality was assumed to remain stable and fertility was assumed to fall to a level of three children per female by the end of the projection period. The fertility of HIV-positive women was assumed to be lower than that of HIV-negative women. For the whole of Namibia, this reduction in fertility was assumed to be $20 \%$. In the case of North-Central Namibia, the assumption concerning the fertility-reducing effect of HIV infection was further developed on the basis of the age structure and magnitude of HIV-related sub-fertility as revealed by the parish register results. HIV infection was assumed to develop into AIDS in a period of ten years. For children, this development was assumed to occur in a shorter timeframe.

The aim of these projections was simply to demonstrate the demographic consequences if the HIV epidemic continues as it has until now. The impact of possible future increases in coverage by ARV treatment, improved prevention techniques or behavioural changes towards safer sexual practice were not included. 


\section{Results}

\subsection{Fertility prior to independence: fertility trends in 1960-1989}

\subsubsection{The onset of fertility decline}

Prior to the study period, the study population had experienced a decline in fertility in the 1940s and an increase of fertility in the 1950s (Notkola and Siiskonen 2000). During the 1960s, although total fertility was high and relatively stable, some yearly fluctuation did occur (PIII). Total marital fertility fluctuated to a greater extent than total fertility among all women. In the 1960s, total fertility was 6.4 and total marital fertility was almost 10 children per female (Figure 5). In the following decade, total fertility was still stable, but fertility among different age groups developed in different directions.

Figure 5. Total Fertility Rate and Total Marital Fertility Rate in North-Central Namibia, 1960-1989.

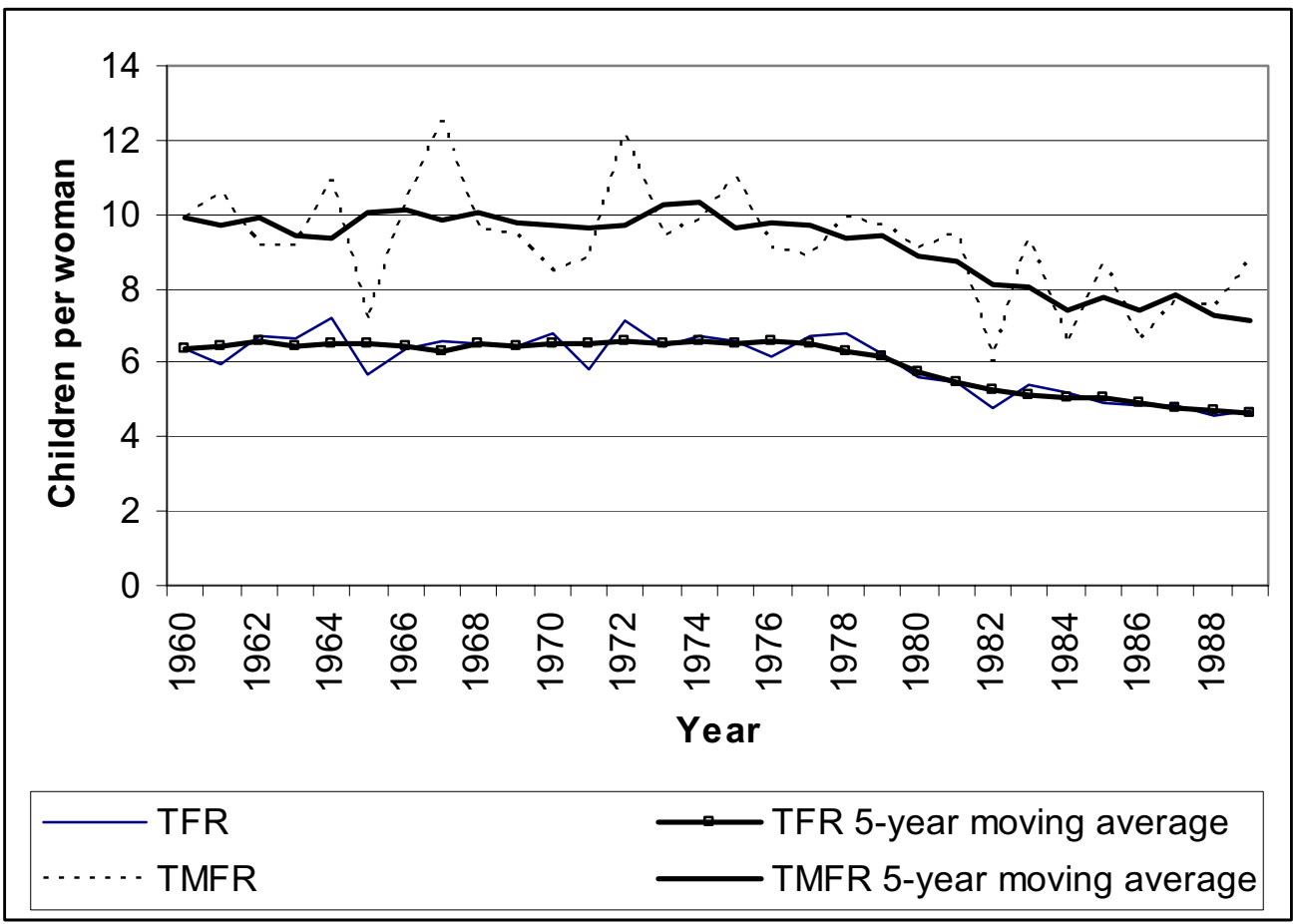

Source: PIII, based on parish-register data. 
Total marital fertility was still close to ten at the beginning of the 1970s, but started to fall in the late 1970s, slightly earlier than the decline in overall total fertility (PIII). The 5 -year moving average of Coale's index of marital fertility $\left(I_{g}\right)$ for the sample congregations was above 0.7 until the late 1970s, meaning that marital fertility was slightly more than $70 \%$ of that of the Hutterites (Figure 6). The $I_{g}$ figure began to decline in the late 1970s and fell below 0.7 in 1978-79. In 1979, Coale's index of marital fertility had fallen $10 \%$ below its plateau level, and the decline then continued until independence and beyond, right up to the end of the research period for the present study. In the "Princeton European Fertility Project", the onset of fertility decline was defined as occurring in that year when the decline in $I_{g}$ was $10 \%$ below its plateau level in a declining $I_{g}$ which did not return to its plateau level (Coale and Treadway 1986).

Figure 6. Coale's index of marital fertility, North-Central Namibia, 1960-1999.

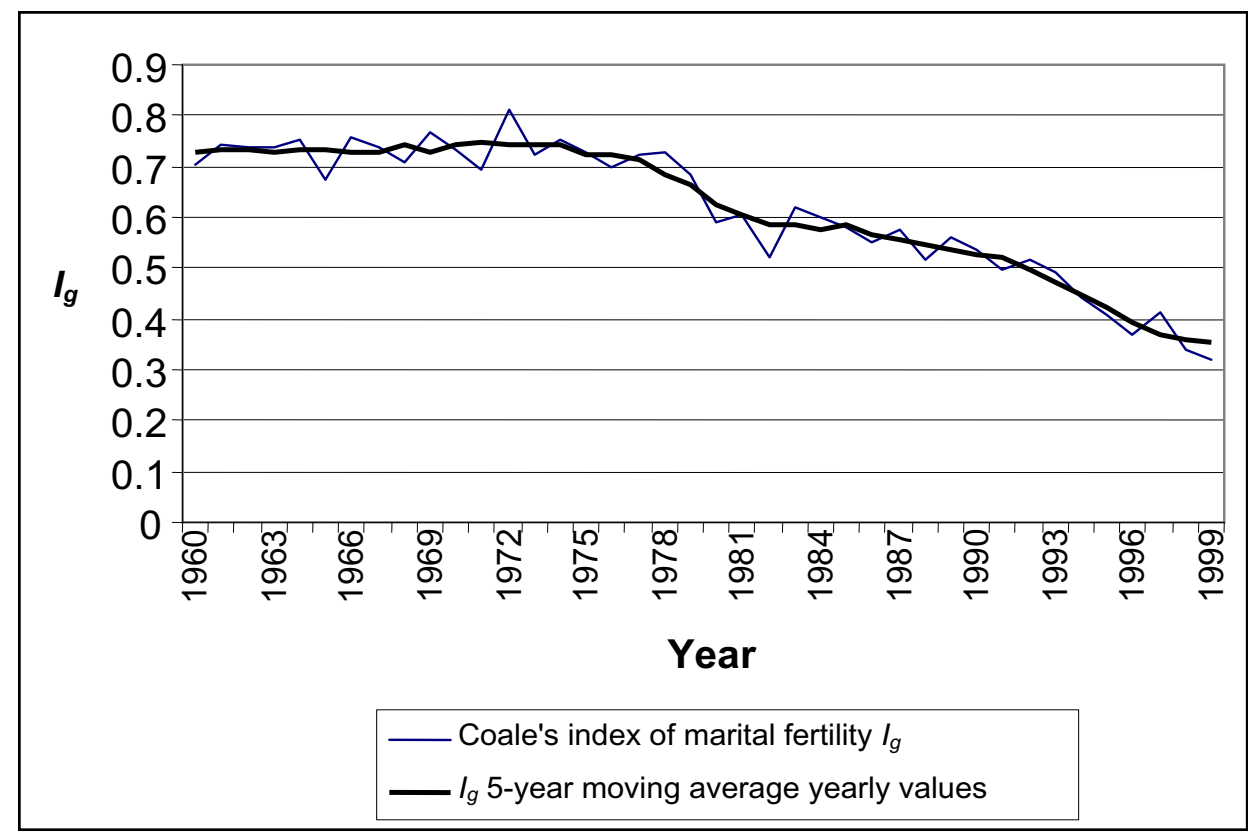

Source: PIII, based on parish-register data.

\subsubsection{Variation in the onset of fertility decline in different age groups}

In the early 1970s, the fertility of adolescents began to increase while that among most of other age groups started to decline at different time points (see Figures 7 and 8). In the 1960s, Age-Specific Fertility Rates were highest in the 25-29 and 30-34 age groups. The fertility of women aged 25-29 began to fall at the beginning of the 1970s, as did fertility in the oldest age group, i.e. women aged 45-49. These two groupings 
were followed by women of 30-34 and 35-39, whose fertility began to decline in the mid-1970s. The fertility of women aged 40-44 started to fall in the late 1970s, and it was at this time that the peak in ASFR moved to the 30-34 age group. Finally, in the beginning of the 1980s, fertility began to decline among women aged 20-24. Before the onset of fertility decline, a period of increased fertility was experienced in every age group.

Figure 7. Age-Specific Fertility Rates (yearly values of 5-year moving averages) among women aged 15-34 in 1960-1989, by 5-year age group.

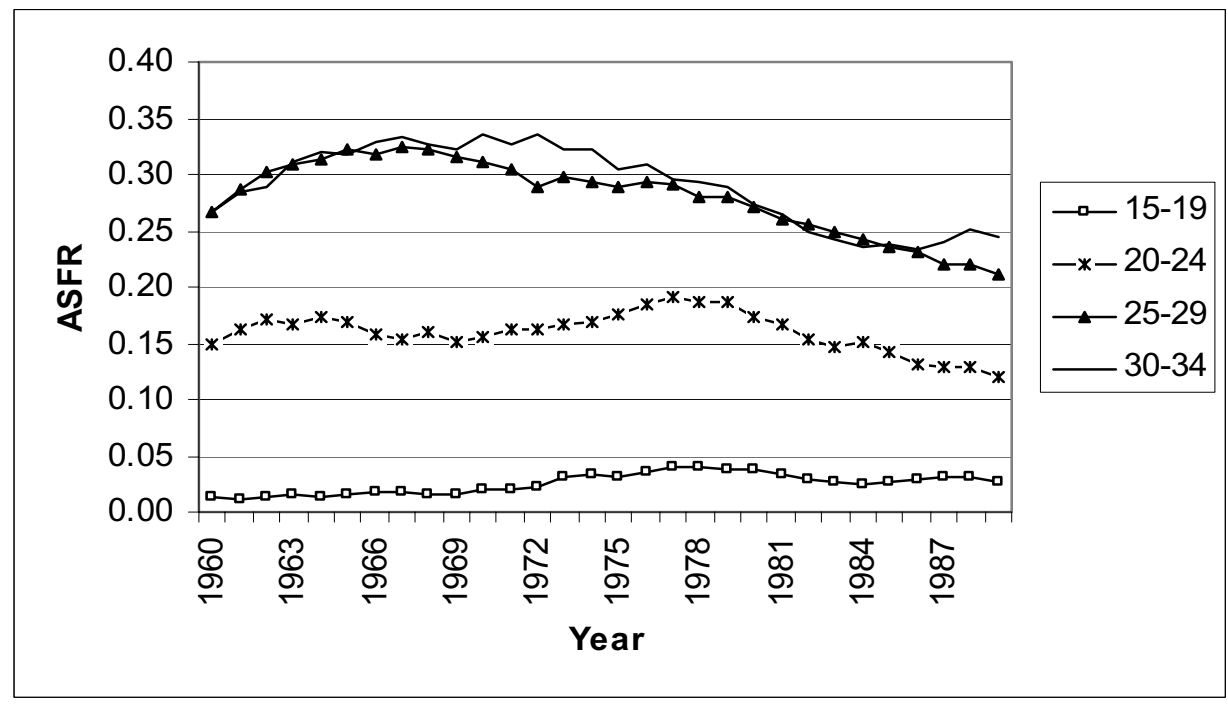

Source: Parish-register data.

Figure 8. Age-Specific Fertility Rates (yearly values of 5-year moving average) among women aged $35-49$ in $1960-1989$, by 5-year age group.

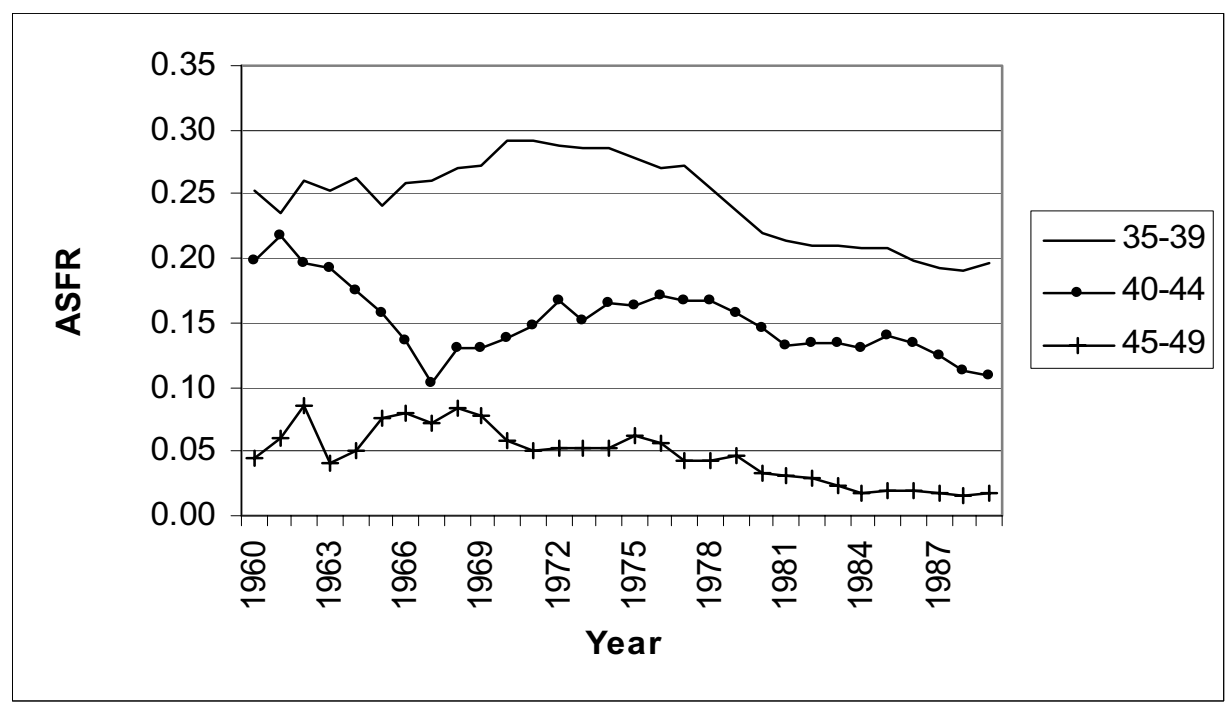

Source: Parish-register data. 
Despite the changes in Age-Specific Fertility Rates during the 1970s, the total fertility rate was relatively stable and averaged 6.5 for the decade (PIII). Total fertility showed no sign of a decline in the period 1970-79, in spite of the decline in fertility among women aged 25-29 and 45-49 throughout the 1970s, the decline of fertility among women in their thirties from the middle of the decade and the decline in fertility among women aged 40-44 that began in the late 1970s. These declines were compensated for by increased levels of fertility among women aged 15-19 and 20-24, as well as by the periods of higher fertility that preceded fertility decline in some age groups.

Finally, at the beginning of the 1980s, the decline in fertility among all age groups other than adolescents (15-19 year olds) resulted in total fertility starting to fall (PIII). The decline was rapid in the first half of the 1980s, but slowed late in the decade. Total fertility averaged 5.1 during the period 1980-89. Despite the decline in total fertility, fertility among adolescents remained high throughout the decade.

\subsubsection{The age structure of fertility}

Age-Specific Fertility Rates (ASFR) show that fertility is highest in three age groups (25-29, 30-34 and 35-39) (PIII), with peak levels occurring in the 25-29 and 30-34 age groups (see Figure 9). This is a typical age pattern for fertility in the former Ovamboland region: peak fertility occurs in older age groups than in other regions of Namibia (cf. GRN/MoHSS and Macro International 1993; PI) and in older age groups than the average for sub-Saharan Africa (cf. Robinson 1987).

When Age-Specific Fertility Rates are compared by 10 -year periods, changes between the 1960s and the 1970s are quite small (PIII). ASFRs of the 25-29 and 45-49 age groups fell, that of the 30-34 age group stayed at the same level, and ASFRs of the 15-19, 20-24, 35-39 and 40-44 age groups increased. Comparison of the ASFRs for the 1970s and the 1980s shows that fertility declined in all age groups except for women aged 15-19, and that the changes were more substantial that those between earlier decades. A similar decline was identified in Marital Age-Specific Fertility Rates, which also fell in the 1980s after being almost stable in the 1960s and 1970s. Contrary to the situation as regards the fertility of all women, there was no increase in marital fertility among women aged 15-19 in the 1980s (see Figure 5 in PIII).

Standardized fertility distributions (which show the age pattern of fertility if the TFR is 1, see Moultrie and Timæus 2003) indicate that the age structure of fertility has remained very similar throughout the period 1960-89 (see Figure 10). Women aged 25-29 and 30-34 make the largest contributions to the total fertility rate, and are followed by women aged 35-39. During the period 1960-1989, the relative contribution of adolescent fertility increased slightly, and that of women aged 45-49 fell by a modest extent. 
Figure 9. Age-Specific Fertility Rates (ASFR) in North-Central Namibia, 1960-1989.

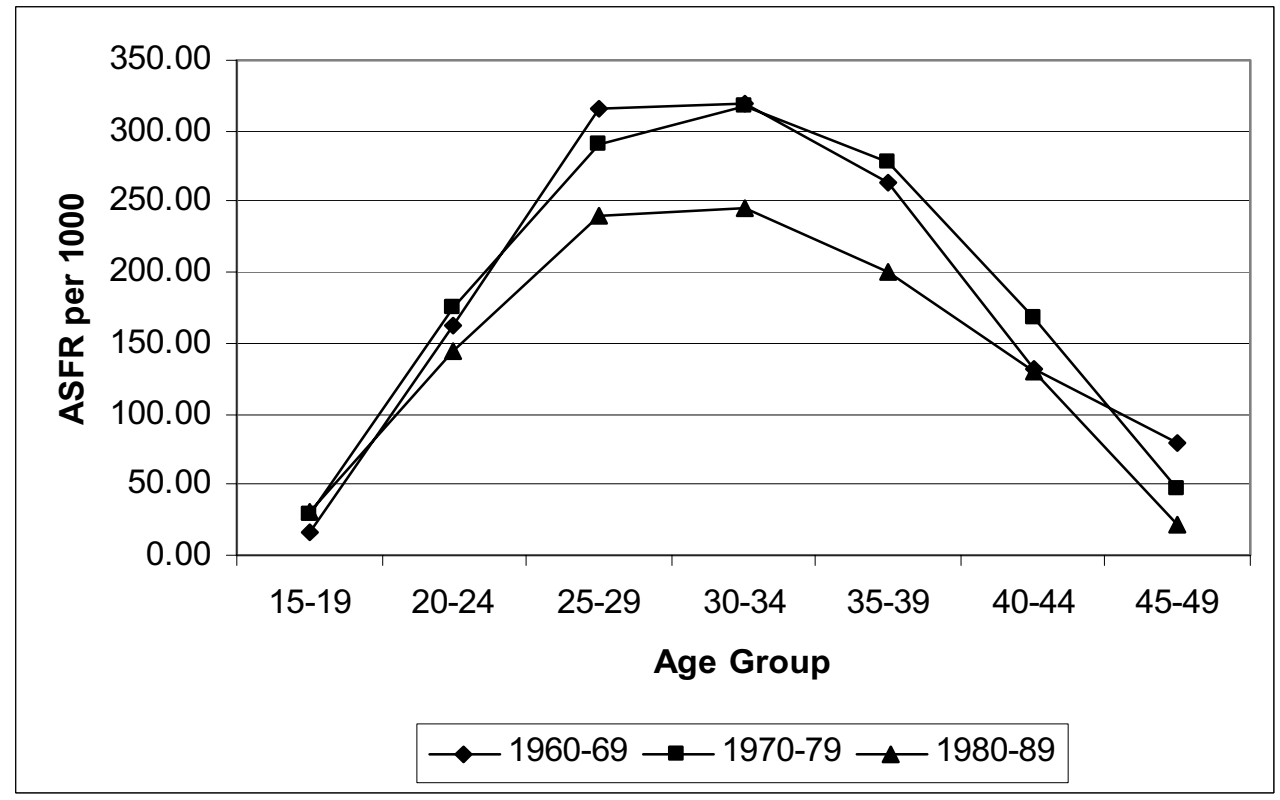

Source: PIII, based on parish-register data.

Figure 10. Standardized age distributions of fertility in North-Central Namibia, 19601989.

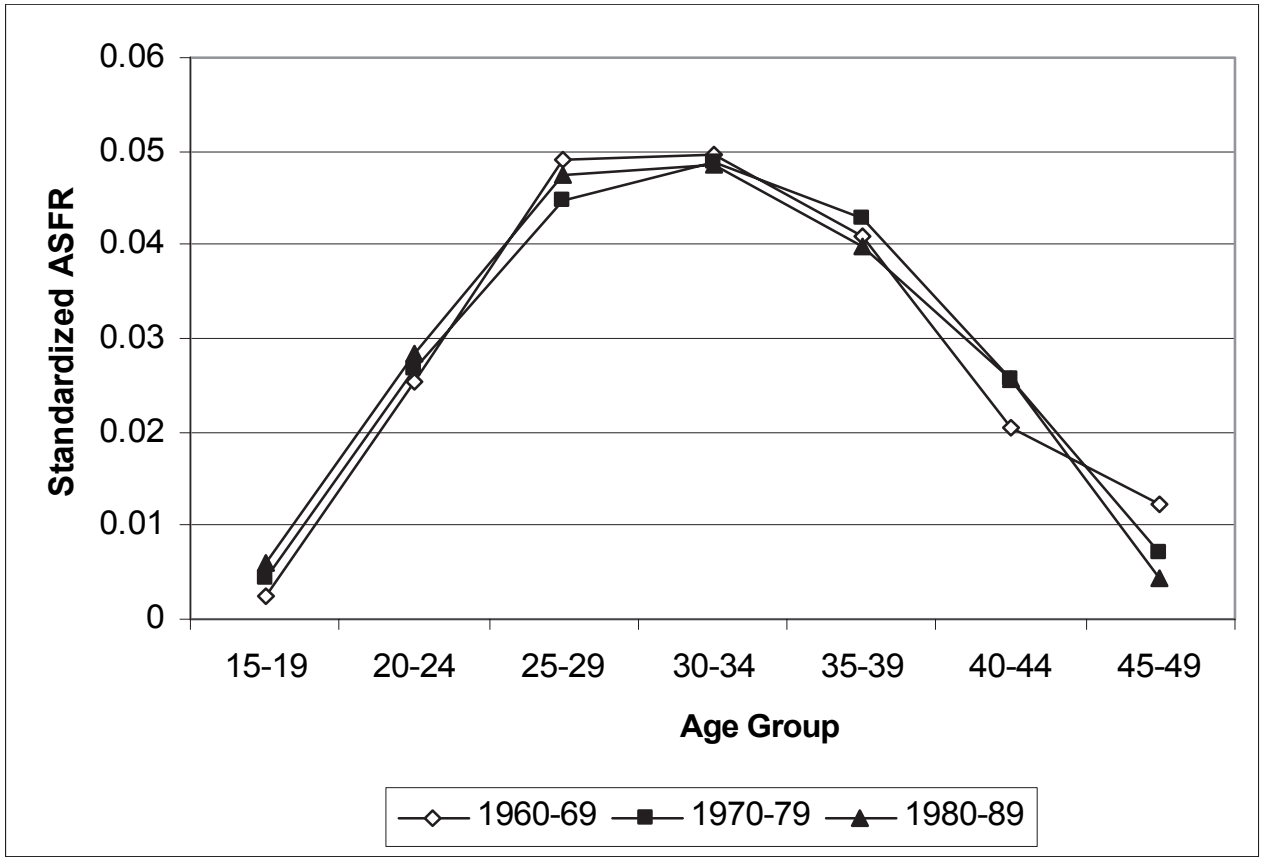

Source: Calculations based on results from PIII. 


\subsubsection{Fertility determinants at the onset of fertility decline}

Age at first marriage among women increased during the study period. In the 1960s, the mean age of females at first marriage was about 24 years and the median was about 23 years (PIII). During the 1970s, age at first marriage began to slowly increase, and at the end of the 1970s, the mean age of females at first marriage was about 25 years. The increase in age of females at first marriage accelerated during the 1980s. During the decade, the mean age of females at first marriage averaged 27 years and the median age was 26 years.

Since the start of marital life was postponed, its connection with the beginning of motherhood was weakened. Premarital fertility increased, i.e. a growing proportion of women gave birth to children before their first marriage (PIII). According to the parish registers, the proportion of women who had a child before marriage among those who married before the age of 30 was $10 \%$ in the 1960 s and $11 \%$ in the 1970 s. In the 1980 s, this proportion was $18 \%$.

There is little information concerning the prevalence of contraceptives prior to the 1990s. Hospital statistics show that contraceptives were distributed in North-Central Namibia during the 1980s (PIII; Notkola and Siiskonen 2000, see also GRN/MoHSS 1995). The main methods of contraception employed were injections and the Pill, and to a lesser extent the IUD. There were more mentions of the provision of contraceptive services in reports by the colonial administration than in reports from Lutheran hospitals during the 1980s (Direktoraat Gesondheid en Welsyn 1984; Directorate Health and Welfare 1985, 1986; Lutheran Medical Mission 1985, 1988, 1991; Lutheran Medical Services 1994), which indicates a difference in policy regarding the distribution of contraceptives in state and church-based hospitals. Although there are mentions in reports by the Lutheran Medical Services of family-planning services being provided in the 1980s, these services only began to be rendered on a routine basis in the Onandjokwe District hospital and in health clinics run by the Lutheran Medical Services in June 1993.

Information on abortions in the study region is lacking. There is evidence that in precolonial times, abortion was used in cases where girls became pregnant before being initiated (McKittrick 1995; Miettinen 2005). Abortions were prohibited by the South African colonial rulers, and the government of independent Namibia has continued the same policy (Lucas 1992; McKittrick 1995).

Information on breastfeeding in the study region before independence is limited. Parish registers show that the birth intervals were shorter if the preceding sibling had died at 
an age of less than 12 months. This difference was already clear in the early 1960s. The probable cause is a shortening of the period of post-partum infecundability resulting from shorter periods of lactation.

Fertility is also affected by permanent sterility, i.e. primary and secondary sterility caused by e.g. sexually-transmitted diseases. According to Notkola and Siiskonen (2000), STDs have been present in the study region since at least the beginning of the 20th century, but were, however, cured in a relatively-efficient manner. Notkola and Siiskonen assume that increasing treatment of STDs contributed to the increase of fertility during the 1960s.

The proportion of women married before the age of 20 who remained childless at the end of their reproductive period can be used as an estimate of primary sterility. The average figure for primary sterility in sub-Saharan Africa is around 3\%, while the highest levels (6\%) are found in Cameroon and in the Central African Republic (Larsen 2000). In North-Central Namibia, the average age of females at first marriage is higher than in sub-Saharan Africa in general, and therefore the proportion of childless females among women married before the age of 30 was investigated. Among these women, the proportion of women in the 1956-1989 marriage cohorts without children at the age of 45 was $3-5 \%$ (PIII).

Information on intrauterine mortality in the study region is very limited. According to statistics from the Lutheran Medical Mission, the rate of stillbirths among deliveries in Onandjokwe hospital was 18 per 1,000 in 1984, 25 per 1,000 in 1985, 12 per 1,000 in 1986, 15 per 1,000 in 1987, and 9 per 1,000 in 1990 (Lutheran Medical Mission $1985,1986,1988,1991)$. For comparison, the number of stillbirths in this hospital in 1987 totalled 44, while the number of women treated for spontaneous abortion was 334. It should be remembered, however, that these statistics include only a fraction of the total number of stillbirths and spontaneous abortions in the study region.

Fecundability is directly dependent on frequency of intercourse. In North-Central Namibia, long-standing traditions of temporary labour migration have resulted in prolonged periods of spousal separation. During the periods of rule by both Germany and South Africa, the places in which people lived were determined by their ethnic group. A system of contract labour was established by the Germans and continued by the South Africans. The aim of the system was to provide cheap labour for commercial farmers, mining companies and the like by making long-term contracts with men. This in turn resulted in extended periods of spousal separation (e.g. Voipio 1980). In their historical study of demographic trends in North-Central Namibia, Notkola and Siiskonen (2000) show that fertility declined during the 1940s and 1950s, and their 
assumption is that the main reason for this was an increasing number of male labour migrants and their lengthened contract periods.

In the study region, levels of mortality began to decline relatively early. In their research into mortality trends in 1925-90, Notkola and Siiskonen (2000) discovered that levels of infant mortality in the study region fell during the 1930s, with a second decline occurring at the end of the 1950s. Levels of child and adult mortality started to fall in at the end of the1940s or in the beginning of the 1950s.

Fertility is also affected by increasing levels of formal education. Educational work in the study region was initiated by missionaries in the early years of the 20th century, and was continued in the schools maintained by ELCIN (Peltola 1958; Lehtonen 1999). In the 1960s, basic education in the study region was placed under the authority of the colonial administration.

\subsubsection{Fertility prior to independence compared to other regions}

Comparison of levels of fertility in the study region with other regions of Namibia is complicated because there is little evidence concerning fertility levels elsewhere in the country. Based on the results of the Southern African Demographic and Health Survey, Mostert (1989, as cited in UNICEF Namibia 1991) states that in Namibia's other northern region, the Okavango in northeastern Namibia, usage of modern contraceptives in 1989 was low. The North-Central Region was not included in the survey.

Lemström (1999) has, however studied fertility in the Okavango region in 1950-1985 and compared it to the situation in Ovamboland (i.e. North-Central Namibia) using registers from Evangelical Lutheran congregations. Parish register data obtained from Okavango was smaller and apparently of poorer quality than data from North-Central Namibia, and this hampered his analysis (Lemström 1999). The Finnish Missionary Society started work in the Okavango region in 1926, more than 50 years after it began working in North-Central Namibia (Peltola 1958). The Okavango region, which borders North-Central Namibia to the east, was also a "native reserve" like Ovamboland, and based on the recommendations of the so-called "Odendaal Commission" it was made into a 'homeland' or Bantustan with its own legislative assembly (founded in 1970) (Katjavivi 1988). During the struggle for independence, people in the Okavango region appear to have been less involved in the armed struggle than people in Ovamboland. As was the case with the Ovamboland and Caprivi regions, the Okavango region was placed under the control of the South African Army at the end of 1970s. Okavango is a mostly rural region in which $95 \%$ of the inhabitants are concentrated in a 5-10 
kilometre area along the southern shore of the Kavango river (Lemström 1999; Yaron, Janssen, and Maamberua 1992).

According to Lemström (1999), parish registers show that total fertility in Okavango was less than six in the early 1950s, increased to seven in the mid-1960s, fell below six in the early 1970s, and then increased to more than six by the end of the 1970s. During the period of the present study, fertility levels in Okavango varied more than in North-Central Namibia, where total fertility was relatively stable. Averages for longer periods show that total fertility has been quite similar in both regions. Fertility was 6.6 in Okavango and 6.4 in North-Central Namibia in 1960-69. In 1970-1985, total fertility averaged 6.2 in Okavango, whereas in North-Central Namibia, total fertility was 6.5 in 1970-79 and then started to fall (Lemström 1999; PIII). Lemström (1999), however, surmises that variation in the mean age at baptism may explain a large part of the variation in total fertility in Okavango. Because mean age at baptism will have varied in concert with total fertility, it could be that the proportion of children who died without being baptised may have been higher in periods of lower fertility. In his conclusions, Lemström posits that the real level of fertility in Okavango in 1950-1985 was about the same as in North-Central Namibia, i.e. close to seven children per female.

The peak level of fertility in Okavango was achieved among younger women than in North-Central Namibia, i.e. in the 20-24 and 25-29 age groups (Lemström 1999; PIII). In both Okavango and North-Central Namibia, adolescent fertility increased during the 1970s. In Okavango, fertility among women aged 15-19 started to increase at the end of the 1970s, in North-Central Namibia the increase started in the beginning of the same decade. Mean age at first marriage among women increased in both regions, but was 1-3 years lower in Okavango than in North-Central Namibia during the study period.

\subsection{Fertility in the study region at the beginning of independence}

\subsubsection{Levels of fertility compared to other regions in Namibia}

During the first years of independence in Namibia, two major sources of regional data on fertility were collected, i.e. the 1991 Population and Housing Census and the 1992 Demographic and Health Survey (NDHS). Comparison of fertility in periods prior to this was made difficult by scarce information concerning fertility in Namibia's other regions. Data sets from the 1991 census and the 1992 NDHS allow comparison of both levels of fertility and the age structure of fertility in the study region with other regions of Namibia. Also, the NDHS in particular provides additional data on fertility determinants in both the study region and elsewhere in Namibia. 
In the regional division employed in the 1992 NDHS, the region handled in the present study corresponds to the 'Northwest Region'. In this region, fertility levels were higher than in the other 1992 NDHS regions (the Northeast Region and the combined Central/South Region). The 1991 Population and Housing Census was published using two different regional divisions. The 27 census districts are based on the division of regions prior to independence, and these also form the basis for the 1992 NDHS regions (for details, see Figure 3 in PI). In this form of regional division, the Northwest Region consists of the Ondangwa and Oshakati census districts. Calculations from census data using the regional division employed in the 1992 NDHS show a similar pattern to that reported in the 1992 NDHS: levels of fertility were highest in the Northwest Region, second-highest in the Northeast Region, and clearly lower in the Central and South Regions (PI, based on 1991 census data from GRN/NPC 1993). The 1991 Population and Housing Census was later published in terms of Namibia's 13 new administrative regions. The Omusati, Oshana, Ohangwena and Oshikoto regions, which together formed the Northwest Health Directorate in the 1990s, correspond closely to the Northwest Region in the 1992 NDHS.

According to the 1992 NDHS, total fertility in the Northwest Region was 6.7 (GRN/ MoHSS and Macro International 1993). According to the 1991 census, it was either 6.9 when calculated by the old census districts or 6.8 when calculated by the new administrative regions (PI; PIII). According to the census data, total fertility in Namibia's other regions was 6.7 in the Northeast Region (or 6.0 in the 1992 NDHS), 5.5 in the Central Region, and 4.2 in the South Region (or 4.1 in the 1992 NDHS for the combined Central/South Regions) (PI, based on 1991 census data from GRN/NPC 1993; GRN/MoHSS and Macro International 1993). Although levels of fertility were highest in the Northwest Region when compared to the other three regions used in the 1992 NDHS, there were districts in the 1991 census in which the fertility levels reported were almost as high as those in Ondangwa and higher than those in Oshakati (e.g. Bushmanland, Kaokoland, Kavango, and Hereroland-East) (PI).

\subsubsection{Regional differences in the age structure of fertility}

The age structure of fertility in the study region differs from that in other regions of Namibia (PI, based on 1991 census data from GRN/NPC 1993). In the early 1990s, both NDHS and census data showed that peak levels of fertility occurred in an older age group than in other regions, thus confirming the age structure of fertility found in parish-register data. In North-Central Namibia, fertility was highest among females aged 30-34, second highest among females aged 25-29, and followed by females aged 35-39. In all Namibia's other regions, peak levels of fertility occurred in younger age groups. 
Standardized Age-Specific Fertility Rates (which show the age pattern of fertility if the TFR is 1) clearly show the differing age structure of fertility in different regions. Compared to other regions in Namibia, fertility in the Northwest Region peaked among older women (see Figure 11). Fertility in the South Region was concentrated in age groups below 30 years. Fertility in the Central Region was at its highest among 2024 year-olds, and in Northeast region, although the fertility peak was wide (as in the Northwest Region) it was concentrated in the 20-24, 25-29, and 30-34 age groups.

Figure 11. Standardized age distributions of fertility in Namibia by region according to the 1991 census.

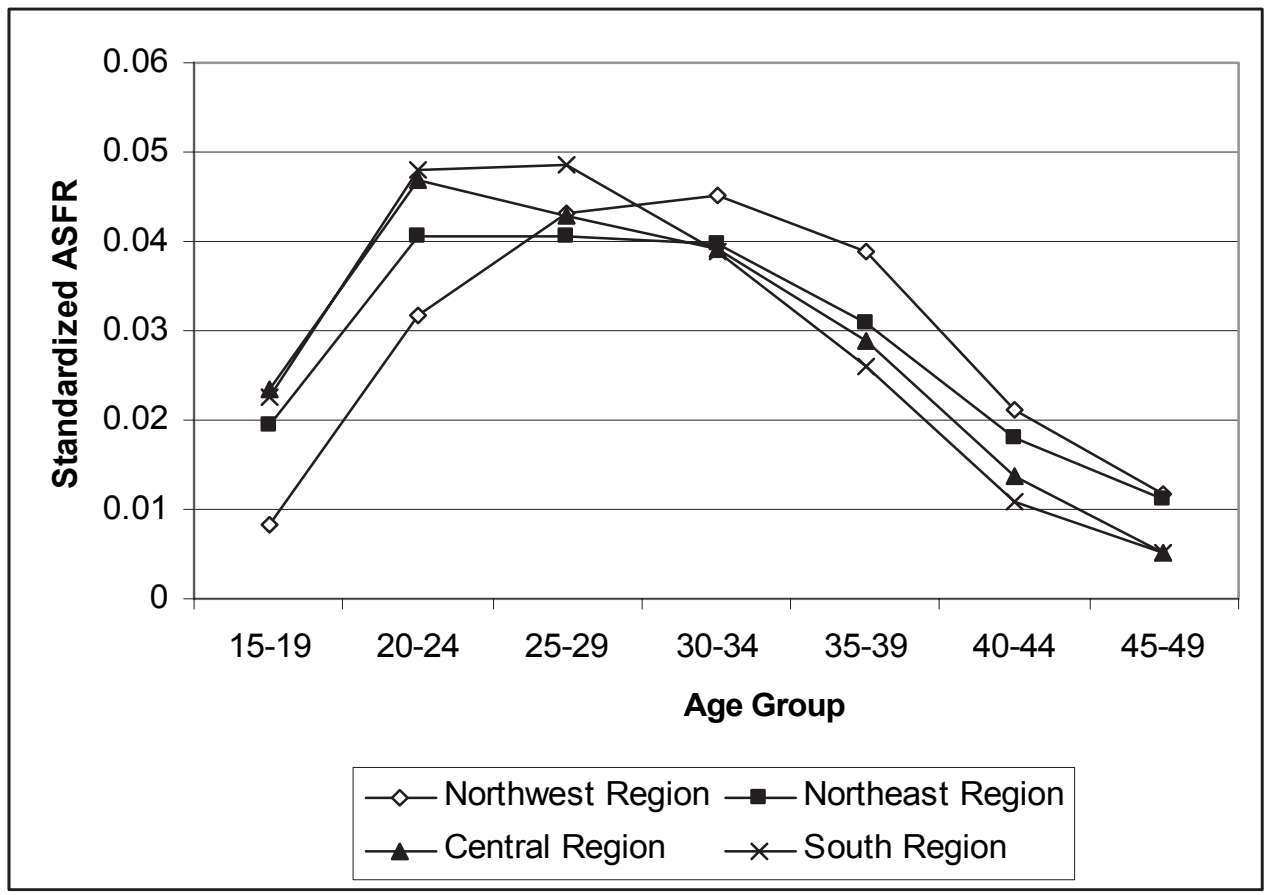

Source: Calculations from results in PI, based on 1991 census data from GRN/NPC 1993.

\subsubsection{Fertility determinants and regional differences in fertility}

At the beginning of independence, fertility appears to have been higher in the study region than in the country's other regions when the regional division employed in the NDHS is used (PI). The 1992 NDHS and the 1991 census provided an opportunity to compare levels of fertility in Namibia's different regions, and both sets of data, especially the NDHS, also provide information concerning the factors that influence fertility levels. The focus of attention now moves to the proximate determinants and other factors that sustain these higher levels of fertility. 
The proportion of never-married women in the study region was higher than in Namibia's other three regions. While the 1992 NDHS confirmed that age at first marriage among women in the study region was high, as revealed by parish-register data, it was higher than in Northeast region, but lower than in the Central and South Regions (GRN/MoHSS and Macro International 1993). The picture was further complicated by the diversity of unions, including consensual unions and polygyny: in the 1992 NDHS, $15 \%$ of currently-married women reported themselves as living in a polygynous union. There are reports of men with wives and children in different regions, for example an "official" wife and children in the rural home and another "unofficial" spouse and family in the region where they work for the majority of the year. Both the proportion of women unmarried at the end of their reproductive period and median age at first marriage were also high when compared to other countries in sub-Saharan Africa, with the exception of Botswana (Cochrane and Samir 1989; IRD 1990).

Marital patterns, however, have only a limited effect on fertility: childbearing often started before marriage, fertility among unmarried women was relatively high, and only a small proportion of never-married women were childless at the end of their reproductive period (PI, based on NDHS 1992). In the study region, being in a marital union (either formal or informal) or outside one does not necessarily determine whether a woman is exposed to pregnancy or not. It appears, therefore, that Stover's (1998) suggestion that the proximate determinant "marriage pattern" be replaced by "sexual activity" would probably be well suited to the situation prevailing in the study region. In the Northwest Region, the proportion of women who stated they had been sexually active in the last four weeks was lower than in Namibia's other three regions (GRN/MoHSS and Macro International 1993). On the other hand, although fertility is not limited to marital unions, the marital status of women does have an impact on their level of fertility. When studying fertility determinants using data from the 1992 NDHS, Hamata (n.d.) found that marital status had a strong effect on fertility in the study region. Similarly, according to the 1991 census, total fertility among never-married women in the four administrative regions of the North-Central Namibia (GRN/NPC 1994a) was 3-4 children lower than levels among women in legal or consensual unions.

According to the 1992 NDHS, only 7\% of currently-married women in the study region stated they were using a modern method of contraception. The modern methods used most widely in the study region were female sterilization $(3.1 \%)$, the Pill $(2.6 \%)$, the IUD (0.7\%), and injections (0.6\%) (GRN/MoHSS and Macro International 1993). If users of traditional methods are added to these figures, the proportion of women using contraception was almost 9\% in 1992. This is in line with the Survey on Household Health and Nutrition in Namibia (HHNS) (UNICEF Namibia 1990) that was conducted in 1990, which also reported only limited use of contraceptives among women in North- 
Central Namibia: $13 \%$ of women in peri-urban areas and $10 \%$ of women in rural areas were using some form of contraception. According to the 1992 NDHS, contraception was less common in the study region than in the Northeast, Central and South regions (GRN/MoHSS and Macro International 1993) of the country. Similarly, when compared the findings of the 1990 HHNS with those by Mostert (1989, as cited in UNICEF Namibia 1991) it appears that in 1989-1990, the prevalence of contraception was lower in North-Central Namibia than in the other regions included in the surveys.

Several surveys in early 1990s (e.g. Ahrenson-Pandikow 1992; Namibia Development Trust 1994) showed that the Pill and injections were the contraceptive methods in most common use, while the 1992 NDHS showed that the female sterilisation was one of the modern methods used most often in both North-Central Namibia and in the country on average (GRN/MoHSS and Macro International 1993). According to hospital reports in 1990-1994 and interviews with family-planning workers in 1994, the contraceptive methods used most often in the study region were injections and the Pill (PIII; Lutheran Medical Mission 1991; Lutheran Medical Service 1994; Oshakati Health Centre 1994a, 1994b; Oshigambo clinic 1994a, 1994b.).

In the study region, the period of postpartum insusceptibility was shorter than in the Northeast Region, but longer than in the Central and South Regions, which reflects the shorter period of breastfeeding associated with these regions (GRN/MoHSS and Macro International 1993). In the early 1990s, labour migration caused extensive periods of spousal separation and thus reduced coital frequency. The effect of this determinant on women living in different regions of Namibia probably varied greatly. Information on foetal mortality and especially regional differences in foetal mortality rates is scarce. Some information was, however, provided by the 1990 HHNS (UNICEF Namibia 1990). According to this survey, miscarriages and stillbirths were more common in the former Ovamboland region than in the Katutura Township in Windhoek, the nation's capital. In North-Central Namibia, the percentage of pregnancies ending to a miscarriage or stillbirth varied from $5-15 \%$ in different sub-regions.

Higher fertility in the study region than in other regions covered by the 1992 NDHS was connected with the high ideal number of children in this region: the mean number offered by NDHS respondents in the study region was 6.2 while actual total fertility according to NDHS data was 6.7 (GRN/MoHSS and Macro International 1993). According to the 1992 NDHS, levels of infant and child mortality were lower in the study region than in the Northeast Region, and in this respect the study region was similar to the combined South/Central Regions. 


\subsection{The first decade of independence}

The decline in fertility in the study region continued in the 1990s (PIII). Total fertility in the sample congregations fell from 5.1 in $1980-89$ to 4.2 in 1990-2000. In the early 1990s, the decline in fertility slowed and the level of total fertility stabilised until another decline began around 1994. The decline in fertility then continued until the end of the research period. Total marital fertility fell from 8.1 in 1980-89 to 5.4 in 1990-2000. The decline in marital fertility did not level off in the way that overall fertility did during the early-middle 1990s.

Age-Specific Fertility Rates reveal a substantial decline in the 25-29 to 40-44 age groups between 1980-89 and 1990-2000. The decline was, however, less than that which occurred between the 1970-79 and 1980-89 (see PIII). Standardized Age-Specific Fertility Rates show that the contribution to total fertility made by women aged 25-39 represented approximately the same proportion in the 1990s as in the 1980s, while the relative contribution to total fertility made by younger women increased and that by older women fell (see Figure 12 and 13). In a similar manner to Age-Specific Fertility Rates for all women, Marital Age-Specific Fertility Rates declined among women in the 25-29 to 40-44 age groups between 1980-89 and 1990-2000.

Figure 12. Age-Specific Fertility Rates in North-Central Namibia, 1980-89 and 1990-2000.

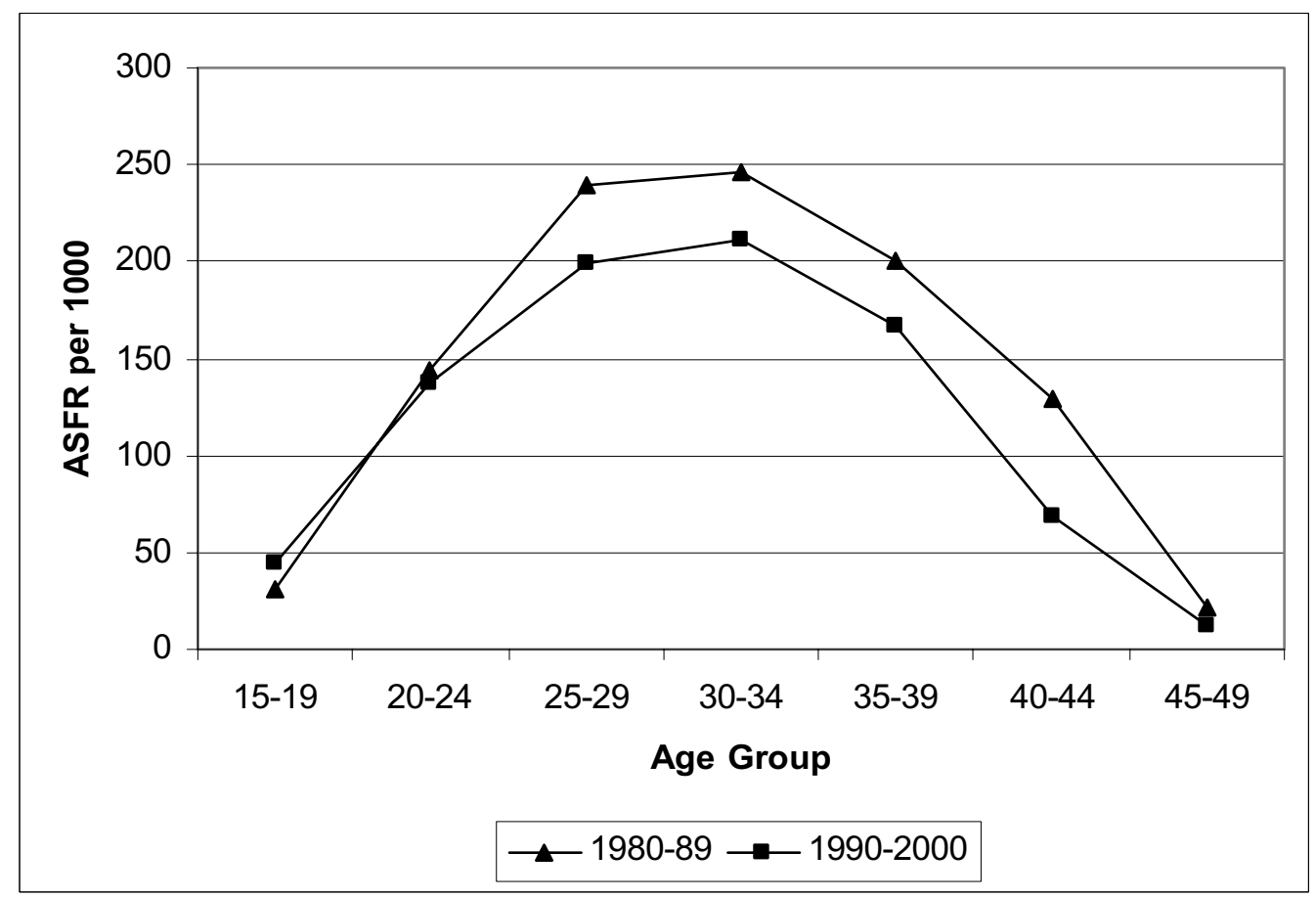

Source: PIII, based on parish-register data. 
Figure 13. Standardized age distributions of fertility in North-Central Namibia, 1980-89 and 1990-2000.

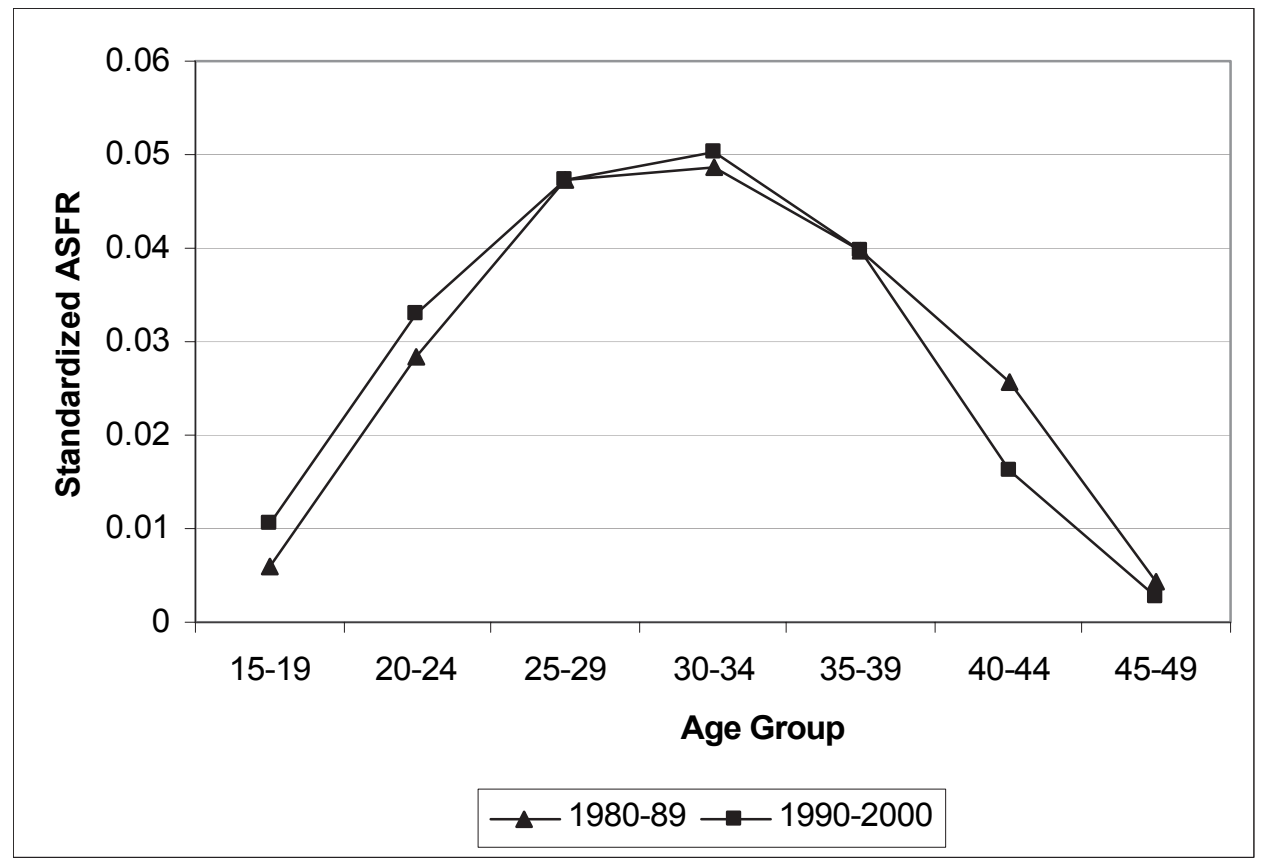

Source: Calculations based on results from PIII.

\subsubsection{Fertility decline and proximate determinants}

Age at first marriage among women continued to increase in the study region during the first decade of Namibia's independence. In the 1990s, parish-register data shows that the mean age of females at first marriage was around 30 years and that the median age at first marriage was 29 years (PIII). The 2000 NDHS reported a similar median age at first marriage, i.e. 29 years, among women aged 30-49 in the Northwest region. During the 1990s, the connection between the beginning of marital life and the beginning of childbearing was weakened even further. In the 1990s, parish-register data shows that the proportion of women who had given birth to a child before getting married was $29 \%$.

The diversity of conjugal unions continued in the 1990s and still exists (LAC 1999, 2000; Research Facilitation Services 2004). Different forms of marriage include marriage in court, marriage in church and traditional marriage. There are also consensual and polygamous unions. Marriage does not necessarily mean that husband and wife are actually living together. Furthermore, while information on this aspect of the situation at the beginning of the 1990s (and earlier) mostly concerned men having multiple partners (or families) in different locations, studies in the 2000 s report women as having multiple partners, primarily to maximise the economic support they receive 
from this source. Whether this is a new phenomenon or just an artefact of improved reporting remains unclear.

There is no information concerning the use of contraception in parish-register data, but NDHS surveys indicate a substantial increase in the prevalence of contraception during the 1990s. According to this source, 26\% of currently-married women were using some modern method of contraception in the Northwest Health Directorate in 2000 (GRN/MoHSS 2003b). In 1992, contraceptive prevalence was only 7\% (GRN/ MoHSS and Macro International 1993). The methods in most common use were injections, condoms, the Pill and female sterilization. The most significant increases occurred in the use of injections (from $0.6 \%$ to $8.9 \%$ ) and the use of condoms (from $0.3 \%$ to $8 \%$ ).

At independence, Namibia inherited the 1975 Abortion and Sterilization Act of South Africa. Under this act, abortion is permitted to save a woman's life, to preserve her physical or mental health, and in cases of rape, incest or foetal impairment. According to estimations made by the United Nations, abortion is not widely practised in Namibia and even unwanted pregnancies are in most cases carried to term. (Lucas 1992; United Nations 2002.)

Post-partum infecundability is primarily dependent on the period of breastfeeding. Parish-register data has no information on breastfeeding practices. Data from the Namibia Demographic and Health Surveys show that in the Northwest Region, the median period of breastfeeding increased from 17.5 months to 19.4 months between 1992 and 2000 (GRN/MoHSS 2003b; GRN/MoHSS and Macro International 1993). In the same period, the median length of postpartum abstinence increased from 9 to 13 months. The consequence was that women were insusceptible to pregnancy for a period of 20 months after delivery in 2000 compared with 15 months in 1992. The proportion of children in the Northwest Region who were breastfed at any time in their lives fell from $97 \%$ in 1992 to $94 \%$ in 2000 .

According to both the 1992 NDHS 1992 and the 2000 NDHS, some 3\% of currently-married women were childless at the age of 45-49, so this proportion remained unchanged during Namibia's first decade of independence (GRN/MoHSS 2003b; GRN/MoHSS and Macro International 1993).

While labour migration has continued, its impact on spousal separation (and thus fertility) may have diminished because of increased freedom of movement between Namibia's different regions and improved methods of transportation. 
As concerns mortality, developments during the 1990s and thereafter reversed what had been a positive trend: infant, child and adult mortality in the study region have all increased (Notkola et al. 2004). Post-neonatal and child mortality began to increase around 1991, and the mortality of males aged 30 years or more and females older than 25 started to increase in 1993. It is presumed by Notkola et al. (2004) that the increase in mortality was a consequence of the worsening state of the HIV epidemic in this region.

Between 1992 and 2000 there was considerable drop in the mean ideal number of children in the study region, i.e. a decline from 6.2 to 3.6 among women in the Northwest Health Directorate (GRN/MoHSS 2003b; GRN/MoHSS and Macro International 1993).

Increasing levels of education probably play a significant role in declining levels of fertility in the study region, where, as in the whole of Namibia, there are notable educational differentials in levels of fertility. In 1991, these differentials were most significant in the administrative regions of Omusati and Oshikoto, where total fertility among women with no education at all was ten and that of women who had completed Grade 12 was three (GRN/NPC 1994a). The impact of raised educational levels on fertility was, however, somewhat reduced by the fact that differences in fertility among women with different levels of education diminished during the 1990s.

Although differences in fertility levels among women with differing levels of education have diminished during the 1990 s, these differences still exist. Information on educational differences in fertility is not available at regional level from the 2001 Population and Housing Census, but in the whole of Namibia, fertility among women at all levels of education appears to have declined between 1991 and 2001 (GRN/NPC 1994a, 2003). For example, while women in Namibia with no education at all had a total fertility of nine in 1991, this group had an average total fertility of just five in 2001, and the fertility of women in other educational groups also fell. It therefore seems probable that a similar decline occurred in the study region within all educational groups.

During the 1990s, the educational level of women in the study region probably increased. Once again, data allowing comparisons between women with primary, secondary and tertiary education is not available from the 1991 and 2001 censuses. Between these two censuses, however, the proportion of the population without any formal education at age 15 or more fell significantly in all the Northwest Health Directorate's four administrative regions (GRN/NPC 1994a, 2003). In Ohangwena, where levels of education are the lowest in the study region, the proportion of people without any formal education at all declined from $32 \%$ to $23 \%$, and in Oshana, the part of the study region where educational levels are highest, this proportion fell from $17 \%$ to 
$8 \%$. These figures do however include men and women who have passed reproductive age. Some indication of the trends in education among women aged 15-49 can be found in the 1992 and 2000 NDHS surveys (GRN/MoHSS 2003b; GRN/MoHSS and Macro International 1993), which provide information concerning respondents at regional level. In the Northwest Health Directorate, in addition to the decline in the number of women without any formal education, the proportion of respondents with either some secondary education or who had completed secondary or higher education increased from $31 \%$ to $54 \%$. It is to be hoped that this reflects improved levels of education among women living in the study region.

In the 1990s, HIV infection affected fertility by several different routes. The impact of HIV infection on fertility is assessed in Section 4.6.

\subsection{Cohort fertility}

The full set of Age-Specific Fertility Rates by birth cohort were produced for cohorts from 1935-39 to 1955-59 (PIII). Although the ASFR of the youngest age group (1519 years) in the 1935-39 birth cohort and the ASFR of the oldest age group (45-49 years) in the 1955-59 birth cohort were partly censored, this had only a minor impact on figures for the total cohort fertility of these birth cohorts.

On a year-by-year basis, total fertility by birth cohort began to decline from 1940-1942. Analysis using 5-year groups of birth year showed that total cohort fertility was 6.4 in the 1935-39 birth cohort and declined to 4.6 in the 1955-59 birth cohort. Age-Specific Fertility Rates by birth cohort show that the decline occurred in the 25-29 and older age groups (see Figure 14).

Fertility among 15-19 year-old women began to increase in the 1955-59 birth cohort. Among the younger birth cohorts (not shown in the figure), fertility among 15-19 yearolds remained at this new higher level until the birth cohort of 1970-74. Fertility levels in the 20-24 age group remained stable in the older birth cohorts, but Age-Specific Fertility Rates in this age group declined in the 1960-64 and 1965-69 birth cohorts. Peak levels of fertility occurred among women aged 30-34 in the oldest birth cohorts and moved to the 25-29 age group in the 1945-49 birth cohort. 
Figure 14. Age-Specific Fertility Rates by birth cohort in North-Central Namibia, 1935-39 to 1955-59 birth cohorts.

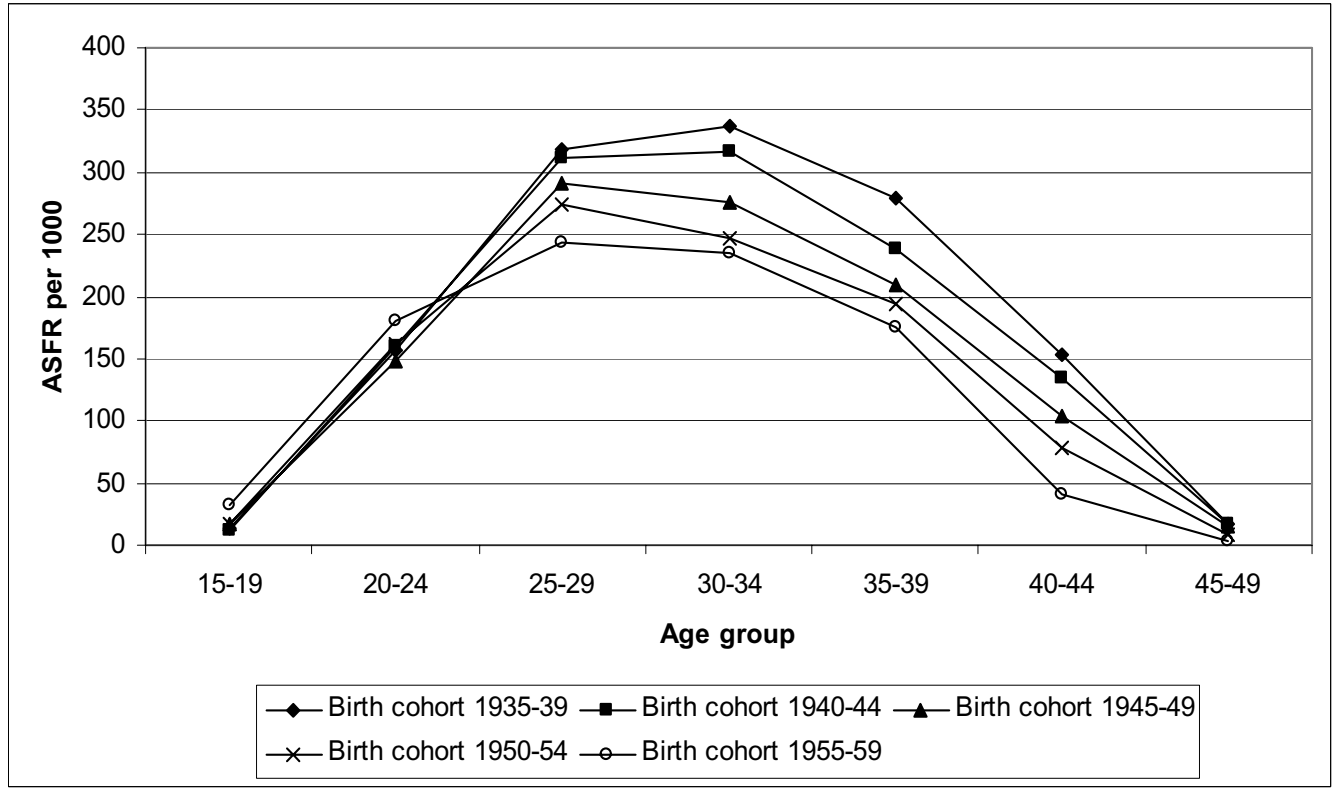

Source: PIII, based on parish-register data.

\subsection{Comparison of parish-register fertility levels with census and NDHS results}

Although comparison between results from the Population and Housing Census and results based on parish-register data is complicated by the differing regions, reference periods and study populations employed, it appears that the census gives higher fertility estimates for the Northwest Health Directorate than those indicated by data from parish registers (see Table 5). The probable cause for this is partly the nature of parish registers, i.e. the absence of children who died before being baptised, and partly by a real difference between levels of fertility in the congregation regions and in the Northwest Health Directorate as a whole. When total fertility estimates based on parish-register data are compared with total fertility levels calculated from census data for the five sample congregation regions, the differences are smaller, but they still exist (PIII). For example, census data shows that fertility in the sample congregation regions in 1991 was lower than the average for the Northwest Health Directorate. The same observation also applies in 2001 (i.e. census data from the sample congregation constituencies reveals lower levels of total fertility than the average for the Northwest Health Directorate). 
The 1992 Namibia Demographic and Health Survey (NDHS) gives almost the same estimate for total fertility in the Northwest Region (6.7 in 1990-1992) as the figure of 6.8 provided by the 1991 census (PIII; GRN/MoHSS and Macro International 1993). Based on the 1992 NDHS data, total fertility among Protestant women living in rural regions and speaking Ovambo languages was 6.8 (NDHS 1992). The 2000 NDHS shows that total fertility in 1998-2000 was 4.7 (GRN/MoHSS 2003b), while data from the 2001 census indicates that total fertility was 4.4 during the 12 -month period prior to the census (PIII).

Table 5. Total fertility in congregations, in congregation regions based on the $1991 \mathrm{Popu}-$ lation and Housing Census data, and in constituencies where congregations are located based on data from the 2001 Population and Housing Census.

\begin{tabular}{llcccccc}
\hline Congregation & $\begin{array}{l}\text { Constituency } \\
\text { of congregation } \\
\text { in 2001 census }\end{array}$ & $\begin{array}{l}\text { Census } \\
\mathbf{1 9 9 1}^{1)}\end{array}$ & $\begin{array}{l}\text { Census } \\
\mathbf{2 0 0 1}^{2)}\end{array}$ & $\begin{array}{l}\text { Parish registers } \\
\text { 1960-69 }\end{array}$ & $\mathbf{1 9 7 0 - 7 9}$ & $\mathbf{1 9 8 0 - 8 9}$ & $\begin{array}{c}\mathbf{1 9 9 0}- \\
\mathbf{2 0 0 0}\end{array}$ \\
\hline Elim & Elim & 5.7 & 2.9 & 6.8 & 6.6 & 6.4 & \\
Nakayale & Anamulenge, & 5.6 & 3.6 & 7.5 & 6.5 & 4.5 & 3.1 \\
& Ogongo, Outapi & & & & & & \\
Okahao & Okahao & 5.6 & 3.1 & 5.7 & 6.1 & 4.6 & 3.3 \\
Oshigambo & Oniipa & 6.4 & 4 & 5.9 & 6.9 & 5 & 4.2 \\
Tsandi & Tsandi & 5.1 & 5.9 & 6.3 & 6.7 & 4.5 & 3.2 \\
Onankali & Onyaanya & & 4 & 3.3 & 4.6 & 6 & 5.2 \\
Omulonga & Onayeana & & 4.2 & & & & 3.7 \\
Oshitutuma & Oniipa & & 4 & & & & 4.5 \\
All & & $\mathbf{5 . 7}$ & $\mathbf{4}$ & $\mathbf{6 . 4}$ & $\mathbf{6 . 5}$ & $\mathbf{5 . 1}$ & $\mathbf{4 . 2}$ \\
\hline Northwest Health Directorate & $\mathbf{6 . 8}$ & $\mathbf{4 . 4}$ & & & & \\
\hline
\end{tabular}

Source: PIII, based on 1) Indirect estimates (P/F ratio method) from a special data set for the congregation regions (GRN/NPC 1994c) and from data tables from the 1991 Population and Housing Census (GRN/NPC 1994b), 2) Published fertility estimates for the constituencies from the 2001 Population and Housing Census (GRN/NPC 2004a, 2005a) and indirect estimates from the 2001 census data tables for the Northwest Health Directorate (GRN/NPC 2003), and 3) Parish-register data.

Lower levels of fertility are also revealed by Age-Specific Fertility Rates when parish-register data is compared to data for the congregation regions from the 1991 Population and Housing Census (see Figure 15) (PIII, based on parish register data and 1991 census data from GRN/NPC 1994c). In this comparison, the difference in reference periods must be remembered. The standardized age structure of fertility shows, however, that despite differences in levels of fertility, its age-structure is almost identical, except for the fact that in parish-register data, fertility in younger age groups is slightly higher and fertility in older age groups is slightly lower than is the case with census data (see Figure 16). 
Figure 15. Age-Specific Fertility Rates for the sample congregation regions, parish registers 1990-2000 and 1991 census data

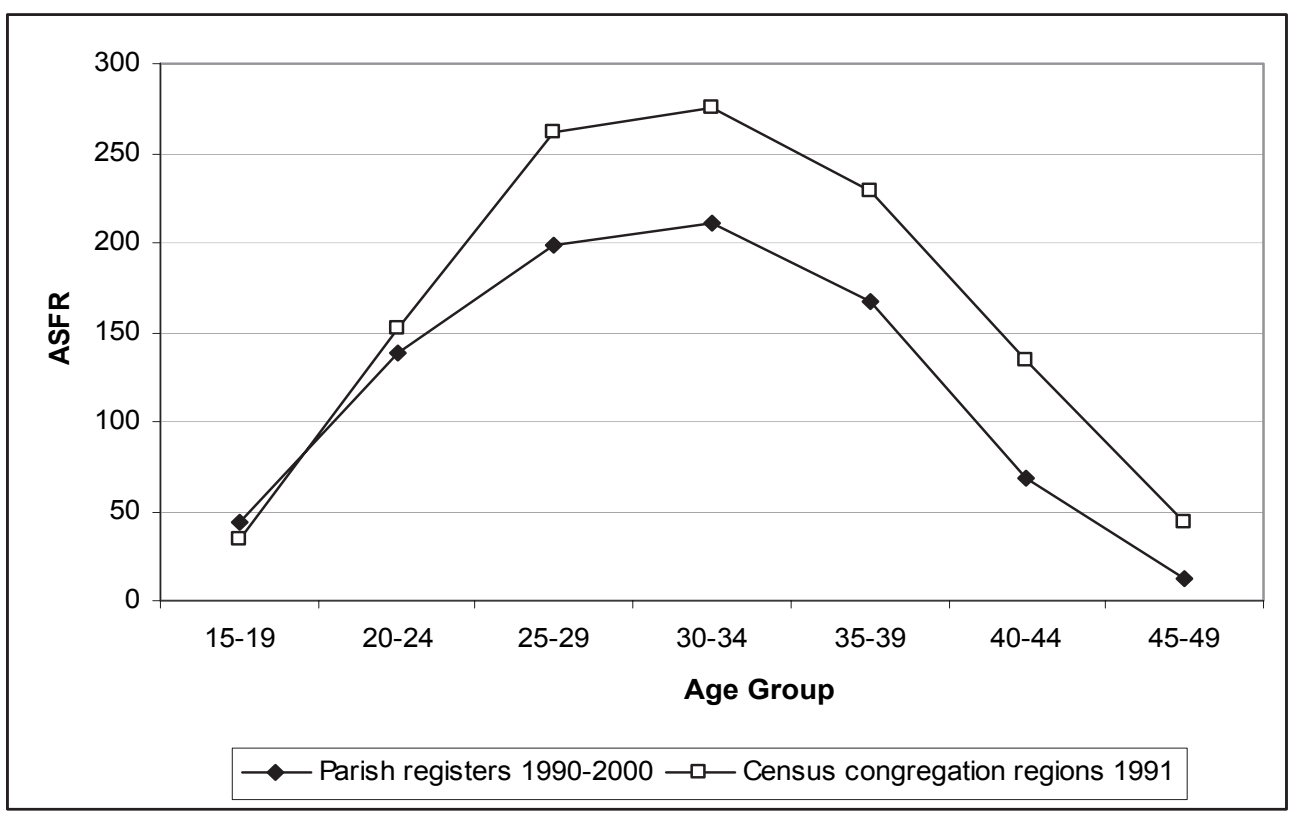

Sources: PIII, based on parish-register data and GRN/NPC 1994c (data tables).

Figure 16. Standardized age distributions of fertility for the sample congregation regions, parish registers 1990-2000 and 1991 census data.

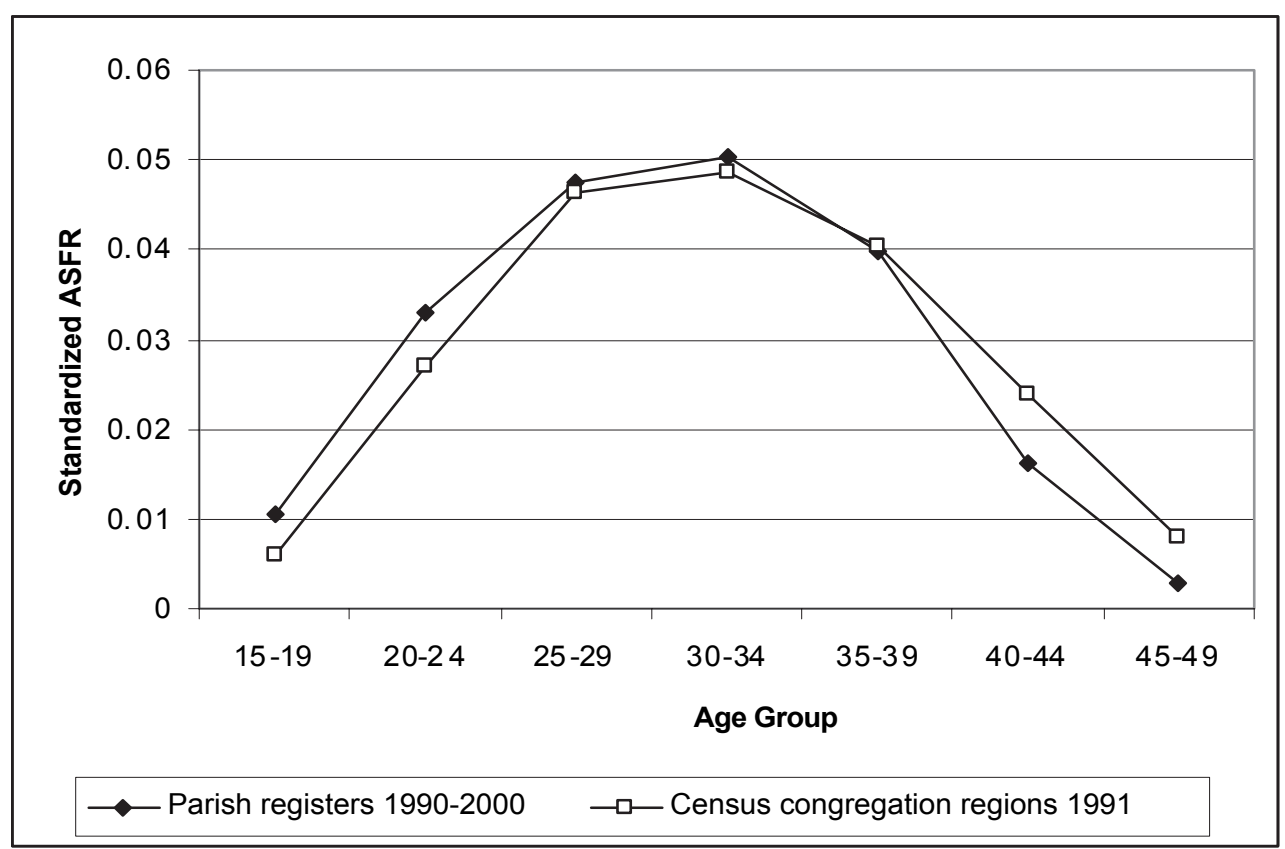

Sources: Calculations based on results from PIII and GRN/NPC 1994c (data tables). 
On average, total fertility based on census data for the five sample congregation regions in 1991 and census data for the constituency regions of sample congregations in 2001 was 0.7 children higher than the figures for total fertility based on parish-register data (rate ratio 1.18). Assuming that this difference was similar in earlier periods, this would mean that the real level of total fertility in the sample congregations was close to 7.6 in $1960-1979$ and 6.0 in 1980-89 (see Figure 17).

Figure 17. Adjusted Total Fertility Rate in the sample congregation areas in NorthCentral Namibia, 1960-1999.

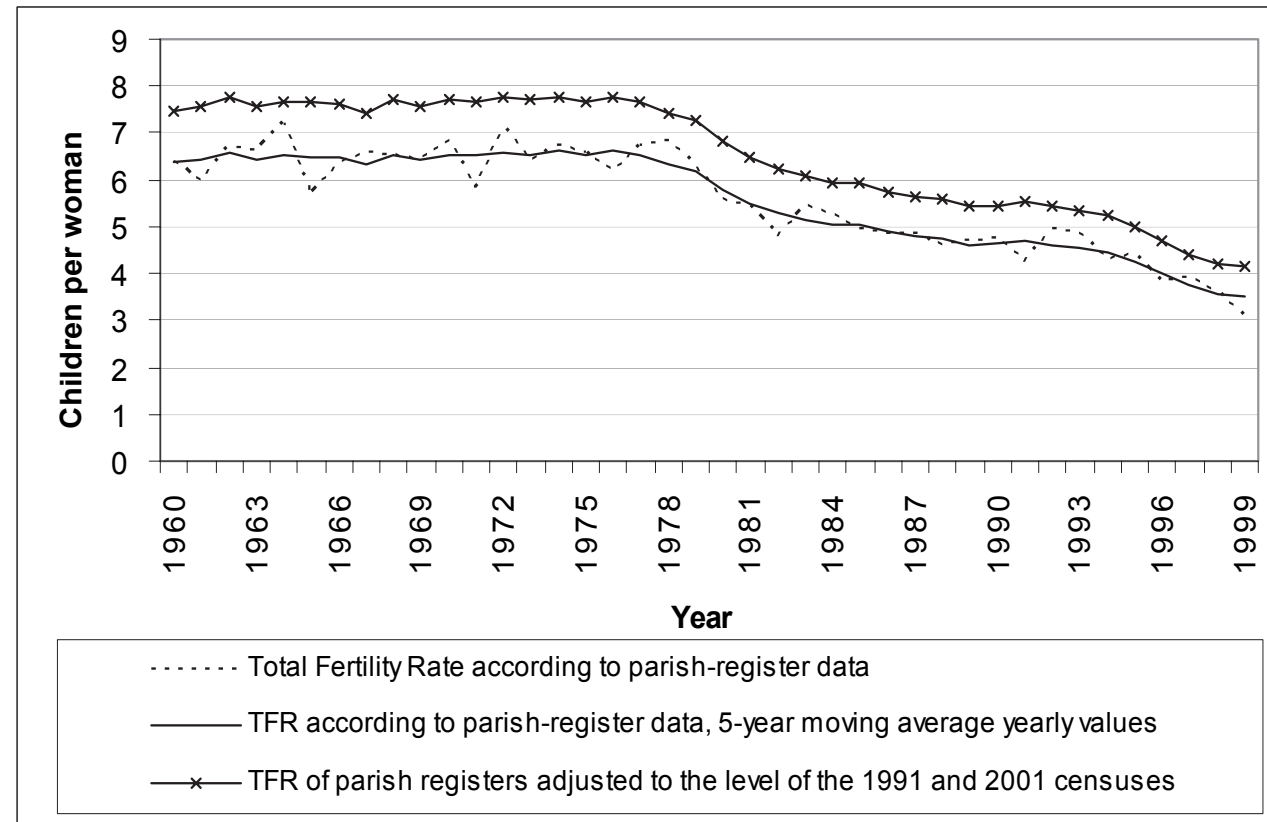

Sources: PIII, based on parish-register data, GRN/NPC 1994c (data tables), and GRN/NPC 2004a, 2005a.

\subsection{The impact of HIV on fertility}

\subsubsection{The state of the HIV epidemic in the study region}

During the 1990s, the prevalence of HIV infection among pregnant women increased very rapidly in the study region and the rate of increase was higher than the average for Namibia. In the first round of sentinel surveys, there was only a single sentinel site, Oshakati, in the former Northwest Health Directorate (see Table 6). It should be remembered, however, that Oshakati is an urban centre, and as the prevalence of HIV infection is usually higher in urban areas than it is in rural ones, actual prevalence in the whole region was probably lower than the figure for Oshakati. The Tsumeb region is located outside North-Central Namibia, i.e. the former Ovamboland. Without 
including Tsumeb, the average prevalence of HIV infection in sentinel sites would have been $25 \%$ in 2002 and 22\% in 2004 (GRN/MoHSS 2003a, 2005). There were 24 HIV sentinel sites in Namibia in 2004, the highest figure for the prevalence of HIV infection (42\%) was in Katima Mulilo, and the lowest (9\%) was in Opuwo.

Results from the 2004 HIV sentinel surveillance of pregnant women were the first to show a decline in HIV prevalence at national level since the beginning of the 1990s (GRN/MoHSS 2005). The drop is also visible in the study region. Between 2002 and 2004, prevalence rates declined at every sentinel site located in the study region except Oshikuku and Engela, where HIV prevalence remained unchanged. A decline or stabilisation in HIV prevalence rates was also found in a majority of the sentinel sites located elsewhere in Namibia, but not at all of them.

Table 6. HIV prevalence among pregnant women in the Northwest Health Directorate (NWHD), 1992-2004.

\begin{tabular}{lccccccc}
\hline Sentinel & \multicolumn{7}{c}{ Year } \\
\cline { 2 - 8 } Site & $\mathbf{1 9 9 2}$ & $\mathbf{1 9 9 4}$ & $\mathbf{1 9 9 6}$ & $\mathbf{1 9 9 8}$ & $\mathbf{2 0 0 0}$ & $\mathbf{2 0 0 2}$ & $\mathbf{2 0 0 4}$ \\
\hline Oshakati & 4 & 14 & 22 & 34 & 28 & 30 & 25 \\
Onandjokwe & & 8 & 17 & 21 & 23 & 28 & 22 \\
Oshikuku & & & & & 21 & 27 & 27 \\
Tsumeb & & & & & & 25 & 16 \\
Uutapi & & 7 & 18 & 17 & 23 & 19 & 19 \\
Engela & & & & & & & \\
Average of sentinel & $\mathbf{4}$ & $\mathbf{1 0}$ & $\mathbf{1 9}$ & $\mathbf{2 4}$ & $\mathbf{2 4}$ & $\mathbf{2 5}$ & $\mathbf{2 1}$ \\
sites in NWHD & 4 & 8 & 15 & 17 & 19 & 22 & 19 \\
\hline Namibia & & & & & & &
\end{tabular}

Source: GRN/MoHSS 2005.

Compared to the rates in 2002 and assessed by 5 -year age group, HIV prevalence in 2004 at national level was slightly lower in every 5 -year age group among females aged less than 35 (GRN/MoHSS 2005). The report on 2004 HIV sentinel surveillance was the first to provide information concerning the age pattern of HIV prevalence at regional level. In this report, women are divided into two broad age groups, under-25 and 25 or over, and HIV prevalence at each sentinel site in 2002 and 2004 is reported using these age groups. Data on HIV prevalence is also given for 5-year age groups at national level as before. For women in North-Central Namibia who are aged less than 25, some sites show a declining trend in HIV-prevalence while others show an increase. The situation is similar in sentinel sites located in Namibia's other regions. In the study region, the increase in HIV prevalence among these young women was largest in Oshakati, where it increased from 20\% to 24\% between 2002 and 2004. HIV prevalence among women aged less than 25 also increased in Oshikuku and 
Onandjokwe, but fell in Engela and Uutapi. Among women 25 or older, HIV prevalence declined at all the sentinel sites located in North-Central Namibia. At national level, there were both increasing and decreasing trends in HIV prevalence among women 25 or older at different sentinel sites.

Information on the HIV epidemic is also provided in annual reports published by the Ministry of Health and Social Services. Reports on the Oshana and Oshikoto regions show that the number of positive HIV tests and in-patient deaths due to HIV infection increased between 2002 and 2003, whereas in Omusati, the number of HIV-related deaths fell slightly, even though HIV infection remained the leading cause of mortality among men and women aged 18-49 in hospitals (GRN/MoHSS 2004c, 2004d, 2004e). For Ohangwena, a comparison between different years was not presented, but in 2003, HIV infection was reported as being the leading cause of death among hospital patients aged 18-49 (GRN/MoHSS 2004b). In 2001-2003, HIV was the leading cause of maternal mortality at the Onandjokwe hospital (van Dillen et al. 2006). According to the annual health report for the Omusati Region (GRN/MoHSS 2004c), HIV was also the most common cause of maternal mortality in 2003-2004. In the other three administrative regions of North-Central Namibia, the cause of maternal mortality was not reported.

The decline in HIV prevalence between 2002 and 2004 should be interpreted with caution until further information is available. The decline could be the first sign of an encouraging development since the beginning of the epidemic in the study region, or it could, in the worst case, simply reflect increasing levels of mortality among people infected by HIV. At national level, although HIV prevalence among pregnant women declined between 2002 and 2004, UNAIDS estimates that HIV prevalence among all men and women aged 15-49 increased slightly from $19.5 \%$ to $19.6 \%$ between 2003 and 2004 (UNAIDS 2006).

\subsubsection{The impact of HIV on the fertility of HIV-infected women}

In the future, the HIV epidemic will have a major impact on the size and age structure of the Namibian population. At national level, population projections illustrating the demographic effect between 1991 and 2026 show that in 2026, if the spread of HIV infection continues at the level it was between 1992 and 1996, the country's population will be more than 800,000 people smaller than it would be in the situation without HIV (PII). 
Assessment of the impact of HIV infection on fertility in the study region was complicated by the nature of parish-register data: this source does not include information on either the HIV status of women or the cause of their death. An indirect method for estimation was therefore applied. Based on mortality estimates by Notkola et al. (2004) and the Ministry of Health and Social Services (GRN/MoHSS 2003c; see also Onandjokwe District DDC 2003; Onandjokwe Lutheran Medical Service 1999), as well as experience in regions affected by HIV infection elsewhere in southern Africa (e.g. Hoosegood et al. 2004), the assumption was made that during the 1990s, a significant proportion of deaths among females of fertile age occurred among women who were infected by HIV (for details, see PIV). In other words, it was assumed that a substantial proportion of the deaths of women who died at age 50 or less during 1990 and thereafter was caused by HIV/AIDS. To allow the fertility of these HIV-infected women to be studied, the fertility histories of these individuals were compared with the fertility of other women.

The fertility histories of women who died at an age of less than 50 years in the year 1990 (or thereafter "HIV-infected women") show that their fertility was lower that that of other women ("non-HIV-infected women") during the period 1980-2000 (PIV). The difference in fertility between these two groups was already substantial in the 1980s: total fertility among HIV-infected women was $79 \%$ of that of non-HIV-infected women in the period 1980-1989. The impact of HIV increased as the moment of a woman's death approached: in 1990-2000, total fertility among HIV-infected women was only $61 \%$ of that of non-HIV-infected women. During the twenty years between 1980 and 2000 , total fertility among HIV-infected women was approximately $74 \%$ of that among non-HIV-infected women. These findings concerning a significant fertility-reducing effect connected with HIV infection are in agreement with results obtained in eastern and central Africa (e.g. Zaba and Gregson 1998).

Age-Specific Fertility Rates for the two groups are close until individuals enter the 20-24 age group. After this, HIV-infected women had lower levels of fertility than those who were not infected (see Figure 18) (PIV). In the study region, subfertility connected with HIV started at an older age than, for example, in Uganda (e.g. Carpenter et al. 1997; Fabiani et al. 2006; Zaba and Gregson 1998). The most probable explanation for this difference is the atypical age pattern of fertility in the study region when compared to the average for sub-Saharan Africa (e.g. Robinson 1987). In the study region, peak levels of fertility among non-HIV-infected women are encountered relatively late, i.e. among women aged 30-34 years (e.g. PI, PIV). 
Figure 18. Age-Specific Fertility Rates among HIV-infected and other women in NorthCentral Namibia, 1980-2000.

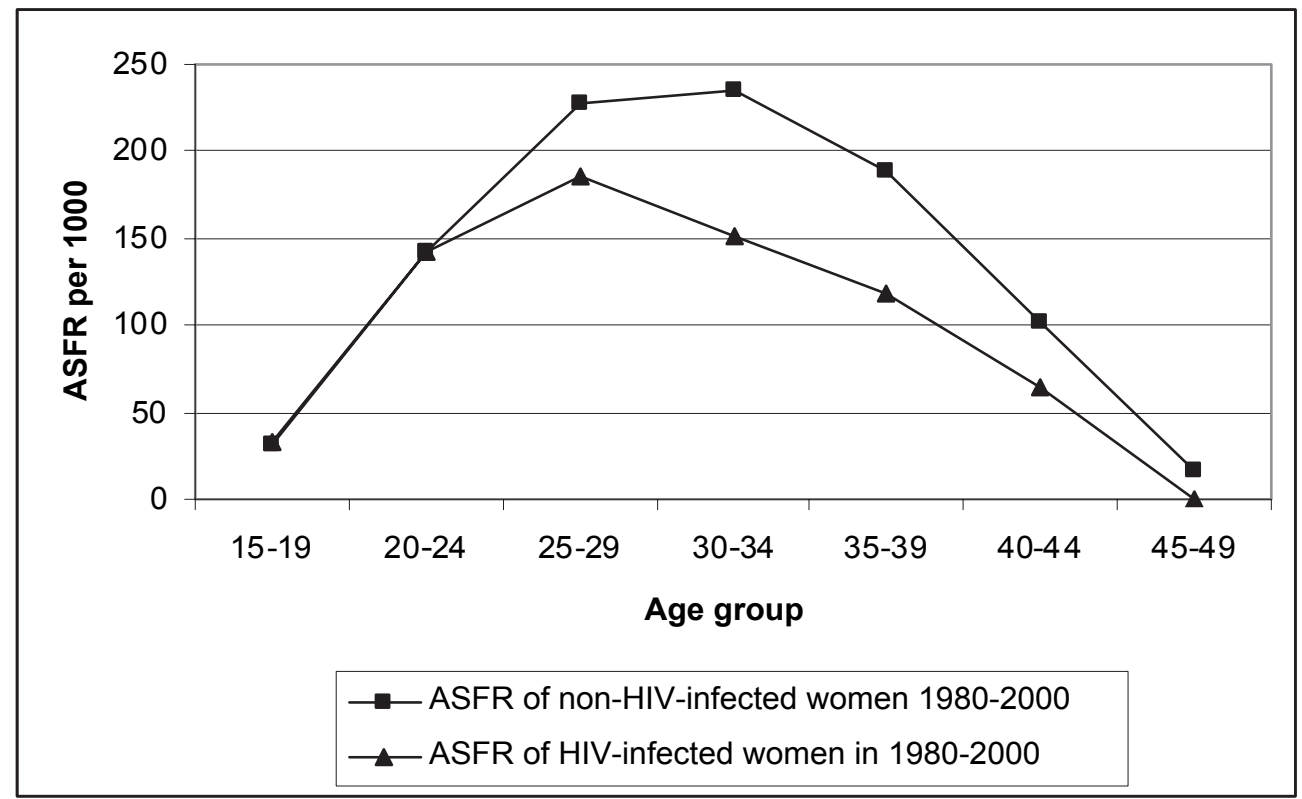

Source: PIV, based on parish-register data.

When the fertility histories of the HIV-infected women were examined retrospectively from the time of their death, a similar difference in fertility between HIV-infected and non-HIV-infected women was identified. During the period 11-20 years before a woman's death, a clear reduction in fertility only occurred among women aged 2529 and 30-34 (PIV). In the period 0-10 years before death, the reduction in fertility increased as the HIV disease progressed (cf. Ross et al. 2004; Sedgh et al. 2005), and subfertility was found also among women in older age groups.

There was some evidence indicating lower age at first marriage and a higher proportion of premarital births among HIV-infected than non-HIV-infected women (PIV). Mean age at first marriage among HIV-infected women (25.3 years) was one year lower than among non-HIV-infected women (26.4 years). It was also more common for HIV-infected women to give birth to children before their marriage.

In addition to HIV and other sexually transmitted diseases, there are some other diseases which result in impaired fertility. For example, genital tuberculosis, malaria and filariasis may cause coital inability, conceptive failure or foetal deaths (Larsen 1996), although experience from Tanzania shows that the fertility-reducing effect of malaria is greatly reduced by prophylaxes. As malaria is one of the conditions causing deaths in the study region (e.g. GRN/MoHSS 2004d), it is possible that some of the deaths 
among women who died in their reproductive years were the result of malaria. There is also the possibility of co-infection, since HIV infection increases both the risk of malaria transmission and fatal outcomes (Korenromp et al. 2005).

To verify the connection between HIV infections and fertility reduction, a period prior to the HIV epidemic was studied. A similar examination of the fertility histories of women who died at an age of less than 50 years before the HIV epidemic, i.e. in 196679 , did not show any reduction in fertility before death (PIV). This finding is likely to confirm the link between HIV infection and the lower levels of fertility identified.

Also, the actual impact of HIV on fertility can be assumed to be even more pronounced than that observed, since it is quite probable that the group of women who died included women whose demise resulted from causes that are not related to HIV and which do not reduce an individual's fertility before death. In addition, the group of other women includes those HIV-infected women who have not yet died.

\subsubsection{The impact of HIV on fertility determinants}

There is, unfortunately, very little information concerning the effect of HIV on proximate determinants of fertility in North-Central Namibia. Few women in the region are aware of their own HIV status. According to the 2000 NDHS, 17\% of women in the study region reported that they had been tested for HIV, a proportion lower than in the South and Central Health Directorates, but higher than in the Northeast Health Directorate (GRN/MoHSS 2003b). The majority of the fertility-reducing impact of HIV is therefore likely to be the result of biological factors or such HIV-related behavioural factors which affect women regardless of their HIV status. Also, some part of the levels of subfertility observed was quite probably a consequence of the effect of co-infections involving other STDs. Indeed, significant fertility reductions in the 1980s, and 11-20 years before death, could indicate existing subfertility prior to HIV infection (cf. Ross et al. 1999).

Surveys from other countries show that spontaneous abortions and stillbirths are more common among HIV-infected women (e.g Gray et al. 1998), and also that pathological sterility may increase as a result of HIV infection. Recent information on intrauterine mortality in the study region is scarce, but some indication of the increase in the proportion of stillbirths can be found. While the proportion of stillbirths among deliveries in Onandjokwe hospital varied from 12 to 25 per 1,000 in 1984-1987 and was 9 per 1,000 in 1990, the annual health report on the Oshana Region shows that the stillbirth rate in 2003-2004 was 32 per 1,000 deliveries (GRN/MoHSS 2004d; Lutheran Medical Mission 1985, 1986, 1988, 1991). Primary sterility in the study region, when measured as the proportion of women who are childless at the end of their reproductive period, 
does not appear to have increased during the 1990s (PI; PIII; GRN/MoHSS 2003b; GRN/MoHSS and Macro International 1993). It is, however, both possible and more plausible that HIV infection increases the level of secondary rather than primary sterility, i.e. it affects women who have started bearing children.

Likewise, there is no means for estimating the effect of the influence exerted on breastfeeding in the study region by the HIV epidemic. It is, however, likely that infant mortality will have shortened the period of postpartum infecundability since periods of breastfeeding will be shorter. Information on the impact of increased infant mortality on fertility via the replacement or insurance effects is lacking. It is also possible that increased morbidity lowers fecundability by reducing coital frequency among HIVinfected women or women whose male partner is infected, but no information on this particular aspect is available.

According to the 2000 NDHS, $71 \%$ of women in the Northwest Health Directorate had heard messages about condoms within the past few months (GRN/MoHSS 2003b). The use of condoms increased between 1992 and 2000, very probably as a result of campaigns aimed at preventing HIV infection. Among sexually-active women, 17\% reported that they were using condoms as their current method of contraception. No information exists on whether the use of condoms has replaced methods of contraception that are more effective from the viewpoint of preventing conception.

It is possible that the availability of information concerning HIV infection affects both the onset of sexual activity and the number of sexual partners, but measurement of this effect is difficult. According to data from the 1992 and 2000 NDHS, the median age at first birth and median age at first sexual intercourse have not changed in a notable manner between the two surveys (GRN/MoHSS 2003b; GRN/MoHSS and Macro International 1993). Age at first marriage increased during the 1990s, as it did before the decade began, but there are no reasons to believe that this development was affected by HIV. It is likely, however, that a proportion of the observed subfertility among HIV-infected women in the study region is the result of marital breakdown and widowhood. 


\subsubsection{The impact of HIV on fertility at population level and its contribution to fertility decline}

In the study region, subfertility among HIV-infected women, together with the high prevalence of HIV infection among women, resulted in a decline in fertility at population level, i.e. in the average fertility of all women, not only those infected by HIV (PIV). The effect of HIV infection on fertility at population level was assessed by applying the age pattern and magnitude of the HIV-associated fertility reduction identified in parish registers to fertility in the study region based on the Population and Housing Censuses, and to the population of the study region after division into subpopulations by HIV status.

Average total fertility in the former Northwest Health Directorate, 4.4 children per female according to the 2001 Population and Housing Census, was found to consist of a total fertility of 4.8 among non-HIV-infected women and a total fertility of 3.7 among HIV-infected women (PIV). At population level therefore, the fertility reduction resulting from HIV infection was around half a child per woman, while the levels of subfertility associated with HIV infection resulted in approximately one child less being born to HIV-infected women than to non-HIV-infected women. This reduction in total fertility at population level resulting from HIV infection is in accordance with results obtained by e.g. Zaba and Gregson (1998).

The fertility reduction resulting from HIV infection is realised in fewer children being born. In the Northwest Health Region in 2001, 7\% fewer children were born because of the subfertility associated with HIV infection (PIV). The mechanisms by which the disease reduces the number of children born are twofold: reduced levels of fertility and increased levels of mortality which reduce the number of potential mothers. To compare the magnitude of these mechanisms, two population projections were made, one with and one without the fertility and mortality effects of HIV infection. These projections show that compared to the number of children that would be born if the population did not suffer from HIV infection in 2001 or thereafter, the combined effect of fertility and mortality reductions associated with HIV infection will result in $39 \%$ fewer children being born in 2026. The bulk of this reduction is caused by increased mortality among women: without any of the subfertility associated with HIV infection, i.e. if HIV infection only influenced the number of children born by reducing the number of potential mothers, the number of children born in the study region in 2026 would still be $31 \%$ less than the number born if the population did not suffer from HIV infection in 2001 or thereafter.

According to estimates from the 1991 and 2001 Population and Housing Census data tables and the published results of the 1996 Intercensal Demographic Survey, total 
fertility in the Northwest Health Directorate declined from 6.8 to 5.3 between 1991 and 1996, and fell to 4.4 in 2001 (PIII; GRN/NPC n.d.). In parallel with this decline in fertility, the prevalence of HIV infection in the region grew rapidly (GRN/MoHSS 2005). HIV sentinel surveillance shows that HIV prevalence among pregnant women increased from 4\% to 24\% between 1992 and 2000 (see Table 6). This information can be used to estimate the contribution made by HIV infection to fertility decline during the 1990s. Information on HIV prevalence in the 1980s is limited, but it appears likely that levels of HIV prevalence were not high enough to have any pronounced effect on fertility at population level.

According to Zaba and Gregson (1998), each 1\% of female HIV prevalence is associated with a $0.4 \%$ decline in total fertility at population level, a finding which is in line with results based on data from parish registers. This means that between 1992 and 2000, the fertility reduction resulting from HIV infection increased from less than $2 \%$ to almost $10 \%$ of total fertility. The reduction in the number of children born to each woman as a result of HIV infection would therefore have been 0.1 children at the beginning of the 1990s and 0.4-0.5 in 1996-2000 (PIII).

In Figure 19, the magnitude of the reduction in fertility resulting from HIV infection is illustrated in the context of levels of total fertility and also compared to the level of total fertility in the former Northwest Health Directorate based on data from the 1991 Population and Housing Census. The first year for which HIV sentinel results exist is 1992. Figure 19 shows that levels of subfertility among HIV-infected women explain a substantial proportion of the total decline in fertility. The absolute reduction caused by HIV was at its highest ( 0.52 children) in 1998 . Using the level of fertility in 1991 as a basis for comparison, the reduction in fertility resulting from HIV infection explained more than a quarter (25-29\%) of the decline in total fertility during most of the 1990s.

The estimate of HIV prevalence used here is based directly on HIV prevalence among pregnant women, and this may underestimate HIV prevalence among all women. The actual reduction in fertility resulting from HIV infection may therefore be slightly higher. For example, Heuveline (2003) estimates that the ratio of HIV prevalence in pregnant women to HIV prevalence among all women changes according to the duration of the HIV epidemic in a region, so that as the duration of epidemic increases, HIV prevalence among pregnant women increasingly underestimates HIV prevalence among all women. This starts to be a problem once the epidemic has lasted 15 years. According to Heuveline, after an epidemic has lasted 15 years, HIV prevalence among pregnant women is $90 \%$ of that among all $15-50$ year old women. Thus, assuming that the HIV epidemic in Namibia began in 1986 (Slotten 1995; United Nations 2003), 
the fertility reduction in 2001 resulting from the HIV epidemic would have been 0.54 children instead of the 0.48 children presented in Figure 19.

Figure 19. Total fertility in Northwest Health Directorate in 1991-2001, and the reduction in fertility resulting from HIV infection and other factors compared to the TFR in 1991.

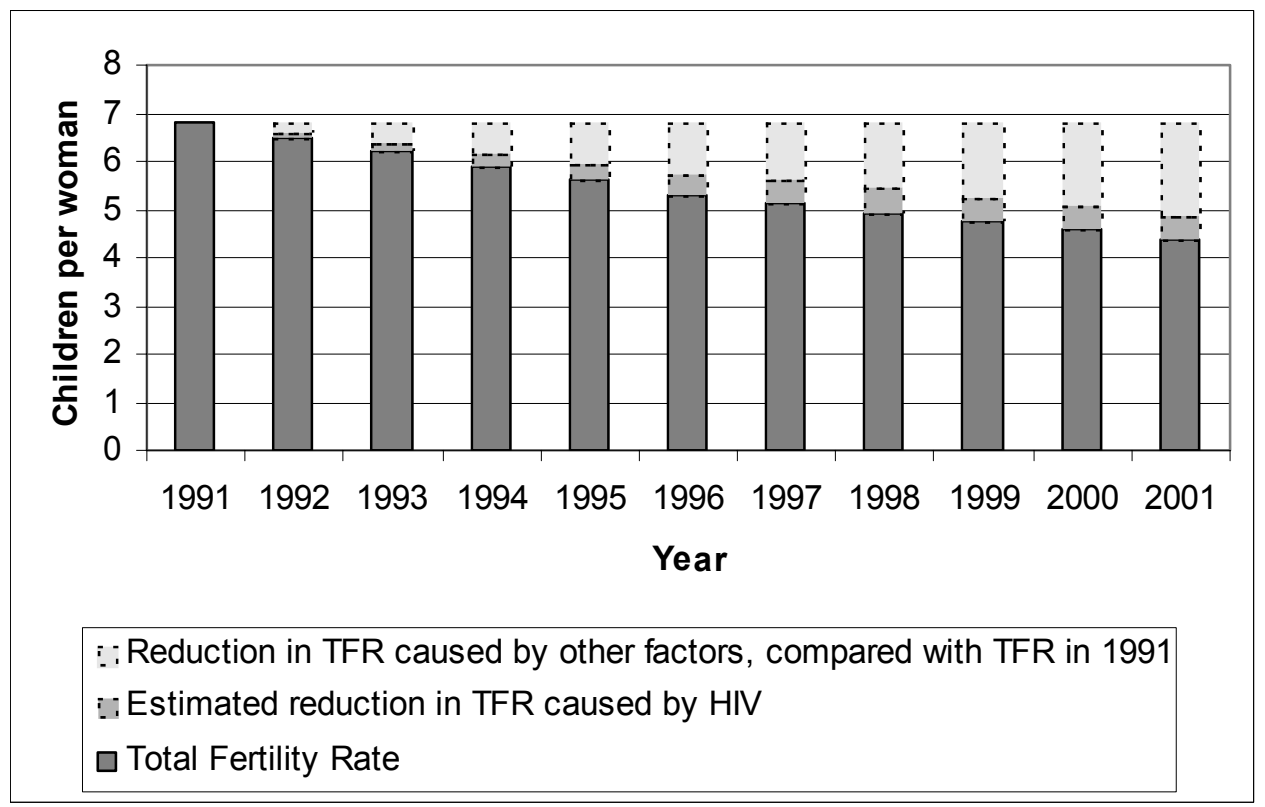

Sources: Level of fertility: 1991, 1996, and 2001: Population and Housing Censuses (PIII, based on GRN/NPC 1994b (data tables), 2003 (data tables)), and 1996 Intercensal Demographic Survey (GRN/NPC n.d.). HIV prevalence: HIV sentinel surveillance 1992-2002 (GRN/MoHSS 2003a, 2005). Please note that yearly values for TFR are based on extrapolation from data for 1991, 1996 and 2001, and that yearly values for HIV-prevalence are based on extrapolation from data for 1992, 1994, 1996, 1998, 2000 and 2002. 



\section{Conclusion and discussion}

\subsection{Main findings}

This study is an examination of developments in fertility in North-Central Namibia during 1960-2001. During this period, a sustained decline in fertility started in the study region. According to data from parish registers, the level of fertility declined from more than six children per female in the 1960s and 1970s to about five in the 1980s and just over four in the 1990s (PIII). Adjustments to the level of fertility based on parish-register data made in order to correspond to levels of fertility based on data from 1991 and 2001 censuses in the congregation areas resulted in levels of fertility declining from approximately 7.6 in 1960-79 to 6.0 in 1980-89, and then to 4.9 in 1990-1999.

Fertility decline started in 1980, stagnated for a short period in the early 1990s following the end of the war of independence, and then continued until the end of the study period (PIII). These trends are similar to those by identified by Garenne and Zwang (2006) in their research on premarital fertility at national level in Namibia based on NDHS data.

Cohort fertility was also examined in addition to period fertility (PIII). Cohort fertility rates confirm that a real decline in the number of births completed by each woman occurred during this transition, not just a change in the timing of fertility.

Experience from North-Central Namibia has shown that prior to the fertility decline reported in this study, levels of fertility have varied substantially: Notkola and Siiskonen (2000) report different phases during the 20th Century in which fertility in the study region has declined and then increased. Although data concerning the historical development of fertility in Africa is scarce, varying levels of fertility in pre-transitional societies have been reported, for example in Tanzania by Colwell (2000) and Koponen (1986), and in Uganda by Kuhanen (2005). In the period included in the current study, i.e. from 1960 to 2001, fertility was high during the two first decades. It should however be noted that in the late 1950s, before the beginning of the study period, there was an increase in levels of fertility in the region. This increase, in turn, was preceded by a period of high fertility in the 1930s and a period of lower fertility in the 1940s and most of the 1950s. Even at its highest point during the period of the current study, total fertility did not return to the level it was in the middle of the 1930s, i.e. eight children per female (Notkola and Siiskonen 2000). If these historical facts are not taken into account, this study would convey a picture of fertility development which is too simplistic, i.e. one where fertility declines from "high and stable" levels to low levels during a process of fertility transition. 
Assessment of Age-Specific Fertility Rates showed that fertility in different age groups developed in different directions (PIII). In contrast to other age groups, the fertility of adolescents increased during the study period, which is in line with findings by Garenne and Zwang (2006). The onset of fertility decline in other age groups varied to a substantial degree, and it was only in the middle of the 1980s that the last age group, women aged 20-24, entered fertility transition. In the 1970s, although the level of total fertility remained unchanged, this apparent stability hid a wide range of developments in ASFRs in different groups: some declined, others increased, and some were stable.

Also, the determinants forming the background to fertility decline varied during the transition process (PIII). In the 1980s, increasing age at first marriage and spousal separation played important roles. Contraception was already available and in use in the 1980s, but its importance as an agent in fertility decline increased significantly in the 1990s. The spread of HIV infection and its associated fertility-reducing effect contributed to fertility decline in the study region in the 1990s (PIII; PIV). Even though there is insufficient information concerning the determinants through which HIV infection had a negative impact on fertility, it is probable that a major part of the reduction resulted from the biological effects of increased levels of foetal loss and a reduced likelihood of conceiving. It is also probable that behavioural effects, i.e. marital break-up, played some role in the latter. A proportion of the rise in the use of contraception during the 1990 s, i.e. the increased employment of condoms, could be a result of campaigns intended to prevent HIV infection.

One of the definitions of fertility transition is that it is "a shift from natural to controlled fertility". Controlled fertility, in its turn, is defined as existing when a woman or a couple jointly change their behaviour to limit or space births (according to the number of children they already have). Although fertility began to decline in the study region in the early 1980s, it is not possible to use the available data to estimate whether this was a result of conscious choices being made to limit or space out births. Hospital records concerning the use of contraceptives during the 1980s (PIII), however, indicate that the decline in fertility in that decade may, at least in part, have resulted from the desire to limit or space births, in addition to probably being one consequence of the war of independence. In the $1990 \mathrm{~s}$, the increasing use of contraceptives indicates that the shift from natural to controlled fertility really had taken place.

HIV infection spread rapidly in North-Central Namibia during the final decade of the study period (PII; PIII; PIV). The HIV epidemic will have a major impact on the size and age structure of Namibia's future population (PII). The pronounced impact of HIV infection on population growth and structure has also been a conclusion in other studies 
which have assessed the demographic impact of HIV infection in Namibia (Jakobsen 2000; Phororo and Venditto 2003; Sanderson et al. 2001; World Bank 2001) and it has been taken into account in the latest national population projections (GRN/NPC 2006a). The impact of the HIV epidemic on Namibia's demographic development will be affected, however, by improvements in the prevention and treatment of HIV in the future. There are encouraging reports concerning improved coverage by ARV treatment in Namibia since 2003. Based on country reports, UNAIDS estimated that in 2005, $25 \%$ of HIV-infected pregnant women received a complete course of antiretroviral prophylaxis to reduce the risk of mother-to-child transmission and $35 \%$ of people with advanced HIV infection received antiretroviral combination therapy (UNAIDS 2006). According to another assessment by UNAIDS, based on the 3 by 5 Progress Report, coverage of antiretroviral therapy was estimated to be as high as $71 \%$ in Namibia in 2005 (UNAIDS 2006; WHO and UNAIDS 2006).

The impact of HIV infection on fertility in North-Central Namibia indicates that the disease has a strong fertility-reducing effect (PIV). When this effect is combined with high levels of HIV prevalence among women, the fertility reduction at population level associated with HIV infection is pronounced (PIII; PIV). During the 1990s, subfertility caused by HIV infection explained a large proportion of the decline in total fertility. The disease also affects the number of children by reducing the number of potential mothers. In the future, population growth will be adversely affected to a greater extent by the mortality-increasing effect of HIV infection than by its fertility-reducing effect.

\subsection{Explanations for fertility decline in the study region}

Fertility decline in North-Central Namibia is linked to the study region's history and the social, economic, and cultural changes that have taken place there. These include the changes resulting from the introduction of Christianity, the use of contract labour and labour migration, the war of independence, as well as increasing levels of female education, urbanisation and waged labour. The improved availability of modern contraceptive methods has also introduced ways of controlling fertility.

The introduction of Christianity, which began in the late 19th century, has had a pronounced impact on the social system of the study region (e.g. Becker 2004; Hailonga 2005; McKittrick 1997; 2002; Miettinen 2005; Tuupainen 1970). Missionaries opposed the initiation rite for girls. This institution played an important role in education about reproductive issues and in the community's control over adolescent fertility, and even though it survived the strong opposition it faced from the churches, the rite probably 
lost some significance because of this. Both the introduction of Christianity and formal education have contributed to a reduction in social controls on adolescent reproduction by kin and community. Christianity also shaped the marital system in the study region, with its attempt to root out polygyny and promote life-long marriage. When combined with the absenteeism of men working in other regions, this increased the vulnerability of women and resulted in changing family systems. The difficulty of obtaining divorce in a Christian marriage may also be a factor that contributes to an unwillingness to make a formal commitment (Research Facilitation Services 2004), especially in a social environment in which both remaining unmarried and reproduction outside wedlock are not subject to strong sanctions.

Marital and courtship systems in the study region are complicated and include both different modes of union and multiple simultaneous partners for men and women (e.g. Hailonga 2005; LAC 1999, 2000; Research Facilitation Services 2004; Tersbøl 2002). Economic transactions play an important role in these relationships. On one hand, young people may emphasise the importance of independence, on the other, the safety offered by a formal marriage is appreciated, and both permanent relationships and children have social value. Although the connections between childbearing and marriage have been loosened, high age at first marriage and the large proportion of women who remain unmarried affect levels of fertility.

Labour migration has significantly influenced both the economy and social structure in the study region. During the colonial era, many men were absent because of labour migration to work on temporary contracts. Economically, labour migration has provided both households and communities in the study region with an additional source of income, while the fact that men were absent also hindered successful agricultural activity (Kouvalainen 1980). Wages earned by contract labourers were also small and not intended to provide a living for a family in the north. The contract labour system resulted in many problems (Morris 1974; Voipio 1980), including the separation of spouses, STDs contracted from short-term relationships outside marriage, and some men having a second family in the region where they worked. The absenteeism of men increased the vulnerability of women (McKittrick 1997, 2002). The demographic effect of spousal separation has in fact been so great that Notkola and Siiskonen (2000) expressed the opinion that this explained the decline in total fertility that took place in the 1940s. After Namibia became independent, the tradition of labour migration has continued (Winterfeldt 2002), and while it still mostly concerns men, young women are also migrating to an increasing degree. The effect this has on fertility through spousal separation may, however, be diminished by improved opportunities for transportation. 
Peak levels of fertility were found among older women than in other regions of Namibia or in sub-Saharan Africa in general. This finding is confirmed by data from both the NDHS and Population and Housing Censuses (GRN/NPC 1994b, 1994c, 2003; NDHS 1992) as well as by the published results that are based on them (GRN/MoHSS and Macro International Inc. 1993; GRN/NPC 1994a). This pattern of fertility being concentrated among older women in North-Central Namibia than in other regions of Namibia is accompanied by higher median age at first sexual intercourse, at first birth and at first marriage among women in the study region when compared to other regions (GRN/MoHSS 2003b; GRN/MoHSS and Macro International 1993). While there is no clear explanation concerning this phenomenon, it does appear plausible that there is a connection with the migrant labour system which has resulted in a large proportion of the region's young men being absent from North-Central Namibia.

The war of independence was a cause of insecurity and spousal separation and may also have resulted in the postponement of marriages during the 1970s and 1980s. Female involvement in the war probably affected the role of women in Namibian society, as did urbanisation and the opportunities for waged employment connected with the war economy (Pendleton, LeBeau, and Tapscott 1992; Van der Merwe 1989).

Improved access to modern methods of contraception may have contributed to their increased use. Before independence, both family-planning services and other health services in Namibia were segregated according to ethnic groups, and services provided in the country's northern regions were poor (e.g. Lucas 1992). Among occupants of North-Central Namibia, the acceptance of contraceptives may have improved following independence because their distribution could no longer be interpreted as an attempt by the colonial rulers to extend control over the African majority.

The contribution of education to fertility decline in the study region is probably that of a background determinant. Educational work by missionaries and churches was important because it provided broad population groups with access to formal education during the early colonial period (Lehtonen 1999). During the apartheid period, high schools under church administration maintained high-quality education in the study region. It is possible that the sample congregation regions were forerunners in fertility decline in North-Central Namibia because educational levels in these regions are higher. In the whole of the North-Central Health Directorate, levels of education among women increased during the 1990s, and the educational differences associated with differing levels of fertility are pronounced. It is a fact, however, that fertility also declined within all educational groups during the 1990s. According to Hamata (n.d.) and Arowolo (2000), education is an important determinant of fertility in Namibia, even though Uchudi (2000), who used DHS data to compare the impact of education in 
different countries, noticed that in Namibia in 1992, the impact of women's advanced education (i.e. more than five years attending school) did not have a positive impact on the desire to stop having children. It did, however, have some positive effect on adaptation to modern methods of contraception, although this effect was weaker than in many of the other countries studied.

\subsection{Comparison to other regions in southern Africa}

The high age at first marriage in Namibia, a finding confirmed by this study, is quite exceptional in sub-Saharan Africa. Garenne (2004b) investigated median age at first marriage among women in 32 sub-Saharan African countries using WFS and DHS data. He found a cluster of locations in southern Africa, including Namibia, Botswana and South Africa, where the age at first marriage was high. In the most recent birth cohort, i.e. women born in 1965-69, median age at first marriage was 26.9 years in Namibia, 25.5 years in Botswana and 25.2 years in South Africa, but much lower in the other countries. For all 32 countries, the weighted average was 18.3 years. In the other southern African countries included in this assessment, median age at first marriage was below 20 years.

Fertility decline in North-Central Namibia has similarities with the situation in rural South Africa (e.g Garenne et al. 2000, 2006), with increasing age at first marriage and high levels of premarital fertility. There is also a likeness with neighbouring Botswana (e.g. Gaisie 1995a, 1995b; Letamo and Letamo 2002), since all of these are areas from which migratory labour is sourced.

In Botswana, as in North-Central Namibia and many regions in rural South Africa, age at first marriage is high and a large proportion of women remain unmarried. According to Gaisie (1995a, 1995b), labour migration to the mines of South Africa was a primary cause of changes in marital patterns in Botswana by the 1970s. Other causes included missionary activity and contacts with European traders. Gaisie states that labour migration weakened the family structure, separated husbands and wives, broke down domestic control, added child rearing in socially-inappropriate environments and introduced infectious diseases. Marriage was delayed to a later age and the proportion of people who never married increased, as did courting and love affairs outside marriage. A decline in polygyny further reduced marriage opportunities and led to an increasing proportion of households being headed by women. 
Labour migration alone does not provide a sufficient explanation for changes in patterns of nuptiality, as has been shown in Lesotho, where age at first marriage has not increased in a similar manner to the way it has in Botswana and North-Central Namibia in spite of extensive labour migration to other regions. Timæus and Graham (1989) explain this difference between Botswana and Lesotho by variations in agricultural systems: in Lesotho, early marriage was necessary to provide men who migrated to work on a temporary basis in other regions with access to land in their region of origin.

Despite the differences in timing and magnitude, shifts of fertility in the study region bear some resemblance to the changes in Zimbabwe reported by Muhwava and Timæus (Muhwava 2002a; Muhwava and Timæus 1996): in both countries, fertility decline started during a period of war and continued after independence was gained. Fertility decline began during the war period, in the 1970s in Zimbabwe and in the 1980s in North-Central Namibia. After the civil war in Zimbabwe ended, there was possibly a baby boom, while fertility decline in North-Central Namibia halted for a period shortly after the end of the war of independence. Following these phases, sustained declines in fertility occurred in both countries. In both Zimbabwe and North-Central Namibia, a major element in declining levels of fertility during the war was probably spousal separation. Muhwava (2002a) also makes the assumption that women were postponing births during the conflict in Zimbabwe. In contrast, the impact of war on fertility levels in Angola was different, since fertility decline did not begin during the war period (Agadjanian and Prata 2001, 2002).

\subsection{Factors contributing to the spread of HIV infection and consequences of the epidemic}

In the 1990s, the HIV epidemic spread quickly in Namibia and even faster in the study region. Behind the spread of HIV infection lie many social, cultural and economic factors. The rapid spread of HIV infection in North-Central Namibia was facilitated by migration patterns in the region (LeBeau et al. 1999, 2002; Webb and Simon 1995), as labour migration to other regions and occasional returns home are combined with complex sexual networks. The high risk of contracting HIV among migrants is associated with the social disruption and changes in behaviour that result from migration. Also, migrant workers working on a temporary basis in the study region, including, for example, military and police personnel, may also contribute to the spread of HIV infection by engaging in short-term relationships with local women. Transportation workers, for example truck drivers, have also been seen as a factor that facilitates the spread of HIV infection, as have the extensive use of alcohol and its impact on behaviour. Poverty is linked to the spread of HIV infection in several ways: it reduces 
access to the knowledge and methods required to avoid infection, increases levels of fatalism, and allows the more-urgent problems of daily life to supplant the risk of contracting HIV. Poverty also sometimes forces people to engage in risky sexual behaviour in order to make a living.

Cultural factors and factors related to gender roles play an important role in the spread of HIV infection in the study region. The ability of women to negotiate safer sexual practices is restricted (LeBeau et al. 1999, 2002; Iipinge et al. 2004), while men are not willing to move towards safer forms of sexual behaviour, for example the consistent use of condoms, especially when they are under the influence of alcohol (Iipinge et al. 2004). The use of condoms is also restricted by either the male or female partner (or both) wishing to conceive (Tersbø1 2002). Transactional sexual relationships, in which males support their female partners economically, either by money or gifts, contributes to the spread of HIV infection in southern Africa (see e.g. Kalipeni, Craddock, and Ghosh 2004). This phenomenon is common in Namibia, both in the study region (e.g. Tersbøl 2002) and elsewhere (e.g. Ricardo 1998).

While levels of knowledge concerning modes of HIV transmission and methods of protection have increased throughout the 1990s and the 2000s, the extent of changes towards safer sexual behaviour has not matched corresponding hopes (Bonal, Brulé and Shikoyeni 1998; Campbell 2003; NANASO 1995; NISER 1991; Schwarz 2003; SIAPAC 1997; van den Bos and Vesentini 1999; van Zyl and Spilker 2001; Zimba and Mostert 1992). According to Fox (2002), this is a result of health campaigns which are based on the 'rational choice' approach, which make simplified assumptions about human motivation: making individuals the reference point and ignoring the cultural context of the HIV pandemic. There is, however, evidence of behavioural change connected with HIV-prevention campaigns (Stanton et al. 1998; UNICEF Namibia 2002)

The social role of men in the study region emphasises sexual virility, the importance of multiple sexual partners, and taking the leading role in decision making on sexual issues (Becker 2001; Brown et al. 2005; Fox 2002; Mufune 2003). Traditionally, sexual issues are not discussed between partners (Iipinge et al. 2004). Poverty also plays an important role (LeBeau et al. 2002). Women who are dependent on the economic support provided by their male partners have limited power to protect themselves from contracting HIV (Iipinge et al. 2004; LeBeau et al. 2002). Both rape and pressure to engage in sexual intercourse are a reality both inside and outside sexual relationships, including marriage (Iipinge et al. 2004; see also Jewkes, Penn-Kekana, and Rose-Junius 2005).

There are also certain population groups which are especially vulnerable to contracting HIV. These include, for example, sex workers (Iipinge and Angula 2000; LAC 2002). 
Sex work, or prostitution, here means situations that involve the active solicitation of money for sexual favours. Sex workers are seldom able to negotiate with their clients regarding the consistent use of condoms. According to a recent study, sexual work is also increasingly common among boys and young men who offer their services to men (Male sex workers... 2005). Sex workers usually end up doing what they do because of a lack of access to other ways of making a living. Selling sexual favours is sometimes the last resort for abandoned and orphaned children.

In the future, HIV will affect different economic sectors in Namibia as well as the country's whole economy. Both families and communities are affected by the sickness and deaths that occur among their members. Taking care of people who are ill, as well as orphans and other children made vulnerable by the epidemic, will be a major challenge in the future (GRN/MoHSS 2002c; GRN/MoHSS and UNICEF 1998; Ojo and Delaney 1997; Phororo 2001; Rompel 2003; SIAPAC 2002). In the study region, these phenomena will be pronounced - not only because HIV prevalence is high, but also because people who have migrated to work in other regions often return to the northern regions when they have become ill (Notkola 2004).

For example, resources in both the farming sector (Impact of HIV/AIDS on... 2001; Phororo 2001) and the private sector (Phororo 2003; Phororo and Mohamed 2001) will be affected by the HIV epidemic. The healthcare sector has to bear the primary burden of the increasing morbidity associated with the HIV pandemic (Ojo and Delaney 1997; Pendukeni 2004), as well as handling increasing levels of ARV treatment and other preventive care for people suffering from HIV infection. At the same time, many healthcare workers are themselves affected by HIV infection and AIDS. The increased burden on the healthcare sector has resulted in caring for HIV patients being transferred from hospitals to so-called "home-based" care, and voluntary organisations play an important role in supporting both people who are ill and orphaned children.

HIV will have a dual impact on the basic education sector by slowing down the increase in the number of pupils and increasing levels of illness and death among the educators (Goveia 2000; GRN/MBESC 2002). The growing number of orphans and other children affected by HIV infection and AIDS is a challenge because of the high risk that they will drop out of the educational system. HIV will also affect Namibia's tertiary educational institutions and there is a requirement for both institutional strategies and cooperation in combating HIV (Katjavivi and Otaala 2003; Otaala 2000). HIV also challenges leaders at different levels in society to improve their understanding of their leadership roles in the battle against the epidemic (Otaala 2003). 
Estimates of the impact on Namibia's national economy vary. According to some scholars (Sanderson et al. 2001), the HIV epidemic will not have a major and devastating impact on economic growth in Namibia, primarily because the country's main exports are not labour intensive and rapidly-increasing levels of schooling will safeguard an educated labour force in the future.

\subsection{Future challenges}

Both North-Central Namibia and some of the other regions in southern Africa which are affected most severely by the HIV pandemic appear to be entering a new type of demographic transition. In this "third demographic transition", fertility is declining in parallel with a rapid increase in levels of mortality. In some locations, mortality rates exceed birth rates, resulting in negative population growth, i.e. population decline. In other regions, the result is slow population growth. In classical demographic transition theory, fertility was assumed to decline from a high natural-fertility regime to a low, controlled-fertility regime in which the level of fertility stabilises close to the replacement level. This view was challenged by the so-called "second demographic transition" and "lowest-low fertility", experienced for example in Europe. The second demographic transition is characterised by low fertility and a diversity of living arrangements, and while it is a process that mainly concerns European countries, especially those in the north, it is one that is also present to some extent in, for example, the United States. In many of the industrialised countries, fertility levels have declined to below replacement level.

The "third demographic transition" especially concerns those regions in sub-Saharan Africa which are seriously affected by the HIV pandemic and which are simultaneously experiencing a decline in fertility levels. In these places, fertility is falling below replacement level because of the combined effect of declining fertility and the increasing mortality resulting from HIV infection. In actual fact, HIV contributes to this process via two separate routes: it increases mortality and reduces fertility. The role played by HIV in this process is therefore somewhat similar to that of "modernisation" in classical demographic transition theory, where socioeconomic change is a factor that contributes to a decline in both fertility and mortality.

This process of a "third demographic transition" is under way in certain regions in southern Africa primarily because of the declining levels of fertility and increasing levels of mortality that result from HIV infection. Garenne et al. (2006) reported that fertility had declined almost to replacement level in Agincourt, a former Bantustan ('Homeland') region in rural South Africa. If current trends continue, fertility will fall 
below the replacement level within the next couple of years. Levels of fertility that are falling below the replacement level have also been identified in KwaZulu-Natal, which is also situated in rural South Africa (Camlin et al. 2004).

The future social and economic consequences of this process remain to be seen. An additional area of uncertainty results from the unusual characteristics of this "third demographic transition". Deaths from HIV infection involve people of working age, leaving both young and old relatively intact (except for increasing levels of infant and child mortality among offspring infected by their mothers). This is changing the age structure of the population, and will cause many problems: at national level, skilled and educated people will be lost at a time when they should be most productive; at family level, children will lose their breadwinners and older generations will lose the family members of working age who would have previously supported them in their old age.

Another item of interest will be what happens to fertility when levels of infant and child mortality substantially increase. According to some researchers, falling mortality is a precondition for fertility decline: will the new increase in mortality influence future fertility levels? Or is the fertility transition, once under way, so all-pervasive that no return to a significantly-increasing trend is possible?

In addition to their link to demographic processes, the consequences of the HIV pandemic for African communities, as well as the consequences at individual and national level, are very important subjects for further research. To reduce the negative impact of the pandemic, it is important to learn more about coping mechanisms and the survival strategies employed by families and communities in the regions most affected. This would help when identifying the best ways to support these communities as they live with HIV, for example how to take care of the huge numbers of orphans and other children affected by the pandemic.

The "third demographic transition" could be moderated or even prevented by the efficient distribution of antiretroviral therapy to people who are currently infected by HIV, and by efficient measures to prevent new cases of HIV infection. In the latter, moves towards safer sexual behaviour will play a crucial role. Such developments, however, will require change in both socio-cultural and economic systems, including a strengthening of the role of women. To enhance protection against HIV infection, it will be important to enhance women's control over their sexuality, to increase equality between the sexes in economic and other terms, and also to make other groups in society more equal. Also, medical innovations such as microbicides and vaccination against HIV infection, which it is hoped will be developed, would be important in future prevention of the spread of HIV. 


\subsection{Requests for future research}

There are many interrelated topics which justify further research. The role played by levels of education in fertility decline in Namibia, for example, would be an interesting topic on its own. More information is also needed about the mechanisms through which HIV infection affects levels of fertility in Namibia.

An interesting study topic would be the combined demographic consequences of declining fertility and increasing mortality, both of which are affected by HIV infection and AIDS. This would provide an opportunity for further research into the "third demographic transition" which also affects many other regions in southern Africa.

From the viewpoint of practical implications for the study region, a very-urgent and important line of research would be the social and demographic consequences of the HIV pandemic. There is a particular need for additional research to identify the best ways of supporting families and communities in North-Central Namibia in their struggle with the social and demographic consequences of HIV infection and AIDS.

Parish registers have proved a promising source of information for fertility research in Africa, despite the possible under-registration of children who have died before being baptised. The strength of information derived from parish registers is that this source provides a long-term register-based data source. Problems associated with limited information concerning background variables could be avoided by combining data from parish registers with other data sources. The inventory and storage of parish registers, as well as their use in demographic research, should be encouraged elsewhere in sub-Saharan Africa. 


\section{References}

Adams, Fiona and Wolfgang Werner. 1990. The land issue in Namibia: an inquiry. With contributions by Peter Vale. Namibia Institute for Social and Economic Research (NISER), University of Namibia. Windhoek, Namibia: University of Namibia.

Agadjanian, Victor and Ndola Prata. 2001. War and reproduction: Angola's fertility in comparative perspective. Journal of Southern African Studies 27(2): 329-47.

----. 2002. War, peace and fertility Angola. Demography 39(2): 215-31.

Ahrenson-Pandikow, Helena. 1992. Survey of attitudes towards the use of contraceptives in Namibia. Namibian Institute for Social and Economic Research (NISER) Research Report, No. 15. Windhoek, Namibia: NISER.

Arowolo, O.O. 2000. Fertility in Namibia. In: Population-development-environment: background readings on Namibia, edited by Ben Fuller, Isolde Prommer, and Wolfgang Lutz, pp. 253-71. International Institute for Applied Systems Analysis (IIASA) Interim Report IR-00-031. Laxenburg, Austria: IIASA.

Barnett, Tony and Alan Whiteside. 2002. AIDS in the twenty-first century: disease and globalization. Chippenham, Great Britain: Palgrave Macmillan.

Becker, Heike. 2001. 'I am the man'. Historical and contemporary perspectives on masculinities in northern Namibia. Paper presented at: AIDS in context. International Conference. Explaining the Social, Cultural and Historical Roots of the Epidemic in Southern Africa, 4-7 $7^{\text {th }}$ April, 2001, Johannesburg, South Africa.

---- 2003. Women, politics and peace in northern Namibia. In: Women and peace in Africa, pp. 47-74. Paris, France: UNESCO.

---- 2004. Efundula: women's initiation, gender and sexual identities in colonial and post-colonial northern Namibia. In: Re-thinking sexualities in Africa, edited by Signe Arnfred, pp. 35-56. Uppsala, Sweden: Nordic Africa Institute.

Benoit, Daniel and Bernard Lacombe. 1977. Towards getting precise data in contemporary Africa for the years 1920-30. In: African historical demography I: Proceedings of a Seminar Held in the Centre of African Studies, 29th and 30th April, 1977, edited C. Fyfe and David McMaster, pp. 68-70. Edinburgh, Great Britain: University of Edinburgh.

Blacker, C.P. 1947. Stages in population growth. Eugenics Review 39: 88-101.

Blanc, Ann. K. and Shea O. Rutstein. 1994. The demographic transition in southern Africa: yet another look at the evidence from Botswana and Zimbabwe. Demography 31(2): 209-15.

Bonal, Rolando R., Gérard J. Brulé, and Ellen N. Shikoyeni. 1998. Learner's knowledge, attitude and practices concerning STD/AIDS in Oshela Secondary School, Kongo District, Ohangwena Region. Kongo District, Namibia.

Bongaarts, John. 1982. The fertility-inhibiting effects of the intermediate fertility variables. Studies in Family Planning 13(6/7): 179-89.

----. 2002. The end of the fertility transition in the developing world. In: Completing the fertility transition. Part three: Country Papers, pp. 288-307. New York, NY: United Nations Population Division, Department of Economic and Social Affairs. 
----. 2003. Completing the fertility transition in the developing world: the role of educational differences and fertility preferences. Population Studies 57(3): 321336.

Bongaarts, John and Robert G. Potter 1983. Fertility, biology and behaviour: an analysis of proximate determinants. New York, NY: Academic Press.

Bos, E. 1998. Do Antenatal clinic HIV data underestimate or overestimate HIV prevalence? Or both? Paper prepared for the Conference on Measurement of risk and modelling the spread of AIDS, organized by the IUSSP Committee on AIDS and the University of Copenhagen, June 2-4, 1998, Copenhagen, Denmark.

Brown, Jill, James Sorrell, and Marcela Raffaelli. 2005. An exploratory study of constructions of masculinity, sexuality and HIV/AIDS in Namibia, Southern Africa. Culture, Health \& Sexuality 7(6): 585-98.

Bulatao, Rodolfo A. 2001. Introduction. Population and Development Review 27 Supplement: Global fertility transition: 1-14.

Caldwell, John C. 1976. Toward a restatement of demographic transition theory. Population and Development Review 2(3/4): 321-66.

---- 1982. The theory of fertility decline. London, Great Britain: Academic Press.

----. 2001. The globalization of fertility behaviour. Population and Development Review 27 Supplement: Global fertility transition: 93-115.

----. 2005. On net intergenerational wealth flows: an update. Population and Development Review 31(4): 721-40.

Caldwell, John C., I.O. Orubuloye, and Pat Caldwell. 1992. Fertility decline in Africa: a new type of transition? Population and Development Review 18(2): 211-42.

Calleja, Jesús M. Carcía, Lawrence H. Marum, César P. Cárcamo, Lovemore Kaetano, James Muttunga, and Ann Way. 2005. Lessons learned in the conduct, validation, and interpretation of national population based HIV surveys. AIDS 19 (suppl. 2): S9-S17.

Camlin, Carol S., Michel Garenne, and Tom A. Moultrie. 2004. Fertility trend and pattern in a rural area of South Africa in the context of HIV/AIDS. African Journal of Reproductive Health 8(2): 39-54.

Campbell, Bob. 2003. Namibia school learners and HIV/AIDS. Research report 1: Quantitative data. Department of Educational Studies, University of York. York, Great Britain: University of York.

Carpenter, Lucy M., Jessica S. Nakiyingi, Anthony Ruberantwari, Samuel S. Malamba, Anatoli Kamali, and James A.G. Whitworth. 1997. Estimates of the impact of HIV infection on fertility in a rural Ugandan population cohort. Health Transition Review 7 (Suppl. 2): S113-S126.

Casterline, John B. 2001. The pace of fertility transition: national patterns in the second half of the twentieth century. Population and Development Review 27 Supplement: Global fertility transition 17-52.

Chimere-Dan, Orieji. 1997. Non-marital teenage childbearing in southern Africa: the case of Namibia. African Population Studies 12(2): 87-95.

Cleaver, Tessa and Marion Wallace. 1990. Namibia women in war. Guildford and King's Lynn, Great Britain: Zed Books. 
Cleland, John. 2001a. Potatoes and pills: an overview of innovation-diffusion contributions to explanations of fertility decline. In: Diffusion processes and fertility transition: selected perspectives, edited by John B. Casterline, pp. 39-65. Washington, DC: National Academy Press.

---- 2001b. The effects of improved survival on fertility: a reassessment. Population and Development Review 27 Supplement: Global Fertility Transition: 60-92.

----. 2002. Education and future fertility trends, with special reference to mid-transitional countries. In: Completing the fertility transition. Part two background papers, pp. 187-202. New York, NY: United Nations Population Division, Department of Economic and Social Affairs.

Cleland, John, Nelson Onuoha, and Ian Timæus. 1994. Has sustained fertility decline begun in sub-Saharan Africa? In: The onset of fertility transition in sub-Saharan Africa, edited by Thérèse Locoh and Véronique Hertrich, pp. 1-20. Liège, Belgium: International Union for the Scientific Study of Population.

Coale, Ansley J. and Paul Demeny. 1983. Regional model life tables and stable populations. Second Edition. Studies in Population. New York, NY: Academic Press.

Coale, Ansley J. and Roy Treadway. 1986. A summary of the changing distribution of overall fertility, marital fertility, and the proportion of married in the provinces of Europe. In: The decline of fertility in Europe, edited by Ansley J. Coale and Susan Cotts Watkins, 31-181. Princeton, New Jersey: Princeton University Press.

Cochrane, Susan and Samir F. Farid. 1989. Fertility in sub-Saharan Africa: analysis and explanation. World Bank Discussion Papers 43. Washington, DC: World Bank.

Colwell, Stacey. 2000. Infant and child mortality on Kilimanjaro, 1894-1935. Harvard School of Public Health Research Paper, No. 174. Boston, MA: Harvard School of Public Health.

Cooper, Allan D. 1997. State sponsorship of women's rights and implications for patriarchism in Namibia. Journal of Modern African Studies, 35(3): 469-83.

Cownie, David. 2001. Findings of SIAPAC study on orphans in Namibia. In: First National conference on orphans and other vulnerable children, Windhoek 8-10 May 2001. Full report, pp. 26-9. Organised by Directorate of Developmental Social Welfare Services, Ministry of Health and Social Services. Windhoek, Namibia: Ministry of Health and Social Services.

Crampin, Amelia C., Judith R. Glynn, Bagrey M.M. Ngwira, Frank D. Mwaungulu, Jörg M. Pönnighaus, David K. Warndorff, and Paul E.M. Fine. 2003. Trends and measurement of HIV prevalence in northern Malawi. AIDS 17(12): 1817-25.

Curto, José C. 2002. "As if from a free womb": baptismal manumissions in the Conceição Parish, Luanda, 1778-1807. Portuguese Studies Review 10: 26-57.

Davis, K. and J. Blake. 1956. Social structure and fertility: an analytic framework. Economic Development and Cultural Change 4: 211-35.

Dickson, Kim Eva. 2003. Adolescent fertility: a population concern. In: Fertility: current South African issues of poverty, HIV/AIDS and youth. Seminar proceedings, pp. 59-71. Human Sciences Research Council (HSRC) and Department of Social Development. Cape Town, South Africa: HSRC Publishers. 
Dierks, Klaus. 2002. Chronology of Namibian history: from pre-historical times to independent Namibia. Second updated and revised edition. Windhoek, Namibia: Namibia Scientific Society.

Direktoraat Gesondheit en Welsyn. 1984. Jaarsverslag 1983/84 [Annual report 1983/84]. Direktoraat Gesondheit en Welsyn, Administrasie vir Owambo’s.

Directorate Health and Welfare. 1985. Jaarsverslag 1984/85 [Annual report 1984/85]. Directorate Health and Welfare, Administrasie vir Owambo's.

----. 1986. Jaarsverslag 1985/86 [Annual report 1985/86]. Directorate Health and Welfare, Administrasie vir Owambo's.

Du Pisani, André. 1986. SWA/Namibia: The politics of continuity and change. Johannesburg, South Africa: Jonathan Ball Publishers.

Durlauf, Steven N. and James R. Walker. 2001. Social interactions and fertility transitions. In: Diffusion processes and fertility transition: selected perspectives, edited by John B. Casterline, pp. 115-37. Washington, DC: National Academy Press.

Dyson, Tim and Mike Murphy. 1985. The onset of fertility transition. Population and Development Review 11(3): 339-440.

Dzekedzeke, Kumbutso and Knut M. Fylkesnes. 2006. Reducing uncertainties in global HIV prevalence estimates: the case of Zambia. BMC Public Health 6(1):83. [online]. [Cited in June 2006]. Available from: <http://www.biomedcentral.com/ content/pdf/1471-2458-6-83.pdf>

Easterlin, Richard A. and Eileen M. Crimmins. 1985. The fertility revolution: a supplydemand analysis. Chicago, IL: University of Chicago Press.

Eirola, Martti. 1985. Namibiana in Finland 1: Opas suomalaisiin Namibiaa ennen vuotta 1938 koskeviin arkistolähteisiin [Guide for archival sources in Finland concerning Namibia before year 1938]. University of Joensuu, Faculty of Arts, Studies in History, No. 2. Joensuu, Finland: University of Joensuu.

----. 1992. The Ovambogefahr: The Ovamboland reservation in the making. Political responses of the kingdom of Ondonga to the German colonial power 1884-1910. Studia Historica Septentrionala 22. Rovaniemi, Finland: Pohjois-Suomen Historiallinen Yhdistys - Societas Historica Finlandiae Septentrionalis.

Eirola, Martti, Seppo Rytkönen, Harri Siiskonen, and Seppo Sivonen. 1983. The cultural and social change in Ovamboland 1870-1915. University of Joensuu Publications of Social and Regional Sciences, No. 39. Joensuu, Finland: University of Joensuu.

ELCIN (= Evangelical Lutheran Church in Namibia). 1992. ELCIN statistics 1991. Ondangwa, Namibia: Evangelical Lutheran Church in Namibia.

----. 2002. ELCIN statistics: reports and tables 2001. Ondangwa, Namibia: Evangelical Lutheran Church in Namibia.

----. 2003. ELCIN statistics: reports and tables 2002. Ondangwa, Namibia: Evangelical Lutheran Church in Namibia.

El Obeid, Selma, John Mendelsohn, Marc Lejars, Norbert Forster, and Gérard Brulé. 2001. Health in Namibia: progress and challenges. Research and Information Services of Namibia (RAISON). Published for the support to Primary Health Care Project of the Ministry of Health and Social Services and Service for Co-opera- 
tion and Cultural Affairs of the French Embassy in Namibia. Windhoek, Namibia: RAISON.

ELOC (= Evangelical Lutheran Ovambo-Kavango Church). 1982. ELOC statistics 1981. Ondangwa, Namibia: Evangelical Lutheran Ovambo-Kavango Church.

Elonheimo, Marjatta. 1994. Interview with a retired missionary worker Marjatta Elonheimo MSc in March, 1994.

Engh, Ida-Eline, Libor Stloukal, and Jacques du Guerny. 2000. HIV/AIDS in Namibia: the impact on the livestock sector. [online]. Population Programme Service (SDWP), FAO Women and Population Division. [Cited in September 2005]. Available from:

$<$ http://www.fao.org/WAICENT/FAOINFO/SUSTDEV/WPdirect/WPan0046.htm>

Erkkilä, Antti. 2001. Living on the land: change in forest cover in North-Central Namibia 1943-1996. Silva Carelica 37. Joensuu, Finland: University of Joensuu.

Erkkilä, Antti and Harri Siiskonen. 1992. Forestry in Namibia 1850-1990. Silva Carelica 20. Joensuu, Finland: University of Joensuu.

----. 2003. Academic partnership: the University of Joensuu and the University of Namibia. Paper presented on 10 April 2003, in a seminar Namibia siirtymästrategiapäivät, organised by the Ministry Foreign Affairs of Finland.

Evian, Clive. 2000. Primary AIDS care: a practical guide for primary health care personnel in the clinical and supportive care of people with HIV/AIDS. Third edition, first edition in 1993. Parow, South Africa: Jacana Education.

Fabiani, Massimo, Barbara Nattabi, Emingtone O. Ayella, Martin Ogwang, and Silvia Declich. 2006. Differences in fertility by HIV serostatus and adjusted HIV prevalence data from antenatal clinic in northern Uganda. Tropical Medicine \& International Health 11(2): 182-7.

Feltz, Gaëtan. 1990. Catholic missions, mentalités, and quantitative history of Burundi, ca. 1900-1962. In: Demography from scanty evidence: central Africa in the colonial era, edited by Bruce Fetter, pp. 113-29. Boulder, Colorado: L. Rienner Publishers.

Feyisetan, Bamikale and John B. Casterline. 2000. Socio-economic status, fertility preferences and contraceptive change in sub-Saharan Africa. African Population Studies 15(2): 1-15.

Finnish Missionary Society. 1933. Tilastotaulut Suomen Lähetysseuran työstä lähetysalueellaan Ambomaalla [Statistical tables concerning the work of the Finnish Missionary Society in Ovamboland]. Hha Minutes of the missionaries' meetings, appendix. Archives of the Finnish Missionary Society, National Archives of Finland, Helsinki, Finland.

----. 1942. Tilastotaulut Suomen Lähetysseuran työstä lähetysalueellaan Ambomaalla [Statistical tables concerning the work of the Finnish Missionary Society in Ovamboland]. Hha Minutes of the missionaries' meetings, appendix. Archives of the Finnish Missionary Society, National Archives of Finland, Helsinki, Finland.

----. 1951. Tilastotaulut Suomen Lähetysseuran työstä lähetysalueellaan Ambomaalla [Statistical tables concerning the work of the Finnish Missionary Society in Ovamboland]. Hha Minutes of the missionaries' meetings, appendix. Archives of the Finnish Missionary Society, National Archives of Finland, Helsinki, Finland. 
----. 1960. Tilastotaulut Suomen Lähetysseuran työstä lähetysalueellaan Ambomaalla [Statistical tables concerning the work of the Finnish Missionary Society in Ovamboland]. Hha Minutes of the missionaries' meetings, appendix. Archives of the Finnish Missionary Society, National Archives of Finland, Helsinki, Finland.

Fitzgerald Ann M., Bonita F. Stanton, Nancy Terreri, Hannu Shipena, Xiaoming Li, Joshua Kahihuata, Izabel B. Ricardo, Jennifer S. Galbraith, and Anna Marie de Jaeger. 1999. Use of western-based HIV risk-reduction interventions targeting adolescents in an African setting. Journal of Adolescent Health 25(1): 52-61.

Fox, Tom. 2002. The culture(s) of AIDS - cultural analysis and new policy approaches for Namibia. In: Namibia society sociology, edited by Volker Winterfeldt, Tom Fox, and Pempelani Mufune, pp. 317-31. Windhoek, Namibia: University of Namibia Press.

Fylkesnes, Knut, Zacchaeus Ndhlovu, Kelvin Kasumba, Rosemary Mubanga Musonda, and Moses Sichone. 1998. Studying dynamics of the HIV epidemic: populationbased data compared with sentinel surveillance in Zambia. AIDS 12(10): 1227-34.

Gage, Anastasia J. 1998. Premarital childbearing, unwanted fertility and maternity care in Kenya and Namibia. Population Studies 52(1): 21-34.

Gaisie, S. Kwesi. 1995a. Determinants of fertility decline in Botswana. African Population Studies, 10(1). [online]. Union of African Population Studies. [Cited in January, 2004] Available from: <Http://www.uaps.org $>$

----. 1995b. Fertility transition in Botswana: an African perspective. Southern African Journal of Demography 5(1): 35-47.

Garenne, Michel. 2002. Sex ratios at birth in African populations: a review of survey data. Human Biology 74(6): 889-900.

----. 2004a. Sex ratios at birth in populations of eastern and southern Africa. Southern African Journal of Demography 9(1): 91-6.

----. 2004b. Age at marriage and modernisation in sub-Saharan Africa. Southern African Journal of Demography 9(2): 57-77.

Garenne, Michel, Stephen Tollman, and Kathleen Kahn. 2000. Premarital fertility in rural South Africa: a challenge to existing population policy. Studies in Family Planning 31(1): 47-54.

Garenne, Michel and Veronique Joseph. 2002. The timing of fertility transition in sub-Saharan Africa. World Development 30(10): 1835-43.

Garenne, Michel, Stephen M. Tollman, Kathleen Kahn, and Mark Collinson. 2006. Fertility trends and net reproduction in Agincourt, Rural South Africa: 1992 - 2004. Scandinavian Journal of Public Health. In print.

Garenne, Michel and Julien Zwang. 2006. Premarital fertility in Namibia: trends, factors and consequences. Journal of Biosocial Science 38(2): 145-67.

Glynn, Judith R., Anne Buvé, Michel Garaël, Maina Kahindo, Isaac B. Macauley, Rosemary M. Musonda, Eva Jungmann, Francis Tembo, and Leopold Zekeng. 2000. Decreased fertility among HIV-1-infected women attending antenatal clinics in three African cities. Journal of Acquired Immune Deficiency Syndromes 25(4): 345-52.

Gouws, N.B. 1987. The demography of whites in South Africa prior to 1820. Southern African Journal of Demography 1(1): 7-15. 
Goveia, Jeffrey Joseph. 2000. Education and the epidemic: the effects of HIVIAIDS on basic education in Namibia. Professional report presented to the Faculty of the Graduate School of the University of Texas at Austin in partial fulfilment of the requirements of the Degree of Master of Public Affairs. University of Texas at Austin.

Gray, Ronald H., Maria J. Wawer, David Serwadda, Nelson Sewankambo, Chuanjun Li, Frederick Wabwire-Mangen, Lynn Paxton, Noah Kiwanuka, Godfrey Kigozi, Joseph Konde-Lule, Thomas C Quinn, Charlotte A Gaydos, and Denise McNairn. 1998. Population-based study of fertility in Women with HIV-1 infection in Uganda. Lancet 351(9096): 98-103.

GRB/CSO (= Government of the Republic of Botswana/Central Statistical Office). 2004. Demography and tourism statistics [online]. [Cited in March, 2004.] Available from: <http://www.cso.gov.bw/cso/demo_stats.html>

Gregson, Simon. 1994. Will HIV become a major determinant of fertility in sub-Saharan Africa? Journal of Development Studies 30: 650-5.

Gregson, Simon, Tom Zhuwau, Roy M. Anderson, and Stephen K. Chandiwana. 1997. HIV and fertility change in rural Zimbabwe. Health Transition Review 7(Suppl. 2): S89-S112.

Gregson, Simon, Basia Zaba, and Susan-Catherine Hunter. 2002. The impact of HIV1 on fertility in sub-Saharan Africa: causes and consequences. In: Completing the fertility transition. Part two: background papers, pp. 104-36. New York, NY: United Nations Population Division.

GRK/NCPD, GRK/CBS, and Macro International. 1999. Kenya Demographic and Health Survey 1998. Government of Republic of Kenya, National Council for Population and Development (NCPD), Central Bureau of Statistics (CBS) (Office of Vice President and Ministry of Planning and National Development) [Kenya], and Macro International Inc. (MI), Maryland, USA. Calverton, Maryland: NDPD, CBS and MI.

GRN/MoHSS (= Government of the Republic of Namibia/Ministry of Health and Social Services). 1992. Integrated health care delivery: the challenge of implementation. A situation analysis and practical implementation guide. Windhoek, Namibia: Ministry of Health and Social Services.

----. 1995. Family Planning Policy. Windhoek, Namibia: Ministry of Health and Social Services.

----. 2002a. The format and guideline for the 2001/2002 annual report: districts and regions. Ministry of Health and Social Services, Directorate Policy, Planning and Human Resource Development, Division Planning. Windhoek, Namibia: Ministry of Health and Social Services.

----. 2002b. The format and guideline for the 2001/2002 annual report: national directorates. Ministry of Health and Social Services, Directorate Policy, Planning and Human Resource Development, Division Planning. Windhoek, Namibia: Ministry of Health and Social Services.

----. 2002c. Second national conference on orphans and other vulnerable children. "Facing Challenges, Ensuring Futures". Windhoek, Namibia 25-27 June 2002. Full Report. Windhoek, Namibia: Ministry of Health and Social Services. 
----. 2003a. Report of the 2002 national HIV sentinel survey. Ministry of Health and Social Services, Directorate of Primary Health Care and Nursing Services, National AIDS Co-ordination Programme. Windhoek, Namibia: Ministry of Health and Social Services.

----. 2003b. Namibia Demographic and Health Survey 2000. Windhoek, Namibia: Ministry of Health and Social Services.

----. 2003c. Epidemiological report: HIV/AIDS \& STIfor the year 2001. AIDS Co-ordination Programme. Windhoek, Namibia: Ministry of Health and Social Services.

----. 2004a. The technical efficiency of district hospitals in Namibia. Ministry of Health and Social Services, Directorate Policy, Planning and Human Resource Development. Windhoek, Namibia: Ministry of Health and Social Services.

----. 2004b. Ohangwena region annual report 2003/2004. Windhoek, Namibia: Ministry of Health and Social Services.

----. 2004c. Omusati region annual report 2003/2004. Windhoek, Namibia: Ministry of Health and Social Services.

----. 2004d. Oshana region annual report 2003/2004. Windhoek, Namibia: Ministry of Health and Social Services.

----. 2004e. Oshikoto region annual report 2003/2004. Windhoek, Namibia: Ministry of Health and Social Services.

----. 2005. Report of the 2004 national HIV sentinel survey. Windhoek, Namibia: Ministry of Health and Social Services.

----. n.d. (no date) Namibia Health Information System (HIS2K). Description, documents, manuals, forms download. [online]. Ministry of Health and Social Services. [Cited in October 2005]. Available from: <http://www.healthnet.org.na/policies.asp >

GRN/MoHSS (= Government of the Republic of Namibia/Ministry of Health and Social Services) and Macro International Inc. 1993. Namibia Demographic and Health Survey 1992. Windhoek, Namibia: Ministry of Health and Social Services and Macro International Inc.

GRN/MoHSS (= Government of the Republic of Namibia/Ministry of Health and Social Services) and UNICEF. 1998. More than the loss of a parent: Namibia's first study of orphan children. Windhoek, Namibia: Ministry of Health and Social Services and UNICEF.

GRN/MBESC (= Government of Republic of Namibia/Ministry of Basic Education, Sport and Culture). 2002. The impact of HIV/AIDS on education in Namibia. Prepared by Abt Associates South Africa Inc. Windhoek, Namibia: Ministry of Basic Education, Sport and Culture and Ministry of Higher Education, Training and Employment Creation.

GRN/NPC (= Government of the Republic of Namibia/National Planning Commission). 1992. 1991 Population and housing census. Preliminary report. National Planning Commission, Central Statistics Office. Windhoek, Namibia: National Planning Commission.

---. 1993. 1991 Population and housing census. Report A. Statistical tables. Volumes I-V. (Tables for 27 census districts). National Planning Commission, Central Statistics Office. Windhoek, Namibia: National Planning Commission. 
---- 1994a. 1991 Population and housing census: basic analysis with highlights. National Planning Commission, Central Statistics Office. Windhoek, Namibia: National Planning Commission.

----. 1994b. 1991 Population and housing census. Report B. Statistical tables. (Tables for 13 administrative regions). National Planning Commission, Central Statistics Office. Windhoek, Namibia: National Planning Commission.

----. 1994c. Population and housing census. Statistical tables for sub-regions of Elim, Nakayale, Oshigambo, Okahao, and Tshandi congregations. Unpublished statistical tables. National Planning Commission, Central Statistics Office. Windhoek, Namibia: National Planning Commission.

---- 2003. 2001 Population and Housing Census national report: basic analysis with highlights. National Planning Commission, Central Bureau of Statistics. Windhoek, Namibia: National Planning Commission.

----. 2004a. 2001 Population and Housing Census. Oshikoto region: basic analysis with highlights. National Planning Commission, Central Bureau of Statistics. Windhoek, Namibia: National Planning Commission.

----. 2004b. 2001 Population and Housing Census. Oshana region: basic analysis with highlights. National Planning Commission, Central Bureau of Statistics. Windhoek, Namibia: National Planning Commission.

----. 2005a. 2001 Population and Housing Census. Omusati region: basic analysis with highlights. National Planning Commission, Central Bureau of Statistics. Windhoek, Namibia: National Planning Commission.

---- 2005b. 2001 Population and Housing Census. Ohangwena region: basic analysis with highlights. National Planning Commission, Central Bureau of Statistics. Windhoek, Namibia: National Planning Commission.

----. 2006a. Population projections 2001 - 2031. National and regional figures. National Planning Commission, Central Bureau of Statistics. Windhoek, Namibia: National Planning Commission.

---- 2006b. Namibia Household Income \& Expenditure Survey 2003/2004. Preliminary report. National Planning Commission, Central Bureau of Statistics. Windhoek, Namibia: National Planning Commission.

----. n.d. (no date). Printout of selected results from the 1996 Intercensal Demographic Survey. National Planning Commission, Central Bureau of Statistics. Windhoek, Namibia: National Planning Commission. Undated.

GRSA/DoH, MRC and Macro International. 2002. South Africa Demographic and Health Survey. Full report. Government of Republic of South Africa, Department of Health and Medical Research Council, South Africa, and Macro International Inc. Pretoria, South Africa and Calverton, Maryland: GRSA/DoH, MRC and Macro International.

$\mathrm{GRZa} / \mathrm{CSO}$ (= Government of Republic of Zambia/Central Statistical Office), GRZa/ CBH (=Government of Republic of Zambia/Central Board of Health), and ORC Macro. 2003. Zambia Demographic and Health Survey 2001-2002. Calverton, Maryland: Central Statistical Office, Central Board of Health, and OCR Macro. GRZ/CSO (= Government of Republic of Zimbabwe/Central Statistical Office) and Macro International Inc. 1995. Zimbabwe Demographic and Health Survey 1994. Calverton, Maryland: Central Statistical Office and Macro International Inc. 
----. 2000. Zimbabwe Demographic and Health Survey 1999. Calverton, Maryland: Central Statistical Office and Macro International Inc.

Gustafsson, Kalle. 2003. "A continent of slaves" - Anti-slave-trade rhetoric and the image of Africa in Finland, 1809-1877. A paper presented at the Nordic Africa Days, Uppsala, Sweden, October 5-7, 2003.

----. 2004. Slave trade in Ovamboland 1850-1913. Master's thesis. Department of African Studies, University of Helsinki, Finland.

Hailonga, Panduleni. 1993. A study to identify the knowledge, attitudes and behaviours of adolescents with regard of teenage pregnancy in Katutura. Windhoek, Namibia: Ministry of Health and Social Services.

----. 2005. Adolescent sexuality and reproductive behaviour in Namibia: a socio-historical analysis. Maastricht, the Netherlands: Shaker Publishing.

Hamata, Sylvia Amanda. n.d. (no date). Fertility determinants in Namibia. Unpublished and undated manuscript. Windhoek, Namibia.

Henry, Louis. 1953. Fondements théoriques des measures de la fécondité naturelle. Revue Institut International de Statistique 21(3): 135-51.

Heuveline, Patrick. 2003. HIV and population dynamics: a general model and maximum-likelihood standards for East Africa. Demography 40(2): 217-45.

Hiltunen, Maija. 1986. Witchcraft and sorcery in Ovambo. Mänttä, Finland: Suomen Antropologinen Seura - The Finnish Anthropological Society.

---. 1993. Good magic in Ovambo. Transactions of Finnish Anthropological Society 33. Jyväskylä, Finland: The Finnish Anthropological Society.

Hirschman, Charles. 1994. Why fertility changes. Annual Review of Sociology 20: 203-33.

Hosegood, Victoria, Anna-Maria Vanneste, and Ian M. Timæus. 2004. Levels and causes of adult mortality in rural South Africa: the impact of AIDS. AIDS 18(4): 663-71.

Hunter, Susan-Catherine, Raphael Isingo, J. Ties Boerma, Mark Urassa, Gabriel M.P. Mwaluko, and Basia Zaba. 2003. The association between HIV and fertility in a cohort study in rural Tanzania. Journal of Biosocial Science 35(2):189-99.

Iipinge, Eunice and Margaret Angula. 2000. "Telling their stories": commercial sex workers in Walvis Bay. Gender Training and Research Programme, Social Sciences Division, Multidisciplinary and Consultancy Centre. Windhoek, Namibia: University of Namibia.

Iipinge, Sholastika, Kathe Hofnie, and Steve Friedman. 2004. The relationship between gender roles and HIV infection in Namibia. Windhoek, Namibia: University of Namibia Press.

Iliffe, John. 2006. The African AIDS epidemic: a history. Irthlingborough, Great Britain: James Currey Ltd.

Impact of HIV/AIDS on the different farming sectors in Namibia. 2001. A report by University Central Consultancy Bureau of the University of Namibia and FAO Regional Office for Africa. Windhoek, Namibia: University of Namibia and FAO.

IRD (= Institute for Resource Development). 1990. An assessment of DHS-I data quality. DHS methodological reports 1. Columbia, Maryland: Institute for Resource Development/Macro Systems, Inc. 
Jakobsen, Oddvar. 2000. A model for studying the impact of HIV/AIDS on the size and structure of the Namibian population. In: Population-Development-Environment: background readings on Namibia, edited by Ben Fuller, Isolde Prommer, and Wolfgang Lutz, pp. 297-315. International Institute for Applied Systems Analysis (IIASA). Laxenburg, Austria: IIASA.

Jejeebhoy, Shireen J. 1995. Women's education, autonomy, and reproductive behaviour: experience from developing countries. Oxford, Great Britain: Clarendon Press.

Jewkes, Rachel, Loveday Penn-Kekana, and Hetty Rose-Junius. 2005. "If they rape me, I can't blame them": reflections on gender in social context of child rape in South Africa and Namibia. Social Science \& Medicine 61: 1809-20.

Joutsenniemi, Kaisla. 2006. Äidin siviilisäädyn vaikutus lasten kuolleisuuteen entisellä Ambomaalla Pohjois-Namibiassa [Impact of mother's marital status on child mortality in former Ovamboland region in northern Namibia]. Master's thesis. Department of Sociology, University of Helsinki, Finland.

Kalipeni, Ezekiel, Susan Craddock, and Jayati Ghosh. 2004. Mapping the AIDS pandemic in Eastern and Southern Africa: a critical overview. In: HIV \& AIDS in Africa: Beyond Epidemiology, edited by Ezekiel Kalipeni, Susan Craddock, Joseph R. Oppong and Jayati Ghosh, pp. 58-69. Oxford, Great Britain: Blackwell Publishing. Kamali, Anatoli, Lucy Mary Carpenter, James Alexander Grover Whitworth, Robert Pool, Anthony Ruberantwari, and Amato Ojwiya. 2000. Seven-year trends in HIV-1 infection rates, and changes in sexual behaviour, among adults in rural Uganda. AIDS 14(4): 427-34.

Katjavivi, Peter H. 1986. The rise of nationalism in Namibia and its international dimensions. Thesis submitted for the degree of Doctor of Philosophy in the University of Oxford, St Antony's College. Oxford, Great Britain.

----. 1988. A history of resistance in Namibia. London, Great Britain: James Currey.

----. 1989. The role of the church in the struggle for independence. In: Church and liberation in Namibia, edited by Peter Katjavivi, Per Frostin, and Kaire Mbuende. pp. 3-26. London, Great Britain: Pluto Press.

Katjavivi, Peter H. and Barnabas Otaala. 2003. African higher education institutions responding to the HIV/AIDS pandemic. Paper presented at the AAU Conference of Rectors, Vice Chancellors and Presidents of African Universities (COREVIP), Mauritius, March 17-21, 2005.

Katzenellenbogen, J., D. Yach, and R.E. Dorrington. 1993. Mortality in a rural South African mission, 1837-1909: an historical cohort study using church records. International Journal of Epidemiology 22(6): 965-75.

Keele, Brandon F., Fran Van Heuverswyn, Yingying Li, Elizabeth Bailes, Jun Takehisa, Mario L. Santiago, Frederic Bibollet-Ruche, Yalu Chen, Louise V. Wain, Florian Liegeois, Severin Loul, Eitel Mpoudi Ngole, Yanga Bienvenue, Eric Delaporte, John F. Y. Brookfield, Paul M. Sharp, George M. Shaw, Martine Peeters, and Beatrice H. Hahn. 2006. Chimpanzee reservoirs of pandemic and nonpandemic HIV-1. Science Express [Online], 25 May 2006, pages 1-4. [Cited on 5 June 2006]. Available from: < http://www.sciencemag.org/cgi/rapidpdf/1126531v1.pdf > 
Kemppainen, Kati. 1998. Suomalaisen lähetyksen suhteet anglikaaneihin ja katolilaisiin Lounais-Afrikassa 1919-1937 [The Finnish mission's relationship to the Anglicans and Roman Catholics in South West Africa in 1919 - 1937]. Suomen kirkkohistoriallisen seuran toimituksia 180. Saarijärvi, Finland: Suomen kirkkohistoriallinen seura - Finnish Society of Church History.

Kiljunen, Marja-Liisa. 1980. Apartheid ja afrikkalaiset [Apartheid and Africans]. In: Namibia: viimeinen siirtomaa [Namibia: the last colony], edited by Kimmo Kiljunen and Marja-Liisa Kiljunen, pp. 85-116. Helsinki, Finland: Tammi.

Kirchengast, Sylvia and Eike Meinrad Winkler. 1996. Differential fertility and body build in !Kung San and Kavango females from Northern Namibia. Journal of Biosocial Sciences 28(2): 193-210.

Kirk, Dudley. 1996. Demographic transition theory. Population Studies 50: 361-87.

Kirk, Dudley and Bernard Pillet. 1998. Fertility levels, trends, and differentials in subSaharan Africa in the 1980s and 1990s. Studies in Family Planning 29(1): 1-22.

Knodel, John. 1979. The influence of child mortality in a natural fertility setting. In: Natural Fertility, edited by Henri Leridon and Jane Menken, pp. 273-284. International Union for Scientific Study of Population. Liège, Belgium: Ordina Editions.

Kohler, Hans-Peter, Francesco C. Billari, and Jose Antonio Ortega. 2002. The Emergence of lowest-low fertility in Europe during the 1990s. Population and Development Review 28(4): 641-80.

Koponen, Juhani. 1981. Finland. In: Namibia and the Nordic Countries, by Hans-Otto Sano, Juhani Koponen, Arne Tostensen and Roland Stanbridge, pp. 23-32. Motala, Sweden: The Scandinavian Institute of African Studies.

----. 1986. Population growth in historical perspective: the key role of changing fertility. In: Tanzania - crisis and struggle for survival, edited by Jannik Boesen, Kjell J. Havnevi, Juhani Koponen, and Rie Odgaard, pp. 31-57. Uppsala, Sweden: Scandinavian Institute for African Studies.

Korenromp, Eline L., Brian G. Williams, Sake J. de Vlas, Eleanor Gouws, Charles F. Gilks, Peter D. Ghys, and Bernard L. Nahlen. 2005. Malaria attributable to the HIV1 epidemic, sub-Saharan Africa. Emerging Infectious Diseases 11(9): 1410-9.

Kouvalainen, Marja Liisa. 1980. Ambomaan siirtotyöläisyyden synty [The origin of migrant labour in Ovamboland]. Master's thesis. Department of Social Science History, University of Helsinki.

Kuhanen, Jan. 2005. Poverty, health and reproduction in early colonial Uganda. University of Joensuu Publications in the Humanities, No 37. Joensuu, Finland: University of Joensuu.

Kuusi, Matti. 1970. Ovambo proverbs with African parallels. FF Communications 208. Helsinki, Finland: Academia Scientiarum Fennica.

----. 1974. Ovambo riddles with comments and vocabularies. FF Communications 215. Helsinki, Finland: Academia Scientiarum Fennica.

LAC (= Legal Assistance Centre). 1999. Proposals for law reform on the recognition of customary marriages. Windhoek, Namibia: Legal Assistance Centre.

----. 2000. Proposals for divorce law reform in Namibia. Windhoek, Namibia: Legal Assistance Centre. 
---. 2002. "Whose body is it?" Commercial sex work and the law in Namibia. Windhoek, Namibia: Legal Assistance Centre.

----. 2005. Customary laws on inheritance in Namibia: issues and questions in developing new legislation. Gender Research and Advocacy Project. Windhoek, Namibia: Legal Assistance Centre.

Lamlenn, Samson Bongsuiru. 2000. Issues relating to the measurement of the determinants of fertility: the goodness-of-fit of the Bongaarts' model on Cameroonian data. African Population Studies 15(1): 43-51.

Larsen, Ulla. 1996. Childlessness, subfertility, and infertility in Tanzania. Studies in Family Planning 27(1): 18-28.

----. 2000. Primary and secondary infertility in sub-Saharan Africa. International Journal of Epidemiology 29: 258-91.

LeBeau, Debie, Tom Fox, Heike Becker, and Pempelani Mufune. 1999. Taking risks, taking responsibility: an anthropological assessment of health-risk behaviour in Northern Namibia. Windhoek, Namibia: French Cooperation and Ministry of Health and Social Services.

----. 2002. Agencies and structures facilitating the transmission of HIV/AIDS in Northern Namibia. Society in Transition 32(1): 56-68.

Le Coeur, Sophie, Myriam Khlat, Gaston Halembokaka, Christine Augereau-Vacher, Georges Batala-M'pondo, Gaelle Baty, and Carine Ronsmans. 2005. HIV and the magnitude of pregnancy-related mortality in Pointe Noire, Congo. AIDS 19(1):69-75.

Lehtonen, Lahja. 1999. Schools in Ovamboland from 1870 to 1970. Helsinki, Finland: Finnish Evangelical Lutheran Mission.

Leibenstein, Harvey 1982. Relaxing the maximization assumption in the economic theory of fertility. In: Determinants of Fertility Trends, edited by Carlotte Höhn and Rainer Mackensen, pp. 35-48. International Union for Scientific Study of Population. Liegé, Belgium: Ordina Editions.

Lemström, Ossi. 1999. Hedelmällisyys ja kuolleisuus Kavangossa 1950-1996 verrattuna Ambomaahan [Fertility and mortality in Kavango 1950-1996 compared to Ovamboland]. Master's thesis. Department of Sociology, University of Helsinki, Finland.

Leridon, Henri. 1975. Biostatistics of human reproduction. In: Measuring the effect of family planning programs on fertility, edited by Chandrasekaran, C. and Albert I. Hermalin, pp. 93-131. International Union for Scientific Study of Population. Liége, Belgium: Ordina Editions.

Letamo, Gobopamang and Halima N. Letamo. 2002. The role of proximate determinants in fertility transition: a comparative study of Botswana, Zambia and Zimbabwe. Southern African Journal of Demography 8(1): 29-35.

Lewis, James J.C., Carine Ronsmans, Alex Ezeh, and Simon Gregson. 2004. The population impact of HIV on fertility in sub-Saharan Africa. AIDS 18 (Suppl. 2): S35-S43.

Lindert, Peter H. 1980. Child costs and economic development. In: Population and economic change in developing countries, edited by Richard A. Easterlin, pp. 580. Chicago: The University of Chicago Press.

Lindstrom David P. and Betemariam Berhanu. 1999. The impact of war, famine, and economic decline on marital fertility in Ethiopia. Demography 36(2): 247-61. 
Lucas, David. 1992. Fertility and family planning in southern and central Africa. Studies in Family Planning 23(3): 145-58.

Lutheran Medical Mission. 1985. Annual report of Lutheran Medical Mission of the Evangelical Lutheran Owambo Kavango Church 1984. English Version. Onandjokwe, Namibia.

----. 1986. Annual report of Lutheran Medical Mission of the Evangelical Lutheran Owambo Kavango Church 1985. Onandjokwe, Namibia: Lutheran Medical Mission.

----. 1988. Lutheran Medical Mission: annual report 1987. Ondangua, Namibia: Lutheran Medical Mission.

----. 1991. Lutheran Medical Mission: annual report 1990. Ondangua, Namibia: Lutheran Medical Mission.

Lutheran Medical Service. 1994. Lutheran Medical Service: annual report 1993/4. Ondangua, Namibia: Lutheran Medical Service.

Lutz, Wolfgang (Editor). 1994. Population-development-environment: understanding their interactions in Mauritius. Berlin/Heidelberg/New York: Springer-Verlag.

Lutz, Wolfgang, Lionel Prieto, and Warren Sanderson (Editors). 2000. Population, development and environment on the Yucatán Peninsula: from ancient Maya to 2030. International Institute for Applied Systems Analysis Research Report RR00-14. Laxenburg, Austria: IIASA,

Lutz, Wolfgang and Anne Goujon. 2001. The world's changing human capital stock: multi-state population projections by educational attainment. Population and Development Review 27(2): 323-39.

Lwin, Khin-Sandi. 2001. Psychosocial issues facing OVC in Namibia. In: First national conference on orphans and other vulnerable children. Windhoek 8-10 May 2001. Full Report, pp. 30-2. Organised by Directorate of Developmental Social Welfare Services, Ministry of Health and Social Services. Windhoek, Namibia: Ministry of Health and Social Services.

Löfman, Satu. 1997. Combining multitemporal landsat images for change detection. Master's thesis. Department of Forestry, University of Joensuu, Finland.

Löytönen, Markku. 2003. AIDS and Africa - when will the epidemic level off. Fennia 181(1): 1-11.

Makiwane, M.B. 1996. Why is fertility declining in South Africa: case study of Mtombo, Eastern Cape. African Population Studies 11 (1). [online]. [Cited on September 2005]. Available from: <http://www.bioline.org.br $>$

Male sex workers on increase. The Namibian, 15 November 2005.

Martín, Tessa Castro. 1995. Women's education and fertility: results from 26 Demographic and Health Surveys. Studies in Family Planning 26(4): 187-202.

Mason, Karen Oppenheim. 1997. Explaining fertility transitions. Demography 34(4): 443-54.

Matanyaire. E.J. and Emelia Timpo. 1999. The impact of HIV/AIDS on farming communities in Namibia. Windhoek, Namibia: Food and Agricultural Organization (FAO).

Mbamaonyeukwu, Chuks J. 2000. Signs of fertility transition in Nigeria. African Population Studies 15(1): 23-42. 
McKittrick, Meredith. 1995. Conflict and social change in Northern Namibia, 18501954. A dissertation submitted to the Department of History and the Committee on Graduate Studies of Stanford University in partial fulfilment of the requirements for the degree of Doctor of Philosophy.

---- 1997. Reinventing the family: kinship, marriage, and famine in Northern Namibia, 1948-1954. Social Science History 21(3): 265-96.

----. 2002. To dwell secure: generation, Christianity, and colonialism in Ovamboland. Portsmouth, NH: Heinemann.

Menken, Jane. 1979. Introduction. In: Natural fertility, edited by Henri Leridon and Jane Menken, pp. 3-13. International Union for Scientific Study of Population. Liège, Belgium: Ordina Editions.

Metsola, Lalli. 2001. The liberation narrative and the post-return life stories of Namibian former exiles. Master's thesis. Department of Sociology, University of Helsinki, Finland.

Mhloyi, Marvellous M. 1994. Fertility transition in Zimbabwe. In: The onset of fertility transition in sub-Saharan Africa, edited by Thérèse Locoh and Véronique Hertrich, pp. 87-104. Liège, Belgium: International Union for the Scientific Study of Population.

Miettinen, Kari. 2005. On the way to whiteness: Christianization, conflict and change in colonial Ovamboland, 1910-1965. Helsinki, Finland: Suomalaisen Kirjallisuuden Seura.

Morris, Jo. 1974. The black workers in Namibia. In: The role of foreign firms in Namibia, edited by Roger Murray, Jo Morris, John Dugard, and Neville Rubin, pp. 130-80. Uppsala, Sweden: Africa Publications Trust.

Mostert, W. 1989. Southern African Demographic and Health Survey: Namibia 1989. Fertility and contraception. Human Sciences Research Council (HSRC). Pretoria, South Africa: HSRC.

Moultrie, Tom A. and Rob Dorrington. 2004. Estimation of fertility from the 2001 South Africa Census data. CARe Monograph 12. Centre for Actuarial Research (CARe), University of Cape Town. Cape Town, South Africa: CARe.

Moultrie, Tom A. and Ian M. Timæus. 2002. Trends in South African fertility between 1970-1998: an analysis of the 1996 Census and the 1998 Demographic and Health Survey. Technical Report. Burden of Disease Research Unit, Medical Research Council. Tygerberg, South Africa: Medical Research Council.

----. 2003. The South African fertility decline: evidence from two censuses and a demographic and health survey. Population Studies 57(3): 265-84.

Mufune, Pempelani. 2003. Changing patterns of sexuality in northern Namibia: implications for the transmission of HIV/AIDS. Culture, Health \& Sexuality. 5(5): 425-38.

Muhwava, William. 2002a. The onset of fertility transition in Zimbabwe: a re-analysis of census and survey data using robust demographic techniques. African Population Studies 17(1): 1-17.

----. 2002b. The influence of the service availability environment on contraception during the course of fertility transition. African Population Studies 17(2): 37-60.

----. 2003. Patterns of contraceptive use at the edge of fertility transition in Zimbabwe. African Population Studies 18(1): 19-34. 
Muhwava, William and Ian Timæus. 1996. Fertility decline in Zimbabwe. Centre for Population Studies Research Paper 96-1. London: Centre for Population Studies, London School of Hygiene and Tropical Medicine, University of London.

Nahmias, A.J., J. Weiss, X. Yao, F. Lee, R. Kodsi, M. Schanfield, T. Matthews, D. Bolognesi, D. Durack, A. Motulsky, P. Kanki, and M. Essex. 1986. Evidence for human infection with an HTLV III/LAV-like virus in Central Africa. Lancet 327(8492): 1279-80.

Namibia Development Trust. 1994. Improving the legal and socio-economic situation of women in Namibia. Uukwambi, Ombalantu and Uukwanyama integrated report. Volume 1. Namibia Development Trust (NDT) with assistance from the Social Impact Assessment and Policy Analysis Corporation (SIAPAC), the Friedrich Ebert Foundation (FES), and the Centre for Applied Social Sciences (CASS). Windhoek, Namibia: NDT.

NANASO (= Namibian Network of AIDS Service Organisations). 1995. Sexual knowledge, attitudes and practices among Namibian youth. A baseline survey. Windhoek, Namibia: NANASO.

NDHS 1992 (= Namibia Demographic and Health Survey 1992). Individual Data Files NMIQ23RT.DAT, obtained from Macro International Inc. in 1993, and NMIR21RT.SAV, available from Macro International Inc. <http:/www.measuredhs.com/start.cfm>

NDHS 2000 (= Namibia Demographic and Health Survey 2000). Individual Recode Data File (NMIR41RT.SAV). Available from Macro International Inc.

$<$ http://www.measuredhs.com/start.cfm>

Newell, Colin. 1988. Methods and models in demography. Guildford and King's Lynn, Great Britain: Belhaven Press.

Nhonoli, A.M.M. 1954. An enquiry into infant mortality rate in rural areas of Unyamwezi. East African Medical Journal 31(1): 1-12.

NISER (= Namibian Institute for Social and Economic Research). 1991. National AIDS Awareness Survey. Windhoek, Namibia: University of Namibia (NISER).

Notestein, F.W. 1945. Population: the long view. In: Food for the world, edited by T.W. Schultz, pp. 36-57. Chicago, IL: Chicago University Press.

Notkola, Veijo. 1996. Parish records from Namibia 1925-1990 - an attempt to analyze fertility and mortality in Ovamboland. Yearbook of Population Studies in Finland 33: 295-305.

----. 2004. Namibia ennen aidsia ja sen puhkeamisen jälkeen [Namibia before and after AIDS]. In: Vertailevan tutkimuksen ulottuvuuksia [Dimensions of comparative research], edited by Risto Alapuro and Ilkka Arminen, pp. 233-43. Vantaa, Finland: WSOY.

Notkola, Veijo, Harri Siiskonen, Andres Vikat, and Ossi Lemström. 1998. Kuolleisuuden aleneminen Ambomaalla ja Kavangolla [Decline of Mortality in Ovamboland and Kavango]. Sosiaalilääketieteellinen Aikakauslehti 35(2): 245-56.

Notkola, Veijo and Harri Siiskonen. 2000. Fertility, mortality and migration in subSaharan Africa: the case of Ovamboland in North Namibia, 1925-90. Basingstoke, Great Britain: Macmillan Press.

Notkola, Veijo, Ian M Timæus and Harri Siiskonen. 2000. Mortality transition in the 
Ovamboland region of Namibia, 1930-1990. Population Studies 54:153-67.

----. 2004. Impact on mortality of the AIDS epidemic in northern Namibia assessed using parish registers. AIDS 18(7): 1061-5.

Ntozi, James P.M. 2002. Impact of HIV/AIDS on fertility in sub-Saharan Africa. African Population Studies 17(1): 103-24.

Ntozi, James P.M., Immaculate M. Nakanaabi, and Yovani A.M. Lubaale. 1997. Fertility levels and trends in the face of the AIDS epidemic in Uganda. Health Transition Review 7 (Suppl. 2): S145-S155.

Ojo, Kenneth and Mary Delaney. 1997. Economic and demographic consequences of AIDS in Namibia: rapid assessment of the costs. International Journal of Health Planning and Management 12(4): 315-26.

Olenick, I. 1999. Condom use increases among Namibian youths following HIV training. International Family Planning Perspectives 25(4):205-6.

Onandjokwe DDC (District Development Committee). 2003. Onandjokwe district: annual report for the year 2002/2003. Prepared by the Onandjokwe District DDC Members. Onandjokwe Lutheran Hospital. Ondangwa, Namibia: Onandjokwe DDC.

Onandjokwe Lutheran Medical Service. 1999. Annual report for Onadjokwe district for the year 1998/9. Onandjokwe Lutheran Medical Service, Onandjokwe Lutheran Hospital. Ondangwa, Namibia: Onandjokwe Lutheran Medical Service.

Oshakati Health Centre. 1994a. Family planning statistics: visitors in January, February and March, 1994.

----. 1994b. Interview of Nurse D. Namukwambi on 6th April, 1994.

Oshigambo Clinic. 1994a. Family planning register: visitors in February, March and April, 1994.

----. 1994b. Interview of family planning workers on 6th April, 1994.

Otaala, Barnabas. 2000. Discussions, recommendations and summary recommendations. In: HIV/AIDS: the challenge for tertiary institutions in Namibia, edited by Barnabas Otaala, pp. 123-51. Windhoek, Namibia: University of Namibia.

---- 2003. Introduction. In: HIV/AIDS: government leaders in Namibia responding to the HIV/AIDS epidemic, edited by Barnabas Otaala, pp. 2-4. Windhoek, Namibia: University of Namibia.

Peltola, Matti. 1958. Sata vuotta suomalaista lähetystyötä 1859-1959 II: Suomen Lähetysseuran Afrikan työn historia [100 years of Finnish missionary work 18591959 II: The history of work of Finnish Missionary Society in Africa]. Kuopio, Finland: Suomen Lähetysseura.

Peltola, Pekka. 1995. The lost May Day: Namibian workers struggle for independence. Transactions of the Finnish Anthropological Society 35. The Finnish Anthropological Society in association with the Nordic Africa Institute. Jyväskylä, Finland: Gummerus kirjapaino.

Pendleton, W., D. LeBeau, and C. Tapscott. 1992. Socio-economic study of the Ondangwa/Oshakati nexus area. The Namibian Institute for Social and Economic Research (NISER), Research Report 8. Windhoek: University of Namibia.

Pendukeni, Monika. The impact of HIV/AIDS on health care provision: perceptions of nurses currently working in one regional hospital in Namibia. Master's thesis, School of Public Health, University of Western Cape, South Africa. 
Pennington, Renee. 1992. Did food increase fertility? Evaluation of !Kung and Herero history. Human Biology 64(4): 497-521.

Phororo, Hopolang. 2001. Food crops or cash crops in the northern communal areas of Namibia: setting a framework for a research agenda. Namibian Economic Policy Research Unit (NEPRU) Working Paper 80. Windhoek, Namibia: NEPRU.

----. 2002. HIV/AIDS: who suffers in Namibia? Namibian Economic Policy Research Unit (NEPRU) Working Paper 84. Windhoek, Namibia: NEPRU.

----. 2003. HIV/AIDS and the private sector in Namibia: getting the small businesses on board. Hanns Seidel Foundation (HSF) Namibia. Occasional Paper, No. 3/2003. Windhoek, Namibia: HSF Namibia.

Phororo, Hopolang and Grace Mohamed. 2001. HIV/AIDS assessment study in the private sector. Windhoek, Namibia: NEPRU.

Phororo, Hopolang and Bruno Venditto. 2003. The economic effects of HIV/AIDS on 4 O's regions of Namibia. Namibian Economic Policy Research Unit (NEPRU) Research Report. Windhoek, Namibia: NEPRU.

Plattner, I.E. and N. Meiring. Living with HIV: the psychological relevance of meaning making. AIDS Care 18(3): 241-5.

Potts, Deborah and Shula Marks. 2001. Fertility in southern Africa: the quiet revolution. Journal of Southern African Studies 27(2): 189-205.

Poukouta, Prosper. 1994. The fertility of Herero of Ngamiland: is there evidence of recent decline? Population Research Institute Working Paper 94-19. Pennsylvania: The Pennsylvania State University.

Preston, Samuel H. 1978. Introduction. In: Reproductive change in developing countries, edited by J.Cleland, and J. Hobcraft, pp. 235-72. Oxford, Great Britain: Oxford University Press.

----. 1985. Mortality in childhood. In: Reproductive change in developing countries, edited by John Cleland and John Hobcraft, pp. 235-72. Oxford, Great Britain: Oxford University Press.

Pulkkinen, Pia. 1997. Hedelmällisyyden kulttuurinen vaihtelu Namibiassa: kokonaishedelmällisyyden ja väliintulevien tekijöiden tarkastelu Namibian etnisissä ryhmissä [Cultural differences in fertility in Namibia. Total fertility and proximate determinants among the ethnic groups of Namibia]. Master's thesis. Department of Sociology, University of Helsinki, Finland.

Raiskio, Teuvo. 1997. Oudosta kulkijasta ihmiseksi: suomalainen bushmannilähetystyö ja sen välittämä kuva bushmanneista vuosina 1950 - 1985 [From a strange wanderer to a human being: Finnish missionary work among bushmen and the image of bushmen 1950 - 1985]. Doctoral thesis, Department of History, University of Oulu, Finland.

Raitis, Riikka. 1995. Fertility in the Northwest region of Namibia. Yearbook of Population Research in Finland 32: 106-17.

Report of the Commission of Enquiry into South West Africa Affairs 1962-1963. 1964. Pretoria, South Africa: Government of Republic of South Africa.

Research Facilitation Services. 2004. Attitudes towards marriage in Namibia: executive summary. Research Facilitation Services and Health Communication Partnership, 
Based at Johns Hopkins University, Center for Communication Programs. Windhoek, Namibia: Research Facilitation Services.

Ricardo, Mukonda. 1998. HIV awareness and teenage girls'sexual motives and predispositions in Caprivi: human relations perspective. Presented to the Faculty of Humanities and Social Sciences of the University of Namibia as part of the requirement of the award of a BA (social work) degree. Windhoek, Namibia: University of Namibia.

Robinson, W.C. 1987. Regional variation in the age-specific natural fertility curve. Journal of Biosocial Science 19: 57-64.

Rompel, Matthias. 2003. "It will really knock on to everybody's door..." Die sozialen Folgen der AIDS-Epidemie in Namibia. Eine Untersuchung in Katutura and Ovamboland. Dissertation zur Erlangung des Doktorgrades (Dr. rer. soc.) des Fachbereichs Sozial- und Kulturwissenschaften der Justus-Liebig-Universität Grießen, Germany.

Ross, Amanda, Dilys Morgan, Rosemary Lubega, Lucy Carpenter, Billy Mayanja, and James A.G Whitworth. 1999. Reduced fertility associated with HIV: the contribution of pre-existing subfertility. AIDS 13(15): 2133-41.

Ross, Amanda, Lieve Van der Paal, Rosemary Lubega, Billy N. Mayanja, Leigh Anne Shafer, and Jimmy Whitworth. 2004. HIV-1 disease progression and fertility: the incidence of recognized pregnancy and pregnancy outcome in Uganda. AIDS 18(5): 799-804.

Ross, Robert. 1975. The 'white' population of South Africa in the eighteenth century. Population Studies 29(2): 217-30.

Rutenberg, Naomi and Ian Diamond. 1993. Fertility in Botswana: the recent decline and future prospects. Demography 30(2): 143-57.

Rutenberg, Naomi, Ann E. Biddlecom, and Frederick A.D. Kaona. 2000. Reproductive decision-making in the context of HIV and AIDS: a qualitative study in Ndola, Zambia. International Family Planning Perspectives 26(3):124-30.

Saarelma-Maunumaa, Minna. 2003. Edhina Ekogidho - Names as links. The encounter between African and European anthroponymic systems among the Ambo people in Namibia. Doctoral dissertation. Department of Finnish, University of Helsinki, Finland.

Salokoski, Märta. 1992. Symbolic power of kings in pre-colonial Ovambo societies. Licensiate's Thesis. Social Anthropology, Department of Sociology, Faculty of Social Sciences, University of Helsinki, Finland.

----. 2006. How kings are made - how kingship changes. A study of rituals and ritual change in pre-colonial and colonial Owamboland, Namibia. Doctoral Dissertation. Research Series in Anthropology, University of Helsinki. Helsinki, Finland: Helsinki University Printing House.

Sanderson, Warren C., Ben Fuller, Molly E. Hellmuth, and Kenneth M. Strzepek. 2001. Modeling population and sustainable development challenges in the era of HIV/AIDS. Executive summary. International Institute for Applied Systems Analysis (IIASA). Laxenburg, Austria: IIASA.

Saphonn, Vonthanak, Leng Bun Hor, Sun Penh Ly, Samrith Chhuon, Tobi Saidel, and Roger Detels. 2002. How well do antenatal clinic (ANC) attendees represent the 
general population? A comparison of HIV prevalence from ANC sentinel surveillance sites with a population-based survey of women aged 15-49 in Cambodia. International Journal of Epidemiology 31(2): 449-55.

Schwartz, Bastian. 2003. Young Namibians and HIV \& AIDS. Briefing paper based on the 2003 UNICEF Namibia AHPP Baseline Study. Windhoek, Namibia: UNICEF Namibia.

Sedgh, Gilda, Ulla Larsen, Donna Spiegelman, Gernard Msamanga, and Wafaie W. Fawzi. 2005. HIV-1 disease progression and fertility in Dar es Salaam, Tanzania. Epidemiology and Social Science 39(4): 439-45.

Shemeikka, Riikka. 1999. HIV/AIDS: the major demographic challenge of Namibia. Yearbook of Population Research in Finland 35: 65-81.

Shemeikka, Riikka and Veijo Notkola. 2005. Fertility reduction caused by HIV/AIDS and its demographic impact in northern Namibia. In: What are we doing there? Experiences and lessons learned from development cooperation in health care and social welfare (1990-2005), edited by Ursula Aaltonen and Simo Mannila, pp. 207-26. Saarijärvi, Finland: National Research and Development Centre for Welfare and Health (STAKES).

Shemeikka, Riikka, Veijo Notkola, and Harri Siiskonen. 2005. Fertility decline in North-Central Namibia: an assessment of fertility in the period 1960-2000 based on parish registers. Demographic Research [Online]. 30 August 2005, Volume 13, Article 4, Pages 83-116.

Shivute, Oswald. 2005. Thousands flock to Omhedi for crowning. The Namibian 14 November, 2005.

SIAPAC. 1997. Trends in youth sexual knowledge, attitudes and practices: 1995 to 1997. Prepared by Social Impact Assessment and Policy Analysis Corporation Ltd (SIAPAC) for READ, NANASO and the Namibian-German AIDS Control Project. Windhoek, Namibia: SIAPAC.

----. 2002. A situation analysis of orphan children in Namibia. Prepared by Social Impact Assessment and Policy Analysis Corporation Ltd. (SIAPAC) for the Ministry of Health ands Social Services and UNICEF/Namibia. Windhoek, Namibia: SIAPAC.

----. 2003. Impact assessment of HIV/AIDS on the municipalities of Ongwediva, Oshakati, Swakopmund, Walvis Bay and Windhoek. Social Impact Assessment and Policy Analysis Corporation (Pty) Ltd. (SIAPAC). Windhoek, Namibia: SIAPAC.

Sibanda, Amson, Zewdu Woubalem, Dennis P. Hogan, and David P. Lindstrom. 2003. The proximate determinants of the decline to below-replacement fertility in Addis Ababa, Ethiopia. Studies in Family Planning 34(1): 1-7.

Siiskonen, Harri (Editor). 1986. Studying the northern Namibian past: research seminar in Tvärminne, 2-4 December 1985. University of Joensuu, Faculty of Arts, Studies in History 3. Joensuu, Finland: University of Joensuu.

----. 1990. Trade and socioeconomic change in Ovamboland, 1850-1906. Studia Historica 35. Vammala, Finland: Societas Historica Fennica.

----. 1998. Migration in Ovamboland: the Oshigambo and Elim parishes 1925-1935. In: Namibia under South African rule: mobility \& containment 1915-46, edited by Patricia Hayes, Jeremy Silvester, Marion Wallace, and Wolfram Hartmann, pp. 219-40. Oxford, Great Britain: James Currey. 
Siiskonen, Harri, Anssi Taskinen, and Veijo Notkola. 2005. Parish registers: a challenge for African historical demography. History in Africa 32: 385-402.

Sinding, Steven W. 2001. Foreword. Population and Development Review 27, supplement: Global Fertility Transition, ix-x.

Slotten, R.A. 1995. AIDS in Namibia. Social Science \& Medicine 41: 277-84.

Soiri, Iina. 1996. Radical motherhood and awakening gender awareness - Namibian women's independence struggle. Uppsala, Sweden: Nordic Africa Institute.

Soiri, Iina and Pekka Peltola. 1999. Finland and national liberation in southern Africa. Stockholm, Sweden: Nordic Africa Institute.

Stanton, Bonita F., Xiaoming Li, Joshua Kahihuata, Ann M. Fitzgerald, Simeone Neumbo, Geraldus Kanduuombe, Izabel B.Ricardo, Jennifer S. Galbraith, Nancy Terreri, Irene Guevara, Hannu Shipena, Johan Strijdom, Rebecca Clemens, and R. F. Zimba. 1998. Increased protected sex and abstinence among Namibian youth following a high riskreduction intervention: a randomized, longitudinal study. AIDS 12(18): 2473-80.

Stover, John. 1998. Revising the proximate determinants framework: what have we learned in the past 20 years. Studies in Family Planning 29(3): 255-67.

Sule-Odu, A.O., O.T. Oladapo, O.E. Jagun, and J. Awosile. 2005. Microbial isolates and HIV infection in couples attending fertility clinics in Sagamu, Nigeria. Journal of Obstetrics and Gynaecology 25(7): 685-8.

Surkyn, Johan and Ron Lesthaeghe. 2004. Value orientations and the second demographic transition (SDT) in northern, western and southern Europe: an update. Demographic Research [online], Special Collection 3, Article 3. [Cited 10 November 2005]. Available from: $<$ http://www.demographic-research.org $>$

Swartz, Leon. 2003. Fertility transition in South Africa and its impact on the four major racial groups. In: Fertility: current South African issues of poverty, HIV/AIDS and youth. Seminar proceedings, pp. 7-26. Human Sciences Research Council (HSRC) and Department of Social Development. Cape Town, South Africa: HSRC Publishers.

Tabutin, Dominique and Bruno Schoumaker. 2001. Une Analyse Régionale des Transitions de Féconité en Afrique Sub-Saharienne. Paper presented at XXIV IUSSP General Population Conference, Salvador, Brazil on 18 - 24 August 2001. [Cited 30 May 2005]. Available from: <http://www.iussp.org/Brazil2001/s40/S43_02_Tabutin.pdf>

Talavera, Philippe 2002a. Challenging the Namibian sexuality. A case study of the Ovahimba and Ovaherero culture-sexual models in an HIV/AIDS context, Windhoek, Namibia: Gamsberg Macmillan.

----. 2002b. Sexual cultures in transition in the northern Kunene - is there a need for a sexual revolution in Namibia. In: Namibia society sociology, edited by Volker Winterfeldt, Tom Fox, and Pempelani Mufune, pp. 333-46. Windhoek, Namibia: University of Namibia Press.

Tanskanen, Kirsti. 2000. Kinship and family life of the Herero: ideal and reality of Herero women in Windhoek. Master's thesis. Department of Sociology, University of Helsinki, Finland.

Taskinen, Anssi. 2004. Namibiana in Finland 2: inventory of museum and photographic collections concerning Namibia in Finnish museums. University of Joensuu, Faculty of Arts, Studies in History 26. Joensuu, Finland: University of Joensuu. 
Teinonen, Seppo. A. 1949. Lähetystyö avioliiton uudistajana Ambomaalla [Mission as a reformer of matrimony in Ovamboland]. Suomalaisen Teologisen Kirjallisuusseuran julkaisuja 51. Helsinki, Finland: Suomalainen Teologinen Kirjallisuusseura.

Terceira, Nicola, Simon Gregson, Basia Zaba, and Peter R Mason. 2003. The contribution of HIV to fertility decline in rural Zimbabwe, 1985-2000. Population Studies 57(2): 149-64.

Tersbøl, Britt Pinkowsky. 2002. How to make sense of lover relationships - Kwanyama culture and reproductive health. In: Namibia society sociology, edited by Volker Winterfeldt, Tom Fox, and Pempelani Mufune, pp. 347-59. Windhoek, Namibia: University of Namibia Press.

Thomas, Duncan and Ityai Muvandi. 1994a. The demographic transition in southern Africa: another look at the evidence from Botswana and Zimbabwe. Demography 31(2): 185-207.

----. 1994b. The demographic transition in Southern Africa: reviewing the evidence from Botswana and Zimbabwe. Demography 31(2): 217-27.

Thornton, John K. 1977a. An eighteenth century baptismal register and the demographic history of Manguenzo. In: African Historical Demography I: Proceedings of a Seminar Held in the Centre of African Studies, University of Edinburgh, 29th and 30th April, 1977, edited by C. Fyfe and D. McMaster, pp. 416-428. Edinburgh, Great Britain: University of Edinburgh.

----. 1977b. Demography and history in the Kingdom of Congo, 1550-1750. Journal of African History 4: 507-30.

Timæus, Ian and Wendy Graham. 1989. Labour circulation, marriage and fertility in southern Africa. In: Reproduction and social organization in sub-Saharan Africa, edited by Ron J. Lesthaeghe, pp. 365-99. Berkeley, California: University of California Press.

Tokola, Timo, Satu Löfman, and Antti Erkkilä. 1999. Relative calibration of multitemporal Landsat data for forest area change detection. Remote Sensing of Environment 68: 1-11.

Tuupainen, Maija. 1970. Marriage in a matrilineal African tribe: a social anthropological study of marriage in the Ondonga tribe in Ovamboland. Transactions of the Westermarck Society XVIII. Forssa, Finland: Westermarck Society.

Tönjes, Hermann. 1996. Ovamboland. Country, people, mission. With particular reference to the largest tribe, the Kwanyama. Reprinted from 1911. Western Cape, South Africa: Namibia Scientific Society.

Uchudi, Joseph Masudi. 2000. Socio-economic factors and fertility differences in subSaharan Africa: does the spouse's education matter? African Population Studies 15(2): 27-42.

Udjo, Eric. O. 1998. Trends in level and tempo of fertility in Botswana. Genus LIV(34): $285-301$.

UNAIDS (= Joint United Nations Programme on AIDS). 2005a. Three Scenarios. [online]. Geneva, Switzerland: UNAIDS. [Cited on 4 March 2005]. Available from: $<$ http://www.unaids.org/en/AIDS+in+Africa_Three+scenarios+to+2025.asp>

----. 2005b. General information about HIV and AIDS. [online]. Geneva, Switzerland: 
UNAIDS. [Cited in September 2005]. Available from:

$<$ http://www.unaids.org/en/resources/faq/faq general+information+about+hiv + and+aids.asp $>$

----. 2006. 2006 report on the global AIDS epidemic. A UNAIDS 10th anniversary special edition. [online]. Geneva, Switzerland: UNAIDS. [Cited in June 2006]. Available from: $<$ http://www.unaids.org/en/HIV_data/2006GlobalReport/default.asp $>$

UNICEF (= United Nations Children's Fund) Namibia. 1990. Household health and nutrition survey. Report on a survey in Katutura and selected northern areas of Namibia in April-May 1990. UNICEF Namibia, Ministry of Health and Social Services, and Food Studies Group, University of Oxford. Windhoek, Namibia: UNICEF.

----. 1991. A situation analysis of children and women in Namibia. UNICEF Namibia and the Namibian Institute of Social and Economic Research (NISER), University of Namibia, in consultation with the Government of Republic of Namibia. Windhoek, Namibia: UNICEF.

----. 2002. Young people in northern Namibia: assessing communication around HIV prevention. Final report of discussion group sessions 18-22 November 2002, Oshakati, Namibia. A research exercise conducted under the "Right to Know" initiative. Windhoek, Namibia: UNICEF.

UNDP (= United Nations Development Programme) Namibia. 1997. Namibia human development report 1997. The impact of HIV and AIDS in Namibia. The United Nations Development Programme in Namibia. Windhoek, Namibia: UNDP.

----. 2000. Namibia human development report 2000/2001. Gender and violence in Namibia. The United Nations Development Programme in Namibia. Windhoek, Namibia: UNDP.

United Nations. 1983. Manual X: indirect techniques for demographic estimation. Population Studies 81. United Nations, Department of International Economic and Social Affairs. New York, NY: United Nations.

---- 1990. Development and fertility decline: a review of some theoretical approaches. ST/ESA/SER.R/102. New York, NY: United Nations.

----. 2002. Abortion policies: a global review. United Nations Population Division, Department of Economic and Social Affairs. New York, NY: United Nations.

----. 2003. The impact of HIV/AIDS on mortality. Workshop of HIV/AIDS and adult mortality in developing countries, New York, 8-13 September 2003. United Nations Population Division, Department of Economic and Social Affairs. New York, NY: United Nations.

----. 2004. World fertility report 2003. United Nations Population Division, Department of Economic and Social Affairs. New York, NY: United Nations.

Van den Bos, C. and L.S.P. Vesentini. 1999. Determinants of condom use among Namibian youngsters. Department of Health Education and Promotion, Faculty of Health Sciences, University of Maastricht. Maastricht: University of Maastricht.

Van der Merwe, I.J. 1989. The role of war in regional development and urbanization of Namibia. African Urban Quarterly 4(1-2): 263-74.

Van Dillen, Jeroen, Tarek Meguid, and Jos van Roosmalen. 2006. Acta Obstetricia et Gynecologia 85: 499-500. 
Van Zyl, Deon. 2003. An overview of HIV-related research in Namibia since independence. Windhoek, Namibia: Institute for Public Policy Research.

Van Zyl, Deon and Dirk Spilker. 2001. Contracting HIV/AIDS: high-risk sexual behaviour among Namibian youth. Institute for Public Policy Research Briefing Paper 3. Windhoek, Namibia: Institute for Public Policy Research.

Voipio, Rauha. 1980. Sopimustyö ambolaisen silmin [Contract work from an Ovambo viewpoint]. In: Namibia: viimeinen siirtomaa [Namibia: the last colony], edited by Kimmo Kiljunen and Marja-Liisa Kiljunen, pp. 117-57. Helsinki, Finland: Tammi.

Webb, Douglas and David Simon. 1995. Migrants, money and the military: the social epidemiology of HIV/AIDS in Owambo, northern Namibia. The Namibian Economic Policy Research Unit (NEPRU), Occasional Paper No. 4. Windhoek, Namibia: NEPRU.

Weiss, Holger. 1999. "They did not want us to be here”: the beginning of Finnish missionary activity in Northern Namibia and its first setbacks, 1869-1871. Institute of Development Studies, Working paper 1/1999. Helsinki: University of Helsinki.

Westoff, Charles F. and Anne R. Cross. 2006. The stall in the fertility transition in Kenya. DHS Analytical Studies 9. Calverton, Maryland: ORC Macro.

WHO (= World Health Organization). 2004. Scaling up antiretroviral therapy in resource-limited settings: treatment guidelines for a public health approach. 2003 revision. Geneva, Switzerland: World Health Organization.

----. 2005. Antiretroviral drugs for the treatment of HIV infection in adults and adolescents in resource-limited settings. Recommendations for a public health approach (2005-2006 revision). Guidelines Development Group, Brief Meeting Report. Montreux, Switzerland 22-23 $3^{\text {rd }}$ June 2005. Geneva, Switzerland: World Health Organization.

WHO (= World Health Organization) and UNAIDS (= Joint United Nations Programme on AIDS). 2003. Reconciling antenatal clinic-based surveillance and population-based survey estimates of HIV prevalence in sub-Saharan Africa. [online]. Available from: <http://www.who.int>

---. 2006. Progress on global access to HIV antiretroviral therapy: a report on "3 by 5 " and beyond. [online]. Geneva, Switzerland: WHO and UNAIDS. [Cited in June 2006]. Available from: <http://www.who.int/hiv/fullreport_en_highres.pdf $>$

Williams, Frieda-Nela. 1988. Migration and settlement in Ovamboland 1600-1900. Master' Thesis. Department of History, University of Joensuu, Finland.

----. 1991. Precolonial communities of southwestern Africa: a history of Ovambo Kingdoms 1600-1920. Archeia 16. Windhoek, Namibia: National Archives of Namibia.

Wils,A.1996.PDE-Cape Verde: asystems studyofpopulation, development, and environment. International Institute for Applied Systems Analysis (IIASA), Working PaperWP-96-009 Laxenburg, Austria: IIASA.

Wils, Annababette and Anne Goujon. 1998. Diffusion of education in six world regions, 1969-90. Population and Development Review 24(2): 358-68.

Winkler, Eike Meinrad and Sylvia Kirchengast. 1994. Body dimensions and differential 
fertility in !Kung San males from Namibia. Human Biology 6(2): 203-13.

Winterfeldt, Volker. 2002. Labour migration in Namibia - gender aspects. In: Namibia society sociology, edited by Volker Winterfeldt, Tom Fox, and Pempelani Mufune, pp. 39-74. Windhoek, Namibia: University of Namibia Press.

World Bank. 2001. Namibia: selected development impact of HIV/AIDS. Macroeconomic Technical Group, Africa Region. Report No. 22046-NAM. Wold Bank.

Wrigley, E.A. (Editor). 1966. An introduction to English historical demography. London, Great Britain: Weidenfeld and Nicolson.

Yamakawa, S. 2001. Adolescent sexuality in Namibia: an analysis of sexual knowledge, attitudes and practices among secondary school learners in Katutura, Windhoek. Windhoek, Namibia: UNICEF.

Yaron, Gil, Gertie Janssen, and Usutuaije Maamberua. 1992. Rural development in the Okavango region of Namibia: an assessment of needs, opportunities and constraints. Windhoek, Namibia: Gamsberg Macmillan.

Zaba, Basia and Martine Collumbien. 1997. HIV and fertility: modelling the effects of changes in union dynamics. International Population Conference Beijing 1997, Vol. 2, pp. 583-609. Liège, Belgium: International Union for the Scientific Study of Population (IUSSP).

Zaba, Basia and Simon Gregson. 1998. Measuring the impact of HIV on fertility in Africa. AIDS, 12 (Suppl. 1): S41-S50.

Zaba, Basia W., Lucy M. Carpenter, J. Ties Boerma, Simon Gregson, Jessica Nakiyingi, and Mark Urassa. 2000. Adjusting ante-natal clinic data for improved estimates of HIV prevalence among women in sub-Saharan Africa. AIDS 14(17): 2741-50.

Zeller, Wolfgang. 1998. Development aid and institutional change in rural northeastern Namibia: White Toyotas and dust devils in Ibbu. Institute of Development Studies, Working papers 12/98. Helsinki, Finland: University of Helsinki.

Zeller, Wolfgang. 2000. Faites vos jeux! Interests and socio-economic development in the Caprivi-region from a historical perspective. Namibian Economic Policy Research Unit (NEPRU), Occasional paper 19. Windhoek, Namibia: NEPRU.

Zhu, Tuofu, Bette T. Korber, Andre J. Nahmias, Edward Hooper, Paul M. Sharp, and David D. Ho. 1998. An African HIV-1 sequence from 1959 and implications for the origin of the epidemic. Nature 391(6667):594-7.

Zimba, R.F and M.L. Mostert. 1992. The Namibian secondary school students' cognitive, attitudinal and behavioural risks that may promote HIV infection and the spread of AIDS. Department of Educational Psychology, University of Namibia. Windhoek, Namibia: University of Namibia. 



\section{Appendices}

Appendix Table 1. Marriages and excluded marriages by parish and marriage cohort 1956-1995 in parish-register data in Ovamboland

\begin{tabular}{|c|c|c|c|c|c|c|c|c|}
\hline & \multicolumn{4}{|c|}{ Elim } & \multicolumn{4}{|c|}{ Nakayale } \\
\hline & All & Excl. A & Excl. B & Final & All & Excl. A & Excl. B & Final \\
\hline $1956-1965$ & 495 & 9 & 21 & 474 & 240 & 17 & 3 & 223 \\
\hline $1966-1975$ & 261 & 9 & 23 & 234 & 189 & 36 & 18 & 153 \\
\hline 1976-1985 & 165 & 82 & 21 & 83 & 118 & 47 & 22 & 71 \\
\hline 1986-1995 & - & - & - & - & 127 & 92 & 75 & 34 \\
\hline $1996-2000$ & - & - & - & - & 113 & 94 & 72 & 17 \\
\hline \multirow[t]{3}{*}{ All } & 921 & 100 & 65 & 791 & 787 & 286 & 190 & 498 \\
\hline & \multicolumn{4}{|c|}{ Okahao } & \multicolumn{4}{|c|}{ Oshigambo } \\
\hline & All & Excl. A & Excl. B & Final & All & Excl. A & Excl. B & Final \\
\hline $1956-1965$ & 453 & 31 & 22 & 422 & 472 & 26 & 38 & 431 \\
\hline $1966-1975$ & 583 & 76 & 21 & 507 & 340 & 9 & 19 & 318 \\
\hline 1976-1985 & 305 & 87 & 17 & 218 & 232 & 89 & 4 & 142 \\
\hline 1986-1995 & 273 & 125 & 11 & 147 & 140 & 70 & 2 & 70 \\
\hline $1996-2000$ & 126 & 60 & 4 & 66 & 102 & 68 & 7 & 34 \\
\hline \multirow[t]{3}{*}{ All } & 1740 & 379 & 75 & 1360 & 1286 & 262 & 70 & 995 \\
\hline & \multicolumn{4}{|c|}{ Tshandi } & \multicolumn{4}{|c|}{ Onankali } \\
\hline & All & Excl. A & Excl. B & Final & All & Excl. A & Excl. B & Final \\
\hline $1956-1965$ & 393 & 39 & 21 & 354 & - & - & - & - \\
\hline $1966-1975$ & 240 & 57 & 29 & 183 & - & - & - & - \\
\hline $1976-1985$ & 124 & 39 & 20 & 85 & 82 & 29 & 21 & 53 \\
\hline 1986-1995 & 136 & 71 & 33 & 65 & 160 & 69 & 29 & 90 \\
\hline $1996-2000$ & 51 & 40 & 26 & 11 & 92 & 56 & 14 & 36 \\
\hline \multirow[t]{2}{*}{ All } & 944 & 246 & 129 & 698 & 334 & 154 & 64 & 179 \\
\hline & \multicolumn{4}{|c|}{ Omulonga } & \multicolumn{4}{|c|}{ Oshitutuma } \\
\hline
\end{tabular}

1956-1965

1966-1975

1976-1985

1986-1995

1996-2000

-

All

-
65
88

-

$$
\text { - }
$$

$196 \quad 92$

2

7

10

$\begin{array}{rr}- & - \\ - & - \\ 24 & 10 \\ 72 & 27 \\ 50 & 29 \\ 146 & 66\end{array}$

$19 \quad 103$

\begin{tabular}{lrrrr}
\cline { 2 - 5 } & \multicolumn{4}{c}{ All } \\
\cline { 2 - 5 } & Excl. A & Excl. B & Final \\
$1956-1965$ & 2053 & 122 & 105 & 1904 \\
$1966-1975$ & 1613 & 187 & 110 & 1395 \\
$1976-1985$ & 1115 & 404 & 110 & 710 \\
$1986-1995$ & 996 & 495 & 160 & 497 \\
$1996-2000$ & 577 & 377 & 142 & 197 \\
All & 6354 & 1585 & 627 & 4703
\end{tabular}

Notes:

All $=$ Number of marriages in the data

Excl. $A=$ Number of marriages excluded because information about the marriage is incomplete

Excl. $\mathrm{B}=$ Number of marriages excluded because information following the marriage does not exist (i.e. the couple is present in only one main book)

Note: Excl. A and Excl. B are not mutually exclusive.

Final $=$ Number of marriages after the two exclusions 
Appendix Table 2. Births and excluded births by birth cohort in parish-register data in Ovamboland (marriage cohorts 1956-2000)

\begin{tabular}{|c|c|c|c|c|c|c|c|c|c|c|}
\hline & \multicolumn{5}{|c|}{ Elim } & \multicolumn{5}{|c|}{ Nakayale } \\
\hline & All & Excl. A & Excl. B & Excl. $C$ & Final & All & Excl. A & Excl. B & Excl. $C$ & Final \\
\hline 1950-1959 & 173 & 1 & - & 9 & 163 & 130 & - & - & 13 & 117 \\
\hline 1960-1969 & 1155 & - & - & 27 & 1128 & 656 & 2 & - & 22 & 632 \\
\hline $1970-1979$ & 1050 & 4 & 2 & 28 & 1016 & 611 & 6 & 6 & 48 & 551 \\
\hline 1980-1989 & 421 & 7 & 1 & 23 & 390 & 371 & 8 & 4 & 28 & 331 \\
\hline $1990-2000$ & 62 & 1 & - & 1 & 60 & 144 & 26 & 7 & 10 & 103 \\
\hline $2001-$ & 1 & - & - & - & 1 & 14 & 8 & 5 & - & 6 \\
\hline \multirow[t]{3}{*}{ All } & 2862 & 13 & 3 & 88 & 2758 & 1926 & 50 & 22 & 121 & 1740 \\
\hline & \multicolumn{5}{|c|}{ Okahao } & \multicolumn{5}{|c|}{ Oshigambo } \\
\hline & All & Excl. A & Excl. B & Excl. $C$ & Final & All & Excl. A & Excl. B & Excl. $C$ & Final \\
\hline 1950-1959 & 160 & - & - & 58 & 102 & 190 & 1 & - & 29 & 160 \\
\hline $1960-1969$ & 1528 & 22 & 2 & 499 & 1005 & 995 & 6 & - & 23 & 966 \\
\hline $1970-1979$ & 2320 & 34 & 4 & 786 & 1496 & 1355 & 17 & 1 & 18 & 1319 \\
\hline 1980-1989 & 1122 & 33 & 8 & 127 & 954 & 699 & 35 & - & 20 & 644 \\
\hline $1990-2000$ & 500 & 32 & 3 & 38 & 427 & 419 & 48 & - & 22 & 349 \\
\hline 2001- & 11 & 1 & 1 & - & 10 & 14 & 2 & - & - & 12 \\
\hline \multirow[t]{3}{*}{ All } & 5641 & 122 & 18 & 1508 & 3994 & 3672 & 109 & 1 & 112 & 3450 \\
\hline & \multicolumn{5}{|c|}{ Tshandi } & \multicolumn{5}{|c|}{ Onankali } \\
\hline & All & Excl. A & Excl. B & Excl. C & Final & All & Excl. A & Excl. B & Excl. $C$ & Final \\
\hline $1950-1959$ & 277 & - & 2 & 117 & 158 & 8 & 5 & - & 3 & - \\
\hline 1960-1969 & 885 & 8 & 8 & 128 & 741 & 42 & 6 & 3 & 29 & 4 \\
\hline $1970-1979$ & 894 & 21 & 23 & 75 & 776 & 122 & 15 & 8 & 90 & 11 \\
\hline 1980-1989 & 510 & 21 & 10 & 33 & 450 & 258 & 16 & 16 & 77 & 152 \\
\hline $1990-2000$ & 214 & 15 & 5 & 17 & 182 & 348 & 37 & 12 & 22 & 283 \\
\hline 2001- & 3 & - & - & - & 3 & 29 & 10 & 5 & - & 19 \\
\hline All & 2783 & 65 & 48 & 370 & 2310 & 807 & 89 & 44 & 221 & 469 \\
\hline
\end{tabular}




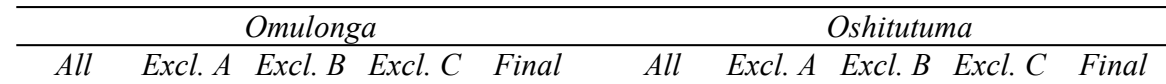

\begin{tabular}{lrrrrr} 
1950-1959 & 2 & - & - & 1 & 1 \\
$1960-1969$ & 8 & - & - & 8 & \\
$1970-1979$ & 47 & 11 & - & 32 & 4 \\
$1980-1989$ & 196 & 26 & - & 60 & 110 \\
$1990-2000$ & 198 & 25 & - & 45 & 128 \\
$2001-$ & 8 & 2 & - & & 6 \\
All & 459 & 64 & - & 146 & 249 \\
\cline { 2 - 6 } & \multicolumn{5}{c}{ All } \\
\cline { 2 - 6 } & All & Excl. A & Excl. B & Excl. C & Final \\
$1950-1959$ & 940 & 7 & 2 & 230 & 701 \\
$1960-1969$ & 5270 & 44 & 13 & 737 & 4476 \\
$1970-1979$ & 6405 & 111 & 44 & 1079 & 5174 \\
$1980-1989$ & 3655 & 151 & 39 & 395 & 3077 \\
$1990-2000$ & 2038 & 197 & 30 & 186 & 1638 \\
$2001-$ & 92 & 24 & 11 & - & 68 \\
All & 18400 & 534 & 139 & 2627 & 15134
\end{tabular}

Notes:

All $=$ Number of births in the data

Excl. A = Number of births excluded due to poor follow-up of the marriage

Excl. $\mathrm{B}=$ Number of births excluded because the mother's date of birth is missing

Note: Excl. A and Excl. B are not mutually exclusive.

Excl. $\mathrm{C}=$ Number of births excluded because the mother was not in follow-up at the time the birth took place, or because the mother's age was under 15 or over 50 .

Final $=$ Number of births on which the analysis of fertility is based.

Note: There were 81 children whose birth date was missing and 110 children who were born before 1950. All these children were excluded from the analysis. 



\title{
Original publications
}

\section{Fertility in the Northwest Region of Namibia}

\author{
RIIKKA RAITIS
}

\author{
Lecturer \\ Department of Sociology \\ University of Helsinki \\ Helsinki, Finland
}

\begin{abstract}
The aim of this paper is to examine fertility in the Northwest Region of Namibia and the effects the principal proximate determinants have on fertility. The main data sources are the 1991 Population and Housing Census and the Namibia Demographic and Health Survey (NDHS) 1992. Indirect methods are used to estimate fertility, the Crude Birth Rate (CBR) and mortality on the basis of the census data and direct methods to calculate fertility from retrospective birth histories of NDHS data.

The level of fertility is higher in the Northwest Region than in other regions of the country. The first principal proximate determinant, the marriage pattern, seems to sustain high fertility in the Northwest Region compared to the South and Central Regions, but not in respect to the Northeast Region. Postpartum insusceptibility is longer in the Northwest Region than in Namibia on average, but shorter than in the Northeast Region. The use of contraceptives is exceptionally low in the Northwest Region compared to the other regions. The ideal number of children is highest in the Northwest Region. The levels of infant and child mortality are relatively low in the Northwest Region and in Namibia on average.
\end{abstract}

Keywords: fertility, proximate determinants of fertility, family planning, Namibia

\section{Introduction}

The aim of this paper is to examine fertility in the Northwest Region of Namibia and the effects the principal proximate determinants have on fertility. Comparisons with the other regions of Namibia and some sub-Saharan African countries are also made.

The regional division used in this paper is based on the 27 old districts of Namibia. The census data have been published based on this division. The collection of the Namibia Demographic and Health Survey (NDHS) data is also based on the old districts of Namibia. In the NDHS and this paper, these districts are used to build four larger regional units, i.e. the Northwest, Northeast, Central and South Regions. For example, the Northwest Region consists of the districts of Oshakati and Ondangwa. The Northwest Region is the area this paper is focusing on; historically this area was known as Ovamboland. At the time of the census and the NDHS, the Walvis Bay area was not part of Namibia; so it is excluded from both data-sets. 
Compared to some neighboring countries, the level of fertility is about the same in Namibia as in Zimbabwe. It is higher than in the Republic of South Africa and Botswana and lower than in Angola and Zambia (Cleland 1994, 72; RoN 1993a, 20).

The high level of fertility in sub-Saharan Africa has been affected by the early and universal marriage pattern, the low proportion of women using contraceptives and prolonged breastfeeding. Breastfeeding, causing long postpartum amenorrhoea, together with postpartum abstinence have traditionally been the most important factors reducing fertility below its maximum biological level. The ideal number of children and infant and child mortality have been high (e.g. Cochrane and Farid 1989).

During the last decade, however, there has been evidence showing that this pattern is not as stable as it has been assumed to be. A change has occurred in the reproductive behavior of women in some African countries, e.g. in the Republic of South Africa, Zimbabwe, Botswana, Kenya and parts of Nigeria. Some estimates show that fertility might be declining also in Namibia. In contrast to Botswana, the Republic of South Africa and Zimbabwe, the two Northern neighbors of Namibia, i.e. Angola and Zambia, do not yet show evidence of a fertility decline. Zambia is, according to some estimates, one of the African countries where the fertility transition may occur next. The decline of fertility has been associated with the increase in the use of contraceptives. This change has been explained by the rise in the level of female education, increased economical stress on large families, decreased infant and child mortality and increased official support to family planning services (Caldwell et al. 1992; Cleland 1994).

Infant and child mortality rates are slightly higher in Namibia than in Zimbabwe and Botswana, but much lower than in Zambia. Life expectancy at birth is longer in Southern Africa than in other parts of the continent (Bucht 1994, 149; IRD 1990; RoN 1993a, 69).

The infant mortality rate is 57 per 1,000 live births (rates are for the period $0-4$ years preceding the NDHS 1992). The child mortality rate is 28 per 1,000 live births. Comparing to the periods 5-9 years and 10-14 years before the survey, both infant and child mortality have slightly declined (RoN 1993a, 68-69).

Child mortality is slightly lower in urban than in rural areas, but the infant mortality rate is almost the same. Differences related to educational level are also small. The only clear pattern is lower child mortality among women with a secondary or higher education compared with children of women with a lower educational level. Usually the educational level of the mother has a stronger declining effect on infant mortality in sub-Saharan Africa. Regional differences in infant and child mortality are more significant. Levels of infant and child mortality are highest in the Northeast Region. The infant mortality rate is about the same in the Northwest Region as in the combined South and Central Regions. The most common causes of child mortality are diarrhoea, measles and acute respiratory infections. Malaria is a serious health problem especially in northern Namibia and tuberculosis in the southern part of the country (IRD 1990; NISER and UNICEF 1991; RoN 1993a, 68-69).

According to indirect estimates of mortality based on census data, life expectancy at birth (two years before the 1991 census) was about 60 years in Namibia on average and 61 years in the Northwest Region.

The population growth rate is high in Namibia. The annual growth rate was $3 \%$ between the years 1981 and 1991 on average. The growth rate in the Northwest Region is about the same as the national average (RoN 1992, 15).

According to the 1991 census, 1.4 million people live in Namibia. The population of the districts of Oshakati and Ondangwa are 384,815 and 233,302 , respectively. Together these two districts form the Northwest Region, where $44 \%$ of the country's total population lives on $6 \%$ of its total area (RoN 1992, 1993b). 
The area of Namibia is very sparsely populated. The population density of the whole country is 1.7 persons per square kilometer. The population distribution is very uneven, however, due to the apartheid policy before independence and variations in natural conditions. In the Northwest Region population density is 12 persons per square kilometer. The proportion of urban population is $32 \%$ in Namibia and $7 \%$ in the Northwest Region (RoN 1992, 1993b).

The age structure of Namibia is young. According to the 1991 census, $42 \%$ of the population is $0-14$ years old. The dependency ratio (the ratio of population under 15 years of age or over 64 years of age per 100 of population aged 15-64 years) is 87 in Namibia. The proportion of young and elderly people is larger in the Northwest Region than in Namibia on average. The dependency ratio is 113 in the Northwest Region.

The sex ratio (number of men per 100 women) is 95 in Namibia. In urban areas, however, men form the majority. In the Northwest Region the difference between the number of women and men is larger than in the whole country on average. The sex ratio is 82 in the Northwest Region and women are the majority in both urban and rural areas.

Population pyramids clearly show the small proportion of people in working ages, especially that of males, in the Northwest Region (Figure 1). One important reason for this is labor migration to the other parts of the country.

Fig u re 1. Population pyramids of Namibia and the Northwest Region.
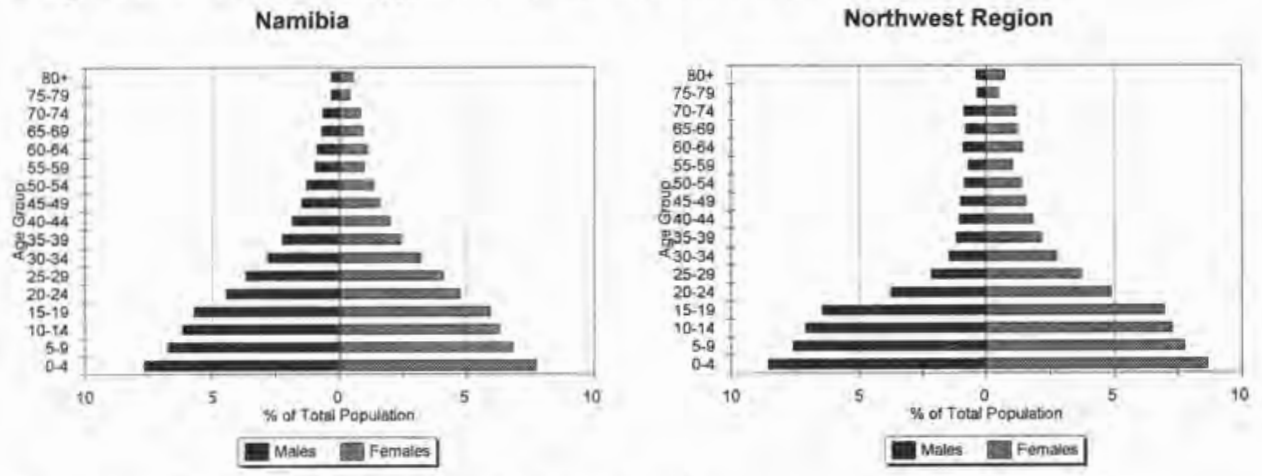

Data Source: RoN 1993c, Tables C01 and C01a.

About half of the population (50.6\%) in Namibia speaks Ovambo languages. The next largest language groups are Nama/Damara (12.5) \%, Kavango languages $(9.7 \%)$, Afrikaans $(9.5 \%)$ and Herero languages $(8 \%)$. The Northwest Region is very homogeneous in respect to languages: almost $99 \%$ of population speaks Ovambo languages.

\section{Data and methods}

This paper will mostly be based on the 1991 Population and Housing Census tables published in 1993 (RoN 1993b, 1993c, 1993d) and on the report and data of the Namibia Demographic and Health Survey (NDHS) 1992 (NDHS 1992; RoN 1993a). The census data are used for indirect estimates of fertility, the Crude Birth Rate (CBR) and mortality and for calculating general demographic indicators of population structure. 
The NDHS 1992 is a nationwide sample survey of 5,421 women aged 15-49 years. The aim of the survey was to provide information on fertility, family planning, child mortality and maternal and child health. The survey is part of the worldwide Demographic and Health Survey Program administered by Macro International Inc., Columbia, Maryland, USA and funded by the World Bank. The NDHS dataset used in some of the calculations in this paper has been obtained from Macro International Inc. Since Namibia achieved her independence in 1990, the 1991 census was the first national census of Namibia and the NDHS 1992 was the first national fertility survey (RoN 1993a).

Indirect fertility estimates from the census data have been done using the Brass method based on comparison of period fertility rates with reported average parities, i.e. the P/F ratio method (United Nations 1983). The idea of this method is to combine the age pattern of the period fertility rates with the level of fertility implied by the average parities of women younger than age 30 or 35 years. Observed age-specific fertility rates derived from data on births during the 12 months preceding the census are assumed to represent the true age pattern of fertility. These are adjusted to agree with the level of fertility indicated by average parities of women in younger age groups. The data on average parities are obtained from the census question about ever-born children.

Indirect mortality estimates from the census data have been made using Trussel's variant of the original Brass method of estimation of child mortality from information on children ever born and children surviving (United Nations 1983). The basic idea is that the proportion of children who have died of the children ever born to women in five-year age groups can be converted into estimates of probability of dying between birth and age $x$, i.e. $q(x)$.

The age pattern of fertility determines the children's length of exposure to the risk of dying in the different age groups of women. Therefore, an adjustment factor is used. This factor is the function of the average parity ratios indicating the age pattern of fertility and coefficients based on Coale-Demeny's Regional Model Life Tables (Coale and Demeny 1983). The Regional Model Life Tables are used in order to take into account the differences in the age pattern of mortality. In this study, the Model Life Tables West have been used. The probability of surviving $1(x)$, i.e. the complement of probability of dying between birth and age $x$, can be converted into mortality levels in the Coale-Demeny Regional Model Life Tables. Trussel's variant also gives an estimate of the time period to which the probabilities refer.

Direct estimates of age-specific fertility rates are calculated from retrospective birth histories in the NDHS 1992. Births occurring to a specific aggregate of women are classified by terms of (1) period, i.e. completed years before the interview when the birth of a child occurred, (2) age, i.e. the completed years of mother at birth of the child and (3) cohort, i.e. women's age at the time of the interview (Verma 1980).

For a woman in cohort $\mathrm{c}$, the total exposure during the period $\mathrm{p}$ is divided into two parts: number of months spent in age a and the number of months spent in the previous age, depending on the month of her birthday and the month of the interview. Birth of a child to a woman in cohort $c$ during the period $p$ may occur at the woman's age a or at her previous age, depending upon the relationship between the month of the birth of the woman, the month of the interview and the month of the birth of her child. Births occurring at age a and previous age during a period $p$ and length of exposure spent at age a and previous age during the period $\mathrm{p}$ are calculated for each individual woman in a cohort c. Data of individual women are aggregated in five year periods, five-year age groups of retrospective ages and five-year age groups for cohorts. ASFRs and TFR are calculated for the period $0-4$ years before the survey. 


\section{Fertility level}

According to the NDHS 1992, the Total Fertility Rate (TFR) is 5.4 children per woman (for the period 0-3 years preceding the survey) (RoN 1993a). Indirect estimates of the census data result in a somewhat higher TFR, i.e. 5.9 (for the 12-month period preceding the census). Due to a smaller variety of background variables in the census both NDHS and census data are used in this article.

According to indirect fertility estimates based on census data, fertility is highest in the Northwest Region, where the TFR is 6.9. In the Northeast Region the TFR is almost as high, or 6.7. TFR is 5.5 and 4.2 in the Central and South Regions, respectively.

NDHS gives a lower TFR for every region: 6.7 in the Northwest Region, 6.0 in the Northeast Region, and 4.1 in the combined South and Central Regions (RoN 1993a).

The age pattern of fertility varies between the regions of Namibia (Figure 2). In the Northwest Region the peak level of fertility is in a relatively old age group, i.e. among the 30-34 year-old women. The fertility peak is wide: the fertility of age groups 25-29 and 35-39 is also high. In the Northeast Region the highest fertility levels are in younger age groups than in the Northwest Region. The fertility peak is composed of three age groups also in the Northeast Region, i.e. age groups 20-24, 25-29 and 30-34. In the Central and South Regions the fertility pattern is totally different from the pattern in the Northwest Region. Age-specific fertility rates are highest among women in age group 20-24 in the Central Region and those in age groups 20-24 and

Fig u re 2. Age-specific fertility rates by region.

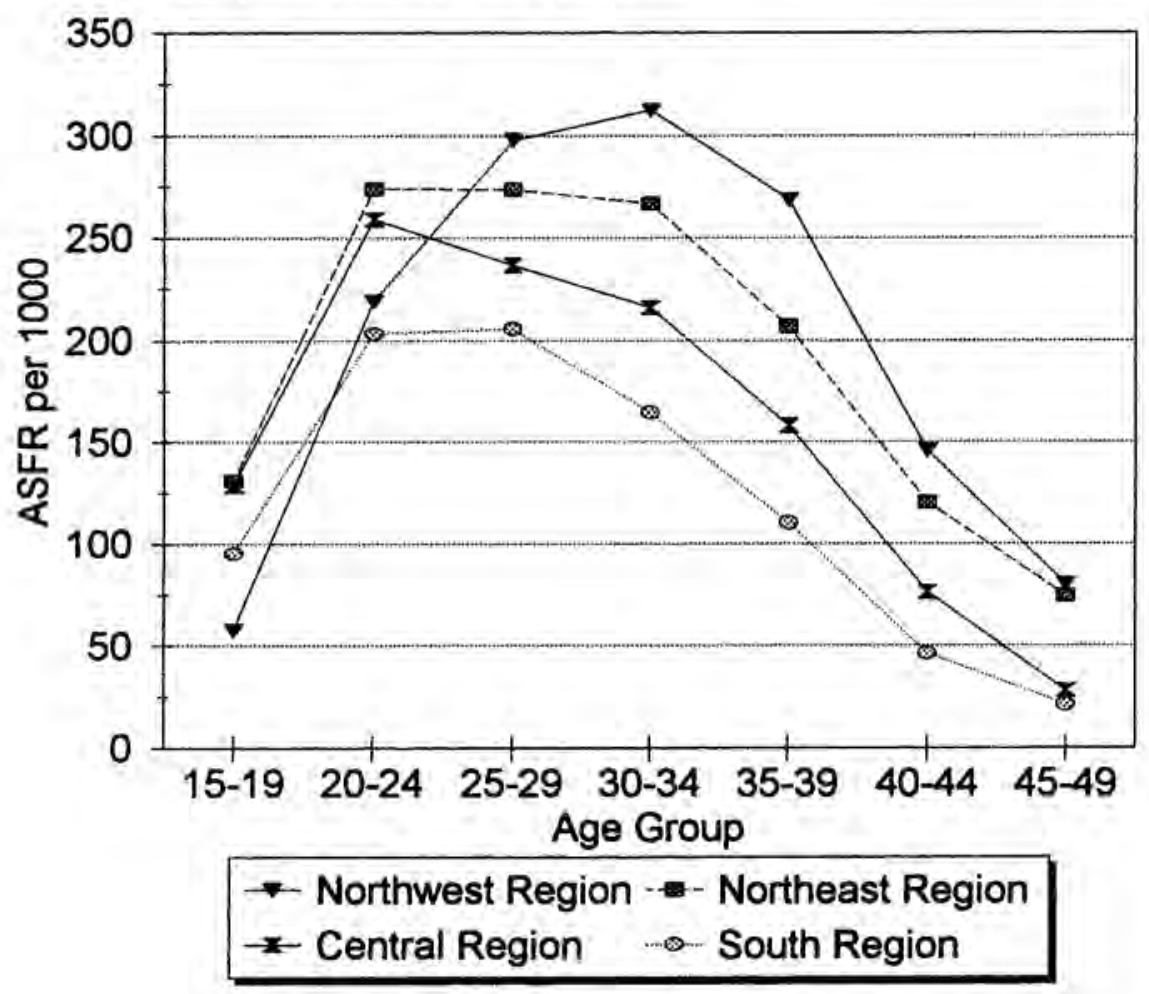

Data source: RoN 1993d, Tables F01 and F06. 
F i g u r e 3. Total fertility rates by district.

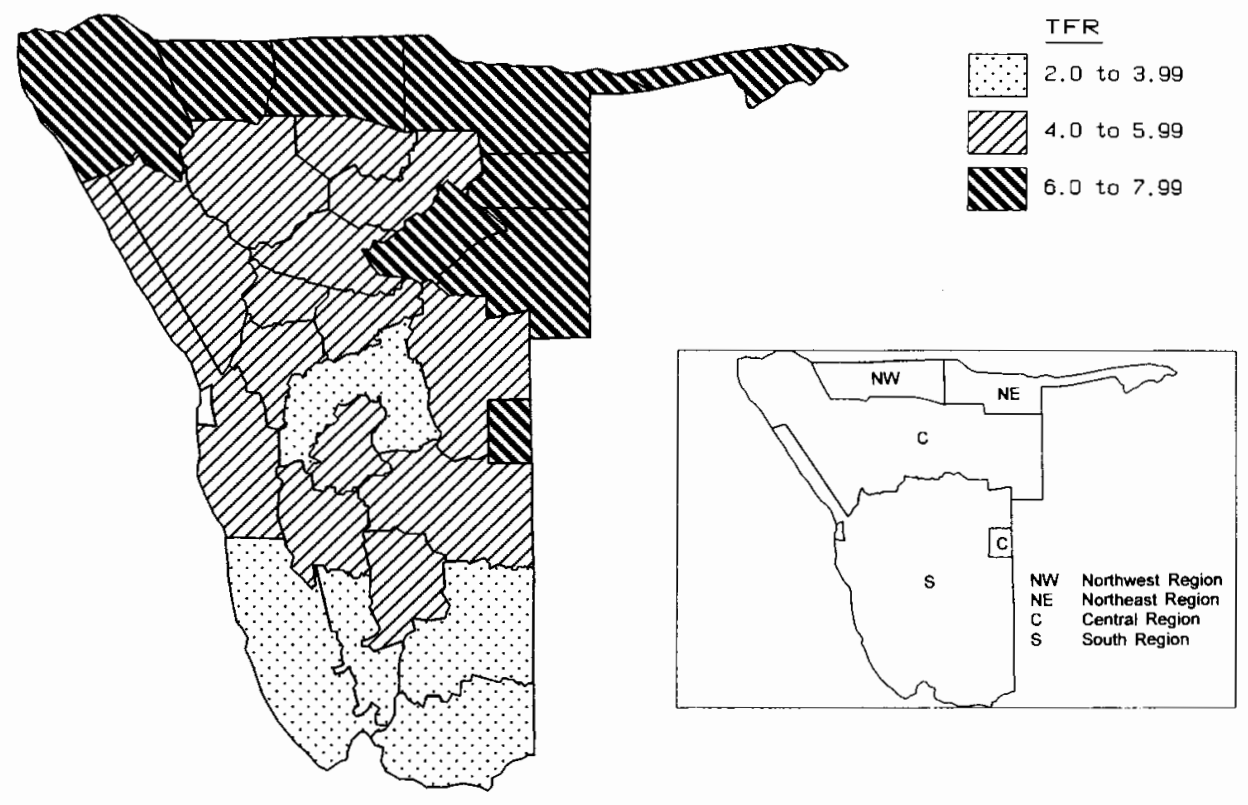

Data source: RoN 1993d, Tables F01 and F06.

25-29 in the South Region. Age-specific fertility rates are based on indirect census estimates.

The large regions mentioned above are not homogeneous in respect to fertility (Figure 3). Circumstances and populations vary in different parts of the country. For instance, the proportion of women over 15 years of age speaking »European» languages, i.e. Afrikaans, English, German and other European languages, is less than $2 \%$ in all of the districts where the TFR level is over 6 . The proportion of women speaking these languages varies from $36.3 \%$ to $66.6 \%$ in districts where the TFR is below 4 .

Fertility differs according to the urbanization of the place of residence and the socioeconomic status of women. According to the NDHS, fertility is higher in rural areas (TFR 6.3) than in urban (TFR 4.0) areas. Fertility decreases with an increase in the educational level. The TFR of women with no education is 6.6 , that of women who have completed primary school is 5.2 and the TFR of women with secondary or higher education is 4.1 (RoN 1993a, 20). According to the census, the proportion of women with no education in age group $25-34$ is lower (14\%) in the Northwest Region than in Namibia on average (18\%). Among women who have attended school, the proportion of women with only a primary education is larger and the proportion with a secondary or higher education is smaller in the Northwest Region than in Namibia on average. The proportion of literate females among rural females aged 10 years or more is higher $(75 \%)$ in the Northwest Region than in Namibia on average $(68 \%)$.

According to the NDHS, the Crude Birth Rate (CBR) is estimated to be 42 per 1,000 in Namibia (0-3 years preceding the survey) (RoN 1993a). The adjusted CBR estimate for the 12 months preceding the 1991 census is somewhat higher, or 42.6. The adjusted CBR is 48.4 in the Northeast Region, 43.8 in the Northwest Region, 39.8 in the Central Region and 36.2 in the South Region. 


\section{Proximate determinants of fertility}

Proximate determinants are the most immediate determinants of fertility. They also act as intermediate factors, for instance socioeconomic and cultural factors affect some of the proximate determinants and these proximate determinants affect fertility. The proximate determinants of fertility are the following: proportions married among females, contraceptive use and effectiveness, prevalence of induced abortion, duration of postpartum infecundability, fecundability (or frequency of intercourse), spontaneous intrauterine mortality and prevalence of permanent sterility (Bongaarts 1982; Bongaarts and Potter 1983).

According to Bongaarts, four of these seven proximate determinants determine the main part of the trends in fertility. These four principal proximate determinants are 1) marriage pattern, 2) postpartum infecundability (mainly affected by breastfeeding), 3) use of contraceptives and 4) induced abortions (Bongaarts 1982; Bongaarts and Potter 1983).

\section{Marriage}

According to the 1992 NDHS, over half of the women aged 15-49 years have never been married. The proportion of never married women is highest in the Northwest Region, or $64 \%$, and lowest in the Northeast Region, or 30\% (RoN 1993a, 48-49). According to the 1991 census, the proportion of never-married among women aged 15 years or more is $45 \%$ in Namibia on average and $51 \%$ in the Northwest Region. Among the 40-49-year-old women, the proportion of unmarried women is $15 \%$ in the Northwest Region and $17 \%$ in Namibia on average. In this age group, the proportion of legally married women is 50\% in the Northwest Region and 52\% in Namibia on average and the proportion of consensually married women is $19 \%$ in the Northwest Region and $17 \%$ in Namibia on average.

The proportion of unmarried women at the end of their reproductive period is high in Namibia compared to most sub-Saharan African countries. Usually the proportion of unmarried women in the age group $45-49$ is $1-3 \%$ in sub-Saharan Africa. The proportion of never-married women is high also in Botswana (Bongaarts, Frank and Lesthaeghe 1984; Cochrane and Samir 1989; IRD 1990).

Couples living together without getting legally married is a relatively common phenomenon in Namibia. According to the census, the proportion of those living in a consensual union is $13 \%$ among all women over 15 years old and 19\% among 30-39 year-old women. However, the proportion of women living in legal marriage is higher than the proportion of consensually married women in every age group. The proportion of legally married women is $30 \%$ among all women aged 15 years or more and over $45 \%$ among 30-39-year-old women.

Among women less than 30 years old, the proportion of unmarried women is larger in the districts of Oshakati and Ondangwa than in Namibia on average. The proportion of legally married or consensually married women is smaller among women less than 30 years old. Among women aged 30 years or more, the proportion of legally married women is only slightly smaller in Oshakati and Ondangwa than in Namibia on average. The proportion of consensually married women is about the same in the Oshakati District than in Namibia on average, but in the Ondangwa District their proportion is higher. The proportion of never-married women in the age group 45-49 is $11 \%$ in Namibia on average. There are wide regional differences in the proportion of unmarried women. It is the lowest in the Northeast Region, where in practice all women in this age group are married. The proportion of never-married women in the age group $45-49$ is $14 \%$ in the Northwest Region. 
The median age at first marriage is 23 years among women who were $45-49$ years old at the time of the NDHS and 25 years among women aged $25-49$ years. This age at first marriage is high compared to sub-Saharan African countries in general. Among the neighboring countries, Botswana also has a high age at first marriage, while it is lower in Angola and Zimbabwe. Regional differences in age at marriage are wide in Namibia. The median age at first marriage is 19 years among 45-49-year-old women in the Northeast Region, 23 years in the Northwest Region, 26 years in the South Region and 27 years in the Central Region. The median age at first birth is lower than the median age at first marriage: 21 years compared with 25 years among women aged 25-49 years at the time of the survey (Bongaarts et al. 1984; IRD 1990; RoN 1993a, $25-26,50$ ).

The mean number of ever-born children is high also among women who have not been married. Compared by age group, the mean number of children ever born to women who have never been married is 1.5-0.6 children lower than the number born to women who are currently married or have been married previously. Calculations based on retrospective birth histories in the NDHS show that the TFR of never married women is 4.4 , one child less than the TFR of all women (rates are for a period of 0-4 years preceding the NDHS 1992). Only $11.3 \%$ of never-married women aged $45-49$ years are childless.

Teenage pregnancy is a problem that results in a high proportion of school dropouts and single mothers among adolescent girls. The lack of information on reproductive health issues and inaccessibility of contraception are only some of the reasons behind this phenomenum. However, parents usually have negative attitudes towards sex education in schools. Teenage pregnancies and premarital sexual relationships are relatively common phenomena in many sub-Saharan African countries, despite traditional values against them (Bongaarts et al. 1984; Caldwell et al. 1992; Hailonga 1993; Hubbard and Tapscott 1992).

The proportion of currently married women living in polygynous unions is highest in the Northeast Region (25\%) and second highest in the Northwest Region (15\%) (RoN 1993a, 48-49).

\section{Postpartum infecundability and abstinence}

Postpartum amenorrhoea, i.e. the period when ovulation has not yet returned after birth, plays an important role in delaying new pregnancies and reducing fertility among populations where family planning is not practiced by use of contraceptives. Prolonged breastfeeding increases the length of postpartum amenorrhoea. In many traditional societies, postpartum abstinence is also practiced: after giving birth women are not supposed to have intercourse for some period of time. Together these two, postpartum amenorrhoea and abstinence, provide protection against pregnancies, i.e. a period of postpartum insusceptibility.

The median length of postpartum amenorrhoea is 8 months in Namibia and that of postpartum abstinence is 6 months. Women are protected against pregnancy, i.e. insusceptible, by either amenorrhoea or abstinence 13 months after they have given birth. Women younger than 30 years have a shorter period of postpartum amenorrhoea but a longer period of abstinence than older women. Among women living in urban areas both postpartum amenorrhoea and abstinence are shorter than among those living in rural areas. An increase in the level of education decreases postpartum amenorrhoea. The insusceptible period is 14 months long among women with no education and 10 months long among women with a secondary or higher education. The duration of postpartum abstinence and breastfeeding varies remarkably between the different areas of sub-Saharan Africa (Bongaarts et al. 1984; RoN 1993a, 54-55). 
Women in the Northeast Region have the longest period of postpartum amenorrhoea and women in the Northwest Region have the longest period of postpartum abstinence. In the South and Central Regions both amenorrhoea and abstinence are shorter than in the other two regions. The length of postpartum insusceptibility is the longest in the Northeast Region (17 months) and the shortest in the South Region (8 months). The length of the insusceptible period is 15 months in the Northwest Region. The length of breastfeeding has a similar pattern: it is longest in the Northeast Region and shortest in the South Region. The median duration of breastfeeding is 17.3 months in Namibia, but the median duration of full breastfeeding, i.e. breastfeeding without any other supplements than water, is only 1.7 months (RoN 1993a, 55, 119).

\section{Contraception and abortion}

Knowledge of contraceptive methods is relatively good in Namibia: $90.4 \%$ of currently married women and $88.5 \%$ of all women know some modern method. In the Northwest Region the percentage of currently married women knowing any modern method is 82 , the lowest of all regions. Knowledge of sources of family planning methods is $82 \%$ among currently married women in the whole country. Only $67 \%$ of currently married women in the Northwest Region know where to obtain contraceptives. Knowledge is better in urban than in rural areas and increases with an increase in educational level (RoN 1993a, 30-31).

The best known methods are injectives, which are familiar to $85 \%$ of currently married women in Namibia. The next best known methods are the pill (82\%), condoms $(71 \%)$ and female sterilization $(60 \%)$. Only $41 \%$ of currently married women knew any traditional method. The best known traditional methods are withdrawal (32\%) and periodic abstinence (30\%). Over $70 \%$ of currently married women knew where to obtain information or devices concerning injectives $(76 \%)$ or the pill $(73 \%)$. Surprisingly few, only $52 \%$ of currently married women, knew where to obtain condoms (RoN 1993a, 30).

The proportion of currently married women currently using any method of family planning is $29 \%$ in Namibia on average. The proportion of currently married women using modern methods is $26 \%$. Only $9 \%$ of currently married women are using any contraceptive method in the Northwest Region, and the proportion using modern methods is $7 \%$. This rate is much lower than in other regions: the proportion of currently married women using any method is $52 \%$ in the South Region, $32 \%$ in the Central Region and $22 \%$ in the Northeast Region. Use of contraceptives is more common in urban than in rural areas and increases with education (RoN 1993a, 35).

The most commonly used modern methods are the pill, injectives and female sterilization. Pills and injectives are, however, subject to high dropout rates in Namibia. Pills have the highest failure rate when measured in pregnancies. Rumors and side effects are important reasons why women stop using contraceptives, especially the injective contraceptive Depo-Provera has been accused of causing side effects. The pill and injectives are, in practice, the only alternatives offered to women in some places (Ahrenson-Pandikow 1992; RoN 1993a, 35).

The most popular traditional method is herbs, which are used by $1.8 \%$ of women. Herbs are the most commonly used method in the Northeast Region, where over $8 \%$ of women use them. In other regions their use is negligible. The second most popular traditional method is periodic abstinence, used by $0.7 \%$ of currently married women in Namibia (RoN 1993a, 35).

According to the NDHS, the most common reason for not using contraceptives is the desire to have more children. The second most common reason was a lack of knowl- 
edge (RoN 1993a, 42). The use of contraceptives is also diminished by the fear of side effects and restricted choices of contraceptive methods (Ahrenson-Pandikow 1992).

Half of the currently married women who knew at least one method reported that both she and her husband approve of family planning. Sixteen percent of women who approve of family planning said that their husband disapproved of it and $15 \%$ of the women said that both she and her husband disapprove of family planning. In the Northwest Region $30 \%$ of the women reported that both she and her husband disapprove of family planning, this proportion being much higher than among women living in other regions. The proportion of women reporting that both husband and wife approve of family planning is $33 \%$ in the Northwest Region. The percentage with the wife approving of family planning but the husband not approving is about the same in the Northwest Region as in Namibia on average. The proportion of women disapproving of family planning is $27 \%$ in Namibia on average and $42 \%$ in the Northwest Region (RoN 1993a, 45).

In Namibia the ideal number of children is five on average. Thus, it is almost as high as the TFR in Namibia. The ideal number of children declines when the level of education increases. The ideal number of children among women with no education is 6.6 and among women with a secondary or higher education it is 4.0. The ideal number of children is higher in rural than in urban areas. There are also regional differences in the ideal number of children: it is highest in the Northwest Region (6.2) and second highest in the Northeast Region (5.8). The ideal number of children is 4.4 in the Central Region and 3.3 in the South Region. There are probably many cultural and economic reasons behind the large ideal number of children, such as women's socialization, which emphasizes their role as childbearers and mothers, and women's need for the assistance of children in food production (Hubbard and Tapscott 1992; NISER and UNICEF 1991; RoN 1993a, 63).

Abortion is illegal in Namibia except in a few extreme circumstances, but it is claimed that illegal abortions are common in Namibia. The discussion of the liberalization of the law on abortion has led to a heated debate and the foundation of two movements: Pro-Choice which campaigns for the liberalization of the abortion law and Pro-Life campaigns against the legalization of abortion (Hubbard and Tapscott 1992; Kavari 1994).

\section{Other proximate determinants}

Frequency of intercourse has impact on the probability of conceiving. Coital frequency is affected by e.g. spousal separation. Large scale male labor migration causes spousal separation in Namibia, but its impact is somewhat reduced by polygyny: many of the men have (unofficial) wives in both the area of the origin and the area of the destination of the migration (Bongaarts et al. 1984; NDT 1994).

Intrauterine mortality, i.e. spontaneous abortions and stillbirths, is generally quite similar among all human populations. Stillbirths may be more common in Africa than elsewhere, but the proportion they form of intrauterine mortality is so small that their impact on fertility differentials between the populations is negligible (Bongaarts and Potter 1983).

The level of primary infertility may be estimated on the basis of the proportion of married women who remain childless. According to the NDHS, $2.6 \%$ of ever married women and 3.4\% of all women aged 45-49 years are childless (RoN 1993a, 22-23). The proportions of childless women are higher in the 1991 census than in the NDHS: the proportion of ever-married, childless women in the age group $45-49$ is $3.5 \%$ and that of all women aged $45-49$ is $4.6 \%$. The proportion of childless women among all women aged $45-49$ is $3.7 \%$ in the Northwest Region. The standard level of childless- 
ness is about $3 \%$ in a number of populations. The highest levels of infertility are found in central Africa, where $20 \%$ of women between $45-49$ years of age may be childless (Bongaarts, Frank and Lesthaeghe 1984). In areas where infertility is common gonorrhea is prevalent. Besides primary infertility, there is also secondary infertility, i.e. infertility that starts after a woman already has one or more children.

\section{Conclusions}

Despite the relatively small area of the Northwest Region, $44 \%$ of the total Namibia population lives there. The population density is higher in the Northwest Region than in Namibia on average. The proportion of the female population is higher in the Northwest Region than in Namibia on average, and the dependency ratio is high because of a large proportion of both young and elderly population. This is a typical population structure in a population where large scale out-migration of people of working age occurs. The population is very homogeneous in respect to language: almost everyone speaks Ovambo languages.

Compared with other regions and the national average, the level of fertility is high in the Northwest Region. The first proximate determinant examined, the marriage pattern, seems to sustain fertility at a higher level in the Northwest region than in the Central and South Regions, because age at first marriage is higher in the Central and South Regions than in the Northwest Region. Women in the Northeast Region, however, marry younger than women in the Northwest Region.

In Namibia, however, the TFR of unmarried women is only one child lower than that of all women, and women often start childbearing before their first marriage. Besides the high fertility of unmarried women, there are some other interesting phenomena in the marriage pattern of Namibia. The proportion of consensually married women is relatively high in Namibia, and compared to many other sub-Saharan African countries (e.g. Cochrane and Farid 1989), a large proportion of women stay unmarried until the end of their reproductive period.

The period of postpartum insusceptibility is long in the Northwest Region compared to the Central and South Regions, but shorter than in the Northeast Region. This is a reflection of the period of breastfeeding being second longest in the Northwest Region compared with other regions. The period of postpartum abstinence being longest also increases the relatively long period of postpartum insusceptibility. The use of contraceptives is very low in the Northwest Region. In respect to this proximate determinant, the situation in the Northwest Region differs considerably from the situation in all other regions.

Another interesting issue is the low infant and child mortality in Namibia. They are low everywhere else but in the Northeast Region: in this respect the Northwest Region belongs to the same group as the South and Central Regions. Usually fertility and the ideal number of children decrease when infant and child mortality are low, as they have decreased in the South and Central Regions. In the Northwest Region, however, fertility is still high. Infant mortality also seems to be less sensitive to the educational level of the mother than in sub-Saharan Africa on average.

\section{References}

Ahrenson-Pandikow, Helena. 1992. Survey of Attitudes Towards the Use of Contraceptives in Namibia. Windhoek, Namibia: Namibian Institute for Social and Economic Research, University of Namibia (NISER). (Paper prepared for the UNFPA). 
Bongaarts, John. 1982. The fertility-inhibiting effects of the intermediate fertility variables. Studies in Family Planning 13(6/7): 179-89.

Bongaarts, John and Robert G. Potter. 1983. Fertility, Biology and Behavior. Studies in Population. London: Academic Press Ltd.

Bongaarts, John, Odile Frank and Ron Lesthaeghe. 1984. The proximate determinants in sub-Saharan Africa. Population and Development Review 10(3): 511-37.

Bucht, Birgitta. 1994. Mortality trends in developing countries: a survey. In: The Future of World Population: What Can We Assume Today?, edited by Wolfgand Lutz, pp. 147-64. London: Earthscan Publications Ltd and Laxenburg, Austria: International Institute for Applied Systems Analysis.

Caldwell, John C., I.O. Orubulove and Pat Caldwell. 1992. A new type of fertility transition in Africa. Population and Development Review 18(2):212-42.

Cleland, John. 1994. A regional review of fertility trends in developing countries: 1960 to 1990. In: The Future of World Population: What Can We Assume Today?, edited by Wolfgand Lutz, pp. 55-82. London: Earthscan Publications Ltd and Laxenburg, Austria: International Institute for Applied Systems Analysis.

Coale, Ansley J. and Paul Demeny. 1983. Regional Model Life Tables and Stable Populations. Second Edition. Studies in Population. New York: Academic Press Ltd.

Cochrane, Susan and Samir F. Farid. 1989. Fertility in Sub-Saharan Africa: Analysis and Explanation. World Bank Discussion Papers 43. Washington: The World Bank.

Hailonga, Panduleni. 1993. A Study to Identify Adolescents' Knowledge, Attitudes and Beliefs Towards Teenage Pregnancy. Windhoek, Namibia: Ministry of Health and Social Services.

Hubbard, Dianne and Chris Tapscott. 1992. Country Gender Analysis Namibia. Windhoek, Namibia: Swedish International Development Authority (SIDA).

IRD (Institute for Resource Development). 1990. An Assessment of DHS-I Data Quality. DHS Methodological Reports 1. Columbia, Maryland: Institute for Resource Development/Macro Systems, Inc.

Kavari, Franna. The great abortion controversy. The Namibian, March 11, 1994: 7.

NISER (Namibian Institute for Social and Economic Research, University of Namibia) and UNICEF. 1991. A Situation Analysis of Children and Women in Namibia. Windhoek, Namibia.

NDHS I992. Namibia Demographic and Health Survey 1992 dataset.

NDT (Namibia Development Trust). 1994. Improving the Legal and Socio-Economic Situation of Women in Namibia: Uukwambi, Ombalantu and Uukwanyama Integrated Report. Volume 1. Windhoek, Namibia.

RoN (Republic of Namibia). 1992. 1991 Population and Housing Census. Preliminary Report. Windhoek, Namibia: National Planning Commission, Central Statistics Office.

-. 1993a. Namibia Demographic and Health Survey 1992. Ministry of Health and Social Services, Namibia and Demographic and Health Surveys Macro International, Inc. Columbia, Maryland and Windhoek, Namibia.

-. 1993b. 1991 Population and Housing Census. Report A: Statistical Tables. Volume I: Geographical, Migration and Household Characteristics. Windhoek, Namibia: National Planning Commission, Central Statistics Office.

-. 1993c. 1991 Population and Housing Census. Report A: Statistical Tables. Volume II: Demographic, Social, Literacy and Educational Characteristics. Windhoek, Namibia: National Planning Commission, Central Statistics Office.

-. 1993d. 1991 Population and Housing Census. Report A: Statistical Tables. Volume IV: Fertility and Disability. Windhoek, Namibia: National Planning Commission, Central Statistics Office.

United Nations. 1983. Manual X: Indirect Techniques for Demographic Estimation. Department of International Economic and Social Affairs. Population Studies 81, ST/ESA/SER.A/81. New York.

Verma, Vijay. 1980. Basic Fertility Measures from Retrospective Birth Histories. World Fertility Survey Technical Bulletins 4. International Statistical Institute. 


\title{
HIV/AIDS: The Major Demographic Challenge of Namibia
}

\author{
RIIKKA SHEMEIKKA \\ Research Scholar, International Institute for Applied Systems Analysis (IIASA) \\ Laxenburg, Austria, and \\ Researcher, Population Research Unit, Department of Sociology \\ University of Helsinki, Finland
}

\section{Abstract}

In Namibia, as in many other countries in Southern Africa, the prevalence of HIV/AIDS has been growing rapidly during the 1990s. According to the HIV Sentinel Surveillance $1996,15.4 \%$ of pregnant women seeking prenatal care were HIV positive, and the highest HIV prevalence was found in the densely populated northern part of the country. The reports of the Health Information System of the Ministry of Health and Social Services show that there were 18,000 positive HIV tests during 1995-1996, and that AIDS has become the leading cause of death among reported deaths.

This paper is based on preliminary results of the research project Evaluating Alternative Paths for Sustainable Development in Namibia, Botswana and Mozambique, a project still continuing at the International Institute for Applied Systems Analysis (IIASA), Laxemburg, Austria. Multi-state population projections presented here include information on educational level and HIV/AIDS status of the population. Data used for the starting population of 1991 and the first five-year period, 1991-1996, is from: the 1991 Population and Housing Census, preliminary results of the 1996 Demographic Sample Survey, and the HIV-prevalence of women seeking antenatal care, based on National HIV Sentinel Surveys 1992-1997. Estimations for fertility and mortality in 1991 are based partly on published census results and partly on calculations made from the census tables. These calculations were made using indirect demographic estimation techniques, i.e. the Brass $P / F$ ratio method and Trussel's variant of the Brass method for the estimation of child mortality from information on children ever born and children surviving. In order to reduce the urban/rural bias of HIV sentinel survey sites, the results were weighted by the agespecific rural and urban populations, which somewhat lowers the national, average HIVprevalence compared with the results published earlier. The population projections were made using the PDEPROJ Software - software designed by IIASA for making multi-state population projections. In addition to being divided by sex and by five-year age groups, the population was divided into categories by educational level (low and high), and HIV/ 
AIDS status (HIV negative, HIV positive, AIDS). These categories are combined into six states (e.g. HIV-negative population with low education, HIV-positive population with low education, population with AIDS and low education etc.). The scenario presented in this paper is only one example of possible future population development. In this scenario, fertility is assumed to decline to around three, mortality - excluding HIV/AIDS mortality - is assumed to remain stable and HIV prevalence is assumed to continue to grow as it has done during the 1990s. In order to show the magnitude of the impact of the HIV/AIDS epidemic in population development, a hypothetical scenario without any HIV/AIDS is also presented.

The results show that HIVIAIDS will have a significant effect on future population size and age structure. In case the current development continues, the population of Namibia will be over 836,000 smaller in 2026 than without HIVIAIDS. There will also be a remarkable impact on the age structure of the population.

Keywords: Namibia, population, population projections, fertility, mortality, HIV/AIDS

\section{Introduction}

Namibia's population was 1.6 million in 1996 and the average population density was 1.9 persons per $\mathrm{km}^{2}$. The population is very unevenly distributed; however, and $60 \%$ of the population lives in the northem part of the country, in a region that represents only $14 \%$ of the country's total land area. Almost $30 \%$ of the population was living in urban areas in 1991. The age structure of Namibia is young $-42 \%$ of the population was under 15 years of age in 1991. The most commonly spoken language is Oshiwambo, which is spoken at home by $51 \%$ of the country's population. Population growth has been rapid in past decades; during 198191 it was over $3 \%$ per year. According to the 1991 census, the total fertility rate (TFR) was 6.1 and has been declining during the $1990 \mathrm{~s}$. Life expectancy at birth was estimated to be 59 years for men and almost 63 years for women in 1991. Migration, especially to urban areas, has been fast during independence. (RoN 1992; RoN 1994a; RoN 1994b.)

HIV/AIDS has become the greatest demographic challenge for Namibia, as for most of the countries in Southern Africa. It seems likely that the rapid population growth of past decades will be slowed down or perhaps even be halted by the fast-spreading epidemic. The current state of affairs requires strong new efforts and approaches from the organizations that collect information, formulate political responses, and study the impacts of the epidemic.

This paper is based on preliminary results of a research project entitled Evaluating Alternative Paths for Sustainable Development in Namibia, Botswana and Mozambique by the International Institute for Applied Systems Analysis (IIASA).) (Shemeikka \& Noymer 1998). The aim of the paper is to estimate the impact of the HIV/AIDS epidemic on the population development of Namibia. As an example of the results of the project, two population projections are presented in this paper: an HIV/AIDS scenario, showing the population development, provided that the development of the epidemic continues the way it did in 1992-1996, 
and a hypothetical scenario of population development without any impact of HIV/AIDS on population. In both scenarios, all other assumptions are similar. Neither of these two scenarios can be seen as actual population forecasts; their purpose is more to illustrate the possible magnitude of the impact of the HIV/AIDS epidemic on population in the future, provided that the current development continues and that the other assumptions about fertility and mortality are fulfilled. This paper first describes the state of the HIV/AIDS epidemic in Namibia, both compared with the neighboring countries and within the different regions of the country itself. The second part of the paper presents population projections with and without the impact of HIV/AIDS and discusses the possible consequences of the HIV/AIDS epidemic on an individual and national level.

\section{HIV/AIDS in Namibia and several other Southern African countries}

UNAIDS and WHO have been reporting on the high HIV/AIDS prevalence in sub-Saharan Africa. They estimate that by the end of $1998,22.5$ million people will be living with HIV/ AIDS in sub-Saharan Africa and 33.4 million world-wide. Of all the new infections in the world in 1998, 70\% occurred in sub-Saharan Africa, and HIV prevalence among the 15-49year-old population was estimated to be $8 \%$. During the 1990 s, the epidemic has shifted southwards within sub-Saharan Africa; Namibia, among other countries in Southern Africa, has experienced very rapid growth in HIV/AIDS prevalence during this decade. (UNAIDS \& WHO 1998a; UNAIDS \& WHO 1998b)

HIV prevalence is very high in Namibia and almost all of the neighboring countries, i.e. Angola, Zambia, Zimbabwe, Botswana and South Africa. Prevalence is highest in Botswana and Zimbabwe and lowest in Angola. Among pregnant women in major urban centers the highest HIV prevalence was found in Botswana, 38.5\% in 1997, and the lowest in Angola, 1.5\% in 1995. UNAIDS estimated that at the end of 1997, HIV prevalence among the 15-49-year-old population, male and female combined, was above $25 \%$ in Botswana and Zimbabwe and between $10-20 \%$ in all the other above- mentioned countries, except for Angola, where it was estimated to be only $2 \%$. (RoB 1997; UNAIDS \& WHO 1998a.)

Altogether, UNAIDS estimated that there were 6.6 million people, both adults and children, living with HIV/AIDS in the afore-mentioned countries by the end of 1997. The main mode of transmission in Southern Africa, as in sub-Saharan Africa in general, is heterosexual intercourse. In Angola, a relatively high proportion of transmissions occurred via blood and blood products, i.e. $24 \%$ of reported AIDS cases, and also via drug needles, i.e. $9 \%$ of reported AIDS cases. In Zambia, blood and blood products accounted for $5 \%$ of reported AIDS cases, and in South Africa, homosexual contact between men accounted for $7 \%$ of reported AIDS cases. Unfortunately, there is no data on the modes of transmission in Namibia. UNAIDS estimates vertical transmission to be $35 \%$ in sub-Saharan Africa; i.e. $35 \%$ of the babies born to HIV-infected mothers will be infected with HIV/AIDS. (UNAIDS \& WHO 1998a.) 


\section{The state of the HIV/AIDS epidemic in Namibia}

Estimations of the HIV/AIDS epidemic in Namibia are mainly based on HIV sentinel surveillance of pregnant women seeking prenatal care, and on monthly reports of the Health Information System (HIS) by the Ministry of Health and Social Services. In addition, HIV infections of potential blood donors and STD patients provide some information on the state of the epidemic. Unfortunately, all this data is very restricted in the background variables available. In HIV Sentinel Surveillance data, only information on age and sentinel site of women is available. In the HIS reports, information is mostly restricted to region, omitting the sex and age of the HIV/AIDS cases. Providing additional background information e.g. on education or marital status, and in the HIS reports, on sex and age, would be very useful for understanding the epidemic.

The first HIV/AIDS case in Namibia was reported in 1986. Both HIV sentinel surveillance data and health reports indicate that HIV/AIDS has been spreading fast during the $1990 \mathrm{~s}$. UNAIDS estimated that there were 150,000 people in Namibia, both adults and children, living with HIV/AIDS by the end of 1997, and that 14,000 AIDS deaths have occurred since the beginning of the epidemic. (RoN 1996; UNAIDS \& WHO 1998a; UNDP 1997).

\section{HIV sentinel surveillance data}

HIV sentinel surveillance is a national sero-survey of antenatal care users. Pregnant mothers are considered a good indicator group for the sexually active population. About $80 \%$ of women in Namibia are using antenatal services. The surveillance was conducted among pregnant women seeking antenatal care at five sentinel sites in 1992, at ten sentinel sites in both 1994 and 1996, and at four sentinel sites in 1997. The surveillance took place as anonymous screening of blood samples of women who used antenatal services. The sentinel sites, hospitals and clinics were selected with consideration given to the geographical distribution of the population, the urban/rural division of population and a sufficient number of first-visit antenatal care seekers. Seven out of ten sites were located in the northern part of the country, where more than $60 \%$ of the population lives. Six sites were located in urban and four in rural areas. During the 8-week survey period, all the women who visited an antenatal clinic for the first time during the current pregnancy were selected. The requested sample size per sentinel site was 250 . Blood samples originally collected for other purposes were labeled by the code of the sentinel site and the age of the woman; all the identifying information was removed. Samples were forwarded to the Central Laboratory at Windhoek, where they were tested for HIV antibodies. All the samples were tested by a highly sensitive first line ELISA' (Abbot, HIV $1+2,3$ rd generation including subtype 0 ). Non-reactive samples were recorded as negative, and reactive samples were tested by a highly specific ELISA (Behring, HIV1+2). Samples positive on both ELISAs were recorded as positive.

Based on results of the tests, the Case Management and Surveillance Unit at the National AIDS Control Programme performed the data entry and analysis. HIV-point prevalence rates

${ }^{1}$ Enzyme-Linked ImmunoSorbent Assay test used to detect specific antibodies in the blood. 
with $90 \%$ confidence intervals were calculated for each sentinel site. Cases with the age unknown were distributed according to the age structure of the sentinel site. Age distribution of the women included in the survey was compared with that of all women giving birth and that of women testing for HIV in the survey.

In 1996, 1,854 blood specimens were received. The requested sample size of 250 was achieved at two sentinel sites (Windhoek and Oshakati). The smallest sample size was provided by Andara, with only 86 samples. The rest of the sentinel sites provided sample sizes between 132 and 249. Age was missing in 25 specimens. The mean age of HIV-positive women did not differ from the mean age of HIV-negative women. The age distribution of women included in the survey and that of those who were HIV-positive resembled the age structure of all women giving birth during the January - August 1996, indicating that the sample is representative of pregnant women as far as age is concerned.

According to the results, HIV prevalence is highest among women aged 20-34 years (Figure 1). In 1996, the proportion of HIV-positive women was $17.6 \%$ in urban areas and $10.4 \%$ in rural areas. (RoN 1996.)

Figure 1. Age-specific HIV prevalence in pregnant women, 1994 and 1996. Source: RoN 1996.

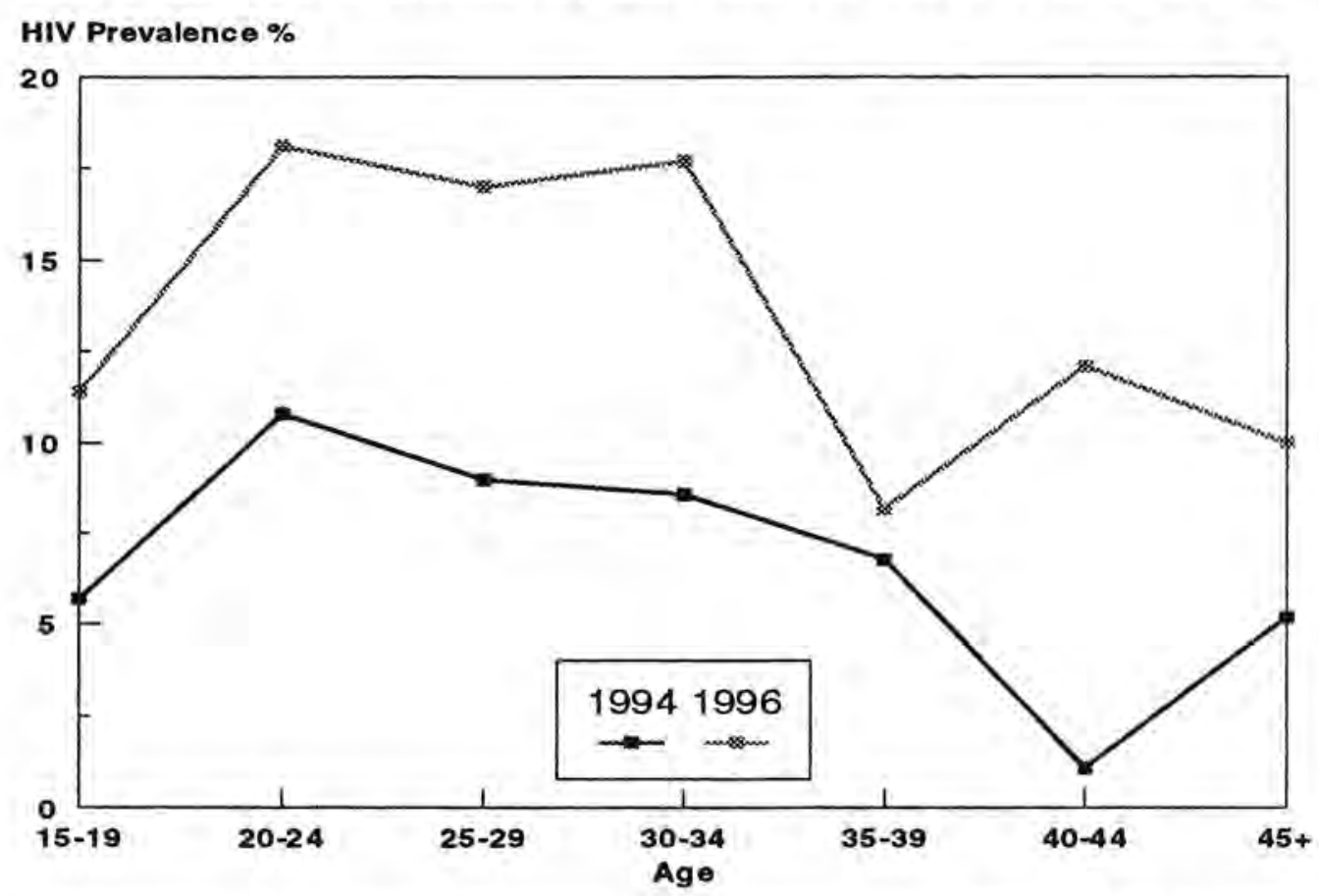

The proportion of all HIV-positive women increased from $4.2 \%$ in 1992 to $15.4 \%$ in 1996 (Figure 2). The regional differences between the sentinel sites are significant, and HIV is most widely spread in the densely populated northern regions. The highest HIV prevalence is found in Katima Mulilo, an urban center located on the Caprivi strip, where the prevalence was above $20 \%$ already in 1994. In 1997, HIV prevalence among pregnant women in Katima 
Mulilo was $25.5 \%$. In Oshakati, another northern urban center, $22.4 \%$ of pregnant women were HIV positive in 1996. HIV prevalence in Windhoek, the capital city, was $16 \%$ in 1996. (RoN 1996; Webb \& Simon 1995.)

Figure 2. HIV prevalence among pregnant women by sentinel site, 1992-1997. Note: Some of the sentinel sites were excluded from the surveillance in 1992 and 1997. Source: RoN 1995;RoN 1996 .

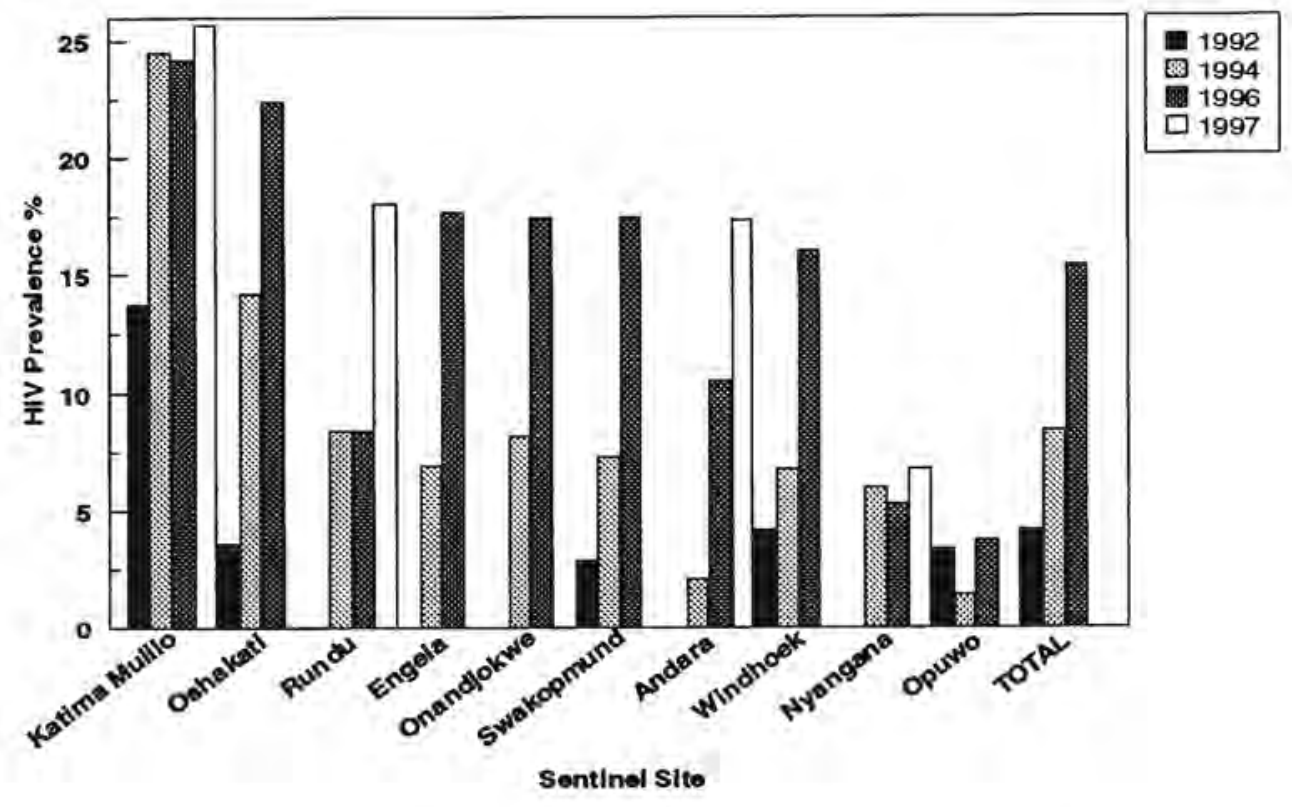

\section{Reports of the Health Information System and Blood Transfusion Services}

The reports of the Health Information System (HIS) of the Ministry of Health and Social Services provide data on positive results of HIV tests, AIDS cases and AIDS deaths. The reports are given separately for the country's four Health Directorates and for Windhoek (Figure 3). According to the reports of the Health Directorates, 18,333 positive HIV tests were made during $1995-96$, i.e. $63 \%$ of the positive HIV tests since the beginning of the epidemic in 1986, and the latest information reveals that more than 11,600 new HIV infections were reported in 1997. The number of AIDS cases was 413 in 1992 and 2,165 in 1996. The number of reported AIDS deaths increased from 86 in 1992 to 775 in 1996. Two northern Health Directorates, the North East and the North West, accounted for $41 \%$ of the positive HIV tests, $72 \%$ of the reported AIDS cases, and $84 \%$ of the reported AIDS deaths in 1996. $60 \%$ of the total population of the country lived in this region in 1991. Also, the highest proportions of reported new AIDS cases per 100,000 of the population are found in northern regions and in the region where the capital city, Windhoek, is located.(The Namibian, January 26 1999; RoN 1996; UNDP 1997). 
Figure 3. Reported AIDS cases by Health Directorate, 1996. Source: UNDP 1997.

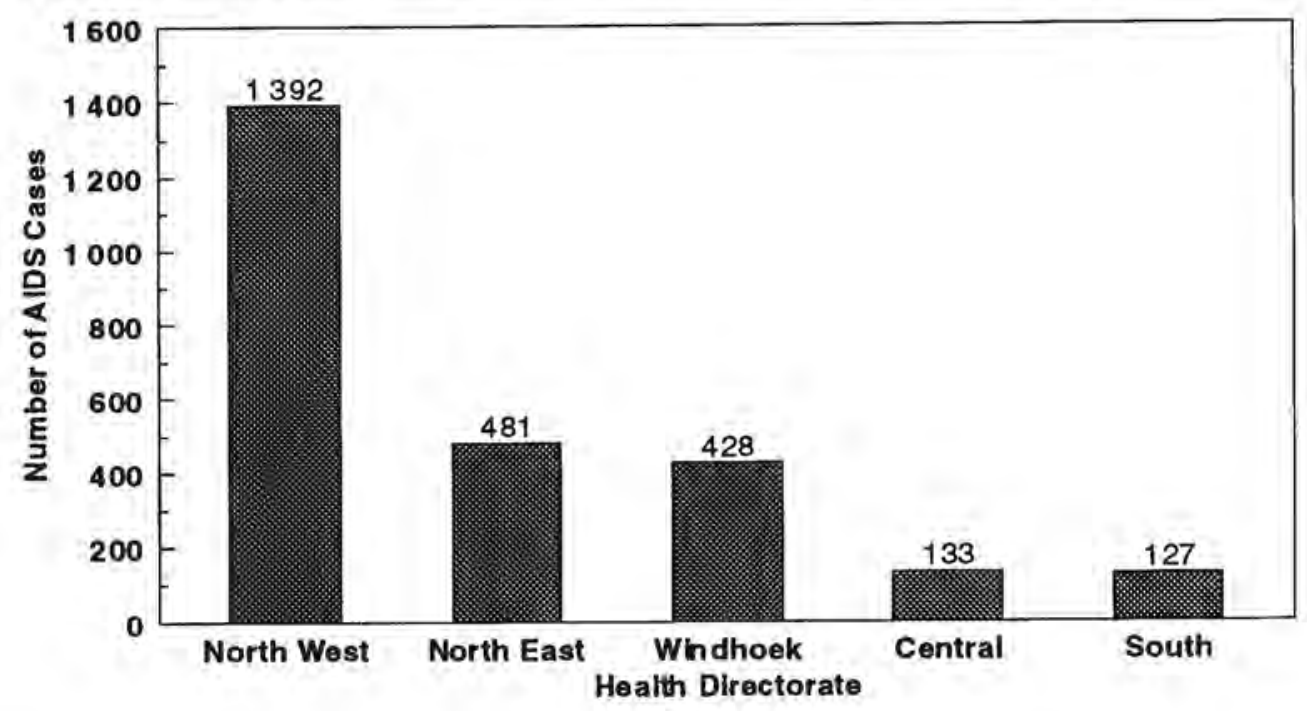

AIDS has become the most common cause of death in Namibia. The proportion of AIDS deaths was $18.6 \%$ of all reported deaths among persons of all age groups in 1997. AIDS was reported as the cause of death in 1,539 cases in 1997, as many as tuberculosis or malaria, the second and third most common causes of death, combined. The proportion of AIDS as a cause of death has risen; it was $12.4 \%$ and $7 \%$ in 1996 and 1995, respectively. Among children less than one year old, AIDS was the sixth most common cause of death in 1996. (The Namibian, January 26 1999; UNDP 1997).

The reports of Blood Transfusion Services provide data on HIV/AIDS on annual basis. HIV prevalence among potential blood donors was only $1.6 \%$ in 1996. In Oshakati, HIV prevalence among potential blood donors was $4.3 \%$ in 1996 . The safety of blood transfusions has been very high in Namibia, with no known cases of HIV transmission at least until 1996. The information on the HIV prevalence among patients with sexually transmitted diseases is scarce in Namibia. In 1993-94, 18.2\% of the STD patients of both sexes were HIV positive; however, these rates are based on a small sample. (RoN 1996; UNDP 1997; U.S. Bureau of the Census 1998.)

\section{Problems with the HIV/AIDS data}

The lack of reliable HIV/AIDS data is a problem in Namibia, as well as in other African countries. HIV sentinel surveys of pregnant women has been estimated to be one of the most reliable sources of information. Other possible sources are for instance the reports of the health officials and the HIV tests of blood donors. All the data sets available are missing important background variables-for instance, HIV sentinel data does not contain information on education, employment or marital status of the respondent, and the HIS report data is lacking even the age and sex of the HIV/AIDS cases. 
The selection of the sentinel sites may also have an impact on the results. In the current selection of sentinel sites, urban areas are over-represented. As HIV prevalence is higher in urban than in rural areas, the average HIV prevalence is higher than it should be. If the results are weighted by the real urban/rural populations, the average HIV prevalence is below $13 \%$ instead of $15.4 \%$. The possible problems in the selection of the sentinel sites will not, however, explain the increase of HIV prevalence in individual sentinel sites.

The rates from HIV reports should also be treated with caution. For example, only a small portion of HIV positive people undergo HIV tests, and the cause of death is reported in less than half all deaths. It is also possible that due to the compounding effect of tuberculosis and HIV/AIDS, part of the deaths reported as caused by tuberculosis have occurred among people with AIDS (UNDP 1997).

\section{Population projections with HIV/AIDS}

The following projections were made by the International Institute of Applied Systems Analysis as a part of a research project entitled Evaluating Alternative Paths for Sustainable Development in Namibia, Botswana and Mozambique, by the author and Mr. Andrew Noymer (Shemeikka \& Noymer 1998).

These population projections are so-called multistate population projections, where the population is divided into subgroups by education and HIV/AIDS status. Multistate population projections by education have their advantages: vital rates, like fertility and mortality, vary according to education. These variations, their changes and changes in the educational structure of the population can be taken into consideration while making multistate population projections with education. In addition to education, some other characteristics can be included into population projections. In earlier research projects by IIASA, for instance, employment status has been used as an additional state in multistate population projections. For countries in Southern Africa, the HIV/AIDS epidemic will have a significant impact on population development. Therefore, both education and HIV/AIDS status have been included as states in these projections.

There are two educational categories in the following population projections. The low education group consists of the part of the population with no formal education and the population with primary education, whereas the high education group consists of the part of the population with secondary and higher education. For HIV/AIDS status there are three categories: HIV negative, HIV positive and AIDS. These categories are combined into six interacting states: low education and HIV-negative population, low education and HIV-positive population, low education population with AIDS, high education and HIV-negative population, high education and HIV-positive population, and high education population with AIDS. The assumptions for fertility and mortality vary for each of the afore-mentioned sub-populations. Projections are made using five-year age groups and five-year time periods. 
Figure 4. Starting population for the population projections: Population of Namibia in 1991.

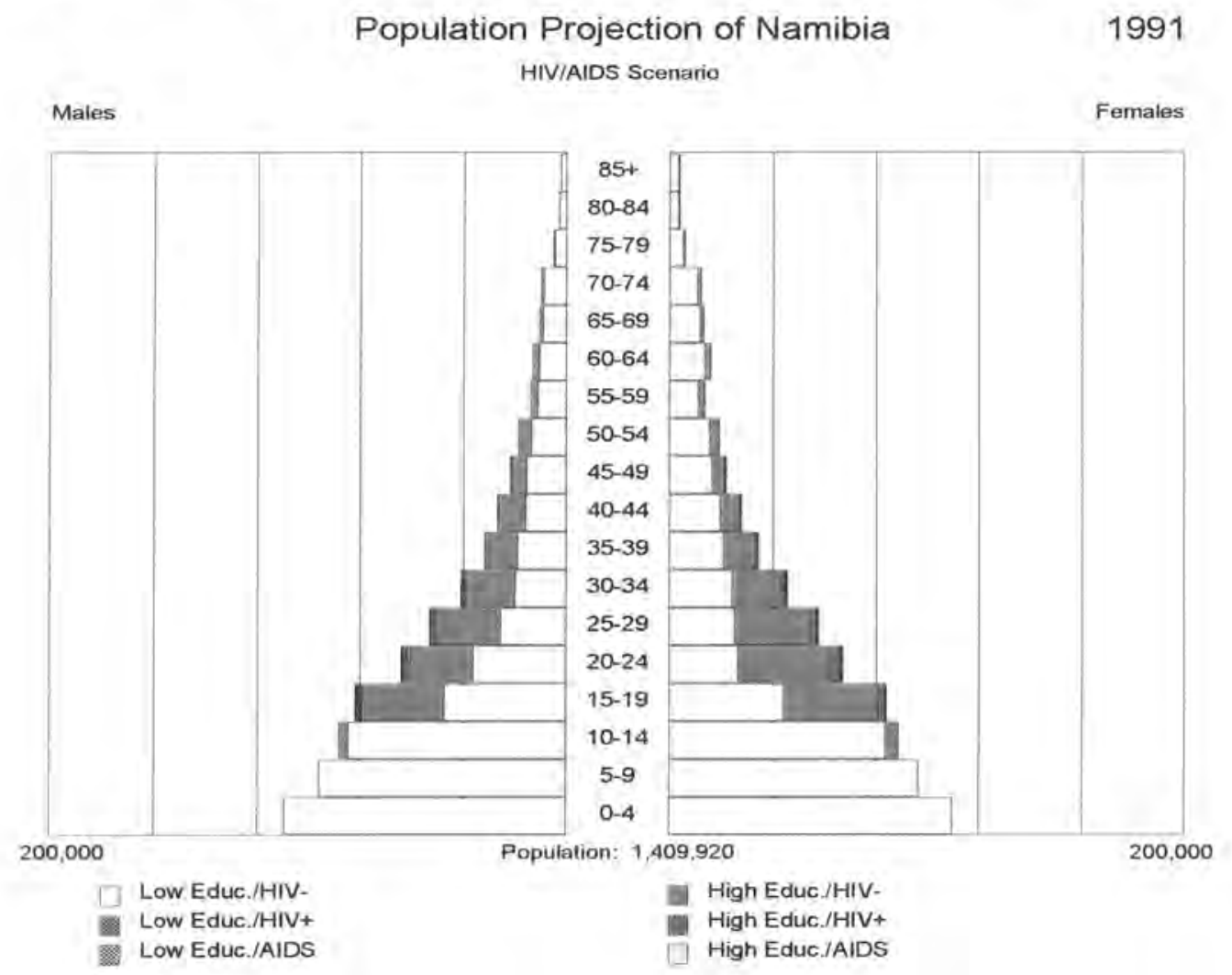

\section{Data, methods and assumptions}

Data for the starting year 1991 (Figure 4) has been obtained from the 1991 Population and Housing Census (RoN 1994b). In the following population projections, it has been assumed that there will be a decline in fertility both among women who are not infected with HIV/ AIDS and among HIV-positive women. Mortality, with the exception of AIDS mortality, is assumed to remain stable. Values for mortality and fertility are based partly on the published rates of the 1991 census analytical report (RoN 1994a), and partly on calculations made from aggregated census data tables (RoN 1993b; RoN 1994b) using indirect methods for estimations of fertility and mortality.

In the 1991 census analytical report, the Total Fertility Rate (TFR) of Namibia was estimated to be 6.1 children per woman. There are significant differences in fertility according to the educational level of the women. TFR for women with no education is 8.8 , for those who completed grade six it is 7.2 , for those who completed grade nine it is 4.2 , and for those who completed grade 12 it is 3.1 ( $R 0 N$ 1994a). These educational rates were used for 
population projections, modified for the two educational categories, "low education" and "high education." The age structure of fertility, i.e. the Age-Specific Fertility Rates, were calculated from the 1991 census data tables (RoN 1994b). Fertility estimates have been made using the Brass method, based on comparison of period fertility rates with reported average parities, i.e. the P/F ratio method (United Nations 1983). According to the first results of the 1996 Demographic Sample Survey, there has been a rapid fertility decline since the 1991 Population and Housing Census. The national TFR was estimated to be 4.7 in 1996, and fertility has been declining in all of the country's 13 administrative regions (Arowolo 1998). This decline has been taken into account while estimating the fertility of the first five-year period of the projections, i.e. 1991-1996. For the scenarios presented in this paper, the national TFR has been assumed to decline to 3 in the 2021-2026 period. This fertility decline corresponds to the scenario "low" in the population projections of the National Planning Commission of Namibia. Rates for both educational categories, low and high fertility, have been assumed to decline. In these projections, HIV-positive women have been assumed to have $20 \%$ lower fertility than women not infected with HIV, and the fertility of women with full-blown AIDS has been assumed to be zero.

Life expectancy at birth and Age-Specific Mortality Rates in starting year 1991 are based on the published estimates from the 1991 census analytical report (RoN 1994a) and indirect mortality estimates from the 1991 census data tables (RoN 1994b). Indirect estimations are made using Trussel's variant of the original Brass method of estimation of child mortality from information on children ever born and children surviving, and Coale and Demeny Regional Model Life Table West (Coale \& Demeny 1983; United Nations 1983). Life expectancy at birth for male population not infected with HIV was estimated to be 59.1 years, and 62.8 years for the female population, in 1991 (RoN 1994a). Information on the educational differences in mortality is lacking, but in these projections a five-year difference in life expectancy between low and high educational groups has been assumed. In the scenarios presented in this paper, mortality, excluding AIDS mortality, has been assumed to remain stable during the projected time period.

Estimations of age-specific HIV and AIDS prevalence in the starting population of 1991 and in the first five-year period 1991-1996 are based on the published data of the sentinel surveys of 1992, 1994 and 1996 (RoN 1995; RoN 1996). As the urban population was overrepresented in the selection of sentinel sites, the age-specific HIV prevalences are weighted with the real urban and rural populations. This somewhat lowers the national HIV prevalence. For instance, in 1996 the national average of HIV prevalence among pregnant women was $15.4 \%$ without weighting and below $13 \%$ when weighted with urban/rural populations. Unfortunately, the information provided by sentinel surveys is very restricted. Therefore, the following assumptions have been made for the scenarios presented in this paper: HIV prevalence of men is assumed to be $80 \%$ of that of women in the same age group; HIV prevalence of the low education group is assumed to be $80 \%$ of the national average, and that of the high educational group to be $120 \%$ of the national average; vertical transmission (mother-to-child transmission) is assumed to be $35 \%$. In addition, HIV infection is assumed to develop into full-blown AIDS in 10 years and life expectancy with AIDS is assumed to be 2.5 years. For children, these developments are assumed to occur faster. 


\section{Results}

Results of two scenarios are presented in figures 5 and 6 . In the first case, it is assumed that HIV/AIDS continues spreading until 2026 as it did between 1992-1996. The second scenario is a hypothetical scenario of population development without any HIV/AIDS in Namibia. The comparison of the two scenarios shows that if HIV transmission will continue at the same level as it did during the 1990s, the population of Namibia will be significantly smaller in 2026 than it would be without the impact of HIV/AIDS. Using the assumptions described above, there would be 836,000 people less in Namibia in 2026 because of HIV/AIDS, than there would without it. In addition, the age structure of the population will be very different from what it would be without HIV/AIDS.

These projections have been made in order to show what the impact would be if the current development continues. The reality will probably differ from these projections, depending on, for instance, changes in people's behavior. Behavior may change as a result of education campaigns and people's concern for their health, as the number of cases of AIDS-related illness and death increase. In addition, a sudden success in developing a cheap medical treatment or prevention for HIV/AIDS would change the demographic impacts of the epidemic. It should also be remembered that in long-term population projections, changes in fertility and mortality are difficult to estimate even for those not infected by HIV/AIDS. Only one scenario of fertility and mortality decline has been presented in this paper, i.e. the scenario in which the fertility of the population not infected with HIV is assumed to decline to 3 in 2026 and in which there is assumed to be no mortality changes, excluding HIV/AIDS mortality.

\section{Consequences of the HIV/AIDS epidemic in Namibia}

Namibia, like other Southern African countries, has faced a rapid worsening of the HIV/AIDS epidemic during the 1990 s. This epidemic will most probably have a strong impact on the demographic development of Namibia. It will slow down the population growth by affecting both mortality and fertility. Because of AIDS, mortality among both the female and male working-age population will increase. Child mortality will increase because of vertical transmission of HIV/AIDS from HIV-positive mothers to their children. The fertility of HIVpositive women and women with AIDS is lower than that of women with no HIV infection. In addition, increased mortality among women of reproductive age will decrease their number, and therefore also the potential number of children to be born. HIV/AIDS will probably also affect population in less direct ways. For instance, the mortality of AIDS orphans will probably be higher than that of children whose mothers are alive. In addition to the size of the population, HIV/AIDS will also change its future age structure.

HIV/AIDS will have an effect on many different levels. Disease and death will cause physical and psychological suffering for the people infected and their families, together with economic disturbances. AIDS orphans and elderly people will suffer when the economic support from the working-age population is diminished. Possible discrimination of infected people in work places and social life will also cause problems on an individual level. On the national 
Figure 5. Population of Namibia in 2026 with the impact of HIV/AIDS.

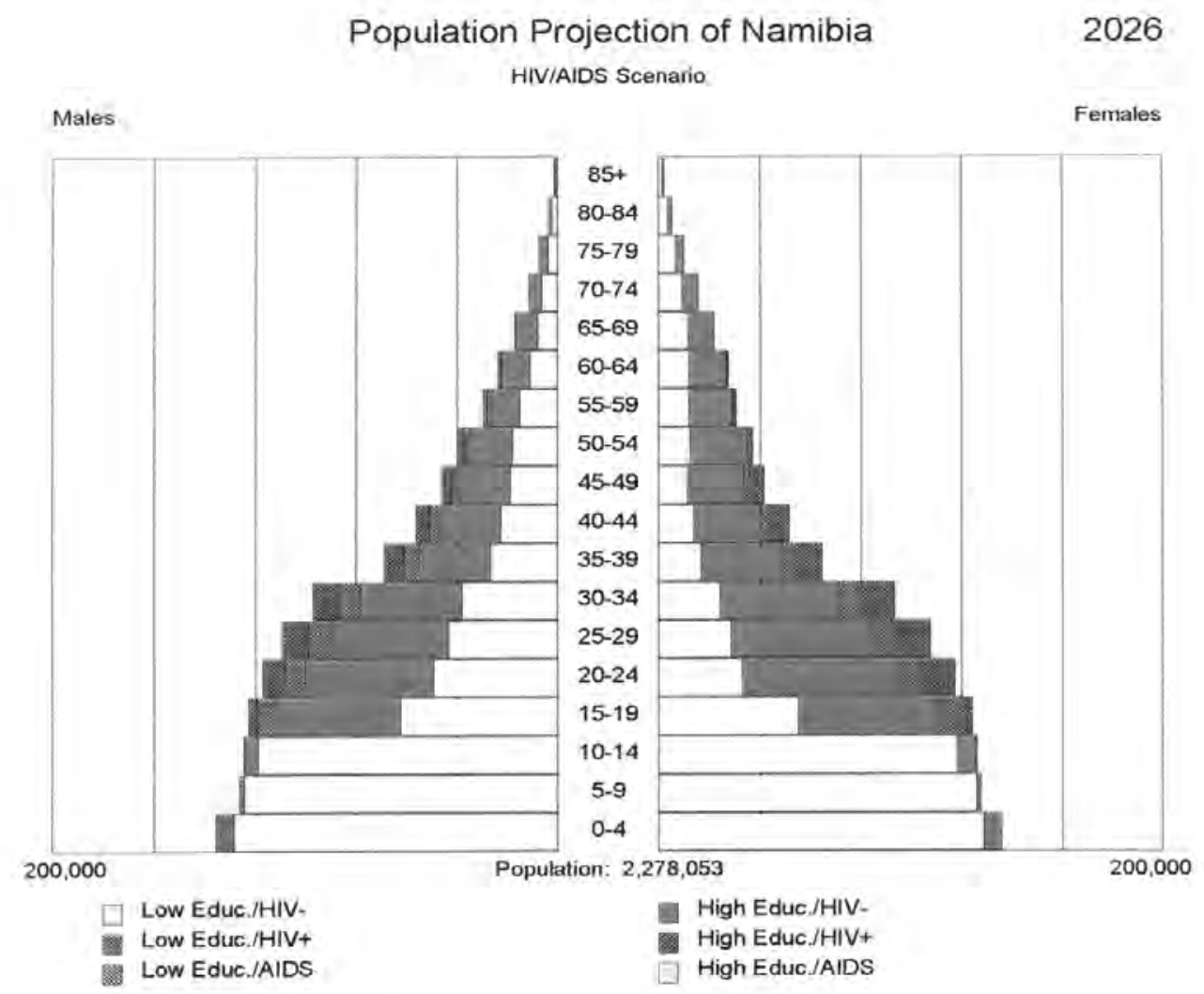

level, economic problems will be caused by e.g. increasing needs for investments in health care. In addition, increasing morbidity and mortality will cause economic losses in human resources and labor productivity. UNDP Namibia estimates that direct and indirect costs caused by HIV/AIDS will amount to 20\% of the GDP by 2001 , compared to $3.2 \%$ in 1996 . These costs consist of e.g. medical costs, proposed disability allowances to people with AIDS, and the value of lost productive years (The Namibian, 26 January 1999).

The volume of impacts of the HIV/AIDS epidemic will depend on changes in reproductive behavior and on the developments in medical science. There are some encouraging experiences, of powerful information campaigns, training, and reproductive health services in some other countries in sub-Saharan Africa, e.g. in Senegal (UNAIDS \& WHO 1998a). Also in Namibia, there are some signs of positive development in reproductive behavior. 
Figure 6. Population of Namibia in 2026 without the impact of HIV/AIDS.

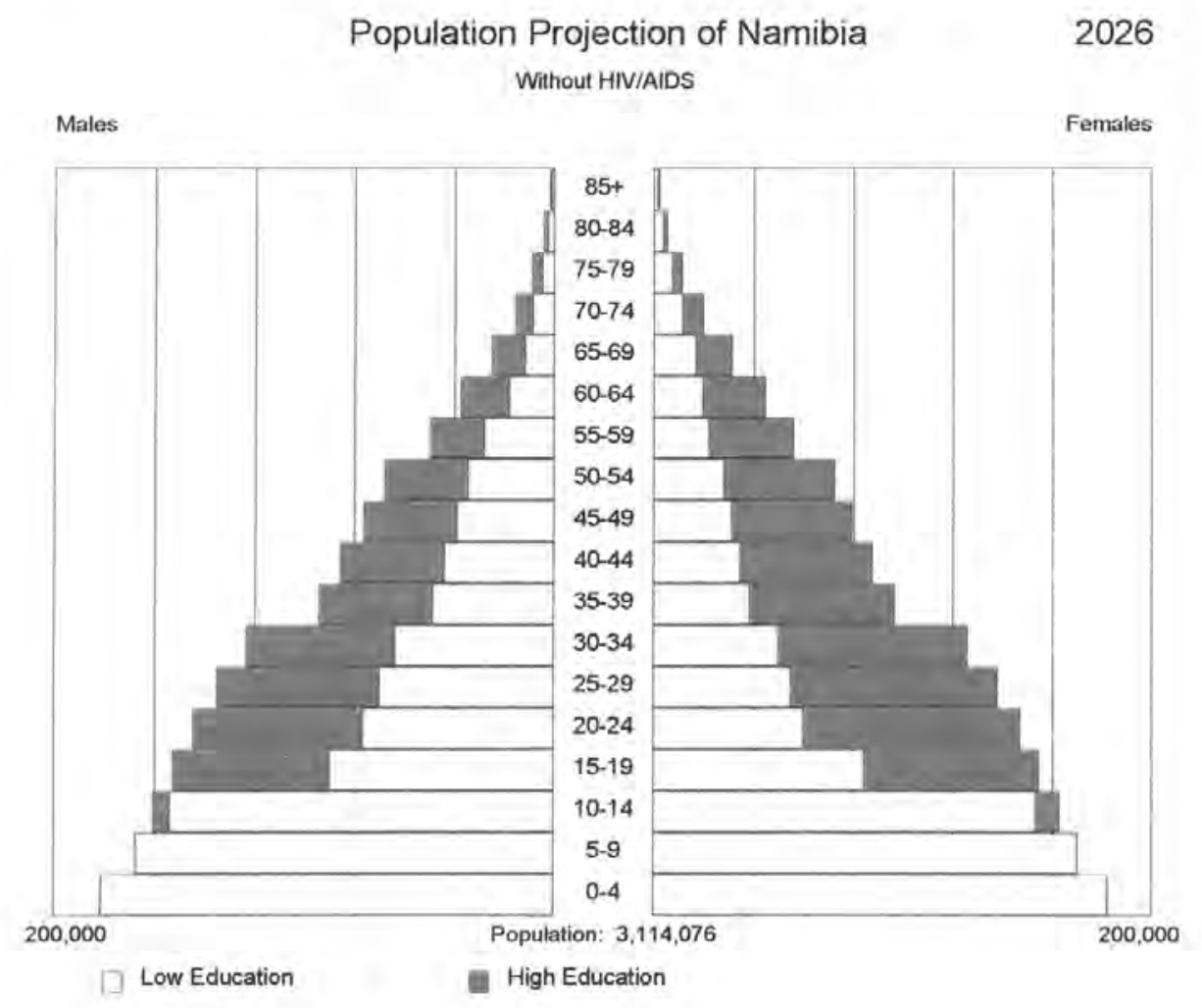

\section{Changes in HIV/AIDS awareness and condom use}

Information on the awareness concerning HIV/AIDS in Namibia is restricted to small sample surveys and should therefore be treated with caution. It seems likely that knowledge of HIV/ AIDS and the ways of transmitting HIV have increased during the 1990s. The 1991 National AIDS Awareness Survey was conducted among a small sample of the adult population in several locations throughout the country. According to the survey, $90 \%$ of the population said they had heard about AIDS, and that the main source of information was radio. $81 \%$ of those who had heard about AIDS knew that it is transmitted through sexual intercourse, and $56 \%$ knew that infected blood can also be a means of transmission. The most common misconceptions were that transmission can occur via kissing (16\%) or through mosquitoes (17\%). Other misconceptions about transmission, such as the virus being transmitted through touching, sharing a glass or shaking hands with someone were al so relatively common (17\%) (multiple responses were permitted). $79 \%$ of respondents said that there is no cure for AIDS, and 
$73 \%$ knew that the disease can be prevented. Out of those who answered that AIDS can be prevented, $64 \%$ said that it can be prevented by not having sex with strangers, $67 \%$ by keeping one faithful partner and $38 \%$ by using a condom (multiple responses were permitted). A baseline survey among Namibian youth, ages 18-25, was conducted in 1995 . The sample was considerably larger, over 2,000 respondents, and the survey was conducted in several different regions. Virtually all respondents knew that AIDS could be transmitted via sexual intercourse, and many respondents knew also that transmission can occur through blood.

Misconceptions about transmission were much more minor than in the 1991 survey. The use of condoms was the most commonly mentioned means of prevention, followed by abstaining from sex and having only one partner. The survey also gave some contradictory results, for instance, one third of male respondents from rural areas agreed with a statement that HIV/AIDS does not really exist. Also, although respondents seemed in principle to have a fairly good knowledge about how to prevent the transmission of HIV, many of them agreed with the statement "there is really little someone can do to prevent AIDS, it is just a fate." This fatalistic attitude was most prevalent among females in the areas where the risk of transmission was high, $80 \%$ and $85 \%$ among females in urban and Caprivi-Okavango TransCaprivi Highway areas, respectively. (NANASO 1995; NISER 1991.)

The use of condom seems to be increasing at least among people under 25 year old. According to the Namibia Demographic and Health Survey 1992, 5.5\% of all women aged 15-49 had ever used a condom, the same proportion as among currently married women. Only $0.5 \%$ of all women were using condoms as their current method of contraception, and this proportion was even smaller among currently married women. Among all women aged 15-19, $2.4 \%$ had ever used a condom and $0.3 \%$ were using it as their current method of contraception. These proportions were slightly higher among 20-24-year-old women. $7.4 \%$ of them had ever used a condom and $0.9 \%$ were using it as their current method of contraception.

There was no significant difference in the use of condoms as the current contraceptive method between women who lived urban and those who lived in rural areas in 1992. Among currently married women, ages $15-49$, the prevalence of condom use was $0.5 \%$ and $0.1 \%$ in urban and rural areas, respectively. According to the Namibian Youth Baseline Survey 1995, conducted among the 18-25-year-old population, the proportion of those using condoms was considerably higher. Among young women, the proportion who had ever used condoms varied from $52 \%$ to $32 \%$ in urban and rural areas, respectively. For male respondents, proportions varied from $81 \%$ in urban to $51 \%$ in rural areas. The proportion of urban males who used a condom during their last sexual intercourse with a casual partner was $88 \%$ and the proportion of urban males who had used a condom during their last intercourse with a regular partner was $45 \%$. Among urban females, $84 \%$ had used a condom with their last casual partner and $54 \%$ during their last intercourse with a regular partner.

In 1992, the educational level of a woman did not make a significant difference in the use of condoms as a current contraceptive method; it was below $1 \%$ in all educational groups. Educational differences in condom use may have changed during the 1990s; unfortunately there is no data available of the present-day situation. In 1999, a pilot project for promoting the 
use of female condoms, i.e. femidoms, will start in four of Namibia's 13 regions. This project is sponsored by private organizations and companies. Femidoms will probably play a part also in the government's new AIDS prevention initiatives which will be announced in early 1999. (The Namibian, 14 December 1998; NANASO 1995; RoN 1993a).

\section{Public reactions to HIV/AIDS}

During the past couple of years, the HIV/AIDS epidemic has received increasing media attention in Namibia. A good example of this was the World AIDS Day Supplement 1998, published in The Namibian by UNAIDS, UNICEF, Ministry of Health, and the Government of Spain. Aside from news on the state of the epidemic and other HIV/AIDS related news, the newspaper provided information on the ways the disease is transmitted and on how to protect oneself from it, instructions on what to do for people who suspect they are infected, and practical guidelines for those who are taking care of sick family members or other people with AIDS. In addition to this special World AIDS Day Supplement, news on HIV/AIDS are published throughout the year. (The Namibian, 27 November; 2 December; 3 December; 4 December 1998.)

A wide range of national and international organizations have been active in the work against HIV/AIDS. Thirty-five NGOs are working for HIV/AIDS prevention under the umbrella of the Namibian Network of AIDS Service Organisations (NANASO). Some of the trade unions and private sector companies and employers are also participating in the work against the HIV/AIDS epidemic. The role of UN organizations, e.g. UNDP, UNAIDS, UNFPA and UNICEF, has been very active and important in both provoking public discussion on the topic and providing information on the state of the HIV/AIDS epidemic and its consequences. (The Namibian, 5 February 1999; UNDP 1997.)

The National AIDS Control Programme (NAPC) was launched within the Ministry of Health and Social Services (MHOSS) in 1990. A Short-Term Plan was made for the years 1990-92 and it was followed by the first Medium-Term Plan for the years 1992-1997. Some of the sectors other than the health sector have also responded to the HIV/AIDS epidemic. For instance, the guidelines for the implementation of the National Code on HIV/AIDS in Employment were published in July 1998. The HIV/AIDS code makes it illegal for an employer to test employees or prospective employees for HIV, or to use a person's HIV status to determine his/her job status, promotion or transfer. It also gives employees with HIV/AIDS the legal right to confidentiality about their HIV status in any aspect of employment. The Code of HIV/AIDS in employment was soon dismissed, however, by the Namibian Defence Forces. A comprehensive policy paper on higher education, tabled in September 1998 by Minister of Higher Education, Vocational Training, Science and Technology, emphasizes the role of the Ministry in information and education on HIV/AIDS. It also states that employees in the higher education sector who have tested positive for HIV/AIDS should be encouraged to continue working, and students should be encouraged to complete their studies, if possible. In some respects, the official reactions to the epidemic have been relatively slow. For 
instance, Namibia's national population policy document, accepted in 1997, HIV/AIDS was still only briefly mentioned among other diseases (RoN 1997). Also, the NAPC has been heavily criticized by NANASO and some other organizations that work against HIV/AIDS in Namibia. Currently, a new five-year Strategic Plan on HIV-AIDS Prevention and Control in Namibia, and the National AIDS Coordination Programme have been prepared by the Government. Both of them will be launched at the end of January 1999, (The Namibian, 28 July; 5 August; 10 August, 19 September; 27 October; 3 December 1998; 5 February 1999; UNDP 1997.)

\section{References}

Arowolo, O, O. 1998. Fertility in Namibia. Unpublished working paper for IIASA (International Institute for Applied Systems Analysis). Windhoek 1998.

RoB (= Republic of Botswana) 1997. Botswana HIV Sentinel Surveillance 1997. Gaborone, Botswana.

Coale, Ansley J. \& Paul Demeny. 1983. Regional Model Life Tables and Stable Populations. New York: Academic Press.

The Namibian. 28 July 1998; 5 August 1998; 10 August 1998; 19 September 1998; 27 October 1998; 27 November 1998; 2 December 1998; 3 December 1998; 4 December 1998; 14 December 1998; 26 January 1999; 5 February 1999; 4 December 1999.

NANASO (Namibian Network of AIDS Service Organizations) 1995. Sexual Knowledge, Attitudes and Practices Among Namibian Youth. A Baseline Survey, Windhoek.

NISER 1991. National AIDS Awareness Survey. Namibian Institute for Social and Economic Research, University of Namibia (NISER), Windhoek.

RoN (=Republic of Namibia) 1992. 1991 Population and Housing Census. Preliminary Report. National Planning Commission, Central Statistics Office, Windhoek.

RoN 1993a. Namibia Demographic and Health Survey 1992. Ministry of Health and Social Services and Demographic and Health Surveys Macro International Inc.

RoN 1993b. 1991 Population and Housing Census. Report A. Statistical Tables. Volumes IV. (Tables for 27 Census Districts). Central Statistics Office, National Planning Commission, Windhoek.

RoN 1994a. 1991 Population and Housing Census: Basic Analysis with Highlights, Central Statistics Office, National Planning Commission, Windhoek.

RoN 1994b. 1991 Population and Housing Census. Report B. Statistical Tables. (Tables for 13 Administrative Regions). Central Statistics Office, National Planning Commission, Windhoek.

RoN 1995. Epidemiological Information on HIV-Infection and AIDS in Namibia. Ministry of Health and Social Services, National AIDS Control Programme, HIV/AIDS/STD Case Management and Surveillance, December 1995. Windhoek.

RoN 1996. National HIV Sentinel Surveillance 1996. Ministry of Health and Social Services, National AIDS Control Programme, HIV/AIDS/STD Case Management \& Surveillance, October 1996. Windhoek 
RoN 1997. National Population Policy for Sustainable Human Development. National Planning Commission, Windhoek.

Shemeikka, Riikka \& Andrew Noymer.1998. Population projections for Namibia and Botswana. Unpublished working paper made for IIASA (International Institute for Applied Systems Analysis). Laxenburg 1998.

UNAIDS \& WHO 1998a. Global HIV/AIDS \& STD Surveillance. Report on the Global HIV/ AIDS epidemic - June 1998. (Published in the Internet.)

UNAIDS \& WHO 1998b. AIDS epidemic update: December 1998. (Published in the Internet.) UNDP 1997. Human Development Report 1997. The Impact of HIV and AIDS in Namibia. UNDP Namibia with UNAID Co-sponsors. Windhoek.

United Nations 1983. Manual X: Indirect Techniques for Demographic Estimation. Department of International Economic and Social Affairs. Population Studies 81. New York 1983.

U.S. Bureau of the Census 1998. HIV/AIDS Surveillance Data Base. January 1998.

Webb, Douglas \& David Simon.1995: Migrants, Money and the Military: The Social Epidemiology of HIV/AIDS in Owambo, Northern Namibia. NEPRU Occasional Paper 4, August 1995. Windhoek. 



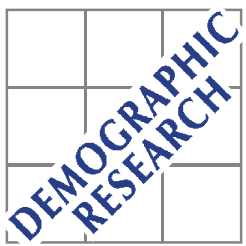

Demographic Research a free, expedited, online journal of peer-reviewed research and commentary in the population sciences published by the Max Planck Institute for Demographic Research Konrad-Zuse Str. 1, D-18057 Rostock · GERMANY www.demographic-research.org

DEMOGRAPHIC RESEARCH

VOLUME 13, ARTICLE 4, PAGES 83-116

PUBLISHED 30 AUGUST 2005

http://www.demographic-research.org/Volumes/Vol13/4/

Research Article

Fertility decline in North-Central Namibia: an assessment of fertility in the period 1960-2000 based on parish registers

Riikka Shemeikka

Veijo Notkola

Harri Siiskonen

(C) 2005 Max-Planck-Gesellschaft. 


\section{Table of Contents}

$1 \quad$ Introduction $\quad 84$

$2 \quad$ Study region $\quad 86$

3 Data 87

$\begin{array}{lll}3.1 & \text { Parish register data } & 87\end{array}$

3.2 Population and Housing Censuses and Demographic and Health 90 Surveys

$4 \quad$ Methods 90

$5 \quad$ Fertility change in the sample congregations 1960-2000 91

$5.1 \quad$ Period fertility 91

5.2 Cohort fertility 95

5.3 Birth intervals, age at first marriage, pre-marital fertility, and 96

5.4 Comparison between parish registers and other data 97

$6 \quad$ Conclusions and discussion $\quad 99$

6.1 Fertility decline started in 1980 and was most rapid during the 99

6.2 Cohort fertility shows a decline in completed number of births $\quad 100$

6.3 Disparity in fertility development between adolescents and other 100

$\begin{array}{lll}6.4 & \text { Contraceptive prevalence increased } & 101\end{array}$

6.5 Causes of fertility decline: The changing cultural and socio- 103

6.6 Contribution of HIV and AIDS to fertility decline 105

$7 \quad$ Acknowledgments 106

$\begin{array}{ll}\text { References } & 107\end{array}$ 


\title{
Fertility decline in North-Central Namibia: an assessment of fertility in the period 1960-2000 based on parish registers
}

\author{
Riikka Shemeikka ${ }^{1}$ \\ Veijo Notkola $^{2}$ \\ Harri Siiskonen ${ }^{3}$
}

\begin{abstract}
This study examines fertility decline in North-Central Namibia in the period 19602000. A Scandinavian-type parish-register system, established in the beginning of 20th Century and still in use, provided register-based data for fertility analysis. Fertility decline began in 1980, was rapid in the 1980s, levelled off in the early 1990s, started again in 1994 and continued until the year 2000. Fertility declined in every age group, except among the 15-19 year olds, whose fertility increased. Cohort fertility started to decline among the 1940-44 birth cohort. During the 1980s, fertility decline was associated with increasing age at first marriage and declining marital fertility, connected to e.g. the War of Independence. During the 1990s, an increase in both the use of contraceptives and HIV-prevalence contributed to the fertility decline.
\end{abstract}

\footnotetext{
${ }^{1}$ M.Sc., Researcher, Department of Sociology, University of Helsinki, Finland; e-mail: riikka.shemeikka@helsinki.fi

${ }^{2}$ Ph.D., M.Sc., Dos., Department of Sociology, University of Helsinki, Finland and Managing Director, Rehabilitation Foundation, Helsinki,

Finland; e-mail: veijo.notkola@kuntoutussaatio.fi

${ }^{3}$ Ph.D., Dos., Professor of general history, Department of History, University of Joensuu, Finland; e-mail: harri.siiskonen@joensuu.fi
} 


\section{Introduction}

Recent decades have witnessed a decline in fertility in several sub-Saharan African countries, including many countries neighbouring Namibia: South Africa, Botswana and Zimbabwe are forerunners in the fertility decline. In South Africa, the decline in fertility began in the 1960s or possibly even earlier, in Zimbabwe it began in the 1970s, and in Botswana in the late 1970s or early 1980s (see e.g. Gaisie 1995, Muhwava and Timæus 1996, Central Statistical Office - Zimbabwe and Macro International 1995, 2000, Moultrie and Timæus 2003, Swartz 2003, Central Statistical Office - Botswana 2004). Fertility is also declining, though at a slower pace, in Zambia (Central Statistical Office - Zambia, Central Board of Health - Zambia, and ORC Macro 2003). In Angola, some researchers estimate that fertility decline had not yet begun in the late 1990s (Agadjanian and Prata 2001), while others consider that the decline began in the early 1990s (Casterline 2001).

Based on the 1992 Namibia Demographic and Health Survey (NDHS), Kirk and Pillet (1998) classified Namibia into the group of countries with a steady fertility decline. In 2001, total fertility in Namibia was 4.1, this level being about the same (or slightly-higher) than in Botswana and Zimbabwe, clearly higher than in South Africa, and notably lower than the level of fertility in Zambia or in Angola.

Within Namibia, however, there were wide regional differences in the level of fertility and the state of fertility transition, as noted by e.g. Tabutin and Schoumaker (2001). Regional differences have their background in the colonial history of the country, among other reasons. The policy of ethnical segregation, practiced first by the German colonial rulers and later by the South Africans, culminated in the foundation of so-called "homelands" on the basis of a report by the Odendaal Commission (Odendaal Commission 1964).

At the beginning of independence, i.e. in the early 1990 s, fertility was highest in the northern part of the country, clearly lower in the central regions, and lowest in southern Namibia (Ministry of Health and Social Services and Macro International 1993, Central Statistics Office 1994a, Raitis 1995). Fertility patterns were connected with the historical context of the regions: in all former "homeland" regions total fertility was above six, except in Damaraland, Namaland and Rehoboth (Odendaal Commission 1964, Raitis 1995). During the 1990s, fertility declined in every region but regional differences remained. According to the 2000 NDHS, total fertility was highest in the Northeast and Northwest Directorates, 4.8 and 4.7, respectively, and lowest in the Central and South Directorates, 3.9 and 3.6, respectively. According to the 2000 NDHS, the national average for total fertility was 4.2 , very close to the figure of 4.1 reported in the 2001 Population and Housing Census. 
Knowledge of demographic trends is scarcer in Namibia than in many other countries in sub-Saharan Africa. Since reliable data on demographic variables from the colonial period have been lacking, the few demographers studying fertility in Namibia have concentrated on censuses and demographic surveys collected after Namibia gained her independence in 1990 (e.g. Raitis 1995, Chimere-Dan 1997, Gage 1998, Arowolo 2000, Hamata n.d.). In-depth studies on fertility decline in Namibia have been lacking so far.

An exception with a wider historical perspective is previous research on the demographic development of Northern Namibia on the basis of parish registers from the historical Ovamboland and the Kavango regions (e.g. Notkola 1996, Lemström 1999, Notkola and Siiskonen 2000, Notkola, Timæus, and Siiskonen 2000, Notkola, Timæus, and Siiskonen 2004). In their research, Notkola and Siiskonen (2000) studied fertility trends in the historical Ovamboland region until the mid-1980s.

Long-term parish register data provides an opportunity to study fertility in the North-Central Namibia during a period preceding the current demographic knowledge: in its time focus, this study fills the gap between studies of historical Ovamboland (Notkola and Siiskonen 2000), and those concentrating on the period after 1990. Because of the longer time focus than studies based on data for the period following independence, it is possible to examine both the timing and details of the current fertility decline. In addition, since they are a long-term register-based data set, parish registers provide an opportunity for using direct demographic analysis methods, including cohort fertility rates, as tools for fertility analysis. In order to study the differences and similarities in the picture of fertility decline given by parish registers and traditional demographic data, comparisons will be made for the period during which more conventional data exists.

The two major aims of this study are 1) to increase knowledge concerning fertility decline in Namibia, and 2) to contribute to research into fertility decline in sub-Saharan Africa in general by introducing an unconventional data set, i.e. parish registers. This study assesses their suitability for fertility analysis, and explores the new opportunities they provide compared to the other types of data. The specific aims of this study are 1) to determine the starting point of the fertility decline among the study population, 2) to examine fertility development among different age groups, 3) to compare cohort and period fertility in order to differentiate between the tempo and quantum effects in fertility decline, and 4) to compare the results based on parish registers with information obtained from the Population and Housing Censuses of 1991 and 2001, and from the Namibia Demographic and Health Surveys (NDHS) of 1992 and 2000.

This paper first describes the data and methods used. Secondly, it briefly provides some contextual information about the study region. Thirdly, it studies the period and cohort fertility using data from parish registers. Fourthly, it compares the results based 
on parish registers with those obtained from the NDHS and census data, and finally, it briefly discusses the processes behind the fertility decline, as well as the contributions made by HIV and AIDS.

\section{Study region}

The former Ovamboland region was defined during the German colonial period in 1884-1915, and was one of the "homelands" founded during South African rule. It is still, in ethnical terms, relatively homogenous: in 2001, inter-intelligible Ovambo dialects were spoken by 93-97 per cent of population in the Ohangwena, Omusati and Oshana regions and by 87 per cent of population of the Oshikoto region (Central Bureau of Statistics 2003).

The former Ovamboland area is part of the current administrative regions of Omusati, Oshana, Ohangwena and Oshikoto. These regions also include some areas outside the former Ovamboland, the most important additions being incorporation of the former Tsumeb area and parts of the Etosha National park into the Oshikoto region, and expansion of the Omusati region in west by incorporation of the Ruacana area (for more details, see Erkkilä 2001). Together, the Omusati, Oshana, Ohangwena and Oshikoto regions form the Northwest Health Directorate. In the 1992 NDHS, the former Ovamboland region was called the Northwest Region, and in the 2000 NDHS this region was called the Northwest Directorate. In this study, the former Ovamboland region is called North-Central Namibia. Because the 2000 NDHS and the population and housing census data are at the level of current administrative regions, we also refer to information about the Northwest Health Directorate, which is a somewhat wider region than North-Central Namibia (i.e. former Ovamboland).

In 2001, 43 per cent of Namibians lived in the Northwest Health Directorate, on an area of land representing ten per cent of the country's total area. Namibia is sparsely populated, the average population density being 2.2 persons per sq. $\mathrm{km}$ in 2001 (Central Bureau of Statistics 2003). The average population density in the Northwest Health Directorate was 9 persons per sq. km. There are, however, wide differences in population densities within the administrative regions, as well as between them.

The very uneven population distribution of Namibia has its roots in both natural conditions and historical events. One explanation for the higher population density in North-Central and North-East Namibia is the more favourable natural environment, especially the better availability of water for irrigation compared to other parts of the country (Erkkilä and Siiskonen 1992). In addition, during the more than one-hundredyear-long period of colonial rule, the majority of the country's land area was reserved for white settlers' commercial farms. This so-called Police Zone covered most of 
Central and Southern Namibia. Indigenous Namibians were forced to live in the reservations, later the "homelands", which served as labour reserves for the needs of commercial farms, mines and the like. Movements between regions were restricted and entry into the Police Zone was restricted to temporary labourers employed within the contract labour system.

Populous Ovamboland was an important source of labour for the central and southern regions, and this was also the region most affected by the war of liberation from 1966 to 1989. North-Central Namibia is still a mostly-rural region, in which subsistence agriculture and communal land-ownership are practised. Agriculture as a means of living is often supplemented, however, by other income strategies, including the labour migration of (mostly) male family members. There are also centres of rapid urban growth, the most important of these being the Oshakati-Ongwediva-Ondangwa complex.

\section{Data}

\subsection{Parish register data}

This paper studies the fertility decline in the North-Central Namibia using parish registers from eight Evangelic-Lutheran congregations. These eight congregations are located in the northern part of the country in the historical Ovamboland region. In order to get a more representative view of the development of the study region, the sample congregations were chosen from different parts of the region.

Collected according to the principles of the Scandinavian parish register system, these data allow the direct analysis of fertility. This is exceptional in the context of subSaharan Africa, where fertility analysis has mainly been based on population censuses and retrospective surveys.

Finnish missionaries started their work in North-Central Namibia in 1870, in a region then known as Ovamboland. They established a parish register system in the new congregations that was similar to the Finnish system. Gradually, congregations were placed under the leadership of local ministers. In 1954, the independent Evangelical Lutheran Ovambo-Kavango Church, later known as the Evangelical Lutheran Church in Namibia (ELCIN), was established. The parish register system has essentially remained the same since the beginning of the $20^{\text {th }}$ century with only minor alterations (for further information on parish register data from former Ovamboland, see Siiskonen, Taskinen, and Notkola 2005). In other words, ministers record baptisms, deaths, migrations, and other events such as confirmations, events that members of their congregations 
experience. In practice therefore, the parishioners participate in a vital registration system.

According to the ELCIN statistics, the former Ovamboland congregations had 552,000 members at the end of 2001. Approximately $71 \%$ of the 780,000 inhabitants of the Ohangwena, Omusati, Oshana and Oshikoto regions were therefore members of the Evangelical Lutheran Church. (ELCIN 2002, Central Bureau of Statistics 2003.)

The data consists of the records of eight congregations, i.e. Elim, Nakayale, Oshigambo, Okahao, Tshandi, Onankali, Oshitutuma and Omulonga (Figure 1). The sample congregations are located in the Omusati and Oshikoto administrative regions. Some of the congregations are the administrative and economic centres of their region, others are more peripheral. The oldest among the sample congregations is Okahao, founded in 1906. The youngest is Oshitutuma, founded in 1982.

\section{Figure 1: Location of the sample congregations}

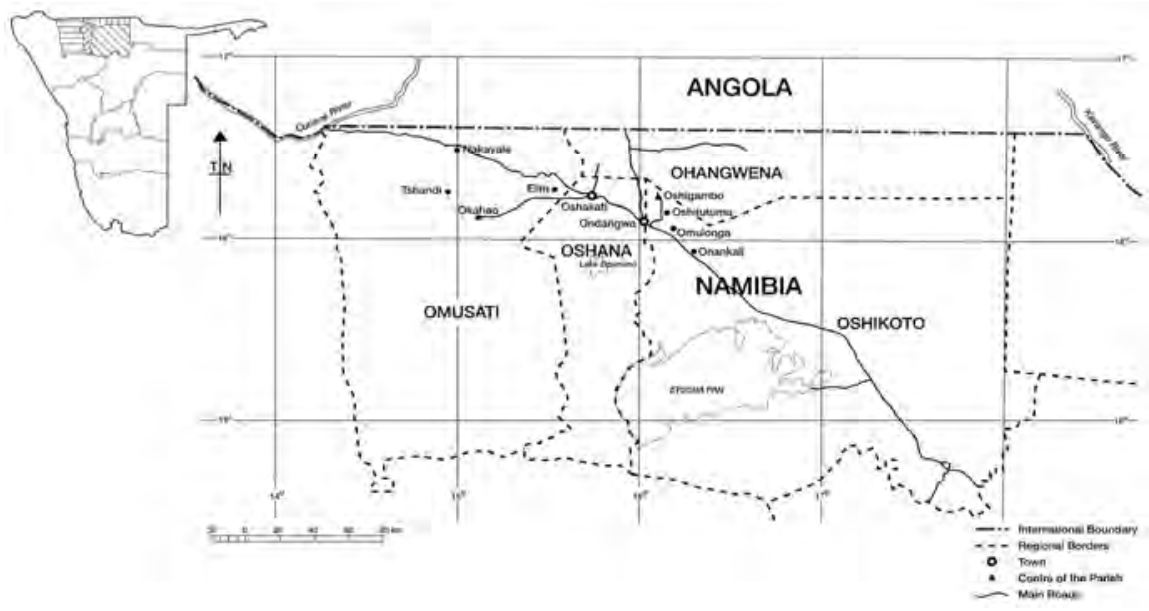

The parish registers of the sample congregations, i.e. the main books (also called family books) and the registers of deaths, baptisms and migration, were microfilmed. From this data, information concerning all the couples married during the years 19562000 was collected. The collected information included deaths, migrations and baptisms among these families, and also information on other events such as confirmations or possible expulsions from the congregation. The follow-up period continued until October 2003.

The original parish register data of the 1956-2000 marriage cohorts consisted of 6,354 marriages, out of which 1,651 (26\%) had to be excluded from the final data either 
because the couple could not be followed from one main book to the next one, or because no information concerning the couple was listed after their marriage. Of the women, 9\% lacked information concerning their year of birth. These cases were not included in the fertility analysis. In cases of missing day of birth, the $15^{\text {th }}$ day of the month was used as the person's birthday, and in case of a missing month of birth, the sixth month (June) was used. The final parish register data consists of 4,703 marriages and information on births, deaths, migrations, and some other events occurring among these families. The data used in fertility analysis for the period 1960-2000 consists of 4,421 women.

The original parish register data included 18,400 children born in the years 19502003. However, some of these births had to be excluded from the final data. The most common reason for excluding a birth was that the mother was not in the follow-up at the time of the birth. Other reasons for exclusion were poor follow-up of a marriage, the unknown birthday of the mother, or that the mother was under 15 or over 50 years old at the time of giving birth. Children whose birthdays were unknown and children born before the year 1950 were also excluded from the data. The total number of births in the final data was 15,134 . The number of births included in the fertility analysis for the years 1960-2000 was 14,365.

In the fertility analysis, the follow-up of women began on each person's fifteenth birthday or following her baptism. The data also therefore includes information on births occurring before a woman was married. When the time of baptism was unknown, follow-up started from the time of a woman's marriage. Follow-up ended if a woman was excommunicated from the parish or migrated out of it, and began again on her return. If the time of in-migration was unknown, the woman concerned was not included in the data unless she had migrated before her marriage. In such cases, followup began from the time of her marriage. Follow-up ended at the time of a woman's death or on her $50^{\text {th }}$ birthday.

One possible weakness of the church register data is that the children who have died before their baptism are missing. Nevertheless, the influence of this factor is reduced by the parental wish to have a weak or sick child baptised before his or her death. The sex ratio at birth (i.e. the number of males per 100 females) in this church register data was 97, while the normal figure is 104-107, probably indicating underreporting of children who have died before baptism. Church register data are therefore more useful for studying changes in fertility levels than studying precise levels of fertility. The mean age of children at baptism was 6.4 months.

In addition to fertility levels, this study examines the changes in age at first marriage, in the proportion of women with children born before marriage, in the proportion of childless women at the end of their reproductive period, and in the 
intervals between the second and third birth and between the third and fourth birth in the sample congregations.

\subsection{Population and Housing Censuses and Demographic and Health Surveys}

In addition to parish register data, this study utilises other available data sets. These include the Population and Housing Censuses of 1991 and 2001, and the Namibia Demographic and Health Surveys (NDHS) of 1992 and 2000. These data sets provide comparative data on fertility levels, as well as additional information on the determinants of fertility, e.g. the use of contraceptives. Reliable and available censuses for Namibia are the Population and Housing Censuses conducted in 1991 and 2001. The results of these censuses have been published both as analytical reports and as aggregate level tables by region, including, e.g., information about all children ever born and on children born in the 12 months preceding the census (Central Statistics Office 1993, 1994a, 1994b, Central Bureau of Statistics 2003). In addition to the 13 administrative regions, the 2001 Population and Housing Census results and tables were published at the level of administrative sub-regions, i.e. constituencies (e.g., Central Bureau of Statistics 2004a, 2004b, 2005a, 2005b). Moreover, Statistics Namibia produced some extra census tables from the 1991 Population and Housing Census for five out of eight of the sample congregations, i.e. for Elim, Nakayale, Oshigambo, Okahao, and Tshandi. These extra tables provided additional information on fertility, education, and the marital status of women in the sample congregation areas.

Data from the Namibia Demographic and Health Surveys (NDHS) of 1992 and 2000 are available both as individual level data-sets for computer analysis, and as published reports presenting the main results of the surveys (Ministry of Health and Social Services and Macro International 1993, Ministry of Health and Social Services 2003b). The 1992 NDHS data consisted of information on 5,421 women, which was representative of four large regional units, i.e. the Northwest, Northeast, Central and South Regions. The 2000 NDHS data consisted of 6,755 women and all the 13 regions of Namibia were included. In addition, the 1996 Intercensal Demographic Survey provide information concerning fertility in 1996 (Central Statistics Office n.d.).

\section{Methods}

The family reconstitution method (Wrigley 1966) was used to collect data from the microfilmed parish registers of the sample congregations (see Siiskonen, Taskinen, and Notkola 2005). Fertility was studied by means of Age-Specific Fertility Rates (ASFR) 
and total fertility (TFR), Marital Age-Specific Fertility Rates (MASFR) and total marital fertility (TMFR), and Coale's index of marital fertility $\left(I_{g}\right)$. Coale's index of marital fertility is an indirectly-standardised ratio which expresses the level of fertility as a proportion of the fertility a population would have had if it had experienced the highest fertility pattern reliably recorded (Newell 1988). These parameters were calculated to produce information on fertility levels and changes in them during the period from 1960 to 2000 .

Cohort fertility (CFR) was calculated so as to distinguish between the 'tempo' effect, i.e. changes in timing of childbearing, and the 'quantum' effect, i.e. changes in the completed child number (Newell 1988). Cohort fertility was calculated starting from the birth cohort of 1920-24 and the last birth cohort included was from the years 197579. The full set of Age-Specific Fertility Rates by birth cohort could be calculated for the 5-year birth cohorts beginning from 1940-44 until 1950-54, and the birth cohorts from 1935-39 and 1955-59 were only modestly affected by age truncation.

Data from the Population and Housing Census was analysed using indirect demographic analysis. Fertility was analysed using the Brass-type method, which is based on a comparison of period fertility with reported average parities, i.e. the socalled P/F ratio method based on the data for all children (United Nations 1983). The $\mathrm{P} / \mathrm{F}$ ratio method was chosen because of its comparability with the published Population and Housing Census results produced using this method.

\section{Fertility change in the sample congregations 1960-2000}

\subsection{Period fertility}

During the period from 1960 until 1979, total fertility was close to 6.5 children per woman (Figure 2). A decline in total fertility did not occur until the late 1970s, but some yearly fluctuation did take place. However, at the beginning of the $1980 \mathrm{~s}$, fertility began to decline. The decline was rapid until late in the same decade. In the late 1980s and early 1990s, the decline in fertility slowed and the level of total fertility remained stable until another decline started around 1994. The decline then continued until the end of the research period. 


\section{Figure 2: $\quad$ Total Fertility Rate in North-Central Namibia, 1960-1999}

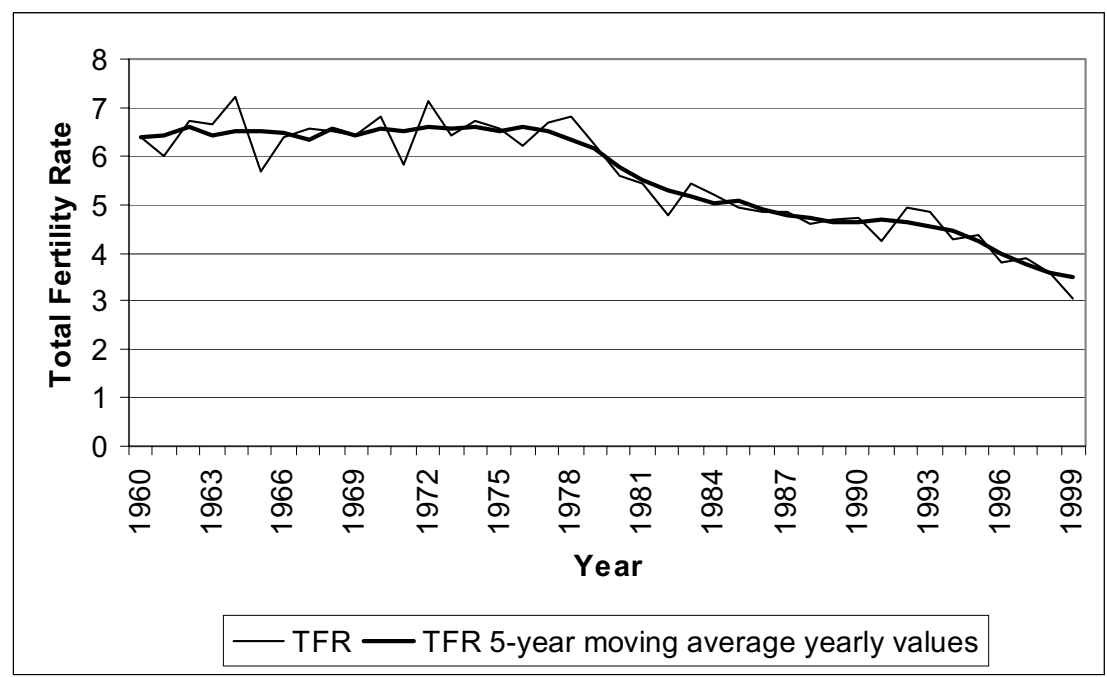

When total fertility is analysed using ten-year periods, it was about the same during 1960-69 and 1970-79, i.e. 6.4 and 6.5, respectively. Fertility declined sharply during the $1980 \mathrm{~s}$, and the total fertility during this decade was 5.1. The decline continued in the 1990s and total fertility fell to 4.2 in 1990-2000.

Marital fertility was high during the 1960s and most of the 1970s, with total marital fertility being around ten until the later half of the 1970s (Figure 3). The decline in total marital fertility began in the late 1970s, slightly earlier than the decline in overall total fertility. Marital fertility continued to decline until the end of the research period. The 5-year moving average of Coale's index of marital fertility $\left(I_{g}\right)$ for the sample congregations was above 0.7 until the year 1978 (Figure 3), meaning that marital fertility was approximately $70 \%$ of that of the Hutterites. In 1978-79, this average was below 0.7 and continued to decline until the end of the research period. The decline in marital fertility did not level off in a similar way to overall fertility during the late 1980s and early 1990s. 
Figure 3: Total Marital Fertility Rate and the Coale's index of marital fertility in North-Central Namibia, 1960-1999

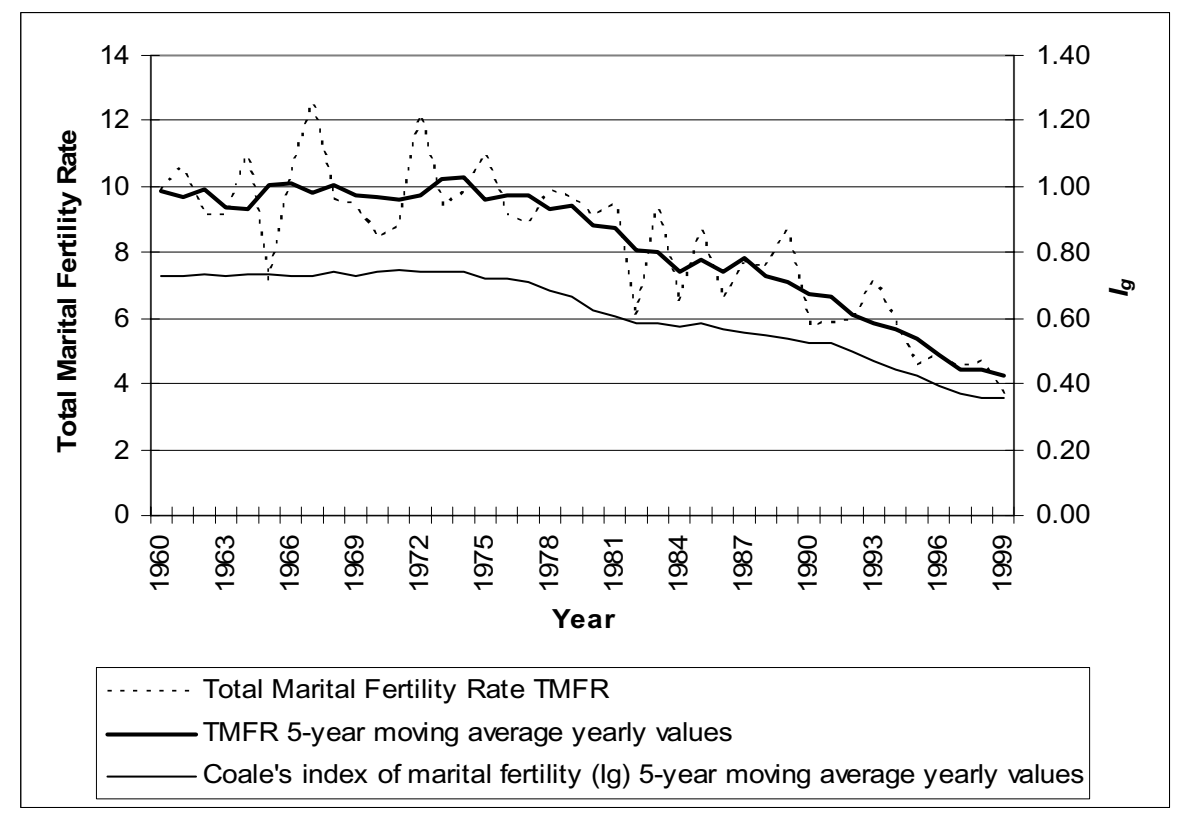

The Age-Specific Fertility Rates (ASFR) for the ten-year periods show that fertility is highest in three age groups (25-29, 30-34 and 35-39), with the peak level occurring in the 25-29 and 30-34 age groups (Figure 4). This is a typical age pattern for fertility for the former Ovamboland region, and this has been confirmed by both the census and Demographic and Health Survey data (e.g. Ministry of Health and Social Services and Macro International 1993, Raitis 1995). In this region, peak fertility occurs in older age groups than in other regions of Namibia (cf. Ministry of Health and Social Services and Macro International 1993, Raitis 1995) and in older age groups than the average for sub-Saharan Africa (cf. Robinson 1987).

During the periods 1960-69 and 1970-79, the level of Age-Specific Fertility Rates was relatively stable. Subsequently, fertility began to decline. The greatest reduction occurred during the 1980s, and the decline continued in the 1990s. Fertility declined in all age groups, except among 15-19 year-old women, whose fertility increased slightly. Throughout the research period, the age pattern of fertility remained fairly stable, except for a slight shift in the fertility peak from the 25-29 age group to the 30-34 age group which occurred between the 1960s and 1970s, and a systematic increase in fertility for the 15-19 age group. 
Figure 4: Age-Specific Fertility Rates (ASFR) in North-Central Namibia, 1960-2000

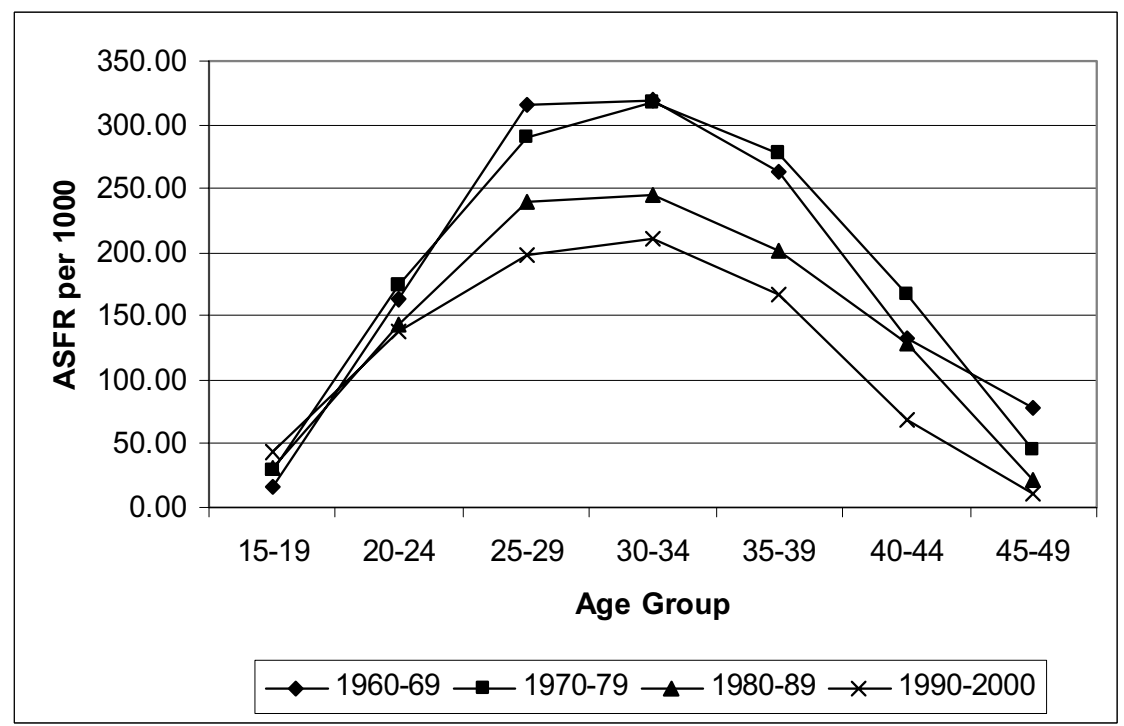

The yearly calculations of Age-Specific Fertility Rates show that the fall in fertility started at a different time in different age groups. The first age group showing a sign of fertility decline was the 25-29 age group, in which fertility declined slowly from the beginning of the 1970s and accelerated from the beginning of the 1980s. The ASFR of the 30-34 age group started to decline in the mid-1970s, and the ASFR of 35-39, 40-44 and 45-49 age groups began to decline in the late 1970s. In chronological terms, the last age group whose fertility started to decline was the 20-24 age group, among whose members fertility began to decline in the beginning of the $1980 \mathrm{~s}$. In contrast to the other age groups, the fertility of 15-19 year-olds started to increase in the early 1970s.

Fertility decline also shows up in the Marital Age-Specific Fertility Rates (Figure 5). The decline was the highest in the 1980s and continued in the 1990s. Contrary to the fertility of all women, there was no increase in marital fertility in the 15-19 age group in the 1980 s. 
Figure 5: Marital Age-Specific Fertility Rates (MASFR) in North-Central Namibia, 1960-2000

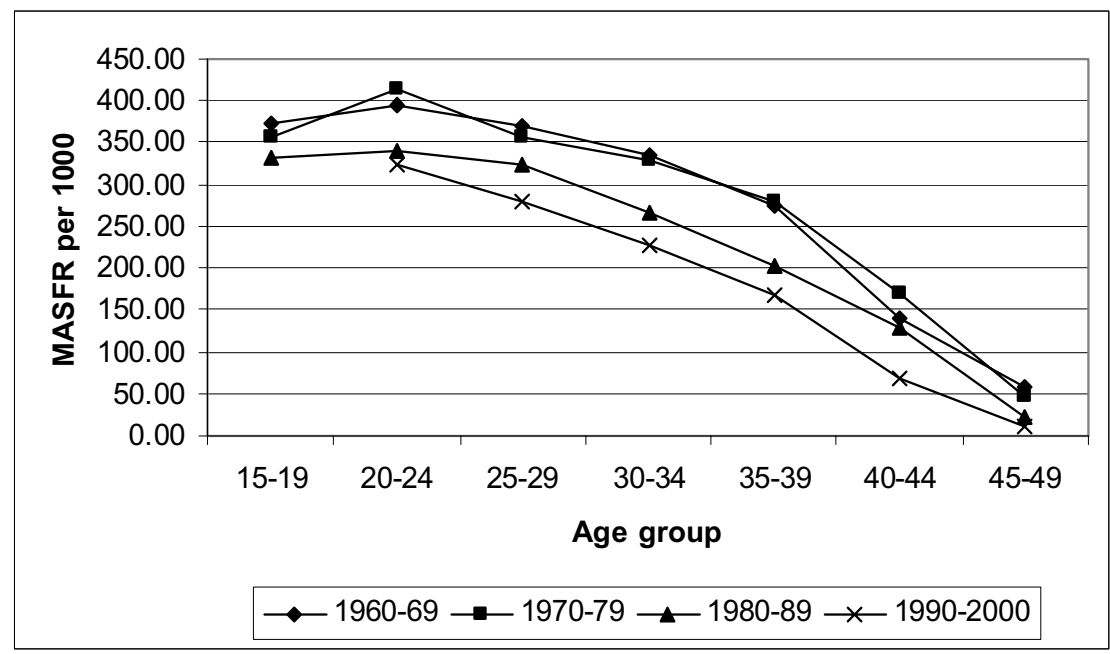

\subsection{Cohort fertility}

The full set of Age-Specific Fertility Rates by birth cohort were produced for the cohorts from 1935-39 to 1955-59. The ASFR of the youngest age group (15-19 years old) was partly censored in the 1935-39 birth cohort, and the same is true of the oldest age group (45-49 years old) in the 1955-59 birth cohort. This had, however, only a minor impact on the total cohort fertility of these birth cohorts. Annual analysis of total fertility by birth cohort shows that the decline in cohort fertility began from the birth cohorts of 1940-1942. Analysis using 5-year groups of birth year shows that total cohort fertility was 6.4 in the birth cohort of 1935-39 and had fallen to six in the birth cohort of 1940-44. In the birth cohort of 1955-59, it was 4.6.

Age-Specific Fertility Rates by birth cohort show that the decline occurred for the 25-29 age group and in age groups older than that (Figure 6). The fertility of 15-19 year-old women started to increase for the birth cohort of 1955-59.

Among the younger birth cohorts (not shown in the figure), the fertility of 15-19 year-olds remained at this new higher level until the birth cohort of 1970-74. Among the 1960-64 and 1965-69 birth cohorts, Age-Specific Fertility Rates also declined for 
the 20-24 age group, in contrast to older birth cohorts, among whom fertility among 2024 year old women remained stable.

\section{Figure 6: Age-Specific Fertility Rates by birth cohort in North-Central Namibia, 1935-39 to 1955-59 birth cohorts}

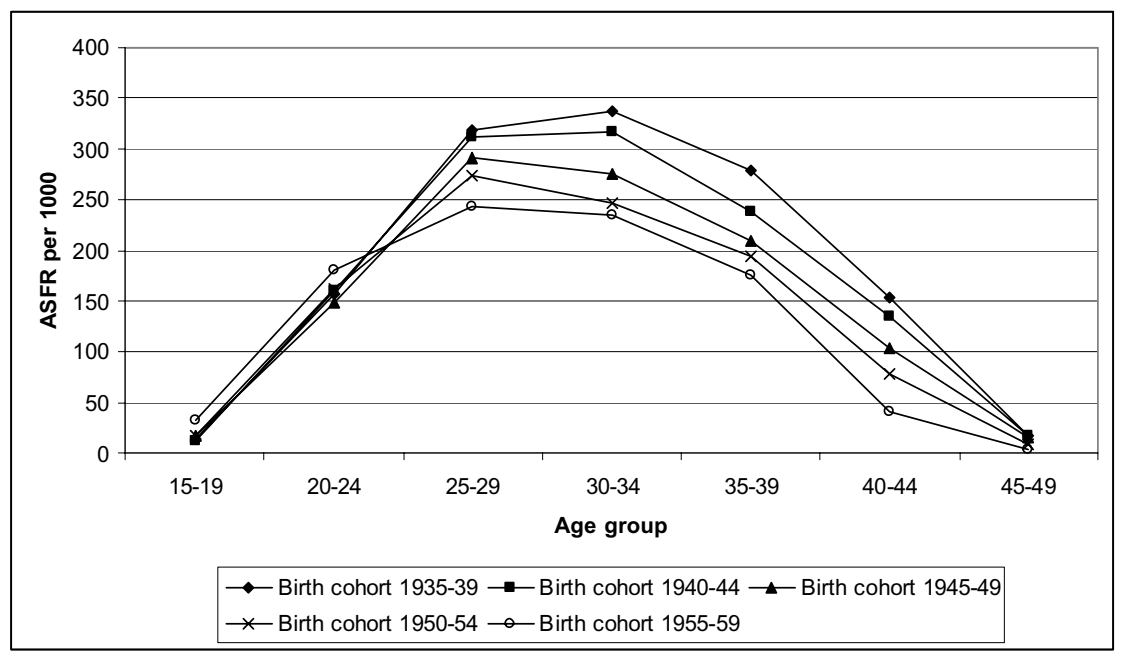

\subsection{Birth intervals, age at first marriage, pre-marital fertility, and childlessness}

Simultaneously with declining fertility, the median duration between births increased. This study examined intervals between the second and third births and intervals between the third and fourth births. The median of birth intervals was around 27 months until the end of the 1970s. It then began to increase and was 29 months at the end of the 1980s. This increase in birth intervals continued until the end of the research period, and in the late 1990s the median of birth intervals was around 34 months. The median length of birth interval was shorter if an older sibling had died at an age of less than one year in the 1960s and 1970s; later decades cannot be studied as there were too few cases.

Age at first marriage was quite stable during the first part of the study period. The mean age of females at first marriage was around 24 years and the median was around 23 years from 1956 until 1969. During the 1970s, age at first marriage began to slowly increase, and at the end of 1970 s, the mean age of females at first marriage was around 
25 years. The increase in the age of females at first marriage accelerated during the 1980 s. In the 1990s, the mean age of females at first marriage was around 30 years and the median age at first marriage was around 29 years. This very high age at first marriage has been confirmed by other studies. According to the 2000 NDHS (Ministry of Health and Social Services 2003b), median age at first marriage was 29 years among 30-49 year-old women in the Northwest Directorate. The increase in the mean age of males at first marriage started later than that for females, i.e. in the 1980s. The median age of males at first marriage was 34 years during the 1990s. The mean age difference between spouses was one year less in the 1970s than it was in the 1980s.

In the 1980s therefore, in parallel with the onset of fertility decline, the starting of marital life was moving to later age groups among both men and women. As women's entry into married life was postponed, its connection with the beginning of motherhood was weakened and the proportion of women who bore children before marriage increased. While $9-11 \%$ of the women who married at an age of less than 30 years had given birth to a child in 1956-1979, the corresponding proportion in the 1990s was $29 \%$. Parish registers also contain information about fathers of children. Provided that this information is accurate, an increasing proportion of couples had a child in common before their marriage. The proportion of women who had a child with their future husbands before marriage was $27 \%$ of all women (married at any age) in the 1990s, in the 1960 s this figure was $10 \%$.

The level of premarital fertility increased slightly during the early 1970 s, was stable in the second half of the 1970s and the first half of the 1980s, and began to increase strongly from the mid-1980s. This increase continued until the end of the research period.

Among the women who married before the age of 30, the proportion of those who were childless at the age of 45 was $2-5 \%$ in the 1956-1989 marriage cohorts, indicating a normal level of primary sterility in a study population in a sub-Saharan African context. Due to age truncation, the proportion of childless women at the age of 45 among women who married before the age of 30 cannot be estimated for the years 1990-2000.

\subsection{Comparison between parish registers and other data}

Comparison of parish register results with other sources is hampered by different regions and periods. Other sources usually provide data for broader administrative units and start from the year 1990 .

A sub-sample of 1991 Population and Housing Census data consisting of five out of eight sample congregations shows that fertility was in general somewhat lower in the 
parish register data than in the census data, although different reference periods, study populations and estimation methods hamper comparison. In the early 1990s, total fertility in the sample parishes was approximately 4.6. According to calculations made from 1991 census data, total fertility in five out of the eight sample congregations varied from 5.1 in Tshandi to 6.4 in Oshigambo (Table 1).

Table 1: Total fertility by congregation and administrative region

\begin{tabular}{|c|c|c|c|c|c|c|}
\hline Congregation & $1960-69$ & $1970-79$ & $1980-89$ & $1990-2000$ & $1991^{*}$ & 2001\# \\
\hline Elim & 6.8 & 6.6 & 6.4 & & 5.7 & 2.9 \\
\hline Nakayale & 7.5 & 6.5 & 4.5 & 3.1 & 5.6 & 3.6 \\
\hline Okahao & 5.7 & 6.1 & 4.6 & 3.3 & 5.6 & 3.1 \\
\hline Oshigambo & 5.9 & 6.9 & 5.0 & 4.2 & 6.4 & 4.0 \\
\hline Tshandi & 6.3 & 6.7 & 4.5 & 3.2 & 5.1 & 5.9 \\
\hline Onankali & 3.3 & 4.6 & 6.0 & 5.2 & & 4.0 \\
\hline Omulonga & & & & 3.7 & & 4.2 \\
\hline Oshitutuma & & & & 4.5 & & 4.0 \\
\hline All congregations & 6.4 & 6.5 & 5.1 & 4.2 & 5.7 & 4.0 \\
\hline Region & $1991^{* *}$ & $1990-92$ *** & $1996+$ & $1998-2000++$ & 2001 ** & \\
\hline Oshana & 5.6 & & 4.8 & 3.3 & 3.7 & \\
\hline Omusati & 5.7 & & 4.9 & 5 & 4 & \\
\hline Oshikoto & 6.7 & & 4.7 & 4.3 & 4.6 & \\
\hline Ohangwena & 7.7 & & 6.9 & 6.5 & 5.3 & \\
\hline $\begin{array}{l}\text { Northwest Health } \\
\text { Directorate }\end{array}$ & 6.8 & 6.7 & 5.3 & 4.7 & 4.4 & \\
\hline
\end{tabular}

Notes:

* Indirect estimates (P/F ratio method) from the 1991 Population and Housing Census data

** The 1991 Population and Housing Census (Central Statistics Office 1993), the 2001 Population and Housing Census (Central Bureau of Statistics 2003), and indirect estimates of 1991 and 2001 census data

*** Namibia Demographic and Health Survey (NDHS) 1992

+ Intercensal Demographic Survey 1996 (Central Statistics Office n.d.)

++ Namibia Demographic and Health Survey (NDHS) 2000 (Ministry of Health and Social Services 2003b)

\# Fertility in the constituency area where congregation is located, according to the 2001 census (Central Bureau of Statistics 2004a, 2005a)

One possible explanation for lower fertility in parish register data is the underregistration of children who died before baptism. Also, comparison between censusbased results from the sample congregation regions and census results for the whole Northwest Health Directorate shows that total fertility in the congregation regions in 1991 was lower than that for the whole Northwest Health Directorate, i.e. 5.7 as compared to 6.8 , respectively.

The 2001 census results were also given by constituency. These administrative sub-regions are a long way from being identical to congregations, but may provide 
some additional information for regions in which congregations are located. The 2001 census results for the same five congregation areas included in the sub-sample of the 1991 census show that fertility was lowest in Elim, i.e. 2.9, and highest in Tshandi, i.e. 5.9. The three other congregations were located in constituencies where total fertility varied from 4.0 to 4.2 .

There are many possible explanations for the difference in fertility between the congregation regions and the average for the Northwest Health Directorate. The 1991 census data show that on average, the proportion of never-married women was higher in every age group in the congregation regions than in the Northwest Health Directorate. It also seems probable that the educational level in congregation regions is higher than the average for North-Central Namibia. In 1991, the proportion of people without any formal education was smaller in the congregation regions than in the Northwest Health Directorate in general. Similarly, in 2001, in constituency regions where congregations were located, the literacy rate was higher and the proportion of people without any formal education was smaller among members of the population aged 15 years or more.

Total fertility based on census data for the five congregation regions in 1991 and for the constituency regions of congregations in 2001 was on average 0.7 children higher than total fertility based on parish register data (rate ratio 1.18). Assuming that this difference was similar in earlier periods, this would mean that the real level of total fertility was close to 7.6 in the period 1960-1979 and 6.0 in the period 1980-89.

For the whole Northwest Health Directorate, the 1991 census estimate is very close to the 1992 NDHS estimate for the 0-3-year period prior to the survey, i.e. 6.8 compared to 6.7, respectively. The 2000 NDHS estimated that total fertility in the period 0-3 years prior to the survey was 4.7 , while the 2001 census estimated that total fertility was 4.4 during the 12 -month period preceding the census.

\section{Conclusions and discussion}

\subsection{Fertility decline started in 1980 and was most rapid during the early $1980 \mathrm{~s}$}

The parish registers of North-Central Namibia proved to be a useful addition to conventional demographic sources, especially in the case of Namibia, where reliable data from the long period of colonial rule have been lacking. These data allowed for precise timing of the onset of fertility decline among the study population, which occurred before the current reliable surveys and censuses were conducted in the independent Namibia. Continuous register-based data also provides an opportunity to study the pace of fertility decline. 
Earlier research on fertility trends in the historical Ovamboland region has shown that in 1925, total fertility was almost eight and total marital fertility around ten (Notkola and Siiskonen 2000). Fertility declined during the 1940s, most likely as a result of the increased migration of male labour. Fertility began to increase in the late 1950 s, with the probable cause being a reduction in infertility resulting from improved treatment of STDs. Simultaneously, increased coverage for vaccinations improved general levels of health in the population. This study shows that fertility was high from the beginning of the 1960s until the end of the 1970s. During this period, the Total Fertility Rate was around 6.5 and the Total Marital Fertility Rate was almost ten. In 1979-80, or in the case of marital fertility some 2-3 years earlier, fertility began to decline from its plateau level (cf. Casterline 2001). This decline continued throughout the research period, and was identified in all the fertility indicators employed. In 1980, the fall in both the TFR and TMFR exceeded $10 \%$, a conventionally accepted marker of the beginning of a fertility transition (cf. Coale and Treadway 1986, Caldwell, Orubuloye, and Caldwell 1992).

During the early 1980s, the pace of fertility decline was highest. After the War of Independence in the early 1990s, the decline in fertility levelled off although marital fertility continued to decline. In 1994, fertility started falling again, and the decline continued until the end of the research period.

\subsection{Cohort fertility shows a decline in completed number of births}

As a long-term register-based data set, parish registers provide an opportunity to study cohort fertility, an opportunity which is relatively rare in sub-Saharan Africa. This examination proved that a real change towards smaller completed number of births per woman has taken place, not only a change in the timing of births along each woman's lifespan. The reduction in cohort fertility started with the birth cohort of 1940. A decline in cohort fertility exceeded the 5\% marker in the 1941 birth cohort (cf. Bongaarts 2002) and the $10 \%$ marker in the 1942 birth cohort. While the completed number of births was 6.4 among women born in 1935-39, it was 4.6 among those born in $1955-59$.

\subsection{Disparity in fertility development between adolescents and other women}

Parish registers also allow for an examination of long-term changes in the fertility rates of specific age-groups. We were therefore able to discover among which age groups the decline began, and whether a decline occurred among women in all age-groups. 
Fertility decline started among 25-29 year-old women in the early 1970s, and the decline in this age group was followed by women of 30-34 years, whose fertility began to decline in the mid-1970s. A comparison of Age-Specific Fertility Rates using 10year periods in the 1960s, 1970s, 1980s, and 1990s show that in the 25-29 age group and among women older than that, fertility declined in every 10 -year period. This is a phenomenon typical of sub-Saharan Africa, where fertility regulation is used more for spacing out births than for stopping childbearing. Cohort fertility declined in the 25-29 age group and among older age groups in the 1935-39 - 1955-59 birth cohorts.

Fertility in the youngest age group, i.e. 15-19 year-old women, increased in all the 10-year periods studied. In terms of cohort fertility, the fertility of the 15-19 age group increased among the birth cohort of 1955-59 and subsequently reached a new, higher level. In this respect, our study region differs from many other regions of sub-Saharan Africa where the fertility of young women is declining as a result of the increasing use of contraceptives by young, unmarried women (see e.g. Caldwell, Orubuloye, and Caldwell 1992, Kirk and Pillet 1998). This phenomenon appears to be typical of the Southern African fertility regime. Our study region shares the experience of increasing adolescent fertility with the neighbouring countries of Botswana, Zambia and Zimbabwe (cf. Chimere-Dan 1997, United Nations 2004). A high level of adolescent fertility has also been reported in South Africa (Garenne, Tollman, and Kahn 2000, Dickson 2003).

An increase in the age of females at first marriage started in the 1970s, accelerated in the 1980s, and continued until the end of research period. Together with an increase in adolescent fertility, this resulted in an increasing level of premarital fertility. In their analysis of South African fertility, Garenne, Tollman, and Kahn (2000) found a twopeaked fertility system, in which extra-marital fertility peaked among the younger age group. This system also seems to be applicable in the case of North-Central Namibia.

\subsection{Contraceptive prevalence increased}

In the early 1970s, the South African colonial government introduced modern contraceptive methods to Namibia. Family planning services were gradually expanded, especially after 1979, when the training of professional and sub-professional nurses began (Ministry of Health and Social Services 1995). Before Independence, family planning services as well as the selection of methods were segregated in accordance with ethnic groups (Lucas 1992). For the indigenous majority, proper advisory services were not available and the methods most commonly used were injectables and the Pill.

Hospital statistics show that the distribution of contraceptives in North-Central Namibia had already started during the 1980s (Notkola and Siiskonen 2000). 
Contraceptives were distributed in hospitals under an action called family spacing. The methods used were the Pill and injections (Depo-Provera). Between 1st April 1984 and 31st March 1985, 20,514 doses of Depo-Provera were given. The Pill was used to a lesser extent. From 1983 to 1984, the number of Depo-Provera doses was 6,735. From 1985 to 1986, Depo-Provera was also distributed less than in the 1984 to 1985 period, so it is possible that a special family planning campaign was initiated in North-Central Namibia in 1984. (Notkola and Siiskonen 2000). During the 1980s, there are also some mentions of IUDs in hospital reports. The Pill possibly outnumbered injections as the primary contraceptive method in the 1990 s, but in the 2000 s, injections once again became the most popular method, followed by the Pill. According to family planning workers in Oshigambo clinic (1994b), the Pill was recommended to younger women and injections were recommended for older women. (Lutheran Medical Mission 1985, 1988, 1991, Lutheran Medical Service 1994, Oshakati Health Centre 1994a, 1994b, Oshigambo Clinic 1994a, 1994b, Onandjokwe District DDC 2003, 2004, Onandjokwe Lutheran Medical Service 1999.)

At the beginning of independence, accusations of malpractice (especially in connection with Depo-Provera) together with pro-natal opinions held by some political leaders may have created prejudices against contraception. On the other hand, those who were interested in using contraceptives faced the problem of insufficient family planning services. (Cleaver and Wallace 1990, Ahrensen-Pandikow 1992, Lucas 1992, Marcus and Baden 1992, Ministry of Health and Social Services 1995.)

Surveys show that contraceptive prevalence was low in the study region in the early 1990s (UNICEF Namibia 1991, Ahrensen-Pandikow 1992, Namibia Development Trust 1994) and increased quickly during the 1990s (Ministry of Health and Social Services 2003b). In 1992, only 7\% of currently-married women were using some modern contraceptive method, while in $2000,26 \%$ of currently-married women and $39 \%$ of all sexually-active women were using modern contraceptives (Ministry of Health and Social Services and Macro International 1993, Ministry of Health and Social Services 2003b).

Primary and secondary sterility are caused by e.g. sexually-transmitted diseases (STDs). These have been present in this region from at least the beginning of the $20^{\text {th }}$ century (Notkola and Siiskonen 2000), but were, however, cured in a relatively-efficient manner. Notkola and Siiskonen assume that increasing treatment of the STDs contributed to the increase of fertility during the 1960s. Primary sterility can be estimated by calculating the proportion of women married before the age of 20 who remain childless at the end of their reproductive period. The average for primary sterility in sub-Saharan Africa is 3-6\%. In North-Central Namibia, the average age at first marriage is higher than in sub-Saharan Africa in general, and we therefore 
examined the proportion of childless females among women married before the age of 30 . Among these women, the proportion remaining childless at the age of 45 is $2-5 \%$.

\subsection{Causes of fertility decline: The changing cultural and socio-economical context in the study region}

The decline in fertility that began in 1980 was connected with long-term social changes in the study region. These changes have deep roots. Christianisation, the contract labour system, increasing levels of female education and the War of Independence are some of the factors which have contributed to this change.

Christianisation, which began in the late nineteenth century, began to erode the initiation into womanhood which was an important part of the system used to control adolescent childbearing, and also played an important role in the education of young women concerning reproduction. The Christian ideal of monogamous and life-long marriage reshaped the marital system, which, together with male absenteeism resulting from the contract labour system, increased women's vulnerability and led to attempts to redefine the marital and social systems (Tuupainen 1970, McKittrick 1997, 2002, Fox 2002).

In the study region, both courtship and the marital system are complicated. Many young women express their hope of protecting their independence by remaining unmarried. At the same time, however, many young women and single mothers are economically dependent on their lovers, and may even have multiple partners to guarantee adequate levels of economic assistance. Even though some young men and women have low regard for marriage as an institution, others seek the safety offered by an official union. Getting pregnant in a lover-relationship may, for the woman, be a means of obtaining increased economic support from her partner, safeguarding the continuity of the relationship, or improving the chances of an official marriage with her partner. The burden of a premarital child is also diminished by the tradition of child fostering; in many cases the child's grandparents rather than the young mother take care of her/him. There are also many types of marital union, and many factors influence the decision on which one will be chosen. Even among married couples, living separately is relatively common. (LeBeau et al. 1999, 2002, Tersbøl 2002, Research Facilitation Services and Health Communication Partnership 2004.)

The contract labour system and the War of Independence caused prolonged periods of spousal separation in the study region during the research period. The contract labour system has a long history in the study region; it was introduced by the German colonial rulers and was continued by the South Africans during their period of administration which started in 1915. The volume of labour migration within the 
contract labour system was so high that it affected levels of fertility in the study region: according to Notkola and Siiskonen (2000), an increasing number of male labour migrants and their lengthened contract periods was the main reason for the decline on fertility during the $1940 \mathrm{~s}$ and $1950 \mathrm{~s}$. The number of labour migrants recruited from Ovamboland increased from 14,557 to 35,577 between 1960 and 1974, respectively (Notkola and Siiskonen 2000). Starting from the 1970s, the system used to control migrant labour started to lose its power. Migrant labour from the study region has continued until the present day, but the improved availability of transportation during the current decade may have diminished its impact on spousal separation.

The War of Independence resulted in spousal separation, and probably also resulted in delayed marriages during the 1970s and 1980s. North-Central Namibia shares the experience of Zimbabwe, where fertility declined during the war and that decline continued after a short period of stagnation after the war ended (Muhwava and Timæus 1996). In the study region, as in Zimbabwe, a significant number of men were expatriated during the war. The exact number of those who left the country is unknown, but within a period of eight months before Namibia's independence in March 1990, 43,387 registered exiles returned to the country, and some $80 \%$ of them returned to their homes in the study region by 1990 (Tapscott and Mulongeni 1990, Webb and Simon 1995). In Angola, Agadjanian and Prata (2002) discovered that war reduced fertility especially in regions most heavily affected by fighting, and also among the moreeducated and more-affluent segments of the population.

Also, the roles women adopted during the fight for independence may have changed both their values and their status in society. The War of Independence was also associated with urbanisation in the study region. The war economy offered working opportunities and attracted young women and men to the expanding cities (Van der Merwe 1989, Pendleton, LeBeau, and Tapscott 1992).

Among socio-economic differentials in fertility, the most extensively studied, and consequently the best known, are educational fertility differentials. Women with a higher educational status have a lower fertility than their counterparts with a lower educational status (e.g. Jejeebhoy 1995, Martín 1995, Wils and Goujon 1998, Lutz and Goujon 2001, Cleland 2002, Bongaarts 2003). Fertility differentials are also closely related to socio-economic factors, especially to female education, in Namibia (Arowolo 2000, Hamata n.d.).

In the study region, education, including female education, began early, once again as a result of the presence of missionaries. During the apartheid period in South Africa, a so-called Bantu education system was introduced. In North-Central Namibia, however, missionary schools and churches continued with their educational work. Educational levels are probably higher in the congregation regions than in NorthCentral Namibia on average: according to the 1991 and 2001 population and housing 
censuses, the average literacy rate is higher and the average proportion of people without any formal education is lower in regions where congregations are located than in other regions of the Northwest Health Directorate on average.

\subsection{Contribution of HIV and AIDS to fertility decline}

Several studies have shown that HIV-positive women have lower level of fertility than their HIV-negative counterparts in sub-Saharan Africa (Ryder et al. 1991, Ntozi, Nakanaabi, and Lubaale 1997, Gray et al. 1998, Glynn et al. 2000, Hunter et al. 2003, Lewis et al. 2004). HIV/AIDS affects the level of fertility via both biological and behavioural mechanisms. HIV-infected women have lower rates of conception and increased rates of foetal loss compared with HIV-negative women, partly because of co-infections with the other STDs (Carpenter et al. 1997, Gray et al. 1998, Zaba and Gregson 1998, Ross et al. 1999, Crampin et al. 2003). Also, HIV/AIDS may change reproductive behaviour in $\mathrm{HIV}$-affected societies and thus affect the level of fertility (Gregson et al. 1997, Zaba and Collumbien 1997, Kamali et al. 2000, Rutenberg, Biddlecom, and Kaona 2000, Gregson, Zaba, and Hunter 2002, Caldwell and Caldwell 2003, Du Plessis 2003, Terceira et al. 2003). Based on the experience of several regions in sub-Saharan Africa, Zaba and Gregson (1998) have estimated the impact of the HIV pandemic on fertility at the population level. According to their results, an increase of $1 \%$ in HIV-prevalence is associated with a reduction of $0.4 \%$ in total fertility.

The results from HIV sentinel surveillance show that HIV-prevalence in 1992 among pregnant women was $4 \%$ in Oshakati in North-Central Namibia. This may be higher than the overall prevalence in the region in general, because Oshakati is an urban centre and most of the region is rural. In 1996, the average HIV-prevalence of three sentinel sites located in the study region was $19 \%$, whereas in 2000 , the average HIVprevalence in four sentinel sites located there was 24\%. In 2004, there were five sentinel sites in the study region. HIV-prevalence among pregnant women varied from $18 \%$ to $27 \%$, depending on the site. HIV-prevalence among pregnant women declined between 2002 and 2004 at all but one of the sentinel sites. The average HIV-prevalence in these sentinel sites declined from $25 \%$ in 2002 to $23 \%$ in 2004 (Shemeikka 1999, Ministry of Health and Social Services 2003a, 2004).

Assuming that the sentinel-site prevalence rates are accurate, and using the $0.4 \%$ reduction in fertility per $1 \%$ HIV prevalence, HIV infections would have caused a decline of $1.6 \%$ in total fertility in the early $1990 \mathrm{~s}$. This means a reduction of approximately 0.1 children per woman in total fertility in the study region. From 1996 onwards, the decline in total fertility would have been around $8-10 \%$, which would mean a reduction of around $0.4-0.5$ children per female in total fertility. Among the four 
administrative regions of the Northwest Health Directorate (Ohangwena, Omusati, Oshana and Oshikoto), the fertility decline varied from 0.1 children to 1.6 children in the years 1996 to 2001, and the average fertility decline for the whole Northwest Health Directorate was 0.9 children between 1996 and 2001 (Central Statistics Office n.d., Central Bureau of Statistics 2003). HIV infections affecting women are therefore probably one important explanation for declining fertility during the second half of the 1990s.

The parish records of North-Central Namibia provide a data set that can be used for register-based demographic analysis. In the sub-Saharan African context, this data set is rather unique. In this study, parish register data has been used to examine fertility trends from 1960 to 2000. It appears that the parish register data can provide important new information on fertility decline in the former Ovamboland region during the past decades. Compared to retrospective surveys, parish register data allows more accurate timing of both the beginning of fertility decline and changes in fertility among different age groups. Long-term data also allows for an examination of cohort fertility, thus helping to distinguish between the tempo and quantum effects of fertility. Although levels of fertility according to parish register data may differ from other data sets, mainly because of the under-registration of children who have died prior to baptism, parish registers appear to be a promising source of data for the analysis of demographic trends.

\section{Acknowledgments}

The authors wish to thank the Evangelical Lutheran Church in Namibia and its clergy for access to these data, $\mathrm{Mr} \mathrm{O}$. Lemström for computing assistance, and $\mathrm{Mr} \mathrm{K}$. Miettinen for his valuable comments. This research was funded by grants from the Academy of Finland and the Emil Aaltonen Foundation. 


\section{References}

Agadjanian, Victor, Ndola Prata. (2001). "War and Reproduction: Angola's Fertility in Comparative Perspective.” Journal of Southern African Studies, 27, 2: 329-347.

Agadjanian, Victor, Ndola Prata. (2002). "War, Peace and Fertility Angola." Demography, 39, 2: 215-231.

Ahrensen-Pandikow, Helena. (1992). Survey of Attitudes Towards the Use of Contraceptives in Namibia. Namibian Institute for Social and Economic Research (NISER), Research Report 15. Windhoek: University of Namibia.

Arowolo, O.O. (2000). Fertility in Namibia. In: Ben Fuller, Isolde Prommer, Wolfgang Lutz, editors. Population-Development-Environment: Background Readings on Namibia. Laxenburg, Austria: International Institute for Applied Systems Analysis (IIASA): 253-271.

Bongaarts, John. (2002). The End of the Fertility Transition in the Developing World. In: Completing the Fertility Transition. Part Three: Country Papers. United Nations Population Division, Department of Economic and Social Affairs: 288307.

Bongaarts, John. (2003). "Completing the Fertility Transition in the Developing World: The Role of Educational Differences and Fertility Preferences." Population Studies, 57, 3: 321-336.

Caldwell, John C., Pat Caldwell. (2003). The Fertility Transition in Sub-Saharan Africa. In: Fertility: Current South African Issues of Poverty, HIV/AIDS and Youth. Seminar Proceedings. Human Sciences Research Council (HSRC) and Department of Social Development. Cape Town, South Africa: HSRC Publishers: 117-123.

Caldwell, John C., I.O. Orubuloye, Pat Caldwell. (1992). "Fertility Decline in Africa: A New Type of Transition?" Population and Development Review, 18, 2: 211-242.

Carpenter, Lucy M., Jessica S. Nakiyingi, Anthony Ruberantwari, Samuel S. Malamba, Anatoli Kamali, James A.G. Whitworth. (1997). "Estimates of the Impact of HIV Infection on Fertility in a Rural Ugandan Population Cohort." Health Transition Review, 7, Suppl. 2: S113-S126.

Casterline, John B. (2001). "The Pace of Fertility Transition: National Patterns in the Second Half of the Twentieth Century." Population and Development Review, 27, Supplement: 17-52. 
Central Bureau of Statistics [Namibia]. (2003). 2001 Population and Housing Census. National Report: Basic Analysis with Highlights. Central Bureau of Statistics, National Planning Commission. Windhoek

Central Bureau of Statistics [Namibia]. (2004a). 2001 Population and Housing Census. Oshikoto Region: Basic Analysis with Highlights. Central Bureau of Statistics, National Planning Commission. Windhoek.

Central Bureau of Statistics [Namibia]. (2004b). 2001 Population and Housing Census. Oshana Region: Basic Analysis with Highlights. Central Bureau of Statistics, National Planning Commission. Windhoek.

Central Bureau of Statistics [Namibia]. (2005a). 2001 Population and Housing Census. Omusati Region: Basic Analysis with Highlights. Central Bureau of Statistics, National Planning Commission. Windhoek.

Central Bureau of Statistics [Namibia]. (2005b). 2001 Population and Housing Census. Ohangwena Region: Basic Analysis with Highlights. Central Bureau of Statistics, National Planning Commission. Windhoek.

Central Statistical Office [Botswana]. (2004). Demography and Tourism Statistics. Http://www.cso.gov.bw/cso/demo_stats.html. Accessed March, 2004.

Central Statistical Office [Zambia], Central Board of Health [Zambia], ORC Macro. (2003). Zambia Demographic and Health Survey 2001-2002. Calverton, Maryland, USA: Central Statistical Office, Central Board of Health, and OCR Macro.

Central Statistical Office [Zimbabwe], Macro International Inc. (1995). Zimbabwe Demographic and Health Survey 1994. Calverton, Maryland: Central Statistical Office and Macro International Inc.

Central Statistical Office [Zimbabwe], Macro International Inc. (2000). Zimbabwe Demographic and Health Survey 1999. Calverton, Maryland: Central Statistical Office and Macro International Inc.

Central Statistics Office [Namibia]. (1993). 1991 Population and Housing Census. Report A. Statistical Tables. Volumes I-V. Central Statistics Office, National Planning Commission. Windhoek.

Central Statistics Office [Namibia]. (1994a). 1991 Population and Housing Census: Basic Analysis with Highlights. Central Statistics Office, National Planning Commission. Windhoek. 
Central Statistics Office [Namibia]. (1994b). 1991 Population and Housing Census. Report B. Statistical Tables. Central Statistics Office, National Planning Commission. Windhoek.

Central Statistics Office [Namibia]. (n.d.) Printout of Selected Results from the 1996 Intercensal Demographic Survey. Central Statistics Office, National Planning Commission. Windhoek

Chimere-Dan, Orieji. (1997). "Non-Marital Teenage Childbearing in Southern Africa: The Case of Namibia." African Population Studies, 12, 2: 87-95.

Cleaver, Tessa, Marion Wallace. (1990). Namibia Women in War. Guildford and King's Lynn, UK: Zed Books.

Cleland, John. (2002). Education and Future Fertility Trends, With Special Reference to Mid-Transitional Countries. In: Completing the Fertility Transition. Part Two Background Papers. United Nations Population Division, Department of Economic and Social Affairs: 187-202.

Coale, Ansley J., Roy Treadway. (1986). A Summary of the Changing Distribution of Overall Fertility, Marital Fertility, and the Proportion of Married in the Provinces of Europe. In: A.J. Coale, S.C. Watkins, editors. The Decline of Fertility in Europe. Princeton: Princeton University Press: 31-181.

Crampin, Amelia C., Judith R. Glynn, Bagrey M.M. Ngwira, Frank D. Mwaungulu, Jörg M. Pönnighaus, David K. Warndorff, Paul E.M. Fine. (2003). "Trends and Measurement of HIV Prevalence in Northern Malawi." AIDS, 17, 12: 18171825 .

Dickson, Kim Eva. (2003). Adolescent Fertility: A Population Concern. In: Fertility: Current South African Issues of Poverty, HIV/AIDS and Youth. Seminar Proceedings. Human Sciences Research Council (HSRC) and Department of Social Development. Cape Town, South Africa: HSRC Publishers: 59-71.

Du Plessis, Gretchen. (2003). HIV/AIDS and Fertility. In: Fertility: Current South African Issues of Poverty, HIV/AIDS and Youth. Seminar Proceedings. Human Sciences Research Council (HSRC) and Department of Social Development. Cape Town, South Africa: HSRC Publishers: 77-116.

ELCIN (Evangelical Lutheran Church in Namibia). (2002). ELCIN Statistics: Reports and Tables 2002. Ondangwa, Namibia.

Erkkilä, Antti. (2001). Living on the Land: Change in Forest Cover in North-Central Namibia 1943-1996. Silva Carelica 37. Joensuu, Finland: University of Joensuu. 
Erkkilä, Antti, Harri Siiskonen. (1992). Forestry in Namibia 1850-1990. Silva Carelica 20. Joensuu, Finland: University of Joensuu.

Fox, Tom. (2002). The Culture(s) of AIDS - Cultural Analysis and New Policy Approaches for Namibia. In: Volker Winterfeldt, Tom Fox, Pempelani Mufune, editors. Namibia Society Sociology. Windhoek: University of Namibia Press: 317-331.

Gage, Anastasia J. (1998). "Premarital Childbearing, Unwanted Fertility and Maternity Care in Kenya and Namibia." Population Studies, 52, 1: 21-34.

Gaisie, S. Kwesi. (1995). "Determinants of Fertility Decline in Botswana." African Population Studies, 10, 1. Union of African Population Studies. Http://www.uaps.org. Accessed January, 2004.

Garenne, Michel, Stephen Tollman, Kathleen Kahn. (2000). "Premarital Fertility in Rural South Africa: A Challenge to Existing Population Policy." Studies in Family Planning, 31, 1: 47-54.

Glynn, Judith R., Anne Buvé, Michel Garaël, Maina Kahindo, Isaac B. Macauley, Rosemary M. Musonda, Eva Jungmann, Francis Tembo, Leopold Zekeng. (2000). "Decreased Fertility Among HIV-1-Infected Women Attending Antenatal Clinics in Three African Cities." Journal of Acquired Immune Deficiency Syndromes, 25, 4: 345-352.

Gray, Ronald H., Maria J. Wawer, David Serwadda, Nelson Sewankambo, Chuanjun Li, Frederick Wabwire-Mangen, Lynn Paxton, Noah Kiwanuka, Godfrey Kigozi, Joseph Konde-Lule, Thomas C. Quinn, Charlotte A. Gaydos, Denise McNairn. (1998). "Population-Based Study of Fertility in Women with HIV-1 Infection in Uganda." Lancet, 351, 9096: 98-103.

Gregson, Simon, Tom Zhuwau, Roy M. Anderson, Stephen K. Chandiwana. (1997). "HIV and Fertility Change in Rural Zimbabwe." Health Transition Review, 7, Suppl. 2: S89-S112.

Gregson, Simon, Basia Zaba, Susan-Catherine Hunter. (2002). The Impact of HIV-1 on Fertility in Sub-Saharan Africa: Causes and Consequences. In: Completing the Fertility Transition. Part two: Background Papers. United Nations Population Division: 104-136.

Hamata, Sylvia Amanda. (n.d.). Fertility Determinants in Namibia. Unpublished and undated manuscript. Windhoek, Namibia. 
Hunter, Susan-Catherine, Raphael Isingo, J. Ties Boerma, Mark Urassa, Gabriel M.P. Mwaluko, Basia Zaba. (2003). "The Association Between HIV and Fertility in a Cohort Study in Rural Tanzania." Journal of Biosocial Science, 35, 2:189-199.

Jejeebhoy, Shireen J. (1995). Women's Education, Autonomy, and Reproductive Behaviour: Experience from Developing Countries. Oxford: Clarendon Press.

Kamali, Anatoli, Lucy Mary Carpenter, James Alexander Grover Whitworth, Robert Pool, Anthony Ruberantwari, Amato Ojwiya. (2000). "Seven-Year Trends in HIV-1 Infection Rates, and Changes in Sexual Behaviour, Among Adults in Rural Uganda." AIDS, 14, 4: 427-434.

Kirk, Dudley, Bernard Pillet. (1998). "Fertility Levels, Trends, and Differentials in SubSaharan Africa in the 1980s and 1990s." Studies in Family Planning, 29, 1: 1-22.

LeBeau, Debie, Tom Fox, Heike Becker, Pempelani Mufune. (1999). Taking Risks, Taking Responsibility: An Anthropological Assessment of Health-Risk Behaviour in Northern Namibia. Windhoek, Namibia: French Cooperation and Ministry of Health and Social Services.

LeBeau, Debie, Tom Fox, Heike Becker, Pempelani Mufune. (2002). "Agencies and Structures Facilitating the Transmission of HIV/AIDS in Northern Namibia." Society in Transition, 32, 1: 56-68.

Lemström, Ossi. (1999). Hedelmällisyys ja kuolleisuus Kavangossa 1950-1996 verrattuna Ambomaahan. (Fertility and Mortality in Kavango 1950-1996 Compared to Ovamboland. In Finnish). Unpublished Master's thesis, Department of Sociology, University of Helsinki, Finland.

Lewis, James J.C., Carine Ronsmans, Alex Ezeh, Simon Gregson. (2004). "The Population Impact of HIV on Fertility in Sub-Saharan Africa." AIDS, 18, Suppl. 2: S35-S43.

Lucas, David. (1992). "Fertility and Family Planning in Southern and Central Africa." Studies in Family Planning, 23, 3: 145-158.

Lutheran Medical Mission. (1985). Annual Report of Lutheran Medical Mission of the Evangelical Lutheran Owambokavango Church 1984. English Version. Onandjokwe, Namibia.

Lutheran Medical Mission. (1988). Lutheran Medical Mission: Annual Report 1987. Ondangua, Namibia.

Lutheran Medical Mission. (1991). Lutheran Medical Mission: Annual Report 1990. Ondangua, Namibia. 
Lutheran Medical Service. (1994). Lutheran Medical Service: Annual Report 1993/4. Ondangua, Namibia.

Lutz, Wolfgang, Anne Goujon. (2001). “The World's Changing Human Capital Stock: Multi-State Population Projections by Educational Attainment." Population and Development Review, 27, 2: 323-339.

Marcus, Rachel, Sally Baden. (1992). Gender and Development in Namibia: a Country Study. Directorate General of Development, Commission of the European Communities BRIDGE (development - gender) Report 6. Institute of Development Studies, University of Sussex, UK and Institute of Development Studies, Brighton.

Martín, Tessa Castro. (1995). “Women's Education and Fertility: Results from 26 Demographic and Health Surveys." Studies in Family Planning, 26, 4: 187-202.

McKittrick, Meredith. (1997). "Reinventing the Family: Kinship, Marriage, and Famine in Northern Namibia, 1948-1954.” Social Science History, 21, 3: 265-296.

McKittrick, Meredith. (2002). To Dwell Secure: Generation, Christianity, and Colonialism in Ovamboland. Portsmouth, NH, USA: Heinemann.

Ministry of Health and Social Services [Namibia]. (1995). Family Planning Policy. Windhoek.

Ministry of Health and Social Services [Namibia]. (2003a). Report of the 2002 HIV Sentinel Survey. Ministry of Health and Social Services, Directorate of Primary Health Care and Nursing Services, National AIDS Co-ordination Programme. Windhoek.

Ministry of Health and Social Services [Namibia]. (2003b). Namibia Demographic and Health Survey 2000. Ministry of Health and Social Services. Windhoek.

Ministry of Health and Social Services [Namibia]. (2004). Media Release: 2004 HIV/AIDS Sentinel Sero Survey Results. Windhoek.

Ministry of Health and Social Services [Namibia], Macro International Inc. (1993). Namibia Demographic and Health Survey 1992. Windhoek: Ministry of Health and Social Services and Macro International Inc.

Moultrie, Tom A., Ian M. Timæus. (2003). "The South African Fertility Decline: Evidence from Two Censuses and a Demographic and Health Survey." Population Studies, 57, 3: 265-284. 
Muhwava, William, Ian Timæus. (1996). Fertility Decline in Zimbabwe. Centre for Population Studies Research Paper 96-1. London: Centre for Population Studies, London School of Hygiene and Tropical Medicine, University of London.

Namibia Development Trust. (1994). Improving the Legal and Socio-Economic Situation of Women in Namibia. Uukwambi, Ombalantu and Uukwanyama Integrated Report. Volume 1. Namibia Development Trust (NDT) with assistance from SIAPAC-Namibia (Social Impact Assessment and Policy Analysis Corporation), FES (Friedrich Ebert Foundation) and CASS (Centre for Applied Social Sciences). Windhoek, Namibia: NDT.

Newell, Colin. (1988). Methods and Models in Demography. Guildford and King's Lynn, UK: Belhaven Press.

Notkola, Veijo. (1996). "Parish Records from Nambia 1925-1990 - An attempt to Analyze Fertility and Mortality in Ovamboland." Yearbook of Population Studies in Finland, 33: 295-305.

Notkola, Veijo, Harri Siiskonen. (2000). Fertility, Mortality and Migration in SubSaharan Africa: The Case of Ovamboland in North Namibia, 1925-90. London: Macmillan Press.

Notkola, Veijo, Ian M. Timæus, Harri Siiskonen. (2000). "Mortality Transition in the Ovamboland Region of Namibia, 1930-1990." Population Studies, 54, 2: 153167.

Notkola, Veijo, Ian M. Timæus, Harri Siiskonen. (2004).'Impact on Mortality of the AIDS Epidemic in Northern Namibia Assessed Using Parish Registers." AIDS, 18, 7: 1061-1065.

Ntozi, James P.M., Immaculate M. Nakanaabi, Yovani A.M. Lubaale. (1997). "Fertility Levels and Trends in the Face of the AIDS Epidemic in Uganda." Health Transition Review, 7, Suppl. 2: S145-S155.

Odendaal Commission (1964). Report of the Commission of Enquiry into South West Africa Affairs 1962-1963. Pretoria, Republic of South Africa.

Onandjokwe District DDC (District Development Committee). (2003). Onandjokwe District: Annual Report for the year 2002/2003. Prepared by the Onandjokwe District DDC Members. Onandjokwe Lutheran Hospital. Ondangwa, Namibia.

Onandjokwe District DDC (District Development Committee). (2004). Onandjokwe District: Annual Report for the year 2003/2004. Prepared by the Onandjokwe District DDC Members. Ondangwa, Namibia. 
Onandjokwe Lutheran Medical Service. (1999). Annual Report for Onadjokwe District for the Year 1998/9. Onandjokwe Lutheran Medical Service, Onandjokwe Lutheran Hospital. Ondangwa, Namibia.

Oshakati Health Centre. (1994a). Family Planning Statistics: Visitors in January, February and March, 1994.

Oshakati Health Centre. (1994b). Interview of Nurse D. Namukwambi on 6th April, 1994.

Oshigambo Clinic. (1994a). Family Planning Register: Visitors in February, March and April, 1994.

Oshigambo Clinic. (1994b). Interview of family planning workers on 6th April, 1994.

Pendleton, W., D. LeBeau, C. Tapscott. (1992). Socio-Economic Study of the Ondangwa/Oshakati Nexus Area. The Namibian Institute for Social and Economic Research, Research Report 8. Windhoek: University of Namibia.

Raitis, Riikka. (1995). "Fertility in the Northwest Region of Namibia." Yearbook of Population Research in Finland, 32: 106-117.

Research Facilitation Services, Health Communication Partnership. (2004). Attitudes Towards Marriage in Namibia: Executive Summary. Research Facilitation Services and Health Communication Partnership, Based at Johns Hopkins University, Center for Communication Programs. Windhoek, Namibia.

Robinson, W.C. (1987). "Regional Variation in the Age-Specific Natural Fertility Curve." Journal of Biosocial Science, 19: 57-64.

Ross, Amanda, Dilys Morgan, Rosemary Lubega, Lucy Carpenter, Billy Mayanja, James A.G. Whitworth. (1999). "Reduced Fertility Associated with HIV: The Contribution of Pre-Existing Subfertility." AIDS, 13, 15: 2133-2141.

Rutenberg, Naomi, Ann E. Biddlecom, Frederick A.D. Kaona. (2000). "Reproductive Decision-Making in the Context of HIV and AIDS: A Qualitative Study in Ndola, Zambia." International Family Planning Perspectives, 26, 3:124-130.

Ryder, R.W., V.L. Batter, M. Nsuami, N. Badi, L. Mundele, B. Matela, M. Utshudi, W.L. Heyward. (1991). "Fertility Rates in 238 HIV-1-Seropositive Women in Zaire Followed for 3 Years Post-Partum.'" AIDS, 5, 12: 1521-1527.

Shemeikka, Riikka. (1999). "HIV/AIDS: The Major Demographic Challenge of Namibia." Yearbook of Population Research in Finland, 35: 65-81. 
Siiskonen, Harri, Anssi Taskinen, Veijo Notkola. (2005). "Parish Registers: A Challenge for African Historical Demography." History in Africa, 32. In Print.

Swartz, Leon. (2003). Fertility Transition in South Africa and Its Impact on the Four Major Racial Groups. In: Fertility: Current South African Issues of Poverty, HIV/AIDS and Youth. Seminar Proceedings. Human Sciences Research Council (HSRC) and Department of Social Development. Cape Town, South Africa: HSRC Publishers: 7-26.

Tabutin, Dominique, Bruno Schoumaker. (2001). Une Analyse Régionale des Transitions de Féconité en Afrique Sub-Saharienne. Paper presented at XXIV IUSSP General Population Conference, Salvador, Brazil on 18 - 24 August 2001. Http://www.iussp.org/Brazil2001/s40/S43_02_Tabutin.pdf. Accessed 30 May, 2005.

Tapscott, Chris, Ben Mulongeni. (1990). An Evaluation of the Welfare and Future Prospects of Repatriated Namibians in Northern Namibia. Namibian Institute for Social and Economic Research, Research Report 3. Windhoek: University of Namibia.

Terceira, Nicola, Simon Gregson, Basia Zaba, Peter R. Mason. (2003). "The Contribution of HIV to Fertility Decline in Rural Zimbabwe, 1985-2000." Population Studies, 57, 2: 149-164.

Tersbøl, Britt Pinkowsky. (2002). How to Make Sense of Lover Relationships Kwanyama Culture and Reproductive Health. In: Volker Winterfeldt, Tom Fox, and Pempelani Mufune, editors. Namibia Society Sociology. Windhoek: University of Namibia Press: $347-359$.

Tuupainen, Maija. (1970). Marriage in a Matrilineal African Tribe: A Social Anthropological Study of Marriage in the Ondonga Tribe in Ovamboland. Transactions of the Westermarck Society XVIII. Forssa, Finland: Westermarck Society.

UNICEF Namibia. (1991). A Situation Analysis of Children and Women in Namibia. UNICEF Namibia and the Namibian Institute of Social and Economic Research (NISER), University of Namibia, in consultation with the Government of Republic of Namibia. Windhoek: UNICEF Namibia.

United Nations. (1983). Manual X: Indirect Techniques for Demographic Estimation. Population Studies 81. New York: United Nations, Department of International Economic and Social Affairs. 
United Nations. (2004). World Fertility Report 2003. New York; United Nations Population Division, Department of Economic and Social Affairs.

Van der Merwe, I.J. (1989). "The Role of War in Regional Development and Urbanization of Namibia." African Urban Quarterly, 4, 1-2: 263-274.

Webb, Douglas, David Simon. (1995). Migrants, Money and the Military: The Social Epidemiology of HIV/AIDS in Owambo, Northern Namibia. The Namibian Economic Policy Research Unit (NEPRU), Occasional Paper No. 4. Windhoek, Namibia: NEPRU.

Wils, Annababette, Anne Goujon. (1998). "Diffusion of Education in Six World Regions, 1969-90." Population and Development Review, 24, 2: 358-368.

Wrigley, E.A. (Editor). (1966). An Introduction to English Historical Demography. London: Weidenfeld and Nicolson.

Zaba, Basia, Martine Collumbien. (1997). HIV and Fertility: Modelling the Effects of Changes in Union Dynamics. International Population Conference Beijing 1997, Vol. 2. Liège, Belgium: International Union for the Scientific Study of Population (IUSSP): 583-609.

Zaba, Basia, Simon Gregson. (1998). "Measuring the Impact of HIV on Fertility in Africa." AIDS, 12, Suppl. 1: S41-S50. 


\section{Fertility Reduction Caused by HIVIAIDS and its Demographic Impact in Northern Namibia}

\section{Introduction}

Sub-Saharan Africa was estimated to have 25.4 million people who were HIVpositive at the end of 2004 . The region thus has $64 \%$ of the HIV-positive people in the world, while having only $10 \%$ of the world's population (UNAIDS \& WHO 2004). In many of the countries in the region, the epidemic is ubiquitous and selfsustaining. HIV/AIDS has spread to the entire population, not just to certain risk groups, and is transmitted mainly through heterosexual intercourse. At the end of 2004, there were some four million adults in sub-Saharan Africa who were HIVpositive and required antiretroviral medication (ARV) to inhibit the progress of the disease, yet only 310,000 were receiving such medication (WHO \& UNAIDS 2004).

In the 1990s, the focus of the pandemic shifted from central and eastern Africa to southern Africa. At the end of 2003, the situation was most difficult in Botswana and Swaziland, where nearly $40 \%$ of the adult population were HIVpositive (UNAIDS 2004). In Namibia, $21.3 \%$ of the adult population were HIVpositive - ranking sixth worst in sub-Saharan Africa and in the entire world. The HIV epidemic in Namibia is estimated to have begun in 1986, which is when the first HIV-positive cases were diagnosed (Slotten 1995; UN Population Division 2003). The number of HIV-positive adults and children was estimated at 210,000 at the end of 2003 (UNAIDS, UNICEF \& WHO 2004).

The prevalence of HIV/AIDS in Namibia is highest in the major cities and the densely populated area of northern Namibia. The present article focuses on the North West Health Directorate in northern Namibia (see El Obeid et al. 2001, 5), the main part of which is the area formerly known as Ovamboland. The principal information sources on the HIV epidemic in Namibia are HIV tests on pregnant women, carried out as sample-based surveys in certain health clinics at two-year intervals. At the national level, the prevalence of HIV-positive results among pregnant women increased from 4\% to 22\% between 1992 and 2002. In Oshakati, which is located in the study area, the prevalence increased from $4 \%$ to $30 \%$ over 
the same period (GRN/MoHSS 2003a). In 2002, there were six clinics conducting HIV tests on pregnant women in the study area; these clinics showed an average HIV prevalence of over $25 \%$.

Studies of the demographic impact of HIV/AIDS usually focus on examining the increase in mortality and morbidity rates. However, HIV/AIDS affects population size and structure through fertility as well as mortality, since HIVpositive women have a lower level of fertility than other women. The fertility of HIV-positive women has mostly been studied in eastern and central Africa, to a lesser extent in Southern Africa, and not at all in Namibia. The number of children born is also decreasing with the decrease in the number of women due to increased mortality among women of childbearing age. However, the impact of HIV-associated subfertility and the change in demographic structure caused by HIV/AIDS on the number of children born on all population levels has hitherto been all but ignored in research.

This study focuses on fertility reduction due to HIV/AIDS and its demographic impact in the North West Health Directorate in northern Namibia. The object of the study is to estimate 1) to what extent the fertility of HIV-positive women is reduced in various age groups; 2) how HIV/AIDS affected the total fertility rate in the population in 2001 ; 3) what the impact of HIV-associated subfertility was on the number of children born in 2001, and what will it be in 2026; and 4) how the change in population size and structure, i.e. the decrease in the number of potential mothers, caused by AIDS mortality and lower fertility of HIV-infected women, will affect the number of children born in 2026.

\section{Impact on fertility of HIVIAIDS based on earlier research}

Previous studies, mainly focusing on central and eastern Africa, have shown that the fertility of HIV-positive women is lower than that of other women in subSaharan Africa (Glynn et al. 2000; Gray et al. 1998; Hunter et al. 2003; Lewis et al. 2004; Ntozi et al. 1997; Ryder et al. 1991). HIV/AIDS has an impact on fertility both through biological mechanisms and through behavioural changes. The biological impact consists of HIV-positive women having a lower probability of conceiving and a higher probability of miscarriage (Carpenter et al. 1997; Crampin et al. 2003; Gray et al. 1998). Fertility reduction starts at the earliest asymptomatic stage of HIV infection and increases as HIV disease progresses (Ross et al. 2004). In some HIVpositive women in sub-Saharan Africa, the observed subfertility is due to other, concurrent sexually transmitted diseases (Gray et al. 1998; Ross et al. 1999; Zaba \& Gregson 1998). Furthermore, fertility disturbances in HIV-negative women childlessness or low fertility - may lead to the breakup of their relationship or 
marriage and thus to a life situation where the risk of HIV infection increases (Ross et al. 1999).

In areas where HIV infections are common, the HIV pandemic may also have an impact on fertility through behaviour (Caldwell \& Caldwell 2003; Du Plessis 2003; Gregson et al. 1997; Gregson et al. 2002; Terceira et al. 2003; Zaba \& Collumbien 1997). If the beginning of sexual relations is postponed or the use of condoms increased, the probability of pregnancy also decreases. Behavioural changes of this kind have been observed for instance in Uganda, particularly among young people (Kamali et al. 2000). In Zambia, by comparison, behavioural changes have principally been observed among HIV-positive people who are conscious of their infection (Rutenberg et al. 2000). It is difficult to estimate to what extent the HIV pandemic has influenced behavioural changes in the population as a whole. It is also by no means self-evident that all changes related to the HIV pandemic have an adverse effect on the number of children born; some changes may even increase it, through what are known as the 'replacement effect' and the 'insurance effect' (Knodel 1979; Preston 1978). 'Replacement effect' means that a couple has more children to compensate for those who die young. 'Insurance effect' means that a couple has more children than they would if the mortality rate were lower, to insure against some of their children dying in the future.

\section{Data}

The former Ovamboland today consists of four administrative regions: Omusati, Ohangwena, Oshana and Oshikoto. These regions also include some areas that did not belong to the former Ovamboland, the most important additions being incorporation of the Tsumeb and Ruacana areas, as well as parts of the Etosha National park. These four regions comprise the North West Health Directorate, roughly corresponding to the North West Region in the Namibia Demographic and Health Survey (NDHS) 1992 material (GRN/MoHSS 1993).

In 2001 , the study area had a population of 780,000 , or $43 \%$ of the total population of Namibia (GRN/NPC 2003). In that same year, the parishes of the Evangelical Lutheran Church in Namibia in the area had 552,000 members (ELCIN 2002 ), or $71 \%$ of the area's population. However, the true percentage of ELCIN members in the area's population is difficult to ascertain, since some members have remained members of their original parish even though they have moved out of the area. Thus, it is probable that the true percentage of ELCIN members in the population of the area is somewhat lower (Siiskonen et al. 2005). The study area is predominantly agrarian and ethnically rather homogeneous. Ovambo dialects are the mother tongue of $87 \%$ to $97 \%$ of the population, depending on the region. Fertility is higher in this area than in Namibia on average, but it declined throughout 
the 1990s. In 2001, the total fertility rate was 4.4 children per woman (GRN/NPC 2003). The fertility rate peaks in the age groups 25 to 29 and 30 to 34 - at a higher age than in other areas in Namibia (GRN/MoHSS 1993; Raitis 1995).

The Finnish Missionary Society began missionary work in Ovamboland in 1870. Finnish missionary workers employed the Scandinavian parish records system in the congregations they founded, and initially they even kept the records in Finnish. The system has remained largely unchanged from the beginning of the 20th century to this day (Siiskonen et al. 2005). The system consists of individual records into which data on baptisms, migrations and deaths in the congregation are entered, and the 'main book' which contains data collated by family. The main book makes it easier to use the parish records in research. There is thus in practice a population register system for parishioners.

This study draws on the records of eight congregations: Elim, Nakayale, Oshigambo, Okahao, Tshandi, Onankali, Oshitutuma and Omulonga. The oldest of these is Okahao, founded in 1906, and the youngest is Oshitutuma, founded in 1982. The congregations are scattered throughout the study area, in both central and peripheral locations (see Shemeikka et al. 2005). The results from the parish records have been found to correlate rather well with sample-based studies and census data estimates (Notkola \& Siiskonen 2000), although the exact level of fertility according to parish register data is slightly lower, mainly because of the under-registration of children who have died prior to baptism (Shemeikka et al. 2005).

Data on all couples who married between 1956 and 2000 and on their children were collected from the congregations studied. The family reconstruction method (Wrigley 1966) was used to build up study material that includes information on e.g. births, deaths, and migrations in the families involved. For the purposes of studying fertility, data on children that the women had had before marriage was also collated; premarital fertility is thus included in the analysis. Follow-up of the families began in 1956 and continued up to October 2003.

Out of the 6,354 married couples in the original material, 1,651 had to be excluded from the final data either because the couple could not be followed from one main book to the next one, or because no information concerning the couple was listed after their marriage. After verification, the final material consisted of 4,703 married couples. Of the women, 9\% lacked information concerning their year of birth, and they were thus excluded from the fertility analysis. If the month of birth was missing, month 6 (June) was used by default; if the day of birth was missing, day 15 was used by default.

The original material contained 18,000 children born between 1950 and 2003. Some of these had to be eliminated from the final material, usually because the mother was not in the follow-up at the time of birth. Other reasons for elimination include poor follow-up of a marriage, unknown age of the mother, or the mother 
being under 15 or over 50 at the time of birth. The final material contained over 15,000 births. As the present study focuses on the impact on fertility of HIV/ AIDS, the focus was on data from 1980 onwards; for this period, the study material included 2,749 women giving birth to 4,783 children.

The parish records of northern Namibia are rather unique in population research in Africa. They have been used in two consecutive study projects, the first of which concerned long-term demographic development in the study area (Lemström 1999; Notkola \& Siiskonen 2000; Notkola et al. 2000), the other concentrating on the demographic impact of HIV/AIDS (Notkola 2004; Notkola et al. 2004; Shemeikka et al. 2005; Siiskonen et al. 2005). A third study project was launched in early 2005 to focus on the impact of the pandemic on communities, on their survival strategies and on how families and communities could best be supported in their efforts to survive the HIV pandemic. These study projects have been implemented jointly by the University of Helsinki, the University of Joensuu, the University of London, the University of Namibia and the Evangelical Lutheran Church in Namibia.

The first Population and Housing Census in independent Namibia was conducted in 1991. The results of the Census were published as a summary analysis (GRN/NPC 1994a) and as aggregate tables with two different regional divisions (GRN/NPC 1993; 1994b), which enable further calculations. The second Census was conducted in 2001, and its results have also been published in tables by administrative region in addition to a summary analysis (GRN/NPC 2003). Both materials were used in the present study. In addition to the above two censuses, a sample-based interim study was conducted in 1996; this is where the information on fertility in the study area in 1996 used in the present study derives from (GRN/ NPC n.d.).

\section{Methods}

Previous research based on parish records shows that mortality both among children and in the working-age population has increased severely during the HIV epidemic: mortality among women aged 20 to 64 increased by a factor of 3.5 between 1993 and 2000 (Notkola et al. 2004). The parish record materials also allow an analysis of the fertility of HIV-positive women. Although the parish records contain no indication of HIV status or cause of death, it is highly likely that most of the women who have died at childbearing age during the HIV epidemic have died of causes related to HIV/AIDS. Because mortality among women has increased by a factor of 3.5 during the epidemic, it could be estimated that two-thirds, or even at the most cautious estimate, one half of these deaths are related to HIV/AIDS. This hypothesis is supported by a report by the Namibian Ministry of Health and 
Social Services that attributes a substantial part of mortality in the working-age population in Namibia to HIV/AIDS (GRN/MoHSS 2003c). Studies conducted elsewhere in southern Africa also show that a major percentage of mortality among women of childbearing age is related to AIDS; for instance, in KwaZulu Natal, only $27 \%$ of the mortality among women aged 15 to 44 was due to something other than AIDS (Hosegood et al. 2004). Thus, any woman who died under the age of 50 in 1990 or after was classified as 'presumably HIV-positive', while women who had survived beyond the age of 50 were classified as 'presumably HIV-negative'. The follow-up of the women continued to 2003, and thus women who died under the age of 50 in 2001-2003 were also classified as 'presumably HIV-positive'.

The fertility histories of the 'HIV-positive' women (i.e. those who had died under the age of 50 in 1990 or later) were compared with fertility of the 'HIVnegative' women (i.e. those who had survived beyond childbearing age). The register-based material enabled the use of direct demographic methods, and agespecific fertility rates and total fertility rate were used. We compared the fertility of 'HIV-positive' and 'HIV-negative' women in the period 1980 to 2000 and also the fertility of 'HIV-positive' women in the periods 0 to 10 years before death and 11 to 20 years before death. The impact of widowhood on fertility reduction was factored in by separately examining women who had outlived their husbands. There were 81 women who had died under the age of 50 in 1990 or later; of these, 16 were widowed before their death, in three cases the husband and wife died in the same year, and in seven cases the husband died after his wife.

The follow-up of the women began from their 15th birthday or their baptism, whichever was later, and ended at their 50th birthday or at their death or when they moved out of the congregation, if either of the latter happened before their 50th birthday. Monitoring was also ended if a woman was expelled from the congregation or if she moved out of the congregation. Monitoring was restarted if a woman re-entered the congregation. Premarital births are included in the data, but the data does not include women who never married in church.

In order to confirm the link between subfertility before death and the HIV epidemic, a similar comparison was conducted for a period before the HIV epidemic comparing the fertility history of women who died under the age of 50 in the period 1966 to 1979 with the fertility of those who survived beyond childbearing age.

Data on the fertility reduction among HIV-positive women derived in the above way were used as a basis for estimating the impact on fertility of HIV/AIDS on the population level. Data was also needed on the total population of the area and its age structure; the prevalence of HIV infection by age group; fertility and its related age structure; and mortality and its related age structure. Migration was excluded from the study. Two software applications were used to make demographic projections: the DemProj and AIDS Impact Model (AIM) components of the 
Spectrum system by Futures Group and the PDEROJ software developed at the International Institute for Applied Systems Analysis (IIASA).

The size and structure of the population of the study area was obtained from the Censuses of 1991 and 2001. Fertility and fertility rates by age group were calculated from the Census data for 1991 and 2001 using the Brass P/F Ratio Method (see United Nations 1983, 30-37). Mortality by age group excluding the impact of HIV/AIDS was based on data from the Censuses of 1991 and 2001, and the calculations were made using the Brass method based on data on children ever born and children surviving, analysed according to the age of the mother (see United Nations 1983, 75-81) and the Regional Model Life Table West (Coale \& Demeny 1983).

The estimates of HIV prevalence in the study area are based on HIV tests conducted on pregnant women in 1992, 1994, 1996, 1998, 2000 and 2002 (GRN/ MoHSS 2003a; Shemeikka 1999). No HIV prevalence data analysed by age group have been published for the study area. The prevalence of HIV among pregnant women does not entirely correspond to the prevalence of HIV among all women in the population (e.g. Bos 1998; Gregson et al. 2002; Heuveline 2003; Saphonn et al. 2002; WHO \& UNAIDS 2003; Zaba et al. 2000). Most scholars assess that HIV tests conducted on pregnant women underestimate the prevalence of HIV among all women. The prevalence of HIV among pregnant women is usually considered to be a relatively good indication of the prevalence of HIV in the entire population, the prevalence among men being lower and the prevalence among women being higher. In the future, information on the prevalence of HIV among men and nonpregnant women will be gained from HIV tests conducted in connection with Demographic and Health Surveys (DHS). In Kenya, for instance, the estimate of the prevalence of HIV in the adult population was lowered on the basis of HIV tests conducted in connection with a DHS (GRK/CBS 2004).

The prevalence of HIV among women and men on average and by age group was estimated using the AIM software on the basis of the prevalence of HIV among pregnant women and the Census data. The resulting age-specific HIV prevalence and AIDS patient prevalence figures were used in two population projections made with the PDEPROJ demographic software: the first included the impact of HIV/ AIDS, while the second was a hypothetical reference projection where HIV/AIDS was assumed to have no demographic impact whatsoever in 2001 or thereafter. In the projection showing the impact of HIV/AIDS, the population was divided into three groups: HIV-negative, HIV-positive and AIDS patients.

It was assumed for the projections that mortality from causes other than AIDS will remain at the 2001 level. The fertility of HIV-positive women was assumed to be falling at the same rate as it did in the period 1980 to 2000, and the fertility rate of women who were AIDS patients was assumed to be zero. In the highest age group for women (45 to 49), fertility was estimated to be falling at the same rate as 
in the three lower age groups. It was further assumed for the projections that the total fertility rate of HIV-negative women would decline to 3 children per woman by 2026 . The prevalence of HIV in the adult population was assumed to have risen to $26 \%$ in 2003 and to remain at that level. ARV medication was assumed to be available to less than $10 \%$ of HIV-positive people in the future, too.

The projections were used to examine the impact of HIV/AIDS on total fertility at the population level, the impact of declining fertility on the number of children born in 2001 on the one hand and in 2026 on the other, and the impact of demographic changes, caused by HIV-associated subfertility and HIV mortality, on the number of children born in 2026 .

\section{Results}

\section{Fertility of HIV-positive women}

The impact of HIV infection on women's fertility was examined by comparing, on the basis of parish records, the fertility history of women who did not survive beyond childbearing age with the fertility of women who did. The fertility of women who died under the age of 50 after 1990 (hereinafter 'HIV-positive') was prior to their death clearly lower than that of women who survived beyond childbearing age (hereinafter 'HIV-negative'). In the period 1980 to 2000, the age-specific fertility rates of 'HIV-positive' women were lower than those of 'HIV-negative' women in the age group 25 to 29 and above (Table 1). For women aged 30 to 34 and above, the age-specific fertility rates of the 'HIV-positive' women was $63 \%$ to $64 \%$ of the age-specific fertility rates of the 'HIV-negative' women. The reduction in fertility was clearly evident as far back as the 1980s. Even looking at the 1980s alone, a lower fertility rate among 'HIV-positive' women than among 'HIV-negative' women, particularly in age groups 25 to 29 and 30 to 34 , can be seen.

TABLE 1. Age-specific fertility rates among 'HIV-positive' and 'HIV-negative' women, 19802000, North West Health Directorate, northern Namibia.

\begin{tabular}{|c|c|c|c|c|c|c|c|}
\hline $\begin{array}{l}\text { Age } \\
\text { Group }\end{array}$ & $\begin{array}{l}\text { ASFR } \\
\text { HIV- }\end{array}$ & $\mathrm{N}$ & $\begin{array}{c}\text { Person } \\
\text { years }\end{array}$ & $\begin{array}{l}\text { ASFR } \\
\text { HIV+ }\end{array}$ & $\mathbf{N}$ & $\begin{array}{c}\text { Person } \\
\text { years }\end{array}$ & $\begin{array}{l}\text { Rate } \\
\text { ratio }\end{array}$ \\
\hline $15-19$ & 32 & 394 & 1348 & 33 & 29 & 91 & 1.04 \\
\hline $20-24$ & 142 & 784 & 2800 & 142 & 49 & 190 & 1.00 \\
\hline $25-29$ & 228 & 1157 & 4314 & 185 & 68 & 275 & 0.81 \\
\hline $30-34$ & 235 & 1404 & 5280 & 151 & 70 & 299 & 0.64 \\
\hline $35-39$ & 188 & 1586 & 6034 & 119 & 57 & 219 & 0.63 \\
\hline $40-44$ & 101 & 1683 & 6443 & 65 & 32 & 123 & 0.64 \\
\hline $45-49$ & 17 & 1474 & 6008 & 0 & 19 & 47 & \\
\hline
\end{tabular}


The total fertility rate of 'HIV-positive' women was 74\% of the total fertility rate of 'HIV-negative' women in the period 1980 to 2000, being 79\% in the period 1980 to 1989 but only $61 \%$ in the period 1990 to 2000 . Although HIV infections were evidently not very common in the 1980s, some of the women who died in the 1990s had become infected in the 1980s. HIV had a greater impact on fertility in the 1990s than in the 1980s, because the 'HIV-positive' group was defined so that the women belonging to that group had died in the 1990s. Their disease was thus more advanced in the 1990s than in the 1980s.

As the disease progresses, the fertility of HIV-positive women continues to decline. This is evident in examining the fertility of 'HIV-positive' women backwards in time from the time of death. In the period immediately preceding death, the difference between 'HIV-positive' and 'HIV-negative' women is the greatest (Figure 1). The total fertility rate of the 'HIV-positive' women 0 to 10 years before death was $71 \%$ of the total fertility rate of the 'HIV-negative' women in the period 1990 to 2000 .

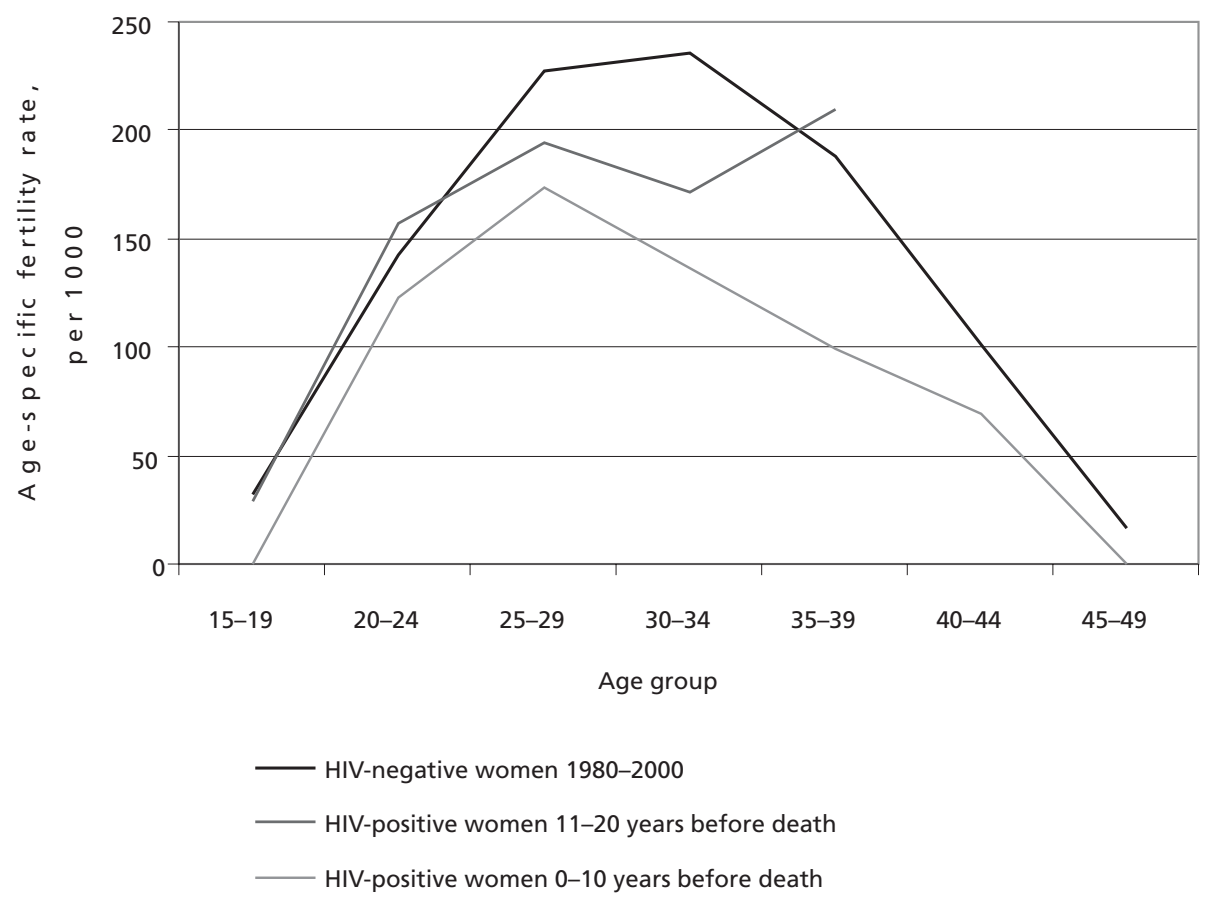

FIGURE 1. Age-specific fertility rates of 'HIV-positive' women 11-20 years and $0-10$ years before death, and fertility rates of 'HIV-negative' women 1980-2000, North West Health Directorate, northern Namibia 
The 'HIV-positive' women whose husbands had not died showed a slightly higher fertility rate than the 'HIV-positive' women on average in age groups 25 to 29,30 to 34 and 35 to 39 (Table 2). However, this is balanced by lower fertility in age groups 20 to 24 and 40 to 44 , so overall the difference is negligible. The 'HIV-positive' women had married about one year younger on average than the 'HIV-negative' women, and also had had children more frequently before marriage.

Subfertility before death has a clear link with HIV/AIDS. A similar comparison for the time preceding the HIV epidemic shows that there was no subfertility before death prior to the spreading of HIV/AIDS to the area. Quite the opposite, in fact: between 1966 and 1979, those women who died at childbearing age had a higher fertility rate before death than those who survived beyond childbearing age (Table 2).

TABLE 2. Age-specific fertility rates of 'HIV-positive' women 0-10 years before death, analysed by whether their husbands survived, and fertility $0-10$ years before death of women who died at childbearing age between 1966 and 1979, North West Health Directorate, northern Namibia

\begin{tabular}{|c|c|c|c|c|c|c|c|c|}
\hline \multirow[b]{2}{*}{$\begin{array}{l}\text { Age } \\
\text { group }\end{array}$} & \multicolumn{2}{|c|}{$\begin{array}{l}\text { HIV negative } \\
1990-2000\end{array}$} & \multicolumn{6}{|c|}{$\begin{array}{l}\text { HIV positive } \\
0-10 \text { years before death }\end{array}$} \\
\hline & $\mathrm{ASFR}^{1}$ & $\begin{array}{l}\text { Person } \\
\text { years }\end{array}$ & $\begin{array}{l}\text { ASFR } \\
\text { All }^{2}\end{array}$ & $\begin{array}{l}\text { Person } \\
\text { years }\end{array}$ & $\begin{array}{l}\text { Rate } \\
\text { ratio }\end{array}$ & $\begin{array}{l}\text { ASFR } \\
\text { Husband } \\
\text { surviving }^{3}\end{array}$ & $\begin{array}{l}\text { Person } \\
\text { years }\end{array}$ & $\begin{array}{l}\text { Rate } \\
\text { ratio }\end{array}$ \\
\hline $15-19$ & 45 & 154 & 0 & 9 & & 0 & 9 & \\
\hline $20-24$ & 141 & 701 & 123 & 49 & 0.87 & 106 & 47 & 0.75 \\
\hline $25-29$ & 201 & 1514 & 173 & 144 & 0.86 & 185 & 119 & 0.92 \\
\hline $30-34$ & 216 & 2187 & 137 & 190 & 0.63 & 145 & 138 & 0.67 \\
\hline $35-39$ & 171 & 2639 & 100 & 181 & 0.58 & 116 & 129 & 0.68 \\
\hline $40-44$ & 68 & 2980 & 70 & 129 & 1.02 & 41 & 98 & 0.59 \\
\hline $45-49$ & 12 & 3205 & 0 & 52 & & 0 & 40 & \\
\hline
\end{tabular}

\begin{tabular}{|c|c|c|c|c|c|}
\hline \multirow{5}{*}{$\begin{array}{l}\text { Age } \\
\text { group }\end{array}$} & \multicolumn{5}{|c|}{ Before pandemic } \\
\hline & \multicolumn{5}{|l|}{ 1966-1979 } \\
\hline & ASFR & Person & ASFR & Person & Rate \\
\hline & Surviving & years & Dead & years & ratio \\
\hline & \multicolumn{2}{|l|}{ women ${ }^{4}$} & \multicolumn{3}{|l|}{ women $^{5}$} \\
\hline $15-19$ & 24 & 5028 & 0 & 34 & \\
\hline $20-24$ & 168 & 6927 & 205 & 88 & 1.22 \\
\hline $25-29$ & 305 & 7094 & 312 & 128 & 1.02 \\
\hline $30-34$ & 319 & 6395 & 345 & 125 & 1.08 \\
\hline $35-39$ & 276 & 4572 & 345 & 61 & 1.25 \\
\hline $40-44$ & 161 & 2445 & 77 & 26 & 0.48 \\
\hline $45-49$ & 50 & 1015 & 138 & 7 & 2.74 \\
\hline
\end{tabular}

Notes:

1 Age-specific fertility rates for women who survived beyond the age of 50 .

2 Age-specific fertility rates for all women who died under the age of 50 in 1990 or later.

3 Age-specific fertility rates for women who died under the age of 50 in 1990 or later and who were not widowed before death.

4 Age-specific fertility rate for women who survived beyond the age of 50 between 1966 and 1979.

5 Age-specific fertility rate 0 to 10 years before death for women who died under the age of 50 between 1966 and 1979. 
The 2001 Census shows that the total fertility rate for the study area was 4.4 children per woman. This figure includes the HIV-positive and the HIV-negative women. Dividing women into three sub-populations (HIV-negative, HIV-positive and AIDS patients) and applying the HIV-related fertility differentials derived from the parish records material to these sub-populations showed that the total fertility rate for the HIV-negative women would have to be 4.8 for the total fertility rate of the entire population to be 4.4. The total fertility rate of the HIV-positive women would then be 3.7 , a differential of 0.9 children per woman.

On the basis of these fertility rates, the number of children born in the area in 2001 was 24,100 . If fertility rates had not varied according to HIV status, i.e. if the total fertility rate for the entire population had been 4.8 , the number of children born would have been 25,900. The lower fertility among HIV-positive women thus caused some 1,800 fewer children to be born (7\%) than would have been the case if fertility did not vary according to HIV status.

HIV/AIDS affects the number of children born both through increased mortality, thus decreasing the number of potential mothers, and through decreased fertility among HIV-positive women. Two demographic projections were made to explore these effects. The first projection takes into account the impact of HIV/ AIDS on mortality and fertility; the second is a theoretical reference where it is assumed that there is no HIV/AIDS in the area. Both are based on the population of the study area as given in the 2001 Census. The total fertility rate for the 'HIVnegative' women was estimated at 4.8 in 2001 and expected to decline to 3 by 2026 . The age-specific fertility rates of the 'HIV-positive' women were again calibrated against those of the 'HIV-negative' women on the basis of the parish records material for 1980-2000. The total fertility rate for the 'HIV-positive' women was expected to decline to 2.31 by 2026 ; in other words, their total fertility rate would continue to be $77 \%$ of that of the 'HIV-negative' women. The fertility rate of AIDS patients was assumed to be zero.

In the population in the HIV/AIDS projection, 21,400 children were born; in the reference projection where the impact of HIV/AIDS on mortality and fertility had been eliminated, 34,800 children were born. The population in the HIV/AIDS projection thus produced 13,400 (39\%) fewer children than would have been born without HIV/AIDS.

Most of the decrease in the number of children by 2026 was due to increased mortality and a consequent decrease in the number of women of childbearing age compared with a situation without HIV/AIDS. If the only factor affecting demographics were the increased mortality caused by AIDS, and if all women had the same fertility rate as the 'HIV-negative' women, the number of children born in the relevant period would be 24,000 , or about $31 \%$ fewer than in the reference projection where HIV/AIDS has no impact on demographics in or after 2001. 


\section{Summary and discussion}

HIV/AIDS has a significant impact on fertility decline in the study region. The fertility rate of 'HIV-positive' women 0 to 10 years before death was about $71 \%$ of that of 'HIV-negative' women. In the period 1980 to 2000, the fertility rate of 'HIVpositive' women was $74 \%$ of that of 'HIV-negative' women. This reduction thus seems to be on a par with that observed in central and eastern Africa (see e.g. Zaba \& Gregson 1998). The true decrease in fertility may be even greater, since the group of 'HIV-positive' women includes women who actually died of other causes, while the group of 'HIV-negative' women includes women who actually are HIV-positive but who are still alive.

Fertility reduction among 'HIV-positive' women in the study area began in older age groups (25 to 29) than in Uganda, for example (20 to 24) (Carpenter et al. 1997; Zaba \& Gregson 1998). This may correlate with the high average age of marriage in the study area: the median age of women entering their first marriage is 29 (GRN/MoHSS 2003b). The decrease was greatest in the age groups 30 to 34 and 35 to 39 .

The fertility reduction of 'HIV-positive' women began in the 1980s, a period from which there is scarcely any data on the HIV/AIDS situation in the area. Furthermore, the decrease in fertility became apparent as early as the period 11 to 20 years before death. The impact on fertility of HIV/AIDS thus began before the increase in mortality, the latter beginning among children in 1991 and among adults in 1993 (cf. Notkola et al. 2004). The 'HIV-positive' group was defined as consistintg of women who had died under the age of 50 in the 1990s or later. Many of them had thus probably been HIV-positive in the 1980s. The impact on fertility of HIV/AIDS begins soon after infection, during the incubation period as the disease slowly progresses (cf. Ross 2004). Since the percentage of HIV-positive women among all women was low in the 1980s and early 1990s, HIV/AIDS probably did not yet have a significant impact on fertility at the population level at that time. Another reason for low fertility among HIV-positive women in the 1980s and 11 to 20 years before death may be that they had low fertility before contracting the disease. In other words, women whose fertility is low to begin with may have a higher probability of contracting HIV than other women (cf. e.g. Ross 1999).

In 2001, the total fertility rate of the entire female population in the study area was 0.4 children per woman less than it would have been without the impact on fertility of HIV. There were 7\% fewer children born than there would have been without that impact. In addition to the reduction in fertility, HIV/AIDS reduces the number of children born through increased mortality, thus decreasing the number of potential mothers. Because of these combined impacts, the projections show that 39\% fewer children will be born in the study area in 2026 than would be the case if HIV/AIDS had no demographic impact after 2001. Most of the differential 
is due to mortality; the impact of HIV/AIDS on mortality alone would lead to $31 \%$ fewer children being born. The impact of HIV/AIDS on decrease in fertility would so seem to be far less significant than the impact on mortality of HIV/AIDS when we consider population growth as a whole.

Many of the means used to prevent HIV/AIDS, for instance increased use of condoms or postponing the beginning of sexual relations, would also decrease the number of unwanted pregnancies. According to the Ministry of Health and Social Services, teenage pregnancies have decreased and the use of family planning services among young people increased between 2000 and 2001 (GRN/MoHSS 2003c). According to Demographic and Health Survey sample-based studies, use of condoms in the study area increased between 1992 and 2000. Of the sexually active women in the study area interviewed in 2000, i.e. women who had had sexual intercourse within one month before the interview, $17 \%$ said that they used condoms for contraception (GRN/MoHSS 2003b). This figure was higher than for any other area in Namibia. $8 \%$ of married women used condoms as contraceptives. The use of contraceptives in all, taking all methods into account, was lower in the study area than in Namibia on average; in 2000, 39\% of sexually active women in the study area used some form of contraception, while the nationwide figure was $52 \%$.

Although there seems to be an ongoing change towards safer sex practices, and the preliminary results of 2004 HIV sentinel surveillance show some signs of possible decline in HIV prevalence rates (GRN/MoHSS 2004), the HIV/AIDS prevention campaigns have not achieved the desired results. One of the main reasons for this is evidently that the education effort has not taken into account the complicated systems underlying sexual relations, having to do with traditional culture and its changes, the roles of men and women, the inequality of women and their financial dependence on men (LeBeau et al. 1999; 2002; Talavera 2002; Tersbøl 2002).

Studies conducted elsewhere in sub-Saharan Africa show that a significant part of the impact of HIV on reduction in fertility is due to other, concurrent sexually transmitted diseases. These probably explain some of the lower fertility among 'HIV-positive' women in the study area, too. There were no data available on sexually transmitted diseases in the study area, but at the national level the prevalence of sexually transmitted diseases among men decreased between 2000 and 2001. Reports of women seeking treatment because of symptoms of sexually transmitted diseases increased, but this may have happened because the reporting system was changed in 2001 (GRN/MoHSS 2003c). Efforts are being made in Namibia to treat other sexually transmitted diseases, not least because this is important for preventing HIV infections; untreated sexually transmitted diseases render patients more likely to contract HIV. Treatment of other sexually transmitted diseases would probably also alleviate the impact of HIV-associated subfertility. 
The Namibian government aims to bring ARV medication to an increasingly large percentage of HIV-positive people and is receiving considerable international support towards this effort. The USA, for instance, is contributing USD 36 million to the AIDS effort in Namibia this year (Maletsky 2005). At the end of 2004, 3,500 to 11,000 Namibians were estimated to be receiving ARV (IRIN 2004a; Maletsky 2005; WHO \& UNAIDS 2004). It is of crucial importance to individuals, families and society as a whole to extend ARV medication to everyone who needs it, and also to succeed in HIV/AIDS prevention efforts. It is difficult to estimate what the impact of increased ARV medication on fertility would be: on the one hand, HIV-positive women would live longer with lower fertility, thus decreasing the total fertility rate of the entire population; on the other hand, ARV medication, in arresting the progress of the disease, would probably also arrest the subfertility among HIV-positive women.

The impact of HIV/AIDS is felt in Namibia at all levels throughout society. HIV/AIDS affects the individual and the family over the long period of illness: the family income decreases, agricultural work is neglected, and drug costs and other medical costs increase (Phororo 2002). The impact of HIV/AIDS on a family depends on which family member is infected and what the financial position of the family was before the infection. The families in the weakest position are those who have no property, such as cattle, to sell in order to secure an income. Children have to take on responsibilities belonging to the parent who falls ill. Because of an increased workload and financial reasons, children may have to drop out of school. Those who stay at school may suffer from attention deficit and discrimination.

At the end of 2003, 57,000 children under the age of 18 in Namibia had lost their mother, father or both parents to HIV/AIDS (UNAIDS, UNICEF \& USAID 2004). The death of a parent, particularly the mother, usually results in the family breaking up. The death of the father may cause the family to lose all its property, such as cattle, to relatives. The family may also lose the title to its farm. Funeral costs may also be an unreasonable financial burden on the family. Children orphaned by AIDS often lose both their father and mother (Grassly \& Timaeus 2003).

Orphaned children are usually cared for by relatives, mostly grandmothers and aunts (SIAPAC 2002). The HIV pandemic also affects the resources of families who avoid actual infection, since in southern Africa one in five families with children have one or more orphaned children in foster care (UNICEF 2003). Children who fall beyond the social safety nets have to manage their own households with the help of their elder siblings or live on the street. Churches and various organizations and communities carry out important work in supporting orphans and their foster families in Namibia and in the study area. The Namibian government has commissioned studies on the situation of orphans in the country. The government has a national policy on orphans and vulnerable children, and efforts are made to support orphaned children and their foster families financially. However, the 
resources of the government, as indeed those of aid organisations and communities, are limited.

HIV/AIDS puts pressure on families, relatives and communities. The study area is an area from which people of working age frequently migrate to other areas to work. Having contracted illnesses related to HIV/AIDS, many move back to their home area, and there is a real risk of the northern reaches of the country thereby turning into a collection of 'death camps' (Notkola 2004).

HIV/AIDS causes problems in many sectors of society. Schools suffer from competent teachers taking sick leave or dying, and at the same time the financial impact of parents' HIV infections on families makes it more difficult for children to attend school. The education sector is suffering, even though investments in education would be important to prevent the spread of HIV/AIDS (Draxler 2004; Kelly 2004). Illness and death among health care employees cause absences and attrition of trained personnel, while HIV/AIDS is increasing the demand for their services. In the absence of resources, the treatment of HIV-positive patients is transferred from hospitals to home-based care. According to a report by the Namibian Ministry of Health and Social Services, the number of HIV patients being treated in hospitals decreased between 2000 and 2001; one of the reasons cited for this was the increase in home-based care. Because of the shortage of resources in public health care, patients in home-based care often need help from various volunteer organizations; churches, for instance, are doing valuable work to support HIV-positive patients.

Agricultural labour and know-how is being lost to illness and deaths. As a result, the cultivated land area is shrinking, farming is turning to less laborious plant species, and food production and agricultural income are decreasing. Absences and deaths in companies are increasing, professional competence is being lost, and the pay, training, insurance and pension costs of companies are rising. Lost employees are not always replaced; in South Africa in particular, the HIV pandemic appears to be leading to an accelerated development of automation in industry and services. Companies have also reacted to the problems caused by HIV/AIDS by providing ARV medication for their employees and by conducting HIV tests when hiring new employees.

The impact of the HIV pandemic on any particular national economy as a whole is usually estimated to be negative. Human capital is eroded as illness and death decimate the trained adult population, and the labour supply decreases while health care costs rise. However, the actual economic impact may depend on the structure of the national economy. Estimates of the future impact of the HIV pandemic on the Namibian national economy vary greatly. For instance, the IMF estimates that HIV/AIDS will rapidly erode the potential for economic growth (IRIN 2004b), but another study estimates that HIV/AIDS will not precipitate an economic disaster in Namibia (Sanderson et al. 2001). The latter is justified by observing that most 
of Namibia's principal exports are not dependent on the size of the population and that although HIV/AIDS erodes the trained working population, educational attainment in general is rising at such a rate that it will eventually become a problem to find employment for all the trained people. Furthermore, investments are also not a problem, since savings have exceeded investments in Namibia for the entire period of the country's independence. Scientists thus disagree widely on the scale of the impact of HIV/AIDS on the national economy.

Combating the HIV pandemic and the problems it is causing calls for cooperation between various levels of society and also between nations. Prevention of new HIV infections is crucial for the future welfare of the study area and of Namibia as a whole, but simple education campaigns are not enough to make this happen. Deeper cultural understanding is needed, and social inequality needs to be addressed. Medical prevention methods, such as medication preventing infections from being transmitted from mother to child and the hopefully forthcoming vaccines and microbicides that will make it easier for women to protect themselves, are important in reducing the prevalence of infections. What is most important for the future of those who are already infected with HIV is to provide good treatment and to root out discrimination and stigmatisation. Openness and support from the community and society are the key here. International support is needed to extend ARV medication to all Namibians who need it.

\section{Acknowledgements}

The authors would like to thank the Evangelical Lutheran Church in Namibia and its clergy for granting permission to use the material employed in this study and Mr Ossi Lemström for his help in processing the material. The study was financed by grants from the Academy of Finland and the Emil Aaltonen Foundation.

\section{BIBLIOGRAPHY}

BOS, E. (1998) Do Antenatal Clinic HIV Data Underestimate or Overestimate HIV Prevalence? Or Both? Paper prepared for the Conference on Measurement of Risk and Modelling the Spread of AIDS, Organized by the IUSSP Committee on AIDS and the University of Copenhagen, June 24, 1998, Copenhagen.

CALDWELL, J. C. \& CALDWELL, P. (2003) The fertility transition in sub-Saharan Africa. In: Fertility: current South African issues of poverty, HIV/AIDS \& Youth. Seminar proceedings, 117123. Department of Social Development in collaboration with the Child, youth, and family development research programme of the HSRC. Cape Town, South Africa.

CARPENTER, L. M., NAKIYINGI, J. S., RUBERANTWARI, A., MALAMBA, S. S., KAMALI, A. \& WHITWORTH, J. A. G. (1997) Estimates of the impact of HIV infection on fertility in a rural Ugandan population cohort. Health Transition Review; 7 (1997) (Suppl 2): S113-S126. 
COALE, A. J. \& DEMENY, P. (1983) Regional Model Life Tables and Stable Populations. Academic Press, New York.

CRAMPIN, A. C., GLYNN, J. R., NGWIRA, B. M. M., MWAUNGULU, F. D., PÖNNIGHAUS, J. M., WARNDORFF, D. K. \& FINE, P. E. M. (2003). Trends and measurement of HIV prevalence in northern Malawi. AIDS; 17 (2003): 1817-1825.

DRAXLER, A. (2004) Vicious or virtuous circle? International Institute for Educational Planning (IIEP) Newsletter XXII (2004) 2: 5.

DU PLESSIS, G. (2003) HIV/AIDS and fertility. In: Fertility: current South African issues of poverty, HIV/AIDS \& Youth. Seminar proceedings, 77-116. Department of Social Development in collaboration with the Child, youth, and family development research programme of the HSRC. Cape Town, South Africa.

EL OBEID, S., MENDELSOHN, J., LEJARS, M., FORSTER, N. \& BRULÉ, G. (2001). Health in Namibia: Progress and Challenges. Research and Information Services of Namibia (RAISON). Published for the "Support to Primary Health Care Project" of the Ministry of Health and Social Services and Service for Co-operation and Cultural Affairs of the French Embassy in Namibia. Windhoek, Namibia.

ELCIN. (2002) ELCIN Statistics: Reports and Tables 2002. Evangelical Lutheran Church in Namibia (ELCIN). Ondangwa, Namibia.

GRK/CBS (= Government of the Republic of Kenya/Central Bureau of Statistics) (CBS) [Kenya], Ministry of Health (MOH) [Kenya], and ORC Macro. (2004) Kenya Demographic and Health Survey 2003. Calverton, Maryland: CBS, MOH, and ORC Macro.

GRN/MoHSS (= Government of the Republic of Namibia/Ministry of Health and Social Services). (1993) Namibia Demographic and Health Survey 1992. Ministry of Health and Social Services and Macro International Inc. Windhoek, Namibia.

----. (2003a) Report of the 2002 National HIV Sentinel Survey. Directorate of Primary Health Care and Nursing Services, National AIDS Co-ordination Programme. Ministry of Health and Social Services. Windhoek, Namibia.

----. (2003b) Namibia Demographic and Health Survey 2000. Ministry of Health and Social Services. Windhoek, Namibia.

----. (2003c) Epidemiological Report. HIV/AIDS \& STI for the Year 2001. AIDS Co-ordination Programme. Ministry of Health and Social Services. Windhoek, Namibia.

----. (2004) Media Release: 2004 HIV/AIDS Sentinel Sero Survey Results. Ministry of Health and Social Services. Windhoek, Namibia.

GRN/NPC (= Government of the Republic of Namibia/National Planning Commission). (1993) 1991 Population and Housing Census. Report A. Statistical Tables. Volumes I-V. (Tables for 27 Census Districts). Government of the Republic of Namibia, National Planning Commission, Central Statistics Office. Windhoek, Namibia.

----. (1994a). 1991 Population and Housing Census: Basic Analysis with Highlights. Windhoek, Namibia: Government of the Republic of Namibia, Central Statistics Office, National Planning Commission.

----. (1994b) 1991 Population and Housing Census. Report B. Statistical Tables. (Tables for 13 Administrative Regions). Government of the Republic of Namibia, Central Statistics Office, National Planning Commission. Windhoek, Namibia.

----. (2001) Population Projections 1991 - 2021. Namibia National and Regional Figures. Government of the Republic of Namibia, Central Bureau of Statistics, National Planning Commission. Windhoek, Namibia.

----. (2003) 2001 Population and Housing Census National Report: Basic Analysis with Highlights. Government of the Republic of Namibia, Central Bureau of Statistics, National Planning Commission. Windhoek, Namibia.

----. n.d. Printout of selected results from the 1996 Intercensal Demographic Survey. National Planning Commission, Central Statistics Office. Windhoek, Namibia. Undated.

GLYNN, J. R., BUVÉ, A., GARAËL, M., KAHINDO, M., MACAULEY, I. B., MUSONDA, R. M., JUNGMANN, E., TEMBO, F. \& ZEKENG, L. (2000) Decreased fertility among HIV-1-infected women attending antenatal clinics in three African cities. Journal of Acquired Immune Deficiency Syndromes 25 (2000):345-352. 
GRASSLY, N. C. \& TIMÆUS, I. M. (2003) Orphans and AIDS in Sub-Saharan Africa. Paper presented at the UN Population Division Workshop on HIV/AIDS and Adult Mortality in Developing Countries, New York, 8-13 September, 2003.

GRAY, R., WAWER, M. J., SERWADDA, D., SEWANKAMBO, N., LI, C., WABWIRE-MANGEN, F., PAXTON, L., KIWANUKA, N., KIGOZI, G., KONDE-LULE, J., QUINN, T. C., GAYDOS, C. A. \& MCNAIRN, D. (1998) Population-based study of fertility in women with HIV-1 infection in Uganda. Lancet 351 (1998): 98-103.

GREGSON, S., ZABA, B. \& HUNTER, S. C. (2002) The impact of HIV-1 on fertility in sub-Saharan Africa: Causes and consequences. In: Completing the Fertility Transition. Part two: Background papers, 104-136. United Nations Population Division.

GREGSON, S., ZHUWAU, T., ANDERSON, R. M. \& CHANDIWANA, S. K. (1997). HIV and fertility change in rural Zimbabwe. Health Transition Review 7 (1997) Suppl 2: S89-S112.

HEUVELINE, P. (2003) HIV and population dynamics: A general model and maximum-likelihood standards for East Africa. Demography 40 (2003) 2: 217-245.

HOSEGOOD, V., VANNESTE, A. M. \& TIMÆUS, I. M. (2004) Levels and causes of adult mortality in rural South Africa: the impact of AIDS. AIDS 18 (2004) 4:663-671.

HUNTER, S. C., ISINGO, R., BOERMA, J. T., URASSA, M., MWALUKO, G. M. P. \& ZABA, B. (2003). The association between HIV and fertility in a cohort study in rural Tanzania. Journal of Biosocial Science 35 (2003)2:189-199.

IRIN. (2004a) Namibia: New hope for Caprivi with launch of AIDS treatment. IRIN PlusNews. IRIN: a UN humanitarian information unit. http://www.irinnews.org.

----. (2004b). Namibia: HIV/AIDS eroding economic growth. IRIN PlusNews. IRIN: a UN humanitarian information unit. http://www.irinnews.org.

KAMALI, A., CARPENTER, L. C., WHITWORTH, J. A. G., POOL, R., RUBERANTWARI, A. \& OJWIYA, A. (2000) Seven-year trends in HIV-1 infection rates, and changes in sexual behaviour, among adults in rural Uganda. AIDS 14 (2000):427-434.

KELLY, M. J. (2004) HIV/AIDS and education. International Institute for Educational Planning (IIEP) Newsletter XXII (2004) 2: 1, 3 .

KNODEL, J. (1979) The influence of child mortality in a natural fertility setting. In Leridon, H. and Menken, J. (Eds.): Natural Fertility, 273-284. Ordina Editions, Liege, Belgium.

LEBEAU, D., FOX, T., BECKER, H. \& MUFUNE, P. (1999) Taking Risks - Taking Responsibility. An Anthropological Assessment of Health Risk Behaviour in Northern Namibia. Department for Cooperation and Cultural Affairs of the French Embassy \& Ministry of Health and Social Services (MoHSS). Windhoek, Namibia.

LEBEAU, D., FOX, T., BECKER, H. \& MUFUNE, P. (2002) Agencies and structures facilitating the transmission of HIV/AIDS in Northern Namibia. Society in Transition 32(2002)1: 56-68.

LEMSTRÖM, O. (1999) Hedelmällisyys ja kuolleisuus Kavangossa 1950-1996 verrattuna Ambomaahan. (Fertility and mortality in Kavango 1950-1996 compared to Ovamboland. In Finnish). Unpublished Master's thesis, Department of Sociology, University of Helsinki, Finland.

LEWIS, J. J. C., RONSMANS, C., EZEH, A. \& GREGSON, S. (2004) The population impact of HIV on fertility in sub-Saharan Africa. AIDS 18 (2004) suppl 2:S35-S43.

MALETSKY, C. (2005). US steps up AIDS assistance to Namibia. The Namibian February 1, 2005.

NOTKOLA, V. (2004) Namibia ennen aidsia ja sen puhkeamisen jälkeen. In Alapuro, R and Arminen, I (eds.), Vertailevan tutkimuksen ulottuvuuksia, 233-243. WSOY, Vantaa.

NOTKOLA, V. \& SIISKONEN, H. (2000) Fertility, Mortality and Migration in SubSaharan Africa: The Case of Ovamboland in North Namibia, 1925-90. Macmillan Press. Basingstoke.

NOTKOLA, V., TIMÆUS, I. M. \& SIISKONEN, H. (2000) Mortality Transition in the Ovamboland Region of Namibia, 1930-1990, Population Studies 54 (2000):153-167.

NOTKOLA, V., TIMÆUS, I. M. \& SIISKONEN, H. (2004) Impact on Mortality of the AIDS Epidemic in Northern Namibia Assessed Using Parish Registers. AIDS 18 (2004): 1061-1065.

NTOZI, J. P. M., NAKANAABI, I. M. \& LUBAALE, Y. A. M. (1997) Fertility levels and trends in the face of the AIDS epidemic in Uganda. Health Transition Review 7 (1997) Suppl 2: S145-S155.

PHORORO, H. (2002). HIV/AIDS: Who Suffers in Namibia? Nepru Working Paper 84. Namibian Economic Policy Research Unit (NEPRU). Windhoek, Namibia. 
PRESTON, S. H. (1978). Introduction. In Cleland, J and Hobcraft, J (eds.), Reproductive Change in Developing Countries, 235-272. Oxford University Press, Oxford.

RAITIS, R. (1995) Fertility in the Northwest Region of Namibia. Yearbook of Population Research in Finland 32 (1995): 106-117.

ROSS, A., MORGAN, D., LUBEGA, R., CARPENTER, L. M., MAYANJA, B. \& WHITWORTH, J. A. G. (1999) Reduced fertility associated with HIV: the contribution of pre-existing subfertility. AIDS 13 (1999): 2133-2141.

ROSS, A., VAN DER PAAL, L., LUBEGA, R., MAYANJA, B. N., SHAFER, L. A. \& WHITWORTH, J. (2004) HIV-1 disease progression and fertility: the incidence of recognized pregnancy and pregnancy outcome in Uganda. AIDS 18 (2004): 799-804.

RUTENBERG, N., BIDDLECOM, A. E. \& KAONA, F. A. D. (2000) Reproductive decision-making in the context of HIV and AIDS: A qualitative study in Ndola, Zambia. International Family Planning Perspectives 26 (2000):124-130.

RYDER, R. W., BATTER, V. L., NSUAMI, M., BADI, N., MUNDELE, L., MATELA, B., UTSHUDI, M. \& HEYWARD, W. L. (1991) Fertility rates in 238 HIV-1-seropositive women in Zaire followed for 3 years post-partum. AIDS 5 (1991): 1521-1527.

SANDERSON, W. C., FULLER B., HELLMUTH, M. \& STRZEPEK, K. M. (2001) Namibia's Future: Modeling Population and Sustainable Development Challenges in the Era of HIV/AIDS. Executive Summary. International Institute for Applied Systems Analysis (IIASA). Laxemburg, Austria.

SAPHONN, V., HOR, L. B., L. Y., S. P., CHHUON, S., SAIDEL, T. \& DETELS, R. (2002). How well do antenatal clinic (ANC) attendees represent the general population? A comparison of HIV prevalence from ANC sentinel surveillance sites with a population-based survey of women aged 15-49 in Cambodia. International Journal of Epidemiology 31 (2002) 449-455.

SHEMEIKKA, R. (1999). HIV/AIDS: The major demographic challenge of Namibia. Yearbook of Population Research in Finland 35 (1999): 65-81.

SHEMEIKKA, R., NOTKOLA, V., SIISKONEN, H. (2005). Fertility decline in North-Central Namibia: An Assessment of Fertility in the period 1960-2000 Based on Parish Registers. Demographic Research, Volume 13, Article 4, Pages 83-116.

SIAPAC. (2002) A Situation Analysis of Orphan Children in Namibia. Prepared by Social Impact Assessment and Policy Analysis Corporation Ltd. (SIAPAC) for the Ministry of Health and Social Services and UNICEF/Namibia. Windhoek, Namibia.

SIISKONEN, H., TASKINEN, A. \& NOTKOLA, V. (2005). Parish registers: A challenge for African historical demography. History in Africa 32 (in press).

SLOTTEN, R. A. (1995). AIDS in Namibia. Social Science and Medicine 41 (1995): 277-284.

TALAVERA, P. (2002). Sexual cultures in transition in the northern Kunene - is there a need for a sexual revolution in Namibia. In Winterberg, V., Fox, T. \& Mufune, P. (eds.), Namibia Society Sociology, 333-346. University of Namibia Faculty of Humanities and Social Sciences, Windhoek, Namibia.

TERCEIRA, N., GREGSON, S., ZABA, B. \& MASON, P. R. (2003). The contribution of HIV to fertility decline in rural Zimbabwe, 1985-2000. Population Studies 57 (2003): 149-164.

TERSBØL, B. P. (2002) How to make sense of lover relationships - Kwanyama culture and reproductive health. In Winterberg, V., Fox, T. \& Mufune, P. (eds.), Namibia Society Sociology, 347-360. University of Namibia Faculty of Humanities and Social Sciences, Windhoek, Namibia.

UNAIDS. (2004) report on the global AIDS epidemic: 4th global report. UNAIDS, Geneva.

UNAIDS and WHO. (2004) AIDS epidemic update: December 2004. UNAIDS and WHO, Geneva.

UNAIDS, UNICEF and USAID. (2004) Children on the Brink 2004. A Joint Report of New Orphan Estimates and a Framework for Action. http://www.unaids.org.

UNAIDS, UNICEF and WHO. (2004) Namibia. Epidemiological Fact Sheets on HIV/AIDS and sexually transmitted infections. 2004 Update. UNAIDS \& WHO. http://www.unaids.org.

UNICEF. (2003) Africa's Orphaned Generations. UNICEF. New York, USA.

UNITED NATIONS. (1983) Manual X: Indirect Techniques for Demographic Estimation. Department of International Economic and Social Affairs. Population Studies 81. New York 
UN POPULATION DIVISION. (2003) The impact of HIV/AIDS on mortality. Workshop on HIV/ AIDS and Adult Mortality in Developing Countries. Population Division, Department of Economic and Social Affairs, United Nations Secretariat, New York, 8-13 September 2003.

WHO and UNAIDS. (2003) Reconciling antenatal clinic-based surveillance and population-based survey estimates of HIV prevalence in sub-Saharan Africa. http://www.who.int.

WHO and UNAIDS. (2004) 3 by 5 Progress Report. WHO and UNAIDS. http://www.who.int.

WRIGLEY, EA (ED.) (1966) An Introduction to English Historical Demography. Weidenfeld and Nicolson, London.

ZABA, B. W., CARPENTER, L. M., BOERMA, J. T., GREGSON, S., NAKIYINGI, J. \& URASSA, M. (2000) Adjusting ante-natal clinic data for improved estimates of HIV prevalence among women in sub-Saharan Africa. AIDS 14 (2000): 2741-2750.

ZABA, B. \& COLLUMBIEN, M. (1997) HIV and Fertility: Modelling the effects of changes in union dynamics. International Population Conference Beijing 1997, Vol. 2, 583-609. International Union for the Scientific Study of Population (IUSSP). Liège, Belgium.

ZABA, B. \& GREGSON, S. (1998) Measuring the impact of HIV on fertility in Africa. AIDS 12 (1998) suppl 1: S41-S50. 
